\title{
Die abstrakte Gestaltung von Sicherheiten als elementarer Ausdruck der Privatautonomie
}

Dissertation zur Erlangung des Doktorgrades der Juristischen Fakultät der Georg-August-Universität zu Göttingen

\author{
vorgelegt von \\ Li Yuan \\ aus Guangdong, VR China
}

Göttingen 2012 
Berichterstatterin: Prof. Wendehorst

Mitberichterstatter: Prof. Costede

Tag der mündlichen Prüfung: 23.02.2012 


\section{Vorwort des Autors}

Die vorliegende Arbeit wurde in den Jahren 2007-2011 erstellt und von der Juristischen Fakultät der Georg-August-Universität Göttingen im Wintersemester 2010/2011 zur Dissertation angenommen. Das Manuskript wurde bereits im November 2010 fertig gestellt. Vor Veröffentlichung der Arbeit wurde diese auf dem Stand von 01.03.2012 aktualisiert.

Von ganzem Herzen danke ich meinem hochverehrten Doktorvater Prof. Wendehorst, die diese Promotion während der gesamten Zeit durch wertvollen Rat und hilfreiche Anregungen begleitet hat.

Ebenfalls möchte ich Herrn Prof. Dr. Costede für die Erstellung des Zweitgutachtens danken.

Ich widme diese Arbeit meinen Eltern, ohne deren unermüdliche Unterstützung und Verständnis diese Arbeit und mein langjähriges Studium in Deutschland gar nicht möglich gewesen wären.

Ganz besonders hervorheben möchte ich meine Frau Shuyi Wu. Von ganzen Herzen danke ich für ihre bedingungslose Unterstützung in den schwierigsten Zeiten meines Studiums in Deutschland.

Göttingen, Frühling 2012

Li Yuan 


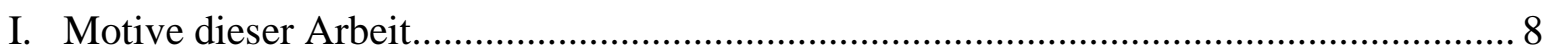

II. Wissenschaftliche Thesen eines möglichen modernen Privatvermögensrechts

III. Allgemeines zur Darstellung komplexen Gegenstands im dynamischen Umfeld

1. Kreditsicherung im engeren Sinne

2. Kreditsicherungsrecht als konkreter Denkgegenstand.

3. Darstellungsweise und deren wissenschaftstheoretischer Hintergrund

a) Einschränkung auf die der Systembildung unentbehrlichen

b) Thesenverifikation, Ökonomische Analyse des Rechts und ihr wissenschaftstheoretische Hintergrund

c) Interne Verweisungen als besondere Darstellungstechnik

B. Einheitliche abstrakte Sicherheit als Musterbild moderner Gestaltung des

Privatvermögensrechts 26

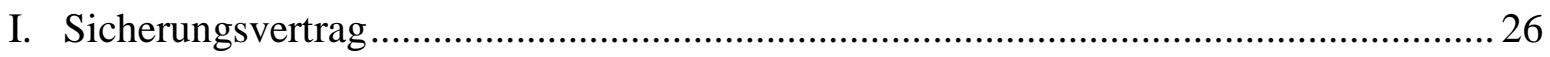

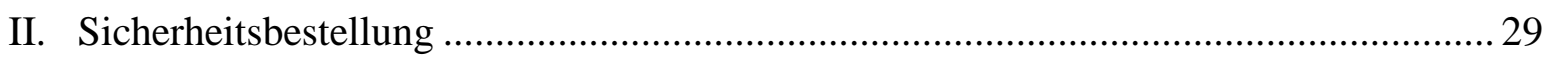

C. Sicherungsvertrag als strukturelle Grundentscheidung ............................................. 31

I. Die dogmatischen Fundamente der gängigen (sicherungsrechtlichen) Gestaltungen....... 31

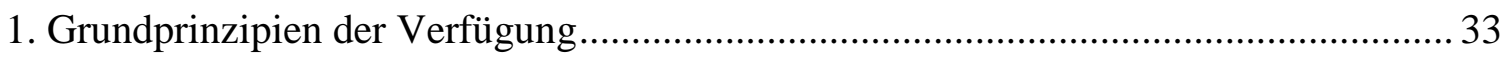

2. Bewertung von Einheits- und Trennungsprinzip .............................................. 45

3. Wichtigste herkömmliche Argumente für das Abstraktionsprinzip ...........................52

II. Abstrakte Sicherheit im Vormarsch....................................................................... 58 


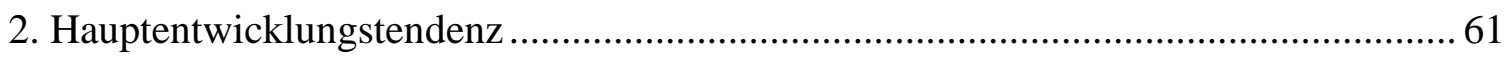

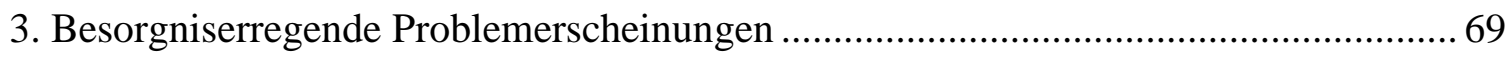

III. Vor- und Nachteile der abstrakten Gestaltung ..................................................... 71

1. Der ökonomische Ansatz der Rechtsanalyse .......................................................... 72

a) Der ökonomische Blickwinkel des Rechts.......................................................... 72

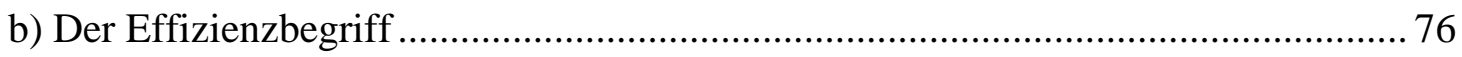

2. Vor- und Nachteile der abstrakten Gestaltung .................................................... 84

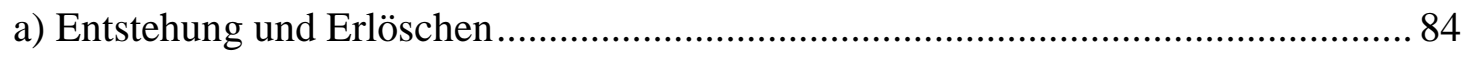

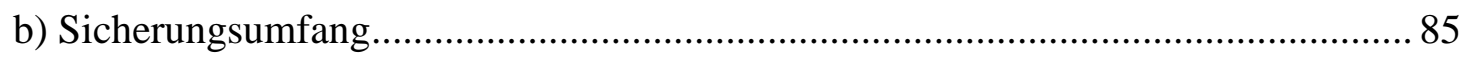

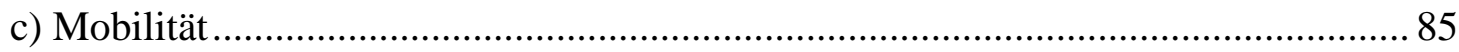

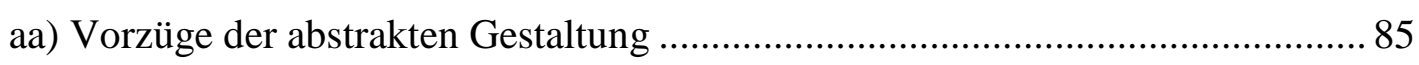

bb) Schwäche - Risikokonzentration als die1. Ursache der Weltfinanzkrise........... 86

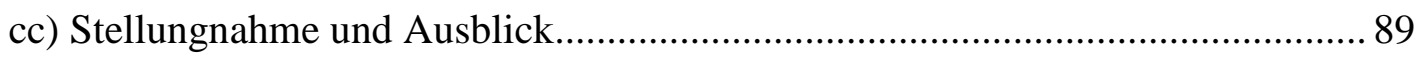

d) Durchsetzung und Bewertung des neuen $\S 1192$ Abs. 1a BGB ............................ 89

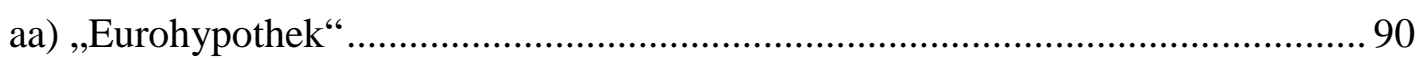

bb) Hintergründe der Einführung des $\S 1192$ Abs. 1a BGB ................................. 92

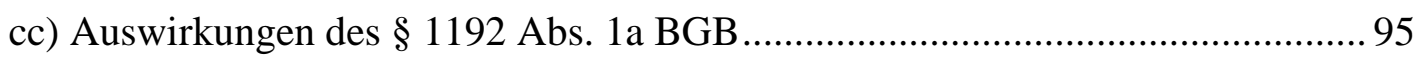

dd) Ist die abstrakte Gestaltung eines Grundpfandrechts systemisch untragbar? .... 97

ee) Wie ist das Risiko der Grundschuld zu begrenzen? ..................................... 99

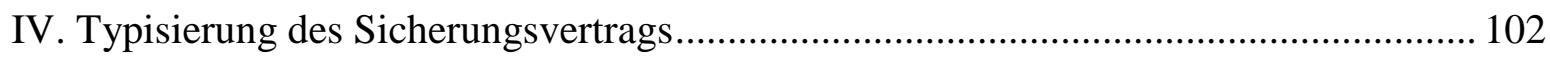


1. Was ist ein Sicherungsvertrag?

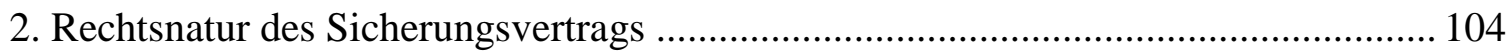

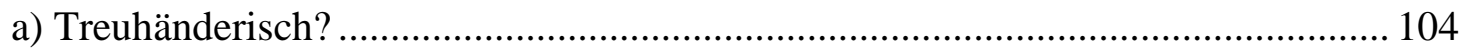

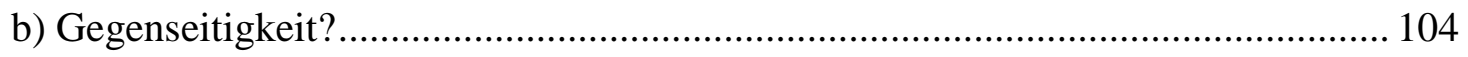

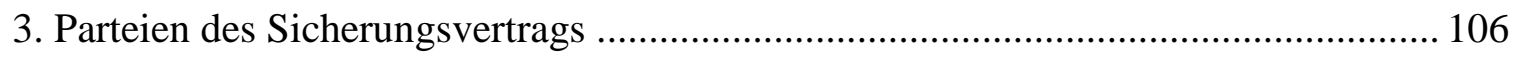

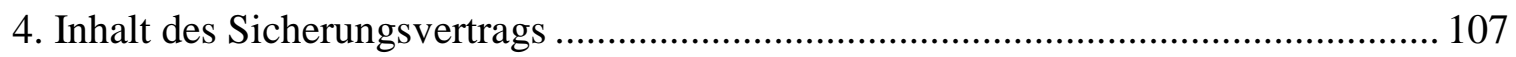

a) Sicherungszweck bzw. Verpflichtung zur Sicherheitsbestellung ........................ 107

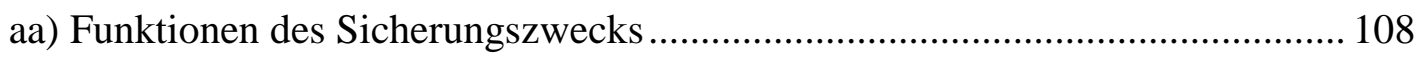

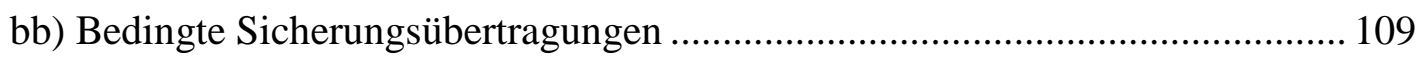

cc) Regulierung der Leistungsstörungen anhand des Sicherungszwecks .............. 110

dd) Zweckwidrige Verfügung über Forderung und/oder Sicherungsgut ............... 112

ee) Ordnungsmäßige Erledigung des Sicherungszwecks ................................... 115

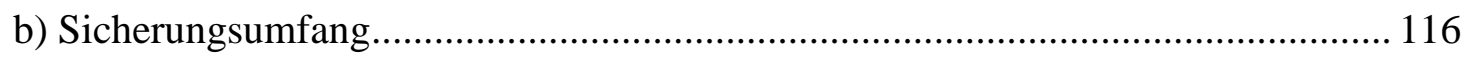

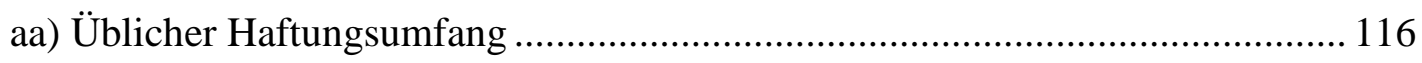

bb) Formularmäßige Erweiterung des Sicherungszwecks/-umfangs .................... 117

cc) Sittenwidrigkeit, Übersicherung und Freigabeklausel ................................ 119

c) Sonstige Pflichten und Rechte aus dem Sicherungsvertrag ................................ 122

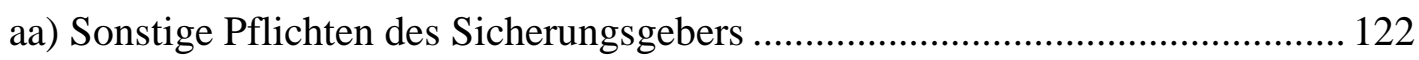

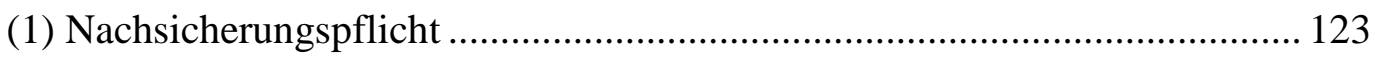

(2) Pflichten zur Werterhaltung des Sicherungsguts..................................... 123

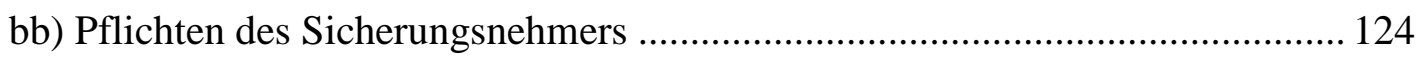


(1) Zweckmäßige Verwendung der Sicherheit.

(2) Rückübertragungspflicht

cc) Kündigungsrecht?

d) Wichtige Sicherungsmodalitäten

aa) Voraussetzungen für die Verwertungsreife

bb) Schutzpflicht aus $\S 242$ BGB.

cc) Art der Verwertung

(1) Verfallklausel bei Sicherungsübereignung

(2) Verwertung durch freihändigen Verkauf?

dd) Bewertung der einzelnen Sicherheiten

e) Formbedürftigkeit des Sicherungsvertrags

aa) Zweck der Formvorschriften

(1) Funktionen der Formvorschriften bei den gesetzlichen Sicherheiten

(2) Interessenlage bei den nichtakzessorischen Sicherungsmitteln.

bb) Folgenabwägung

D. Komplettierende Mechanismen bei der Sicherheitsbestellung

I. Probleme des gegenwärtigen Bestimmtheits- und Publizitätsgrundsatzes

1. Bestimmtheitsgrundsatz

a) Allgemeines Verständnis im deutschen Recht

b) Sicherungskollisionen

c) Einfluss des Bestimmbarkeitskriteriums auf die Sicherungskraft 
d) Anteilserwerb als Lösung des Konflikts?

e) Kann es das „Case-Law“ besser? 146

2. Die Publizität der Mobiliarsicherheiten 154

a) Deutschland 155

aa) Probleme des gegenwärtigen Publizitätsgrundsatzes 155

(1) Besitz als Publizitätsmittel. 155

(2) Publizitätslosigkeit in Deutschland 166

bb) Register als Publizitätsmittel und Die große Diskussion in den 20er Jahren .. 167

b) Reformbewegung für ein europäisches Mobiliarkreditsicherungsrecht 170

aa) Reale Probleme in der EU und für den Welthandel 170

bb) Übernahme des Article 9 UCC oder Schaffung eigenen Systems?

cc) Zusammenfassung 175

c) USA - Informationsasymmetrie als die 2. Ursache der Weltfinanzkrise 175

aa) Problem Nr. 1 - Filing-System Disaster 175

bb) Problem Nr. 2 - dezentralisiertes Registerwesen

d) Lösungsansatz aus der Spieltheorie

e) Zusammenfassung

II. Zentrales elektronisches Register als Lösung 186

1. Institutioneller Hintergrund für den Bedarf eines Zentralregisters 186

2. Das „entsprechende“ Konzept eines allgemeinen Zentralregisters 191

a) Nutzensstrukturen der Akteure als Regelungsgegenstand 191 
aa) Das Nutzenkalkül des Prinzipals

(1) allgemeine Modellierung

(2) Einfluss der Sicherungskraft auf das Nutzenskalkül des Kreditgebers 202

bb) Nutzenkalkül des Agenten

b) Die „entsprechenden technischen“ Zielvorgaben

aa) zentralisiert

bb) abschließend und Auswirkungen auf die Zivilrechtskodifikation

cc) absolut

dd) digitalisiert

3. Konstruktion des elektronischen Zentralregisters

a) Datenerfassung durch RFID-Technologie

aa) Was bedeutet die RFID-Technologie für das Rechtssystem?

bb) Gestaltung des elektronischen Zentralregisters

(1) Was soll erfasst werden?

(2) Registerzwang?

(3) Rechtswirkungen der Eintragung und Prioritätsverhältnis

(4) Einsichts- und Nutzungsrechte

(5) Schutz des RFID-Transponders und der Registereintragungen

b) Datenverarbeitung durch Cloud-Computing. 230

4. Zentrales elektronisches Register als „Game-Changer“

a) Auswirkung auf die Rechtsgrundsätze 
b) Elektronisches Verwertungsverfahren durch die Zentralregisterstelle

c) Informationstransparenz als systemstabilisierender Faktor

5. Machbarkeits- und Akzeptanzprognose.

6. Das neue Registerrecht und Bucheffekten

E. Zusammenfassung und Ausblick 


\title{
A. Einleitung
}

\section{„Our true inheritance lies in our ability to make and shape ourselves, not the creatures but the creators of destiny"}

\author{
- L. S. Stavrianos ${ }^{1}$
}

\section{Motive dieser Arbeit}

Das Eigentum als fundamentale Institution war und ist die dynamischste Kraftquelle sozialer und geistig-kultureller Entwicklung, die die Koordination der Handlungen der Individuen oder Kollektive als Grundproblem der menschlichen Gesellschaft formt. Im Zeitalter der Globalisierung findet bedingt durch die rasante Entwicklung der modernen Techniken (insbesondere der Informationstechnik) eine beachtliche Teilcharakterwandlung des Eigentums statt. Die Werkzeuge, die der Mensch jetzt einsetzt, sind im Vergleich zu denen vor 20 Jahren in Schnelligkeit und Effizienz um ein vielfaches überlegen. Dies schlägt sich z.B. bei der Geschwindigkeit der modernen Logistik; auch bei der marktwirtschaftlichen Preisbildung nieder. Mit Hilfe von Containerschiffen und Interkontinentalflügen werden Waren global produziert und vertrieben; während sich die Preise auf dem globalen Finanzmarkt binnen Sekunden verändern, kann sich die Preisbildung in der Realwirtschaft über Monate hinziehen. Wie das Eigentum in einem solchen dynamischen und komplexen Umfeld zu behandeln und wie das durch die immer feinere Arbeitsteilung erzeugte ständig wachsende Spannungsfeld zwischen Leistung und Gegenleistung zu harmonisieren ist, sind die wichtigsten Grundfragen in diesem Jahrhundert.

Phänomenal für diesen (Teil-)Charakterwandel des Eigentums wird in dem Grundproblem der (weltweiten) Zivilrechtsordnungen reflektiert, nämlich die durch die immer zunehmenden Konflikte zwischen Rechtssicherheit und Effizienz bedingte Rechtsunsicherheit und Ineffizienz. Apodiktisch verkörpern die Schwierigkeiten des (weltweiten)

\footnotetext{
${ }^{1}$ Stavrianos, A Global History: From Prehistory to the $21^{\text {st }}$ Century, S. 39.
} 
Kreditsicherungsrechts dieses Grundproblem, wo sich die Strenge des Handhabens des Erfordernisses der Publizität zugunsten der Rechtssicherheit in umgekehrter Proportion zur Wirtschaftlichkeit der Sicherungsinstrumente ausformt.

Durch diese Arbeit wird der Versuch unternommen, innerhalb knappsten Darstellungsrahmens eine sachgerechte Antwort im Bereich des zivilrechtlichen Vermögensrechtes, wo die Bewegungsvorgänge des Eigentumsverhältnisses geregelt werden, herauszufinden.

Vor dem Hintergrund der Weltfinanz- und Wirtschaftskrise kann man die Dringlichkeit der Anpassung des (Vermögens)Rechtssystems, dessen Wertephilosophie und technischen Rahmenbedingungen im 19. Jahrhundert wurzeln, am besten vor Augen führen, und zwar anhand des (deutschen) Kreditsicherungsrechts als konkreter Denkgegenstand. Alleine mit der traditionellen Rechtsmethodik der historischen Schule können die durch die Unvollkommenheit des Normensystems bedingte Rechtsunsicherheit und Ineffizienz des gegenwärtigen (Kreditsicherungs)Rechts nicht mehr bewerkstelligt werden. Es ist deutlich genug, dass die immer unübersichtlicheren Rechtsprechungen an dieser Stelle auch nicht mehr weiterhelfen können. Infolgedessen ist eine Generalüberholung der tragenden Prinzipien des Vermögensrechts mit Hilfe der objektiven ökonomischen Analyse des Rechts und des Rechtsvergleichs angesagt.

Hinter dem Phänomen „Globalisierung“ verbirgt sich das bisher weitestgehend unerforschte „Sein“ der heutigen Welt. ${ }^{2}$ Die hungernden Afrikaner verstehen darunter die durchschnittlich um 200\% gestiegenen Preise für Grundnahrungsmittel; ${ }^{3}$ die Manager in Wall Street, London oder Frankfurt können wahrscheinlich erst durch die sich rasant ausbreitende Finanzkrise kapieren; ${ }^{4}$ und die normalen Bürger hierzulande spüren sie täglich an Trankstellen hautnah. Wieso ist der bisher sukzessive Prozess der Globalisierung plötzlich so real und bedrohlich

\footnotetext{
${ }^{2}$ M.w.N.: Kutschker/Schmid, Internationales Management, S. 159 ff.

3 "Weltbank: Teure Lebensmittel durch Biotreibstoff. Anteil an Preissteigerung höher als gedacht.", FAZ, 05.07.08, S. 11 .

4 Market Shock: AAA Rating May Be Junk, NYT, 20.07.07; IKB-Krise verschärft sich, auf www.sueddeutsche.de (Süddeutsche Zeitung), 11.08.07; Greenspan spricht von Jahrhundertkrise, Spiegel Online, 05.08.08.
} 
geworden? Spätestens anlässlich dieses simultanen und wiederkehrenden Auftretens von Finanz-, Nahrungs-, Energien- und Umweltkrise sollten wir uns darüber im Klaren sein, wie intensiv Güter- und Finanzmärkte, Produktions- und Geldwirtschaft verflochten sind und wie rasant eine Krise von einem Bereich auf den anderen übergreifen kann.

Durch das Zusammenwirken von verschiedenen Elementen, wie z.B. modernen Informationstechnologien, Verkehrswesen, internationalen Organisationen und Medien usw., beschränkt sich die Entwicklung der Globalisierung längst nicht mehr nur auf den Wirtschaftsbereich.

„Globalisierung betrifft ..... die ganze Welt. Dadurch kommt es ..... zur einer Verflechtung bzw. Verschmelzung. ...... Die Vereinheitlichung bezieht sich auf unterschiedliche Aspekte in den von der Globalisierung betroffenen Lebensbereichen. .....A Aus diesem Grund wird auch gefordert, dass Globalisierung von Vertretern unterschiedlicher Fachgebiete gemeinsam, d.h. multi-, trans- bzw. interdisziplinär und nicht nur innerhalb einzelner Wissenschafts(teil)disziplinen zu erforschen ist. "

„Die aktuell ständig fortschreitende Globalisierung der Märkte bewirkt eine immer stärkere Internationalisierung unseres Zivilrechts, das sich gegenwärtig auf einem Evolutionspfad in Richtung auf die Herausbildung eines Weltzivilrechts befindet. “6

Neue Voraussetzungen erweitern den Horizont, eröffnen völlig neue Denkdimensionen, bringen nicht nur neue Herausforderungen, sondern vor allem auch Chancen mit sich. Ob die Stunde der lang ersehnten Möglichkeit eines Weltrechts ${ }^{7}$ gekommen ist, wage ich zwar nicht vorherzusagen; aber der reale Wettbewerb der Rechtsordnungen ist nicht mehr zu ignorieren. Nach der weiten Definition von Schotter ${ }^{8}$ ist Institution ,a set of rules that constrain

\footnotetext{
${ }^{5}$ Kutschker/Schmid, Internationales Management, S. 176 f.; 171.

${ }^{6}$ Lehmann, Globalisierung und Zivilrecht, S. 736.

${ }^{7}$ Der Traum von einem „Weltzivilrecht“ stammt von Zitelmann (Die Möglichkeit eines Weltrechts, S.7) und wird richtigerweise nach mehr als 100 Jahren noch nicht aufgegeben; s. Lehmann, Globalisierung und Zivilrecht, S. $729 \mathrm{ff}$.

${ }^{8}$ Schotter, The Evolution of Rules, S. 117.
} 
individual behavior and define the social outcomes that result from individual action". 9 Danach wird der Wettbewerb nicht mehr nur zwischen Rechtsordnungen ausgetragen, sondern auch zwischen alternativen Institutionen, wie z.B. Vertrauen und Recht. ${ }^{10} \mathrm{Im}$ Zeitalter der sich rasant ausbreitenden Globalisierung ist der Kampf der Institutionen um die Effizienz und Existenz erbarmungsloser denn je. Die (deutsche) Jurisprudenz ist gezwungen, sich diesem Kampf zu stellen, wenn sie nicht obsolet werden möchte.

Das Hauptziel dieser Arbeit besteht darin, die dem Globalisierungszeitalter gerechten Gestaltungen der Grundprinzipien des zivilrechtlichen Vermögensrechts anhand eines konkreten Denkmodells (Kreditsicherungsrecht) ausfindig zu machen.

Die Auseinandersetzungen der Sicherungsrechte dienen LEDIGLICH dazu, die Defizite der Rahmenbedingen der gegenwärtigen Vermögensrechtsordnungen und deren möglichen Verbesserungsmöglichkeiten konkret $\mathrm{zu}$ demonstrieren, weil die vorangegangenen Untersuchungen mit traditionellen Methoden keine zufrieden stellenden Ergebnisse vorgebracht haben. Der Anspruch auf Vollständigkeit bzgl. untersuchter Gestaltungsvariante kann und wird nicht erhoben.

\footnotetext{
${ }^{9}$ Institutionen sind die Vergegenständlichungen der entsprechenden philosophischen Strömungen, wie z.B. (Neo)Liberalismus, Marxismus, etc. An dieser Stelle ist es mir voll bewusst, dass die in dieser Arbeit verwendeten Instrumentarien und angesprochenen Gedanken auch häufig von verschiedenen Denkschulen in Anspruch genommen werden, z.B. der leitende Gedanke dieser Arbeit - Effizienz. Sie dürfen aber nicht dazu gebraucht werden, diese Arbeit als Befürwortung des Neoliberalismus und Ablehnung anderer Weltbilder abzustempeln, denn das Streben nach Effizienz der menschlichen Gesellschaft ist von der Natur vorgegeben und Effizienz selbst ist eine der Gesellschaftsgrundlagen. Die Gerechtigkeit und Sachmäßigkeit der verschiedenen Denkschulen ist sowohl thematisch, als auch umfänglich nicht Gegenstand dieser Arbeit. Dies gilt insbesondere für die Umverteilungs- und Nachhaltigkeitspolitik im Zeitalter der (zurzeit von dem Neoliberalismus geleiteten) Globalisierung.

${ }^{10}$ s.u. „,Nutzensstrukturen der Akteure als Regelungsgegenstand“: die Kampfansage des „Vertrauens“ ist nicht nur bloß eine solche in normativer Hinsicht, sondern basiert auf solidem Effizienz-Kalkül.
} 
Abb. 1 „Ein Bild sagt mehr als tausend Worte“ - Visualisierung der verschiedenen Routen durch Teile des Internets ${ }^{11}$

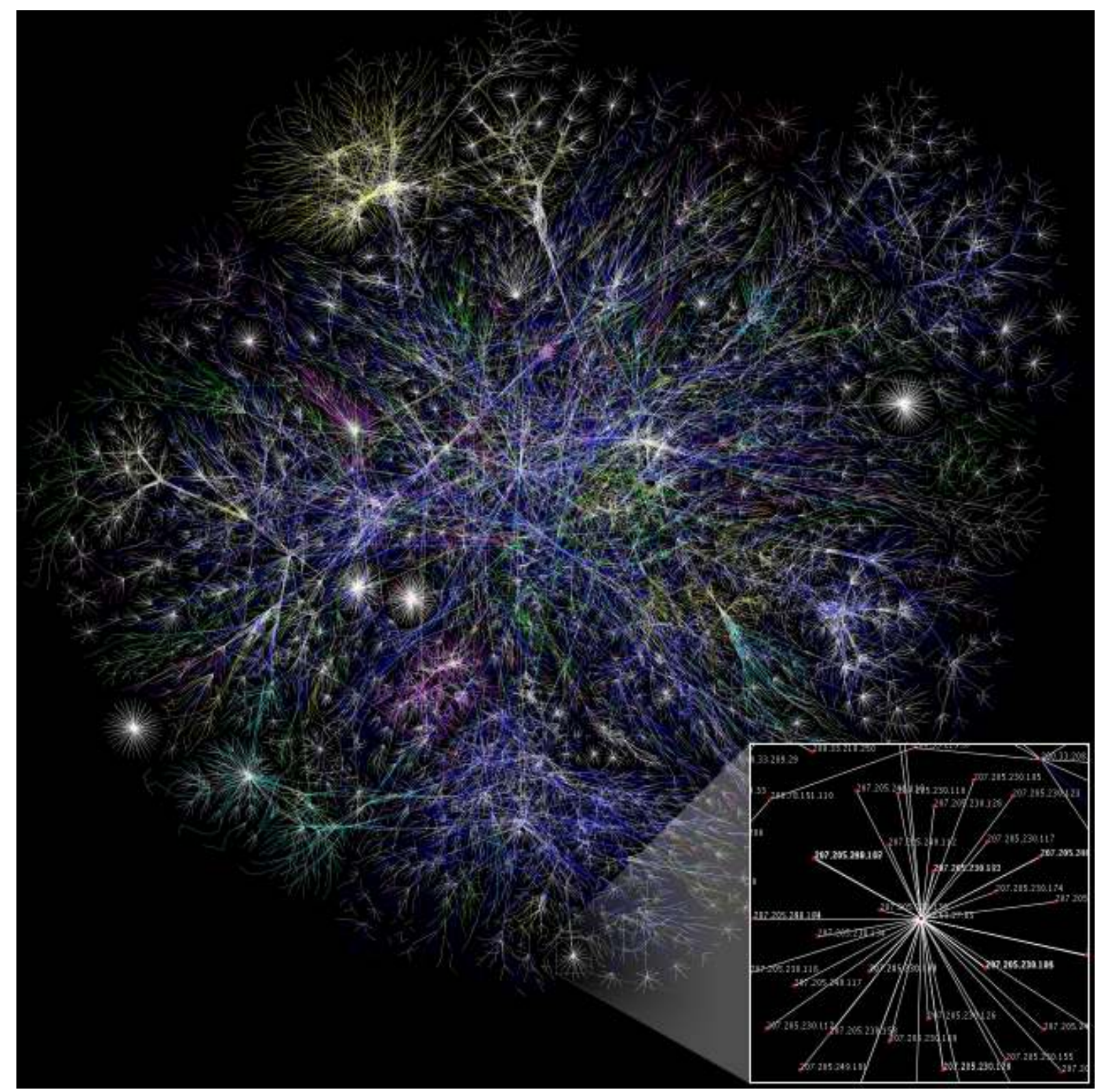

Dieses Schaubild soll dazu dienen, einen anschaulichen Eindruck über die komplexen Flüsse der Informationen, Kapitale und Sachwerte in dem Globalisierungszeitalter zu vermitteln. Das erleichtert das Verständnis darüber, warum die bestehenden Rechtsordnungen ihrer heutigen Aufgabe, nämlich Regulierung vorstehender Bewegungsvorgänge, nicht mehr gewachsen wird.

\footnotetext{
${ }^{11}$ Quelle: Wikipedia, unter Stichwort „Internet“ (Stand: 01.03.2012); http://de.wikipedia.org/wiki/Internet
} 


\section{Wissenschaftliche Thesen eines möglichen modernen}

\section{Privatvermögensrechts}

T1. Sowohl aus (a) juristischer als auch aus (b) ökonomischer Hinsicht bietet das Abstraktionsprinzip die zurzeit denkbar beste Gestaltungsmaxime für den modernen hochkomplexen (globalisierten) Wirtschaftsverkehr, welcher hohe (c) Sicherheit, (d)

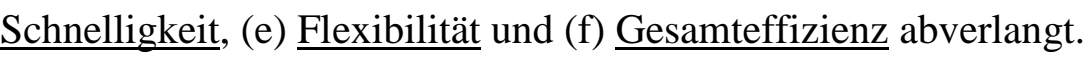

T2. Die (a) Unvollkommenheit der gegenwärtigen Rahmenbedingungen des deutschen Zivilrechts (b) begünstigt die (c) Entfaltung des selbstzerstörerischen Potenzials des historisch entwickelten Abstraktionsprinzips, welches zur Aufhebung der durch die Trennung zwischen Schuld- und Sachenrecht gekennzeichneten deutschen Zivilrechtsdogmatik führt.

T3. Die (a) dogmatische Unvollkommenheit des Abstraktionsprinzips und des deutschen Zivilrechts kann (b) durch Hinzufügen fehlender komplettierender Reglungsmechanismen (zentrales elektronisches Registersystem), behoben werden.

Die vorstehenden Hauptthesen und ihre Bestandteile werden am Anfang der jeweiligen Passagen angeführt. Zusammen mit den konkreten Normenvorschlägen sollten sie die Leichtigkeit der Darstellung und die Verständnisse des komplexen Gegenstands dieser Arbeit gewährleisten. 


\section{Allgemeines zur Darstellung komplexen Gegenstands im dynamischen Umfeld}

Als Teil der Konkurrenz verschiedener Wirtschafts- und Finanzsysteme ist der Wettbewerb der Rechtssysteme ${ }^{12}$ bzgl. deren Werte, Systematik, Rechtssicherheit, Flexibilität, Effizienz und Zukunftsfähigkeit viel „diskreter“ und oft nur als „unauffällige“ Begleiterscheinung des grenzüberschreitenden Verkehrs von Kapital, Informationen und Arbeit zu beobachten, die aber tiefgreifende institutionelle Auswirkungen haben wird. Die Kenntnisgewinnung aus diesen komplexen Phänomenen und ihre Verwertung in der Normenbildung kann man meiner Meinung nach nur anhand eines konkreten Regelungsgebiets darstellen.

Besonders dynamisch, belangvoll und beispielhaft für den Krisenzustand der Zivilrechtsdogmatik ist der unmittelbare Gegenstand dieser Arbeit, nämlich die Gestaltung des Kreditsicherungsrechts. Anhand dieses konkreten Denkgegenstandes wird die Anstrengung unternommen, die sachgerechten Prinzipien des modernen Vermögensrechts im Globalisierungszeitalter darzustellen.

\section{Kreditsicherung im engeren Sinne}

Das Wort Kredit stammt aus dem lateinischen „creditum“ und bedeutet etwa ,auf Treu und Glauben, Anvertrautes“. ${ }^{13}$ Im modernen Wortgebrauch (ital. - frz.) heißt es: Vertrauen in die Fähigkeit und Bereitschaft einer Person oder eines Unternehmens, bestehende Verbindlichkeiten ordnungsgemäß und zum richtigen Zeitpunkt zu begleichen. ${ }^{14}$ Im Hinblick auf den Rechtsbegriff „Kreditsicherung“ fragen sich manche, ob dies ein Widerspruch in sich

\footnotetext{
${ }^{12}$ Wenn in dieser Arbeit von dem Wettbewerb der Rechtssysteme die Rede ist, ist damit nicht der Wettbewerb der Überbietung mit „,investitionsfreundlichen“ Regelungen gemeint, der schädliche soziale Auswirkungen haben könnte, wie z.B. im Bereich des Arbeitsrechts oder Haftungsrechts (vgl. Deffains/Demougin: HoldupProblem und Wettbewerb der Rechtssysteme, S. 251 ff.), sondern der Kampf um die Bestimmungsmacht internationaler Spielregeln und Institutionen (Baumann, Ökonomie und Recht, RNotZ 2007, 297, 301: Die mit US-amerikanischen Geldmitteln nach US-amerikanischem Rechtsvorverständnis erstellten „Doing Business“ Berichte der Weltbank mit Sitz in Washington schlagen den Dritte-Welt-Ländern tendenziell vor, ihre Rechtsordnungen nach dem Vorbild des US-amerikanischen Rechtssystems zu gestalten.).

${ }^{13}$ Duden, Deutsches Universalwörterbuch: unter Stichwort „Kredit“.

${ }^{14}$ Duden, Das Fremdwörterbuch: unter Stichwort „Kredit““.
} 
ist. ${ }^{15}$ Wenn der Gläubiger einerseits dem Schuldner Kredit („Anvertrautes“) gewährt, aber andererseits rechtlich gegen das Ausfallrisiko absichert, befindet er sich m.E. nicht im Widerspruch, weil er sich nur gegen das verhaltensunabhängige Ausfallrisiko (Vertragsbruch) absichern möchte. Dieses Risiko muss nicht unbedingt nur in der Person des Schuldners liegen. Vielmehr ist das Insolvenzrisiko der wettbewerbsorientierten Marktwirtschaft immanent. Mit dem konkurrierenden Verhältnis zwischen Vertrauen und Recht als komplementär einsetzbare Institutionen in einer unsicheren und risikoreichen Welt werden wir uns später noch ausführlicher auseinander setzen.

In der Wirtschaftswissenschaft liegt eine Fülle eingehender Veröffentlichungen vor, die sich mit den Funktionen der Kreditsicherheiten befassen. ${ }^{16}$ Danach kann sich der Gläubiger, der vor Vertragsschluss (ex ante) bestimmte entscheidungsrelevante Sachfragen nicht (vollständig oder kostenlos) beobachten kann, mittels geschickter Handhabung der Kreditsicherung nicht nur gegen das Ausfallrisiko absichern (Sicherungsfunktion), sondern auch ehrliche Kreditnehmer mit guten Projekten finden (Sortierungsmechanismus). Der sanktionierende Charakter der Kreditsicherung wirkt nach dem Vertragsschluss disziplinierend (Anreizsteuerungsfunktion), zwingt den Schuldner zum Verzicht auf opportunistisches Verhalten.

Zur Erreichung dieser Ziele (Kreditsicherung im weiteren Sinne) kann sich der Gläubiger vielfältiger juristischer Instrumente bedienen. Ohne weiteres muss der Kreditnehmer als Vertragspartei Pflichten aus $\S \S 241$ II, 242 BGB, etwa Informationspflicht, Leistungstreuepflicht oder ggf. Schutzpflicht in Form einer Versicherung, beachten, damit er sich nicht schadensersatzpflichtig macht. ${ }^{17}$ Außerdem ist noch an Zurückbehaltungs und Leistungsverweigerungsrechte $\left(\S \S 273,214,320 \mathrm{BGB}^{18}\right.$ ) oder eine Vormerkung ( $\S 883 \mathrm{ff}$.

\footnotetext{
${ }^{15}$ Bülow, Kreditsicherheiten, S. 1 f.; Kessal-Wulf, Kreditsicherung, S. 406.

${ }^{16}$ M.w.N: Bigus/Langer/Schiereck,Warum gibt es Kreditsicherheiten?, S. 573 ff.

${ }^{17}$ Palandt, § 242 Rn. 23 ff.

${ }^{18}$ BGH NJW 1981, 1666, 1668
} 
BGB $^{19}$ ) zu denken. Ferner kann der Kreditgeber innerhalb der Grenzen der $\S \S 138,242$ und 305 ff BGB den Handlungsspielraum des Kreditnehmers einschränken oder sich vertragliche Kontroll- und Einwirkungsrechte verschaffen. ${ }^{20}$

Juristisch gesehen am wirkungsvollsten sind Sicherheiten, die dem Gläubiger unmittelbare Zahlungsansprüche gewähren, also die durch schuldrechtlichen oder dinglichen Vertrag begründeten Rechte, die der Gläubiger in Anspruch nehmen darf, wenn die durch diese Rechte gesicherte(n) Forderung(en) vom Schuldner (oder einem Dritten) nicht (oder nicht in voller Höhe) befriedigt wird (Kreditsicherung im engeren Sinne), ${ }^{21}$ wie z.B. Bürgschaft, § 765 BGB; Eigentumsvorbehalt, § 449 BGB; Pfandrecht, § 1204 BGB; Hypothek, § 1113 BGB; Grundschuld, § 1191 BGB; Sicherungsübereignung und Sicherungsabtretung, $\S$ 311, 930, 398 BGB.

Angesichts deren überragender Bedeutung für die Rechtswissenschaft und Praxis konzentriert sich diese Arbeit im Folgenden ausschließlich auf die Kreditsicherungsrechte im engeren Sinne. Auf die mittelbaren Sicherungsmittel muss leider aus Platz- und Zeitgründen verzichtet werden.

\section{Kreditsicherungsrecht als konkreter Denkgegenstand}

Den besonderen Reiz macht die Komplexität des Kreditsicherungsrechts aus, in der sich viele Schlüsselfragen des (insbesondere Mobiliar-) Sachenrechts verbergen, wie z.B. Wie soll man die Globalisierung juristisch verstehen? Welche Auswirkungen hat sie auf die bestehenden Rechtsordnungen? Wie findet der Wettbewerb der Rechtsordnungen statt? Wohin und zu welchen Folgen wird er führen?

\footnotetext{
${ }^{19}$ Nach Schur (Wirkungsweise von Akzessorietätsprinzip und Sicherungsabrede, Jura, 2005, 361) sollte man zwischen Sicherungsmittel (z.B. Vormerkung, §§ 833 ff. BGB) und Sicherungsrechten (z.B. Grundschuld, §§ $1191 \mathrm{ff}$. BGB etc.) unterscheiden.

${ }^{20}$ Was die mittelbaren Sicherungsmittel bewegen können, zeigt das Bespiel des Mikrokreditprogramms von Muhammad Yunus (Friedensnobelpreisträger von 2006). Die von ihm gegründete Grameen Bak vergibt Kredite ohne Sicherheit (im engeren Sinne) an arme Personengruppen, die sich verpflichten, sich wöchentlich zu treffen, um mögliche Zahlungsprobleme frühzeitig zu erkennen. Außerdem erfolgt die Zahlung stufenweise, so dass das zweite Mitglied erst Geld bekommt, wenn das erste seinen Kredit zurückgezahlt hat (http://www.spiegel.de/spiegel/print/d-49767431.html).

${ }^{21}$ Weber, Kreditsicherungsrecht, S. 10.
} 
Die heutige ,wirtschaftliche“ Globalisierung ist eine der selbstverständlichen Folgen der Expansion der Zirkulation des Kapitals ${ }^{22}$ vom Westen auf den Rest der Welt, nachdem die Barrieren seit Ende des kalten Krieges beseitigt waren. Die Hauptform dieser Bewegung ist der Waren- und Finanzverkehr, ${ }^{23}$ welcher auch die treibende Kraft im Wettbewerb der Rechtsoderungen ist. Juristisch gesehen regelt einerseits das internationale Vertragsrecht die schuldrechtlichen Fragen des globalen Verkehrs. Da die Rechtsverständnisse verschiedener Rechtsorderungen bzgl. des Vertragsrechts nicht weit auseinander liegen, konnte man sich auf vieles einigen. ${ }^{24}$ Andererseits befindet sich das internationale Kreditsicherungsrecht, also der sachenrechtliche Bestandteil des Rechtsverkehrs, ${ }^{25}$ der die schuldrechtlichen Vorgänge absichern soll, in einem verhängnisvollen Zustand. ${ }^{26}$ Die Gründe dafür sind kompliziert: in erster Linie sind Einigungen im Bereich des zuweisenden Sachenrechts auf Grund ganz unterschiedlicher Rechtsanschauungen und Interessen extrem schwierig zu erzielen, und zwar nicht nur auf globaler Ebene, sondern sogar auch innerhalb des Kontinentalsystems. Hinzu kommt noch die Herausforderung bei der Gestaltung des modernen Kreditsicherungsrechts, bei der die sich rasant entwickelnden Verkehrsmittel und Informationstechnik einkalkuliert werden müssen, mit deren Hilfe der internationale Handel floriert. Bevor man diese in Angriff nehmen kann, müssen jedoch die völlig veralteten nationalen Regelungen des Kreditsicherungsrechtes überprüft werden.

Die juristische Umsetzung des „einfache“ Verlangens des ständig wachsenden Waren- und Finanzverkehrs nach hoher Sicherheit, Einfachheit, Schnelligkeit und Flexibilität der Geschäftsabwicklung ist höchst kompliziert und stellt die alten Rechtsordnungen bzw. die bewährten Rechtsprinzipien auf eine harte Probe. So stellt sich die Frage, ob die Publizität der

\footnotetext{
${ }^{22}$ Marx/Engels, Manifest der Kommunistischen Partei, S. 23: vorausgesehen haben Marx und Engels die Globalisierung schon vor mehr als hundert Jahren; für die Auseinandersetzung über die Globalisierung sind Marx und Engels unumgängliche Figuren wie Bentham and Adam Smith.

${ }^{23}$ Wallerstein, A Capitalist World-Economy, S. 55 ff.; mit anschaulicher Abbildung: Kutschker/Schmid, Internationales Management, S. 171.

${ }^{24}$ z.B. im UN-Kaufrecht: vom Vertragsschluss bis typische Rechte und Pflichten der Parteien eines Kaufvertrages.

${ }^{25}$ Bülow, Kreditsicherheiten, S. 1 ff.

26 Djankov/McLiesh/Shleifer, Private Credit in 129 Countries, S. 12; Graham-Siegenthaler,
} Kreditsicherungsrechte, S. 695. 
dinglichen Rechte durch Besitz oder herkömmliches Pfandregister ausreicht? Schränkt die strenge Handhabung des Spezialitätsgrundsatzes den Verkehr ein? Wie weit kann sich das Sachenrecht mit seinem Typenzwang und seiner Typenfixierung der schuldrechtlichen Vertragsfreiheit öffnen, ohne seine Grundlagen aufzugeben? ${ }^{27}$ Wie soll das Spannungsfeld zwischen Bestandsschutz auf der einen Seite und Verkehrsschutz auf der anderen Seite entschärft werden? Die wichtigste aller Fragen: Steht die Abstraktion, die bisher hauptsächlich in der deutschen Rechtsordnung anerkannt wird, zur Disposition des Gesetzgebers?

Zur Beantwortung der oben erwähnten Fragen, die sich gegenseitig bedingen und sich deswegen ständig in einer dynamischen Relation befinden, eignet sich die Gestaltung eines dem Globalisierungszeitalter gerechten Kreditsicherungsrechts meiner Meinung nach als hervorragendes juristisches Denkmodell. Zunächst befindet sich das Kreditsicherungsrecht an der Schnittstelle des Schuld- und Sachenrechts, wo die verschiedenen wirtschaftlichen Interessen zusammenfließen, die juristisch sachgerecht gelöst werden müssen. Darüber hinaus bringt die Suche nach einer gerechten Gestaltung des Kreditsicherungsrechts vor dem Hintergrund des globalen Verkehrs noch mehr Nutzen mit sich. Der grenzüberschreitende Verkehr zwingt wegen des Fehlens internationaler Regelungen zur Auseinandersetzung mit dem Kreditsicherungsrecht in verschiedenen Rechtsordnungen, wenn man die Probleme dauerhaft und nicht nur kollisionsrechtlich lösen will. Die Prinzipien und Gestaltungen des gesamten internationalen Sachenrechts stehen also auf den Prüfstand. Der Warenverkehr tangiert die Normen bzgl. beweglicher Sachen, und die Geldwirtschaft fordert ein hohes Maß an Freisetzung des Bodenwertes durch eine dem globalen Finanzverkehr gerechte Umgestaltung der gegenwärtigen Liegenschaftsregelungen. Schließlich muss man dem Verlangen des Verkehrs nach Schnelligkeit entsprechend auch die Auswirkungen der modernen Informationstechnik bei der institutionellen Rechtsfortbildung berücksichtigen, und überlegen, wie man sie in der Systemgestaltung nutzbringend einsetzen kann.

Von einem rein empirischen Standpunkt ausgehend hofft diese Arbeit am Ende einen kleinen Beitrag zur Erreichung des globalen gesellschaftlichen Wohlstands leisten zu können, und

\footnotetext{
${ }^{27}$ Als allgemeines Problem erkannt: Wolf, Wandel im Sachenrecht, NJW 1987, 2647 ff., 2651; speziell für die Sicherungstreuhand: Bülow, Kreditsicherheiten, Rn. 1099.
} 
zwar durch die Erhöhung der Investitionsbereitschaft auf Grund der effizienteren Gestaltung des Kreditsicherungsrechts. ${ }^{28}$

\section{Darstellungsweise und deren wissenschaftstheoretischer Hintergrund}

\section{a) Einschränkung auf die der Systembildung unentbehrlichen}

Ein besonderes Problem der Darstellung dieser Arbeit ergibt sich naturgemäß aus der Komplexität ihres Gegenstandes. Selbstverständlich ist eine komplette Darstellung der individuellen Gestaltungen des Kreditsicherungsrechts in verschiedenen Rechtsordnungen im vorliegenden Rahmen nicht möglich und auch nicht erforderlich. Viel wichtiger ist die Erörterung der Prinzipien und Methoden unterschiedlicher Rechtsordnungen, die die Rahmenbedingungen für die Rechtsgestaltungen darstellen. Anhand der Herausarbeitung der Vergleichsaspekte und Wertungskriterien werden zunächst die tragenden sachenrechtlichen Prinzipien miteinander verglichen und abgewogen. Erst auf der Grundlage dieser Vorarbeit kann man die Grundsätze ermitteln, die dem modernen Verkehr angemessen sind.

Aufgrund der Vielfältigkeit der Prinzipen und Gestaltungen in verschiedenen Rechtsorderungen und der klaren Gedankenführung halber verzichtet diese Arbeit bewusst auf zweierlei Darstellungsweisen: Erstens die Aneinanderreihung der Handhabungen der Einzelbereiche in verschiedenen Ländern und zweitens die Kategorisierung nach Personenund Realsicherheiten. Sinnvoll scheint mir die Abwägung der Ideen gebenden Teile der Vorgehensweise in verschiedenen Rechtsordnungen, die am Ende zur optimalen Behandlung des jeweiligen Gegenstandes führen soll. Ferner ist die Aufteilung der Sicherheiten anhand ihrer Forderungsgebundenheit dogmatisch viel wichtiger. Im Grundfall der deutschrechtlichen Kreditsicherung wird eine Rechtsbindung zwischen Forderung(en), die gesichert werden soll(en), und Sicherungsmittel durch einen verpflichtenden Vertrag (sog. Sicherungsvertrag im weiteren Sinne) hergestellt. Dabei kann das Sicherungsmittel entweder ein

\footnotetext{
${ }^{28}$ Djankov/McLiesh/Shleifer, Privat Credit in 129 Countries, S. 4 ff.: in einer groß angelegten Studie der Weltbank hat man statistisch festgestellt, dass sich ein besseres bzw. verbessertes System des Kreditsicherungsrechts positiv auf die Gesamtwirtschaft auswirken könnte; Apolte, Wohlstand durch Globalisierung, S. 27 ff, 28: eine neoliberale Ansicht - „... Niemand käme auf die Idee, dass Frau A nach dem Tausch besser dasteht als vorher, zu folgern, dass Herr B deshalb schlechter dastehen müsste. Der Tausch (einer Fußballkarte) ist von beiderseitigem Vorteil“. M.E. ist Globalisierung ein Faktum, das sowohl Vorteile, als auch Nachteile mit sich bringt. Wichtig ist nur, wie wir sie ausbalancieren können.
} 
Haftungssubjekt (Personensicherheiten) oder ein Haftungsobjekt (Realsicherheiten) sein. Je nach der Intensität dieser Bindung zwischen der Forderung und dem Sicherungsmittel kann man die deutschen Sicherheiten in zwei Gruppen aufteilen, nämlich die akzessorischen und die nichtakzessorischen. Die akzessorischen Sicherungsmittel (Bürgschaft, Hypothek, Faustpfandrecht etc.) sind in Entstehung, Umfang, Übertragung, Fortbestand und Durchsetzung von der gesicherten Forderung strikt abhängig. ${ }^{29}$ Diese steife gesetzliche Bestimmung des Hauptrechts über das Nebenrecht kann nicht aufgelöst werden. ${ }^{30}$ Daher haben sich flexiblere Formen der Kreditsicherung entgegen der Intention der historischen Gesetzgeber zahlreicher Rechtsordnungen durchgesetzt. Interessant ist, dass sich diese Tendenz nicht auf das deutsche Kreditsicherungsrecht. Weltweit befindet sich die abstrakte Sicherheit im Vormarsch. Deshalb verdient dieses Phänomen aus dogmatischer Sicht hohe Aufmerksamkeit.

Die entscheidende Frage des rechtsvergleichenden Kenntnisprozesses ist aber: Mit welchen Maßstäben kann man die unterschiedlichen Gestaltungen in verschiedenen Rechtsordnungen miteinander vergleichen? Dieses ewige Problem des Rechtsvergleichs ergibt sich insbesondere aus der Vielfältigkeit der Gestaltungen, die nicht selten von verschiedenen Zielsetzungen ausgehen.

Das angloamerikanische Rechtssystem geht z.B. von der Überzeugung aus, dass man eine gerechte Entscheidung nur von Fall zu Fall finden kann, und die Bildung eines abstrakten begriffslogischen Normsystems ist daher verpönt. ${ }^{31}$ Obwohl diese individuell-privatrechtliche Sichtweise durch die modernen Kodifikationen gelockert wurde, bleibt der Einfluss des traditionellen „Case-Law“ enorm. Hier wurzelt die Zersplitterung des angloamerikanischen Rechtssystems und damit dessen sehr begrenzte Vergleichbarkeit mit den kontinentalen Rechtssystemen. Nicht nur das Fehlen einer allgemeinen Systematik, sondern auch die fremdartige Terminologie bereitet dem Rechtsvergleich erhebliche Probleme. Der Rechtsbegriff „Contract“ ist z.B. wesentlich enger als sein Gegenstück im deutschen Recht,

\footnotetext{
${ }^{29}$ Schloz/Lwowski, Kreditsicherung, Rn. 17 f.; Lettel, Akzessorische Haftung, JA 2004, 238 ff.

${ }^{30}$ Medicus, Akzessorietät, JuS 1971, 497.

${ }^{31}$ Reimann/Ackmann, US-Amerikanische Privatrecht, S. 2, 9 f.
} 
umfasst i.d.R. etwa nur die gegenseitigen Verpflichtungsgeschäfte. ${ }^{32}$ Dingliche Verträge (z.B. zur Sicherheitsbestellung) im Sinne des deutschen Zivilrechts sind im angloamerikanischen Rechtssystem unvorstellbar. Noch verzwickter für einen Kontinentaljurist ist das „Property Law“, das nicht nur die Aufteilung des Sachenrechts in Vollrecht und beschränkte Rechte nicht kennt, sondern auch zwischen dinglichen und obligatorischen Rechten nicht klar unterscheidet. ${ }^{33}$ Im Gegensatz zum einheitlichen Eigentumsbegriff des Kontinentalzivilrechts spaltet man Property nach Personen, Zeit und Propertyright in Law oder in Equity ect. auf. ${ }^{34}$ Diese Vorgehensweise macht das Property Law zum kompliziertesten Gebiet des Common Law, und dies gilt auch für die amerikanischen Juristen. ${ }^{35} \mathrm{Im}$ Gegensatz zum angloamerikanischen System sind die Rechtsordnungen innerhalb des kontinentalen Rechtssystems in vieler Hinsicht vergleichbar, sowohl aufgrund der methodischen Ähnlichkeit und konkreten Kodifikationen als auch wegen der verwandten Rechtsbegriffe.

Als Rechtswissenschaftler neigt man instinktiv zum Rechtsvergleich durch die Überprüfung der logischen Folgerichtigkeit der Untersuchungsgegenstände. ${ }^{36}$ Hinsichtlich des Auffindens der bestmöglichen Gestaltung ist m.E. eine solche Vorgehensweise alleine nicht unbedingt viel erfolgversprechend, denn jede Rechtsordnung bemüht sich, zum Teil auch durch erfinderische Gesetzgebungs- oder Rechtsanwendungstechniken, ${ }^{37}$ das eigene System logisch abzurunden. Eine systeminterne Untersuchung oder die Abgleichung von Rechtsgestaltungen in normativer Hinsicht, die mit unterschiedlichen Methoden oder Zielsetzungen arbeiten, könnte nur dann sinnvoll sein, zumindest für das private Vermögensrecht, wenn externe Wertungskriterien wie z.B. aus der Ökonomischen Analyse bei der Beobachtung der

\footnotetext{
${ }^{32}$ Black’s Law Dictionary unter Stichwort „Contract“; Reimann/Ackmann, US-Amerikanische Privatrecht, S. 23

${ }^{33}$ Reimann/Ackmann, US-Amerikanische Privatrecht, S. 132.

${ }^{34}$ Reimann/Ackmann, US-Amerikanische Privatrecht, S. 132.

${ }^{35}$ Reimann/Ackmann, US-Amerikanische Privatrecht, S. 132.

${ }^{36}$ Vgl. Habilitationsschriften von Prof. Stadler, Gestaltungsfreiheit und Verkehrsschutz durch Abstraktion; Graham-Siegenthaler, Kreditsicherungsrecht im internationalen Rechtsverkehr.

${ }^{37}$ Basler Kommentar zum ZGB Art. 842 ff.: Wie z.B. der Schuldbrief - eine ,geschickte Handhabung“ : um eine Forderung zu sichern verkörpert man ein Grundpfandrecht (Verwertungsrecht) in einer Urkunde; durch Novation nach Art. 855 ZGB wird die Grundforderung durch Schuldbriefforderung getilgt; der Schuldbrief selbst wird als Wertpapier behandelt, dadurch erreicht man die Abstrahierung der Grundforderung und zwar mit Hilfe des Wertpapierrechts (m.M.n. eine sehr komplizierte Lösung!).
} 
jeweiligen Konstruktionen hinzukämen. Erst mit Hilfe von unparteiischen Maßstäben können bestimmte Sachfragen beantwortet werden, also zum Beispiel hier: Mit welchen Rechtskonstruktionen kann man die bestmögliche Gestaltung des Kreditsicherungsrechts im Zeitalter der Globalisierung erreichen?

Die oben erläuterte Grundüberzeugung hat zur Folge, dass die Überprüfungen der logischen Folgerichtigkeit und der ökonomischen und normativen Aspekte erst bei der Untersuchung der konkreten Prinzipien oder Gestaltungen zusammenfließen. Ein „,abstrakter Vergleich“ der „offenen“ Gestaltungsmöglichkeiten ist hier nicht vorgesehen.

Bei der Darstellung der ökonomischen Vergleichsaspekte verfolgt diese Arbeit dieselbe Grundidee der Konzentration auf die dem System unentbehrlichen. Da viele Begriffe, Theorien und Modelle der jungen Institutionenökonomik weit davon entfernt sind, ausgereift $\mathrm{zu}$ sein, ist eine ausführliche Darstellung des gesamten Instrumentariums und der diesbezüglichen wissenschaftlichen Streite nicht möglich und notwendig. Zum Zweck der Veranschaulichung stellt diese Arbeit die analytischen fundierten Ideen mit Hilfe von Kurven oder Grafiken dar, ohne die dahinter stehenden experimentaler oder mathematischer Beweise anzuführen, wenn es für das Verständnis nicht unbedingt nötig wäre. Wer sich dafür interessiert, kann er anhand der angegebenen Fußnoten nachgehen. Die Bandbreite und Darstellungstiefe der in Betracht kommenden Instrumente sollen derart reduziert werden, so dass die am Ende herausgearbeiteten Begriffe, Theorien und Modelle zur Analyse der verschiedenen Rechtskonstruktionen und zur begründeten Gestaltung eines neuen Kreditsicherungsrechts ausreichen. Eine Nebenzielsetzung dieses Abschnitts besteht darin, das Grundwissen der ökonomischen Analyse des Rechts zu vermitteln und die ökonomischjuristische Denkweise einzuüben.

Obwohl das Kreditsicherungsrecht sehr umfangreich ist, versucht diese Arbeit zum Schluss anhand des stufenweise konkretisierten Umrisses die Eckpunkte eines neuen, dem Globalisierungszeitalter gerechten Kreditsicherungsrechts zusammenzustellen, in welchem die tragenden sachenrechtlichen Prinzipien zeitgemäß neu ausgelegt werden. 


\section{b) Thesenverifikation, Ökonomische Analyse des Rechts und ihr}

\section{wissenschaftstheoretische Hintergrund}

Die US-Präsidenten machen häufig Witze über ihre Wirtschaftsberater: „It would have 100 questions and 3000 answers“ (Ronald Reagan); „I want to find a one-armed economist; ...... When I asked my economists for advice, they always answered, on the one hand, ..... on the other hand" (Harry Truman). Aus Sicht der Systemtheorie steckt hinter diesem Witz ein wichtiges Phänomen, das alle Realwissenschaft ${ }^{38}$ betrifft, nämlich das „,black box“ Phänomen. Eine „black box“ ist ein System, wenn es nur durch Input und Output zu beobachten ist. ${ }^{39}$ Alle Geisteswissenschaften haben das gleiche Problem mit der Meinungsvielfalt, da sie nicht die Materie (res extensa), sondern den menschlichen Geist (res cogitans) zum Gegenstand haben. In den Naturwissenschaften kann man sich den Luxus des Experiments auf Grund der Geschlossenheit des Bezugsobjektes leisten, indem man den Forschungsgegenstand unter ganz bestimmten, künstlich erzeugten und beherrschten Bedingungen beobachtet, Daten sammelt und analysiert. Dem Ökonom ist es jedoch nicht erlaubt, Geldpolitik zu manipulieren, um die Mechanismen des Marktes zu studieren. Der Gesetzgeber darf auch nicht verschiedene Gesetze bzgl. der gleichen Sache erlassen, um herauszufinden, welches aus systemischer Sicht am besten funktioniert.

Trotz alledem sind die wissenschaftstheoretischen Grundmethoden aller Realwissenschaften die Gleichen: ${ }^{40}$

Wie erwähnt liegen die Forschungshindernisse der Kulturwissenschaften in deren Systemoffenheit und der Unbestimmbarkeit ihrer Bezugsgegenstände (also in der 1. Stufe) und der daraus resultierenden Unverifizierbarkeit der Hypothesen. In dieser Phase kann ein Naturwissenschaftler das Experiment als Beobachtungswerkzeug einsetzen. Damit „stellt er der Natur durch ein ganz bestimmtes instrumentelles Einwirken eine präzise Frage und erhält

\footnotetext{
38 Anzenbacher, Philosophie, S. 36: Gegenstand der Realwissenschaften sind im Gegensatz zu den Formalwissenschaften (Mathematik, Logik etc.) reale Sachverhalte, wie z.B. die Natur (Naturwissenschaften) oder die menschliche Gesellschaft (Kulturwissenschaften).

${ }^{39}$ Duden - Das große Wörterbuch: unter Stichwort „Blackbox“.

${ }^{40}$ Anzenbacher, Philosophie, S. 25 f.; S. 237 ff., Theorieentwicklung in drei Stufen: 1. Stufe: Beobachtung Beschreibung - Klassifikation; 2. Stufe: Verallgemeinerung durch Aufstellung von Hypothesen; $\underline{3}$. Stufe: Entwicklung der Theorie als Erklärung der Zusammenhänge der Hypothesen.
} 
eine bestimmte, in Beobachtungssätzen formulierbare Antwort“. ${ }^{41}$ Ein Ökonom darf, zumindest in volkswirtschaftlicher Hinsicht, nicht künstlich die Wirtschaftsprozesse manipulieren, kann aber statt des Experimentes objektive Wirtschaftsdaten sammeln und analysieren. Je mehr sich eine Disziplin von empirisch beobachtbaren und bestimmbaren Gegenständen entfernt, desto schwieriger und unsicherer wird es mit der Beobachtung und Verifikation von Hypothesen.

In der Beobachtungsphase können die Juristen nur ganz indirekte Hilfsmittel als Surrogat des Experiments einsetzen. In Betracht kommen etwa die nationalen Rechtsprechungen oder der internationale Rechtsvergleich, welche aber, anders als das naturwissenschaftliche Experiment, keine komplexitätsreduzierende Funktion besitzen und in mancher Hinsicht sogar komplexitätssteigernde Nebenwirkungen haben. Außerdem führen die Systematisierung und Analyse der Rechtsprechungen und der Rechtsvergleich nicht zur Verifikation der Hypothesen oder Theorien. Infolgedessen ist die Meinungsvielfalt bzw. wissenschaftliche Unsicherheit bei der Jurisprudenz von vornherein unvermeidbar, denn die Fundamente (also die Beobachtungssätze) der Hypothesen- und Theorienaufstellung sind nicht hinreichend reduziert und gesichert. ${ }^{42}$

Also liegt das Problem nicht in der Kompliziertheit, sondern in der Komplexität. Bevor uns andere Wissenschaftsdisziplinen genauere Beobachtungs- und Verifikationsmethoden ${ }^{43}$ (vgl. das Beispiel „Endowment-Effekt“ in C, III, 1, b) liefern, können die Rechtswissenschaftler leider nur den alten Weg der Systembildung durch Organisation (Theorienbildung) der Hypothesen der Hypothesen (bzgl. der Beobachtung) nehmen. Im Hinblick auf die Sachlichkeit des Systems könnte die Ökonomische Analyse des Rechts eine kleine Abhilfe wegen der methodischen Anlehnung an die Naturwissenschaften schaffen.

\footnotetext{
${ }^{41}$ Anzenbacher, Philosophie, S. 244.
}

${ }^{42}$ Zur Lösung dieses Problem bzgl. der Beobachtung hat diese Arbeit ein eigenes Konzept entwickelt, z.B. s. D, II, 2, a), aa), (1) und (2) i.V.m. 3, a), bb), (1), .

${ }^{43}$ Vgl. Schanz, Der Manager und sein Gehirn, S. 13: Die bisherige herrschende Meinung ist, dass sich das menschliche Tun anders als naturwissenschaftliche Phänomene keinen Gesetzmäßigkeiten unterwirft (vgl. Fülbier, S. 19). Auf Grund neuer Techniken, wie z.B. Computer- oder Magnetresonanztomographie, sind neue Methoden der Beobachtung des menschlichen Geistes entwickelt worden. Die Neurowissenschaft verschafft einen ganz neuen Zugang für die Kulturwissenschaft. Aber diese Forschungsrichtung ist sehr jung, und es ist noch ein sehr, sehr langer Weg bis sie zuverlässige und brauchbare Werkzeuge liefern kann. 
Angesichts der Komplexität des Gegenstands und der mir zur Verfügung stehenden Ressourcen ist es bedauerlicherweise im Rahmen dieser Arbeit unmöglich, die oben erwähnten wissenschaftstheoretischen Schritte beständig anzuwenden. Verfolgt werden kann daher nur die "Strategie des Im-Hinterkopf-Behaltens“ der Vorgehensweise bei der Auseinandersetzung mit verschiedenen Begriffen, Prinzipien, Gestaltungen und Rechtsinstituten. Besonders viel Wert wird auf das relationelle Denken gelegt, das sich auf die dynamischen Strukturen der Gestaltungsmöglichkeiten bezieht.

\section{c) Interne Verweisungen als besondere Darstellungstechnik}

Alleine die Aufstellung von Thesen und den entsprechenden Normen am Anfang der jeweiligen Passagen oder die sorgfältigen Gliederungen reichen angesichts der Komplexität der Gegenstände meiner Meinung nach nicht aus, die zusammenfließenden Gedankengänge aus ökonomischer Analyse oder verflochtenen Rechtsprinzipien in bestimmten kurzen Aussagen trefflich darzustellen. Außerdem liegen die Lösungen für bestimmte Problemkomplexe (z.B. Abstraktionsprinzip, Bestimmtheitsgrundsatz) häufig außerhalb ihrer Themenkreise (z.B. Publizitätsgrundsatz). Deshalb wird diese Arbeit die internen Verweisungen, wenn nötig, in der Weise in Anspruch nehmen, indem auf die im Bezug genommenen Stellen und Thesenbereiche in den Fußnoten deutlich hingewiesen werden. 


\section{B. Einheitliche abstrakte Sicherheit als Musterbild moderner Gestaltung des Privatvermögensrechts}

Zur Orientierung der gedanklichen Auseinandersetzung bzgl. denkbarer Gestaltungsmöglichkeiten ist es zweckmäßig, das in dieser Arbeit vorzustellende Normenmodell der abstrakt gestalteten einheitlichen Sicherheit sogleich ins Bild zu setzen und die Diskussionen fangen dann anhand konkreter Normenvorschläge an. In der Darstellung konkreter Diskussionsgegenstände werden die entsprechenden wissenschaftlichen Thesen begleitend angeführt, damit man sich beim Lesen besser orientieren kann.

Dieser Gesetzgebungsvorschlag erhebt keinen Anspruch auf Vollständigkeit. Es ist zwar wünschenswert, das gesamte Gefüge des Verfügungssystems sowohl aus schuldrechtlicher als auch aus sachenrechtlicher Sicht, näher zu bestimmen. Dies würde aber den Rahmen dieser Arbeit sprengen und ins Uferlose gehen. Dennoch enthalten die Ausführungen bzgl. des Kreditsicherungsrechts alle wichtigen Diskussionen über die Grundstrukturen des Privatvermögensrechts, die sich in den vorgestellten Normen erkennbar gemacht werden sollen.

\section{Sicherungsvertrag}

\section{$\S 1$ Vertragstypische Pflichten beim Sicherungsvertrag}

(1) Durch den Sicherungsvertrag wird der Sicherungsgeber verpflichtet, dem Sicherungsnehmer eine Sicherheit für die Erfüllung einer (künftigen) Verbindlichkeit nach Maßgabe dieses Gesetzes zu bestellen.

(2) Der Sicherungsnehmer ist verpflichtet, dem Sicherungsgeber die Sicherheit nach Beendigung des Sicherungsverhältnisses zurückzugewähren.

\section{§ 2 Form der Sicherungserklärung}

Zur Gültigkeit des Sicherungsvertrags ist die schriftliche Erteilung der Sicherungserklärung erforderlich. Die Erteilung der Sicherungserklärung kann auch in elektronischer Form erfolgen, wenn sie mit qualifizierten digitalen Signaturen der Parteien versehen ist. 


\section{§ 3 Wertwahrungspflicht des Sicherungsgebers}

(1) Der Sicherungsgeber darf den Wert des Sicherungsgegenstandes während der Dauer des Sicherungsvertrages nicht beeinträchtigen. Darüber hinaus ist der Sicherungsgeber nicht verpflichtet, den Wert des Sicherungsgegenstandes beständig zu erhalten, wenn er sich nach der Übertragung der Sicherheit verringert, soweit nicht aus dem Sicherungsvertrag sich ein anderes ergibt.

(2) Tritt im Laufe des Sicherungsverhältnisses ein Ereignis ein, das den Wert des Sicherungsgegenstandes gefährdet oder beeinträchtigt, so hat der Sicherungsgeber geeignete Maßnahmen zu treffen und dies dem Sicherungsnehmer unverzüglich anzuzeigen.

\section{§ 4 Bewertung der Sicherheit}

Soweit sich aus dem Sicherungsvertrag nicht ein anderes ergibt, richtet sich die Bewertung der Sicherheit nach dem Richtwert, der durch die Zentralregisterstelle zur Zeit der Sicherheitsfreigabe zur Verfügung gestellt wird. Sofern ein solcher Richtwert nicht vorhanden ist, ist der objektive Verkehrswert maßgebend.

\section{$\S 5$ Sicherungsumfang}

Sofern nicht aus dem Sicherungsvertrag sich ein anderes ergibt, haftet der Sicherungsgegenstand für den Bestand der Hauptverbindlichkeit, Zinsen sowie Kosten, die im Zusammenhang mit der Befriedigung aus dem Sicherungsgegenstand anfallen.

\section{$\S 6$ Anspruch des Sicherungsgebers auf Freigabe}

Der Sicherungsgeber kann vom Sicherungsnehmer die Teilfreigabe der Sicherheit verlangen, wenn der Verkehrswert der Sicherheit $150 \%$ des Betrags der gesicherten Forderung überschreitet. Lässt sich ein Verkehrswert nicht ermitteln, so kann der Anschaffungswert der Sicherheit herangezogen werden.

\section{§ 7 Sonderkündigungsrecht}


Der Sicherungsvertrag kann nur aufgrund einer ausdrücklichen Regelung im Sicherungsvertrag gekündigt werden.

\section{§ 8 Zweckbestimmung der Leistung}

(1) Für die Zweckbestimmung der Leistung ist der erklärte Wille des Leistenden maßgebend. Sofern der Wille bei der Zahlung nicht ausdrücklich erklärt worden ist, ist er aus der Interessenlage zu entnehmen.

(2) Die Zweckbestimmung der Leistung kann nachträglich vereinbart werden.

\section{§ 9 Rückübertragungsanspruch}

(1) Nach Erledigung des Sicherungszwecks kann der Sicherungsgeber vom Sicherungsnehmer die Rückübertragung der Sicherheit an sich oder an einen Dritten verlangen.

(2) Der Rückgewähranspruch eines Dritten, der die Sicherheit zur Verfügung gestellt hat, richtet sich nach seiner Vereinbarung mit dem Sicherungsgeber. Sofern eine solche Vereinbarung nicht getroffen worden ist, kann der Dritte anstelle des Sicherungsgebers vom Sicherungsnehmer die Übertragung der Sicherheit an sich verlangen.

\section{$\S 10$ Sicherungsfall und Verwertungsreife}

(1) Der Sicherungsnehmer kann die Verwertungsphase einleiten, wenn die gesicherten Forderungen (Sicherungszweck) trotz Fälligkeit nicht befriedigt werden.

(2) Der Sicherungsnehmer hat dem Sicherungsgeber die Verwertung der Sicherheit vorher anzudrohen. Die Androhung darf unterbleiben, wenn sie untunlich ist. Ist die Androhung untunlich, so wird der Monat von dem Eintritt der Verwertungsberechtigung an berechnet.

(3) Die Verwertung darf nicht vor dem Ablauf eines Monats nach der Androhung beginnen, wenn der Wertverfall der Sicherheit nach ihrer Eigenschaft nicht zu befürchten ist. Sofern der Wertverfall der Sicherheit zu befürchten ist, hat der Sicherungsnehmer dem Sicherungsgeber eine angemessene Frist anzudrohen. 


\section{§ 11 Pflicht des Sicherungsnehmers zur bestmöglichen Verwertung}

Der Sicherungsnehmer hat für die bestmögliche Verwertung hinsichtlich des Verwertungserlöses Sorge zu tragen. Die Erfüllung dieser Anforderung wird vermutet, soweit der Sicherungsnehmer das elektronische Verwertungsverfahren der Zentralregisterstelle in Anspruch genommen hat.

\section{Sicherheitsbestellung}

\section{$\S 12$ Anwendungsbereich}

Soweit es tunlich ist, hat die Bestellung einer Sicherheit an einem Grundstück, einer beweglichen Sache, einer Forderung, einem Wertpapier oder sonstige Vermögenswerte (Sicherungsgüter) nach den Bestimmungen dieses Gesetzes zu erfolgen.

\section{$\S 13$ Sicherheitsbestellung}

(1) Ein Sicherungsgut kann in der Weise belastet werden, dass an denjenigen, zu dessen Gunsten die Belastung erfolgt, eine bestimmte Geldsumme aus dem Sicherungsgut zu zahlen ist.

(2) Die Sicherheit kann auch für eine zukünftige oder bedingte Forderung bestellt werden. ${ }^{44}$

\section{$\S 14$ Registereintragung}

(1) Zur Bestellung der Sicherheit sind die Einigung des Berechtigten und des anderen Teils sowie die Eintragung der Sicherheit in das zentrale Sicherheitsregister erforderlich.

(2) Soweit ein Sicherungsgut mit elektronischer automatischer Identifikationsvorrichtung ausgestattet ist, wird die Einigung in der automatischen Erfassung vermutet.

(3) Ein Verbraucher ist berechtigt, die automatische Erfassung der Einigung zu verweigern.

\footnotetext{
${ }^{44}$ Hier liegt eine wirtschaftlich notwendige Durchbrechung des Bestimmtheitsgrundsatzes.
} 
(4) Die sonstigen formellen Voraussetzungen der Eintragung richten sich nach der Registerordnung. 


\section{Sicherungsvertrag als strukturelle Grundentscheidung}

T1. Sowohl aus (a) juristischer als auch aus (b) ökonomischer Hinsicht bietet das Abstraktionsprinzip die zurzeit denkbar beste Gestaltungsmaxime für den modernen hochkomplexen (globalisierten) Wirtschaftsverkehr, welcher hohe (c) Sicherheit, (d) Schnelligkeit, (e) Flexibilität und (te) Gesanostefflizienz abverlangt.

wichtiger Hinweis $^{45}$

T2. Die (a) Unvollkommenheit der gegenwartigen Rahonembedingumgen des deutschen Zivilirechts (b) begingstigt die (c) Entfaltung des selbstzerstörerischen Potenzials des historisch entwickelten Abstraktionsprinzips, welches zur Aufhebung der durch die Trennung zwischen Schuld- und Sachenrecht gekennzeichneten deutschen Zivilrechtsdogmatik führt.

\section{Die dogmatischen Fundamente der gängigen (sicherungsrechtlichen)}

\section{Gestaltungen}

T1. Sowolhl aus (a) juristischer* als auch aus (b) oflkomomischer Hinsicht bietet das Abstraktionsprinzip die zurzeit denkbar beste Gestaltungsmaxime für den modernen hochkomplexen (globalisierten) Wirtschaftsverkehr, welchere thohe (c) Sicherherit, (d) Schnelligkeit, (e) Elexibilitagit und (E) Gesamiteffizienz abverlangt.

*Mit ,juristisch“" gemeint ist die systematische Klarheit und dogmatische Folgerichtigkeit.

\footnotetext{
${ }^{45}$ Wichtiger Hinweis: Stichwörter mit Hohlbuchstaben bedeuten solche Eigenschaften, die nicht zu den darauf folgenden Themenbereichen gehören, z.B. Die Stichwörter mit Hohlbuchstaben,,(C) Sichertheir , (A $)$ Gesamnteffirzienz" weisen darauf hin, dass der Sicherungsvertrag (Thema) als Rechtsinstitut alleine keine Rechtssicherheit bietet und deswegen die Gesamteffizienz geschadet wird; umgekehrt kennzeichnen die normalen Buchstaben (These des Abschnitts) z.B. „Schnelligkeit, Flexibilität“ solche Eigenschaften, die zur Stärke des Sicherungsvertrags (Thema) als Rechtsinstitut zählen. Die Schwächen des Sicherungsvertrags als

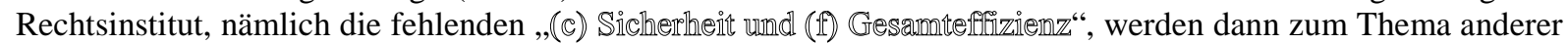
Abschnitte, wo mit dem Problem der fehlenden ,,(c) Sicherheirt und (1) Gesamatefffizienz" des Sicherungsvertrags auseinandergesetzt wird und zur Lösung dieses Problems des Rechtsinstituts (Sicherungsvertrag), z.B. durch Einführung eines (elektronischen) Registers, kommt. Auf dieser Weise werden alle Thesen (s. A, II) nach und nach behandelt. Eine durch Rahmen hervorgehobene These wird solange Thema des nachfolgenden Abschnitts bis eine andere These angezeigt wird.
} 
In jeder Rechtsordnung wird das Sicherungsrecht als Teil des Vermögensrechts und anhand dessen Grundprinzipien konstruiert. Die heutzutage einflussreichsten Zivilrechtsordnungen wie z.B. BGB, CC oder UCC, sind vor allem Produkte der rechtspolitischen Reaktion auf die dramatische Entwicklung der politischen (Ende des Absolutismus) und wirtschaftlichen Lage (Industrialisierung). Die direkte Form dieser Bewegung heißt „Kodifikation“: eine Wortschöpfung des geistigen Vaters der Ökonomischen Analyse des Rechts - Bentham. ${ }^{46}$ Als Teil der rapiden sozialen Reform versuchte man hier ideologische Forderungen der Industriegesellschaft - Freiheit, Gleichheit - institutionell mit „Willensfreiheit“ bzw. „Vertragsfreiheit““ zu festigen. ${ }^{47}$ Mit der Kodifikation wollte der Gesetzgeber des BGB ein Gesetz, das entwicklungsfähig ist und gleichzeitig eine feste Grundlage bietet, schaffen. ${ }^{48}$ Aber ausgerüstet allein mit der begrenzten Elastizität von Einzelregelungen wie z.B. $\S \S 242$, 138, 157, 226 oder 826 BGB, die den sozialen Verhältnissen der Anfangszeiten der Industrialisierung entsprechend konzipiert wurden, ist das BGB (die anderen Rechtsordnungen natürlich auch) hinsichtlich der Wahrung der Balance zwischen Stabilität und Dynamik von der Geschwindigkeit und Komplexität des modernen (globalen) Wirtschaftsverkehrs völlig überfordert. Dieses Phänomen ist im deutschen Kreditsicherungsrecht besonders klar zu beobachten. Obwohl das Recht der Kreditsicherung allgemein als ein eigenständiges Rechtsgebiet anerkannt wird, sucht man eine in sich geschlossene gesetzliche Regelung des Kreditsicherungsrechts oder eine Kodifikation dessen Kernnormen vergebens. Darüber wundert man sich nicht unbedingt bei dem auf Case Law basierenden angloamerikanischen Rechtssystem (der UCC widmet aber einen ganzen Artikel 9 den Sicherungsrechten), bei dem mit der Kodifikation des Zivilrechts prominent gewordenen deutschen Recht aber schon, denn eines der Hauptziele bei der Schaffung des BGB war die Herstellung von Rechtseinheit. ${ }^{49}$ Es überrascht noch mehr, wenn man im BGB gar keine Aussage über die heutzutage in Deutschland meist in Anspruch genommenen Sicherungsmittel, z.B. Sicherungsübereignung und/oder Sicherungsabtretung findet, während die Regelungen bzgl. der Sicherheiten im BGB nach mehr als hundert Jahren nahezu wörtlich

\footnotetext{
${ }^{46}$ Mertens, Gesetzgebungskunst im Zeitalter der Kodifikationen, S. 497 ff.

${ }^{47}$ S. Larenz/Wolf, BGB - AT, S. 431: Funktion des Rechtsgeschäfts ist, die Voraussetzungen und den Rahmen für die rechtsgestaltende Bestätigung des privatautonomen Willens gesetzlich festzulegen.

${ }^{48}$ Honsell, Einleitung zum BGB, S. 8.

${ }^{49}$ MüKo/Säcker, Einl. Rn. 32; Staudinger/Coing/Honsell Einl. Rn. 19.
} 
unverändert geblieben sind. ${ }^{50}$ Selbst wenn die damalige Gesetzgebungstechnik perfekt wäre, stellt sich gleichwohl die Frage, ob die Sicherungsmittel des BGB mit ihren gesellschaftlichen Hintergründen des 19. Jahrhunderts noch zeitgemäß sind. Um diese Frage zu beantworten, setzt sich die folgende Untersuchung rechtsvergleichend mit den Grundprinzipien des BGB und ihren Auswirkungen auf die Sicherungsmittel auseinander.

Ziel der Auseinandersetzung in diesem Abschnitt ist es die sachenrechtlichen Rahmenbedingungen herauszukristallisieren, die ein im BGB nicht vorhandenes klares Konzept der Sicherungsgeschäfte ${ }^{51}$ ermöglichen.

\section{Grundprinzipien der Verfügung}

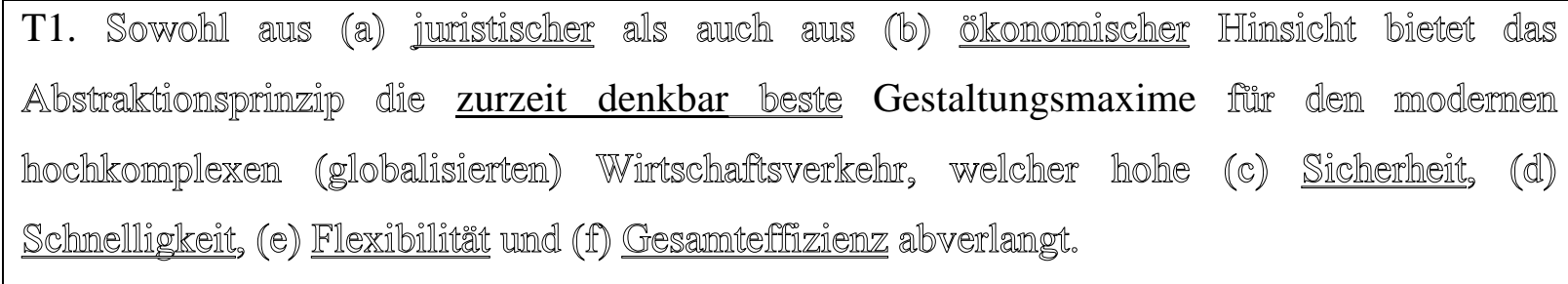

Die technischen Derivate der Willensfreiheit sind die Vertrags- ( $\S 311$ I BGB) und Eigentumsfreiheit ( $\$ 903$ S.1 BGB). Das Eigentum als der elementare Grundpfeiler des privaten Vermögensrechts soll nach Vorstellung des Gesetzgebers des BGB das umfassendste dingliche Recht, also das Vollrecht, sein. ${ }^{52}$ Der Eigentümer kann, soweit nicht das Gesetz oder Rechte Dritter entgegenstehen, mit der Sache nach Belieben verfahren. Die Rechtsstellung des Eigentümers hängt in ihrem Wert aber nicht nur vom umfassenden Inhalt des Eigentums ab, sondern auch von dessen Schutz im Falle einer Eigentumsverletzung. ${ }^{53} \mathrm{Im}$ Sachenrecht herrschen deswegen die vier tragenden Grundprinzipien: Typenzwang und

\footnotetext{
${ }^{50}$ Vgl. Bürgerliches Gesetzbuch für das Deutsche Reich, 1896 und BGB im Schönfelder 2011, fast wörtlich gleich: $§ 232$ ff., 765 ff., 1204 ff.; mit sehr geringfügigen Veränderungen: $§ 1273$ ff., 1113 ff.; 1192 ff.

${ }^{51}$ Wiegand, Staudinger Anh. zu $§ 9929$ ff., Rn.10: Weder die Entstehungsgeschichte noch das BGB selbst lassen ein klares Konzept der Sicherungsgeschäfte erkennen. Vielmehr treten die Diskrepanzen und Widersprüche offen zutage: Während die Verpfändung durch Traditionsprinzip und Akzessorietät an strenge Voraussetzungen geknüpft und ,publik“ gemacht wird, lässt man gleichzeitig ausdrücklich den Eigentumsvorbehalt und stillschweigend die Sicherungsübereignung zu.

${ }^{52}$ BVerfGE 24, 367, 389.

${ }^{53}$ Wolf, Wandel im Sachenrecht, NJW 1987, 2648.
} 
Typenfixierung, Publizitätsgrundsatz, Bestimmtheitsgrundsatz sowie der Grundsatz der Spezialität. ${ }^{54}$ Diese Prinzipien strahlen ein hohes Maß an Rechtssicherheit und Eigentumsschutz aus. Zusammen mit dem Abstraktionsprinzip ergeben sich die starren Rahmenbedingungen des deutschen Kreditsicherungsrechts, die nicht unbedingt den Anforderungen der modernen flexiblen Wirtschaft entsprechen. Das wichtigste Charakteristikum der deutschen Privatrechtsordnung ist das sehr umstrittene Abstraktionsprinzip, welches den zentralen Mechanismus der Zuordnung regelt. Im Gegensatz zum Schuldrecht herrscht in diesem Gebiet, wie schon erwähnt, auf Grund ganz unterschiedlicher Rechtsanschauungen und Interessen die Gestaltungsvielfalt. Da die Sicherungsrechte als subjektive Rechte aus einer gegebenen Verfügungsordnung erwachsen (z.B. sind die in Deutschland üblichen fiduzarischen Sicherheiten in Ländern ohne Abstraktionsprinzip nicht ohne weiteres möglich), ist eine Auseinandersetzung mit den Verfügungsprinzipien unumgänglich, bevor man mit der Erörterung spezieller Probleme beginnen kann. Obwohl diese Arbeit die verschiedenen Rechtsordnungen (unvermeidlicherweise) aus der Perspektive des deutschen Privatrechts betrachtet, soll die Betonung meiner Meinung nach auf der „Sachlichkeit“ der Auseinandersetzung liegen. Denn nur so ist das Auffinden der bestmöglichen Gestaltungsmöglichkeit zu garantieren.

Statisch gesehen besitzt das Eigentum die Funktion als Wertträger, welche seinem Inhaber wirtschaftliche und gesellschaftliche Entscheidungsmacht darüber vermittelt, wer und wie an dem Wert des Eigentums teilhaben kann. ${ }^{55}$ In rechtlicher und wirtschaftlicher Hinsicht entscheidend für diese Entscheidungsmacht ist aber nicht die Zuordnung eines Vermögengegenstands an eine Person (Ruhezustand) selbst, sondern der das Zuordnungsverhältnis verändernde Bewegungsvorgang z.B. durch Rechtsgeschäfte, Leistungen oder Rechtsverletzungen. ${ }^{56} \mathrm{Da}$ es in Bezug auf diese Angelegenheit um die „Nervenzentrale“ jeder Rechtsordnung geht, steht die ganze historisch gewachsene Rechtsordnung und -kultur auf dem Spiel, wenn der zuordnende Mechanismus wesentlich verändert wird. Infolgedessen verteidigt jede Rechtsordnung mit allen Mitteln ihr eigenes

\footnotetext{
${ }^{54}$ Wolf, Sachenrecht, S. $11 \mathrm{ff}$.

${ }^{55}$ Wolf, Sachenrecht, S. 48 f.

${ }^{56}$ Vgl. Medicus, Grundwissen zum Bürgerlichen Recht, Rn. 30 ff.
} 
Zuordnungssystem, und eine Rechtszersplitterung auf der internationalen Ebene ist die unausweichliche Folge. Mit zunehmendem grenzüberschreitendem (Güter- und Finanz)Verkehr, also Bewegung der Werte, ist endlich spürbarer realer Druck und das echte Bedürfnis da, ein einheitlich funktionierendes Werteumschlagsystem zu schaffen.

Das erste Problem bei der Verschaffung einer Übersicht über die Verfügungsprinzipien in internationalem Kontext ist die methodische Meinungsverschiedenheit zwischen dem kontinentalen Zivilrecht und dem angloamerikanischen Privatrecht. Da das Common Law anders als das kontinentale Zivilrecht nicht auf gesetzgeberische Präzision und logische Konsistenz, sondern auf Flexibilität und Sachnähe zielt, ${ }^{57}$ herrschen dort das Denken in einer Vielzahl von Einzelregelungen und die „Case Law“-Tradition; der Wusch nach einer allgemeinen sachenrechtlichen Systematik und die Möglichkeit sich dahin zu entwickeln existieren verständlicherweise nicht. Infolgedessen ist ein direkter Rechtsvergleich der sachenrechtlichen Gestaltungen nicht ohne weiteres möglich. Innerhalb des kontinentaleuropäischen Rechtssystems, wo die gleiche Eigentumskonzeption herrscht, ${ }^{58}$ ist die systematische Zusammenfassung der Vermögenszuordnung hingegen übrig. Aus diesen Gründen setzt folgender Rechtsvergleich zunächst bei den kontinentaleuropäischen Zivilrechtsordnungen an.

Nun kommen wir auf den die Zuordnung verändernden Bewegungsmechanismus, also den wertneutralen Regulierungsgegenstand verschiedener Rechtsordnungen, zurück. In den kontinentalen Rechtsordnungen dürfen und können die relevanten Regelungen auf Grund der Philosophie der Kodifikation und des Umfang eines Gesetzbuches nicht, wie beim angloamerikanischen System, uferlos sein. Infolgedessen versucht man es hier mit der Systembildung über Rechtsgrundsätze. Aus historischer Sicht wachsen die Rechtsprinzipien und Rechtssätze wie ein Baum: Wenn die Willensfreiheit der Stamm wäre, dann wäre der Mechanismus bezüglich des Übergangs der Herrschaft an körperlichen Gegenständen (also die Übereignung im deutschen Recht) der erste Hauptzweig, woraus wiederum die anderen

\footnotetext{
${ }^{57}$ Reimann/Ackmann, US-Amerikanisches Privatrecht, S. 25.

${ }^{58}$ Vgl. die sachenrechtlichen Grundsatze wie etwa die Absolutheit, Spezialität, Publizität, numerus clausus etc.: Seiler, Sachenrecht, in: Staudinger-Eckpfeiler des Zivilrechts, S. 888; Ferid/Sonnenberger, französisches Zivilrecht, 3 A 210 f., 3 A 16 ff.; Patti, Codice Civile Italiano, Art. 832 ff., S. 221 ff.; Sohst, Código civil español, Art. 348 f., S. 92 f.
} 
Regulierungselemente entstammen. Das Ganze wird in der deutschen Rechtssprache „Verfügungssystem“ genannt.

In der Philosophie über die Fahrnisübereignung stecken die „Gene“ der Verfügungssysteme - nämlich die Haltung zur Gestaltung der translativen Funktion des Rechts, woraus die anderen Subverfügungsformen eines Rechtssystems, wie z.B. die Sicherheitsbestellung, generiert werden.

Den strukturell einfachsten Eigentumsübergang findet man im romanischen Rechtskreis mit dem Hauptbeispiel Frankreich (Art. 1583 CC). ${ }^{59}$ Hier reicht für den sofortigen Rechtstransfer schon der bloße Konsens der Parteien über den Gegenstand und Preis. Dieses reine Konsensprinzip gilt sowohl für bewegliche als auch für unbewegliche Sachen; ${ }^{60}$ damit möchte man den Parteien größtmögliche Freiheit in der Gestaltung des Rechtsverhältnisses ohne Rücksicht auf die Einhaltung von weiteren Erfordernissen, wie z.B. Formalitäten, Kaufpreiszahlung oder Lieferung, einräumen. ${ }^{61}$ Nicht aus rechtsvergleichendem Aspekt, sondern nur aus historischer Sicht kann man den Grundgedanken des CC in Form des reinen Konsensprinzips verstehen. Nach der französischen Revolution legte der Code Napoléon als die erste große Kodifikation den Grundstein zur wirtschaftlichen Entwicklung des industriellen Zeitalters. ${ }^{62}$ Die damaligen Redakteure des CC wollten mit der individualistischen und subjektivistischen Ausrichtung der Eigentumskonzeption in erster Linie den institutionalisierten Freiheitsgedanken als Instrument für die Befestigung der Abschaffung des feudalistischen Obereigentums und Stärkung des Nutzungseigentums zum Volleigentum einsetzen. ${ }^{63}$ Man legte viel mehr Wert auf die leichte Verständlichkeit der Sprache als auf Konsequenz und Präzision. ${ }^{64}$ Die Verfasser schufen ein Zivilgesetzbuch für eine überwiegend agrarische Gesellschaft, in der die Hauptform des Eigentumstransfers der

\footnotetext{
${ }^{59}$ Hier am Beispiel des Kaufes: Jeroscheg, Eigentum an beweglichen Sachen, S. 256.

${ }^{60}$ Ferid/Sonnenberger, französisches Zivilrecht, 2 G 131, 3 A 20.

${ }^{61}$ Jeroscheg, Eigentum an beweglichen Sachen, S. 256 f.

${ }^{62}$ Bürge, französisches Privatrecht, S. 3.

${ }^{63}$ Ferid/Sonnenberger, französisches Zivilrecht, 3 A 202.

${ }^{64}$ Ferid/Sonnenberger, französisches Zivilrecht, 1 A 321, 1 A 332.
} 
Hand- und Barkauf war. ${ }^{65}$ Vor diesem geschichtlichen Hintergrund war eine differenzierte Denkweise über die juristische Konstruktion des Eigentumsübergangs noch nicht ausgereift und konnte sich auch nicht durchsetzen, obwohl im CC durchaus viele Ansätze vorhanden sind, die eine Entwicklung in diese Richtung hätten fördern können. Darauf werden wir in einem anderen Zusammenhang zurückkommen.

Unter der geistigen Herrschaft des reinen Konsensprinzips kennt das französische Recht die Denkkategorien „Einheits- oder Trennungsprinzip“ eigentlich nicht. Von dieser Unterteilung kann erst gesprochen werden, wenn man einen anderen einflussreichen kontinentaleuropäischen Rechtskreis in Betracht zieht, nämlich die germanische Rechtsfamilie, wo die dingliche Wirkung eines Rechtsaktes und die Übergabe eine wichtige Rolle bei der Übereignung spielen. Wenn man die möglichen Gestaltungen der

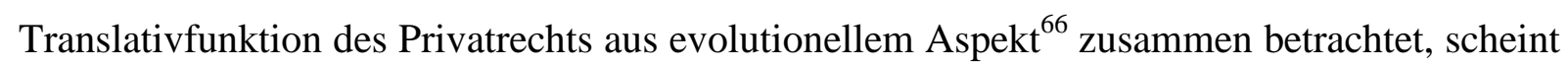
das polnische Zivilgesetzbuch eine weitere konsequente Entwicklungsstufe zu sein. Im Jahr der Einsetzung der Kodifizierungskommission (1919) galten auf dem polnischen Territorium fünf Rechtsordnungen, die zum französischen und germanischen Rechtskreis gehörten. ${ }^{67}$ Ausreichende Zeit und Ressourcen für feine Juristerei hatten die polnischen Redakteure nicht unbedingt, ${ }^{68}$ und dies schlug sich auch in der Kodifikation nieder. Hier werden die strukturell einfachsten und am leichtesten zu verstehenden Prinzipien und Elemente zusammengesetzt, wie z.B. das Konsensprinzip aus dem romanischen Rechtskreis und die Rechtsgeschäftslehre (insbes. bzgl. Willenserklärung und Verfügungsgeschäft) aus der germanischen Rechtsfamilie. Nach Art. $155 \S 1$ kod. cyw. hat ein Vertrag eine Doppelwirkung; er begründet nicht nur die Pflicht zur Übertragung des Eigentums, sondern überträgt es zugleich (Konsensprinzip), es sei denn, dass ein spezielles Gesetz etwas anderes bestimmt oder die Parteien anderes vereinbart haben (Verfügungslehre). ${ }^{69}$ Was die Grundhaltung zur translativen Funktion anbelangt, folgt man hier eindeutig dem Konsensprinzip des

\footnotetext{
${ }^{65}$ Ferid/Sonnenberger, französisches Zivilrecht 1 A 323a; Jeroscheg, Eigentum an beweglichen Sachen, S. 241 f.

${ }^{66}$ Gemeint ist der Grad der strukturellen Differenzierung bzgl. der translativen Wirkung eines privatrechtlichen Rechtsaktes und nicht die zeitliche Reihfolge der Kodifikation.

${ }^{67}$ Liebscher, polnisches Recht, S. 107

${ }^{68}$ Liebscher, polnisches Recht, S. 108 f.

${ }^{69}$ Liebscher, polnisches Recht, S. 172.
} 
französischen Code civil, denn der Eigentumsübergang ist eine gesetzliche Folge des Abschlusses eines (verpflichtenden) Vertrages; ${ }^{70}$ aber angesichts der Differenzierung zwischen Verpflichtungs- und Verfügungsgeschäft kann man nicht mehr von einem „reinen“, sondern nur von einem „dispositiven“ Konsensprinzip sprechen.

Anders als der Code civil, welcher unter kanonischem Einfluss die bloße Willensübereinstimmung für die Übereignung genügen lässt, ${ }^{71}$ hat die wichtigste Form der Übereignung des klassischen römischen Rechts, nämlich die formfreie Übergabe (traditio), ${ }^{72}$ einen großen Einfluss auf die meisten kontinentaleuropäischen Rechtsordnungen. Durch Hinzukommen des Elementes „Übergabe“ kann man eine weitere Differenzierungsstufe des Übereignungsmechanismus (innerhalb des romanischen Rechtskreises) beobachten. Nach Art. 609 II des spanischen Bürgerlichen Gesetzbuchs werden „das Eigentum und die übrigen Rechte an Gütern ...“ als Folge bestimmter Verträge mittels Übergabe erworben; Nach dem spanischen Bürgerlichen Gesetzbuch wird das Eigentum, ganz im Geiste des römischen Rechts, nicht durch den Vertragsschluss allein übertragen, wenn dem nicht die Übergabe folgt; schuldrechtliche Verpflichtung und dingliche Übergabe bewirken gemeinsam den Eigentumsübergang. ${ }^{73}$ Durch das Erfordernis ,traditio“ sieht man schon den ersten Schritt zur weiteren, feineren Unterscheidung der Übereignungsstrukturen. Aber die Übergabe selbst ist nur eine Handlung tatsächlicher Art, an welche die Rechtsordnung unabhängig von dem Willen des Handelnden Rechtsfolgen knüpft. Gestaltungsfreiraum lässt sich dadurch aber nicht gewinnen. In funktioneller Hinsicht ergibt sich kein echter Unterschied zu dem Einheitsprinzip des französischen Code civil.

Einem echten Paradigmenwechsel im Mechanismus der Fahrnisübereignung kann man heutzutage im Einflussbereich des deutschen Rechtskreises begegnen, wo der Akt der Übereignung selbst als eigenständiges Rechtsgeschäft, also dinglicher Vertrag angesehen wird. Im deutschen Recht

\footnotetext{
${ }^{70}$ Vgl. Ferid/Sonnenberger, französisches Zivilrecht, 2 G 201 ff. und Liebscher, polnisches Recht, S. 172.

${ }^{71}$ Jeroscheg, Eigentum an beweglichen Sachen, S. 242.

${ }^{72}$ Lange, Eigentumstradition, S. 38 f.

${ }^{73}$ Sohst, Código civil español, S. 143.
} 
„spricht das Gesetz im Sachenrecht von „Einigung“ und nicht von „Vertrag“; damit soll offenbar zum Ausdruck gebracht werden, dass zwar wie beim Vertrag eine Willensübereinstimmung der Parteien vorliegen muss, dass es sich aber um ein „Einigsein“ besonderer Art handelt, eben um ein „Einigsein“ über eine dingliche Rechtsänderung. “74

Hierdurch sieht man meiner Meinung nach wie scharf das deutsche Recht den Teil des Rechts abgrenzt, auf den es wirklich ankommt. Der Ursprung dieses Rechtsdenkens lässt sich (entgegen Felgenträger) leider nicht mehr ganz genau zurückverfolgen. Nach Jakobs soll dieser Geistesblitz (also der dingliche Vertrag) von Gustav Hugo, einem Göttinger Professor, stammen, und Savigny hat nur das, was von Hugo begonnen und ausgearbeitet wurde, mit dem richtigen Etikett versehen. ${ }^{75}$ Was mir sehr einleuchtend scheint, ist diese Aussage:

„... der dingliche Vertrag wird nicht, wie dies in der deutschen Literatur vor allem durch Felgenträger gewöhnlich ist, als eine originäre Schöpfung Savignys gesehen, sondern als das Resultat eines fortgesetzten, von Hugo in der Ausbildung des Privatrechtssystems begonnenen Denkens, ... “76

Nun haben wir drei Elemente des Übereignungsmechanismus, nämlich der schuldrechtliche Vertrag, der dingliche Vertrag und die Übergabe. Dabei ergibt sich die unvermeidliche Frage: In was für einem Verhältnis sollen die beiden Verträge zueinander stehen? Genau hier spürt man den durch die leichte Verständlichkeit bedingten Einfluss des Konsensprinzips und des Hand- und Barkaufs. Denn die meisten Rechtsordnungen, in denen das Vorhandensein des dinglichen Vertrags anerkannt ist, entscheiden sich für die „Vorgehensweise des Einheitsprinzips“. Danach wird der dingliche Vertrag durch die kausale Gestaltung als eine Art von Annex des schuldrechtlichen Vertrags behandelt. ${ }^{77}$ Nur in Deutschland hat der dingliche Vertrag einen eigenständigen rechtlichen Status, weil hier das Abstraktionsprinzip

\footnotetext{
${ }^{74}$ Baur/Stürner, Sachenrecht, $§ 5$ Rn. 2.

${ }^{75}$ Jakobs, S. 281 ff., insbes. 293: „... kann der von der Forderung, der Obligation wirklich getrennte Titel nur der Vertrag sein, und es kann dieser als ein von dem obligatorischen: die Forderung begründenden Vertrag verschiedener nicht anders als ein dinglicher heißen."

${ }^{76}$ Jakobs, Gibt es den dinglichen Vertrag?, S. 294.

${ }^{77}$ Krimphove, Das europäische Sachenrecht, S. 81 ff.
} 
gilt. Danach ist die rechtliche Wirksamkeit des dinglichen Vertrags völlig unabhängig von dem zugrunde liegenden schuldrechtlichen Vertrag. ${ }^{78}$

Im angloamerikanischen Recht, wo das lebensnahe und praktische Rechtsdenken herrscht, gewinnt das Konsensprinzip selbstverständlich die Oberhand. Wie im französischen Recht existiert hier der sachenrechtliche Übereignungsbegriff, zumindest bei beweglichen Sachen, nicht. Spätestens bis hierhin kann man deutlich feststellen, dass Konsensprinzip und Einheitsprinzip ein nicht leicht zu überwindendes logisches Paar bilden (s. Tabelle der Übereignungsmechanismen), was für einen deutschen Juristen gewöhnungsbedürftig ist. Nach Section 17 S.G.A (England) entscheidet der Parteiwille über den Eigentumsübergang, und bei einem bedingungslosen (unconditional) Vertrag ordnet die „mutmaßende“ Section 18, Rule 1 den Eigentumsübergang einer spezifischen Sache bei dem Vertragsschluss an. ${ }^{79}$ Nach $\S 2-$ 401 (1) UCC und $\S 19$ Rules 1 und 2 USA gilt auch in den vereinigten Staaten von Amerika fast das Gleiche. ${ }^{80}$

Um die komplizierten Mechanismen der Übereignung in verschiedenen Rechtsordnungen verstehen zu können muss man sich unbedingt vier Orientierungselemente merken, also den schuldrechtlichen Vertrag, den dinglichen Vertrag (d.h. die Einigung), das Verhältnis zwischen den beiden und die Übergabe. In folgender Tabelle werden die Anforderungen an den Eigentumsübergang beim Kauf einer beweglichen Sache nach ihrem strukturellen Differenzierungsgrad aufgelistet.

\footnotetext{
${ }^{78}$ Medicus, BGB-AT, S. 92 f.

${ }^{79}$ Bridge, The sale of goods, S. 63

${ }^{80}$ Stone, Uniform Commercial Code, S. 42, 48; White/Summers, Uniform Commercial Code, Vol. 1, S. 184.
} 


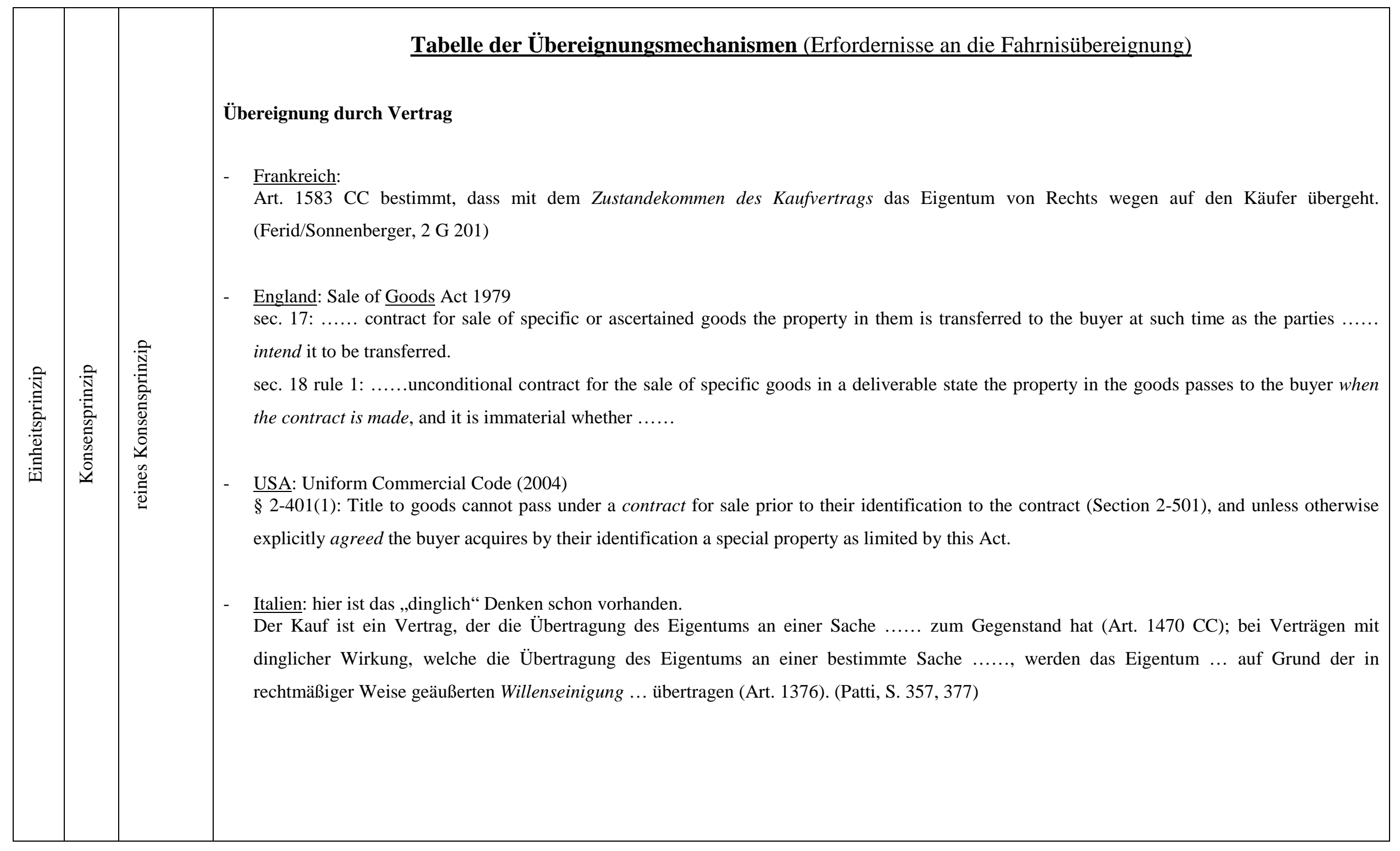




\begin{tabular}{|c|c|c|c|c|c|}
\hline & 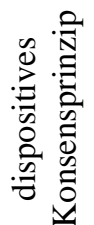 & \multicolumn{4}{|c|}{ 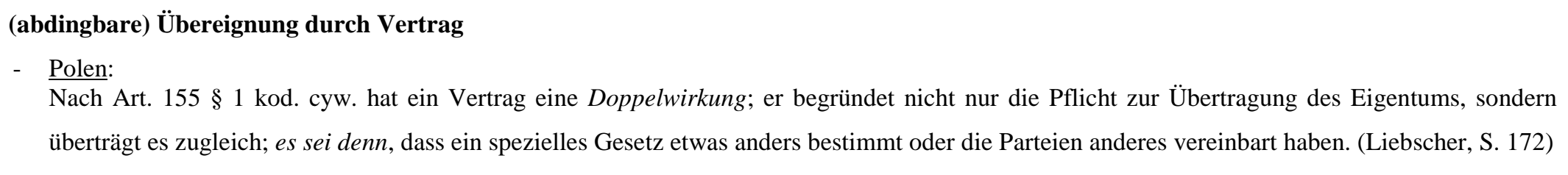 } \\
\hline & & Vertrag & & & ergabe \\
\hline \multirow{2}{*}{ 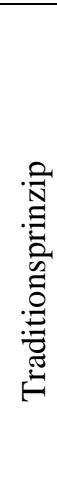 } & & 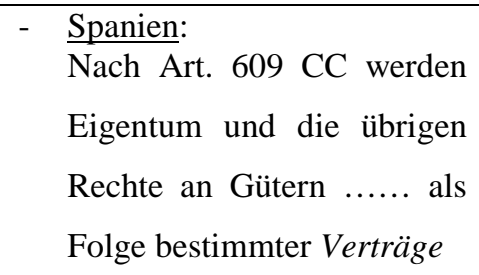 & \multicolumn{3}{|c|}{ mittels Übergabe erworben und übertragen. } \\
\hline & & schuldrechtlicher Vertrag & $\begin{array}{l}\text { dinglicher Vertrag } \\
\text { (Einigung) }\end{array}$ & $\begin{array}{l}\text { Verhältnis zw. den beiden } \\
\text { Verträgen }\end{array}$ & Übergabe \\
\hline
\end{tabular}




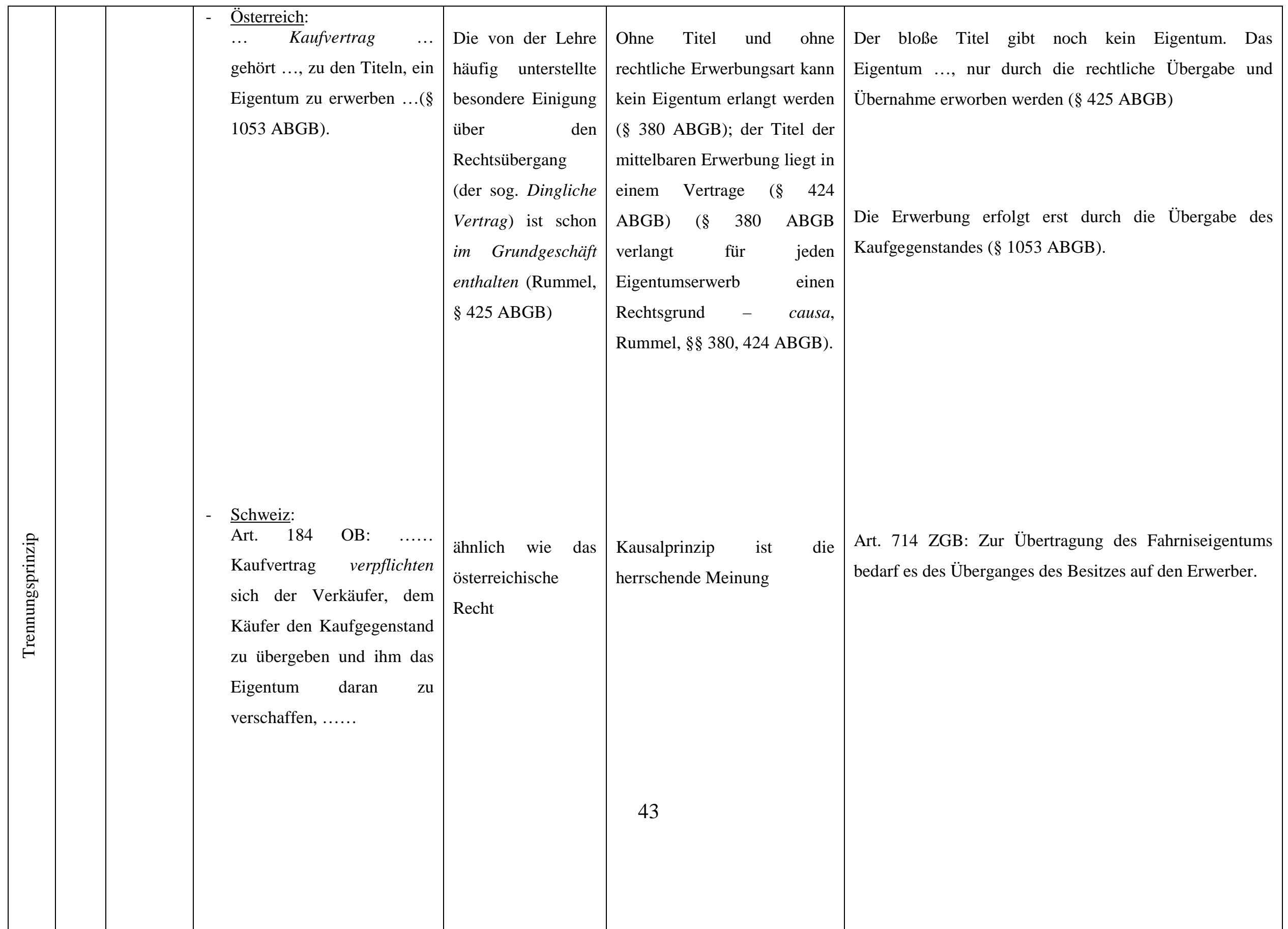




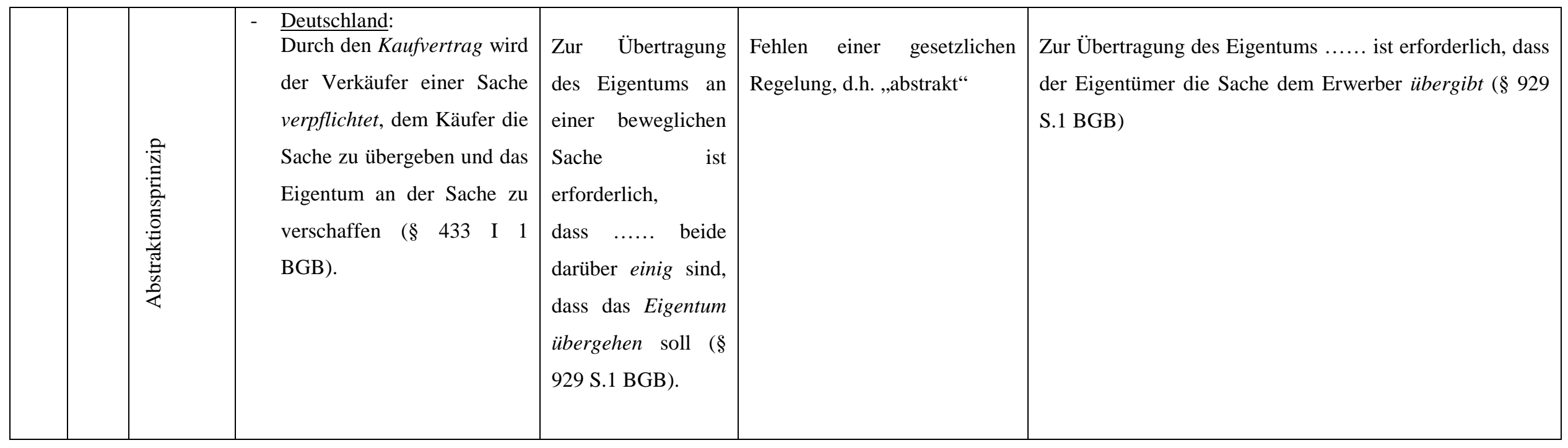




\section{Bewertung von Einheits- und Trennungsprinzip}

T1. Sowolnil aus (a) juristischer als auch aus (b) olkonomischer Hinsicht bietet das Abstraktionsprinzip die zurzeit denkbar beste Gestaltungsmaxime für den modernen hochkomplexen (globalisierten) Wirtschaftsverkehr, wellehere thohe (c) Sicherheit, (dl)

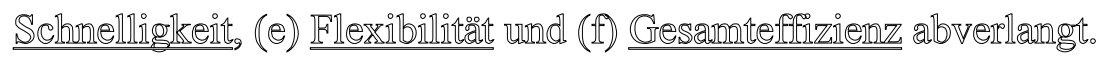

Da die in den vorgestellten Verfügungsmaximen enthaltenen Komponenten für die Gestaltung der Kreditsicherheiten von verschiedener Bedeutung sind, ist ihre allgemeine Beurteilung nicht sinnvoll. Deswegen wird das Traditionsprinzip und sein Kernelement „Übergabe“ im Zusammenhang mit dem Publizitätsgrundsatz diskutiert; und der wichtigste Teil der Bewertung des Abstraktionsprinzips und Kausalprinzips erfolgt erst unter dem Gesichtspunkt „Forderungsgebundenheit der Sicherheiten“. In diesem Abschnitt beschäftigen wir uns zunächst nur mit den weichenstellenden Grundprinzipien für die Gestaltung des privatrechtlichen Gesamtsystems, nämlich dem Einheits- und Trennungsprinzip.

Im französischen Recht kennt man eigentlich nicht die feinen Differenzierungen zwischen Konsens-, Trennungs-, Kausal- oder Abstraktionsprinzip. Aus Sicht des Code civil erfüllt das Vertragsprinzip die Translativfunktion des Rechts.

Mit Konsensprinzip und Einheitsprinzip meinen die Juristen im geistigen Einflussbereich des germanischen Rechtskreises, dass der auf Abschluss des obligatorischen Vertrags gerichtete Wille (Konsens) auch (einheitlich) die dingliche Einigung umfasst, mit der Folge, dass der Eigentumsübergang sich (unmittelbar) mit Abschluss des schuldrechtlichen Vertrags vollzieht. ${ }^{81}$ Welcher der beiden Verfügungsgrundsätzen der „bessere“ ist, ist eine provokante Frage, die unzählige leidenschaftliche Streitigkeiten, insbesondere zwischen den Vertretern des französischen und deutschen Rechts, hervorgerufen hat. Aus Sicht des Code civil besteht kein Bedürfnis für die Entwicklung allgemeiner Rechtsgeschäftsregeln; diese dienen nur der Befriedigung eines theoretischen Purismus. ${ }^{82}$ Die meisten deutschen Juristen sind hingegen von der Überlegenheit des Abstraktionsprinzips überzeugt und wollen ,das

\footnotetext{
${ }^{81}$ Ferid/Sonnenberger, französisches Zivilrecht, 2 G 201

${ }^{82}$ M.w.N. Ferid/Sonnenberger, französisches Zivilrecht, 1 F 3.
} 
Abstraktionsprinzip verteidigen“, und würden die Franzosen fragen, ,was würden sie sagen, wenn man ihr vorschlüge, auf das Vertragsprinzip, ein Stück ihrer historisch gewachsenen Rechtskultur, zugunsten des deutschen Abstraktionsprinzips zu verzichten?“63

Innerhalb der deutschen Jurisprudenz gibt es auch Stimmen, die sich gegen das Trennungsprinzip erheben. Der Vorwurf der fehlenden Volksnähe ${ }^{84}$ ist aber eher populistisch als wissenschaftlich einzustufen. Denn nur in den Fällen des Hand- bzw. Barkaufes steht für die Beteiligten die Einigung über die Eigentumsübertragung (also der dingliche Vertrag) derart im Vordergrund, dass man sich über eine weitere schuldrechtliche Verpflichtung nicht bewusst ist. ${ }^{85}$ Auf dem Wochenmarkt will die Oma durch den „Kauf“ nur an das Eigentum an dem Gemüse kommen, in der Shopping Mall will der Onkel nur das Geschenk für seinen Neffen nach Hause nehmen. Soll man deswegen nur von dinglichen Verträgen sprechen und nicht von obligatorischen? Das dürfte der Grundstruktur aller Rechtsordnungen widersprechen. Deshalb darf man die Bedeutung dieses Endglieds der Konsumkette nie überbewerten, denn auch die anderen Komponenten der Wert- und Warenzirkulation müssen berücksichtigt werden. Der moderne Rechtsverkehr ist nicht weniger hoch komplex als der menschliche Organismus und die entsprechenden Regelungen genauso; niemand erhebt jedoch die absurde Forderung, dass nur diejenigen medizinischen Behandlungsverfahren angewendet werden dürfen, die auch von dem zu behandelnden Patient verstanden werden können! ${ }^{86}$

Bezüglich der Verfügungsgrundsätze können vielleicht andere weniger gefühlsbetonte, sondern sachliche Fragestellungen eher über die verfahrene Situation hinweghelfen. Im

\footnotetext{
${ }^{83}$ Huber, Savigny und das sachenrechtliche Abstraktionsprinzip, S. 512; Wieling, Das Abstraktionsprinzip für Europa!, ZEuP 2001, 306.

${ }^{84}$ M.w.N.: Ferrari, Vom Abstraktionsprinzip und Konsensualprinzip zum Traditionsprinzip, ZEuP 1993, 53, 64.

${ }^{85}$ Larenz, SchR-BT, S. 16.

${ }^{86}$ Gleiche Ansicht M.w.N.: Wieling, Das Abstraktionsprinzip für Europa!, ZEuP 2001, 301 ff. (304).
} 
Hinblick auf das Einheits- und Trennungsprinzip sollte man die Fragen etwa wie folgt stellen: ${ }^{87}$

1. Welches der beiden Prinzipien bringt aus struktureller und systematischer Sicht ein besseres Konzept mit sich (systemischer Aspekt)?

2. Welches Prinzip kann ohne oder zumindest mit wenigen Durchbrechungen auf eine möglichst große Vielzahl von Fällen angewendet werden (juristisch-ökonomischer Gesichtpunkt)?

3. Welches Prinzip kann eine höhere Rechtssicherheit erreichen? (echtssicherheitsstandard)

4. Welches Prinzip gewährt die anpassungsfähigsten Gestaltungsmodelle (Flexibilitätsgrundsatz)?

5. Die entscheidende Frage ist: Welches Prinzip hält der Effizienzprüfung der Ökonomischen Analyse stand (Effizienzmaxime)?

Schwerpunktmäßig werden die letzten drei Fragen aber erst im Zusammenhang mit dem Publizitäts- und Akzessorietätsgrundsatz erörtert.

Die Grundarchitektur betreffend, kann man im Grunde genommen die wichtigen Rechtsordnungen grob in zwei Gruppen einteilen: die ohne Rechtsgeschäftslehre verfassten (etwa Frankreich, Italien, Spanien, die Rechtsordnungen im angloamerikanischen Rechtskreis) und die mit Rechtsgeschäftslehre organisierten (etwa Deutschland, Griechenland, Österreich, Schweiz, Polen, China, Japan). Dieser systemische Unterschied zwischen romanischer und germanischer (genauer gesagt deutscher) Rechtsfamilie bzgl. der Entwicklung einer allgemeinen Rechtsgeschäftslehre kann man in erster Linie nur in geschichtlichen Zusammenhängen verstehen. Obwohl die ersten Entwürfe eines allgemeinen Zivilgesetzbuchs in Frankreich bereits in den Revolutionsjahren 1793 - 1797 erfolgten, ${ }^{88}$ war die Zeitspanne für die Redaktion des im Jahr 1804 eingeführten Code civil im Vergleich zum BGB, dessen

${ }^{87}$ Die Antwort auf diese Fragen, s. D, II, 2, b) und D, II, 4; diese Ergebnisse sind aufgrund juristischer und institutionenökonomischer Analysen gefunden worden. Insoweit darf ich auf die verschiedenen Ausführungen verweisen.

\footnotetext{
${ }^{88}$ Bürge, französisches Privatrecht, S. 4 ff.
} 
Kodifikation mehr als 20 Jahre (vom 28. Feb. 1874 bis 22. Okt. 1895) benötigte, ${ }^{89}$ auffallend kurz. Überspitzt heißt das mit den Worten von Napoleon:

„Ich gebe Ihnen sechs Monate, machen Sie mir ein Zivilgesetzbuch“

- Arrêté consulaire vom 24. Thermidor des Jahres VIII (13. Aug. 1800)

Vor dem turbulenten gesellschaftlichen Hintergrund und innerhalb eines solchen kurzen Zeitrahmens kann keine Kodifikation zur systematischen Klarheit durchdringen. Außerdem war das juristische Abstraktionsvermögen in der Entstehungszeit des Code noch nicht in dem Maße entwickelt, wie es zum Ausgang des 19. Jahrhunderts in Deutschland bei der Abfassung des BGB der Fall war. ${ }^{90}$ Dies sieht man an der Anlehnung der Gliederung des Code an die Einteilung der Institutionen des Gaius; und deswegen herrscht Einigkeit darüber, dass dem Code civil im Unterschied zur wissenschaftlichen Systematik nicht allzu große Bedeutung beigemessen werden sollte. ${ }^{91}$ Bei näherem Betrachten der verschiedenen Mechanismen der Verfügung, genauer gesagt der Fahrnisübereignung, habe ich den Eindruck, dass in den Rechtsordnungen unter der Herrschaft des Konsensprinzips die geistige Anstrengung bei der Durchdringung der rechtlichen Strukturen der Übereignung fehlte. Bei diesem systemisch existenziellen Knotenpunkt überlässt man der Transaktionsform des Alltags, also dem Handund Barkauf, ${ }^{92}$ die Führung, bei welchem der obligatorische und dingliche Teil einer Transaktion zusammenfallen. Ohne die Trennung des dinglichen Teils der Transaktion von dem schuldrechtlichen kann aber logischerweise der Begriff des als Konstruktionselement dienenden Rechtsgeschäftes nicht entstehen, von den vorteilhaften Derivaten des Trennungsprinzips, wie wir später noch sehen werden, ganz zu schweigen.

\footnotetext{
${ }^{89}$ Honsell, Einleitung zum BGB, S. 9 f.

90 Vgl. Ferid/Sonnenberger, französisches Zivilrecht, 1 F 1,1 A 320,1 C 18: das schwache Abstraktionsvermögen zeigt sich auch bei Fehlen für die Konstruktion relevanter Regelungen über die Rechtsfähigkeit juristischer Personen, das Eigentümer-Besitzerverhältnis, den Anspruch ect.

${ }^{91}$ Ferid/Sonnenberger, französisches Zivilrecht, 1 A 313 f.

${ }^{92}$ Vgl. Jeroscheg, Eigentum an beweglichen Sachen, S. 241 f.
} 
Obwohl sie oft angezweifelt wird, ${ }^{93}$ ist die Trennung des Sachenrechts vom Schuldrecht eine rechtstechnische Glanzleistung des BGB, die seine Überlegenheit über alle älteren, heute noch existierenden Systeme begründet und einen der seltenen echten Fortschritte im Rechtswesen markiert. ${ }^{94}$ Dieser Geistesblitz, mit welchem sein Urheber fast die ganze Welt gegen sich aufgebracht hat, stammt nicht wie üblich angenommen von Savigny, sondern von dem Göttinger Professor Gustav Hugo, und der ursprüngliche Funke verbarg sich schon im Geist des römischen Rechts. ${ }^{95}$ In einem seiner Briefe an Hugo staunte so Puchta:

\section{„Ihre Schriften und Rezensionen sind wie Blitze Schlag auf Schlag über Deutschland gefahren. Welche Masse von Erbärmlichkeit und Unwissenheit haben Sie erleuchtet und allmählich aus dem Wege geräumt! Ich erstaune über den schneidenden Gegensatz zwischen Ihnen und Ihrer Mitwelt. “96}

Rein intuitiv gesehen ist die systemische Klarheit, Geschlossenheit und juristischsymmetrische Ästhetik des Trennungsprinzips nicht zu leugnen! Die entscheidende und überlebenswichtigere Frage ist aber, ob die Verwunderung Puchtas über dieses abgerundete Ganze berechtigt gewesen war oder nicht. Das muss man jedoch anhand konkreter Regelungsgegenstände überprüfen, und zwar ganz bestimmt nicht dort, wo das obligatorische und dingliche Rechtsgeschäft ausnahmsweise zusammenfallen, also bei dem Hand- und Barkauf. Als geeigneter Ausgangspunkt kommt die als Ordnungsprinzip dienende Privatautonomie in Betracht, wonach die Einzelnen ihre Rechte grundsätzlich in eigener Entscheidung und Verantwortung gestalten. ${ }^{97} \mathrm{Zu}$ der freien Gestaltung des Eigentumsverhältnisses gehört mindestens die Möglichkeit, dass die Parteien im Kaufvertrag

\footnotetext{
${ }^{93}$ Ranieri, Abstrakte Übereignung im 19. Jahrhundert, S. 91 ff., 97; Medicus, GWB Rn. 37; BGB-AT § 20, Rn. 230; Brox, BGB-AT, Rn. 117 ff.; m.w.N. Wieling, Das Abstraktionsprinzip für Europa!, ZeuP 2001, 303.

${ }^{94}$ Staudinger/Wolfsteiner, Vorbem. zu $§ § 1191$ ff., Rn. 3; m.w.N. Stadler, AcP 189, 425.

95 Jakobs, Gibt es den dinglichen Vertrag?, S. 283 ff., insbes. S. 284, 292: Nachdem die Darstellung des Privatrechts im Verlaufe des 18. Jahrhunderts die systematische geworden war, ...... Frage, in welchem System das Privatrecht vorzutragen und darzustellen ......; die einzelnen Erfordernisse (der Übereignung), ...... die Absicht, es zu übertragen; ...... Hugo hatte Savigny gezeigt, was aus dieser Stelle zu lernen ist.

${ }^{96}$ Jakobs, Gibt es den dinglichen Vertrag?, S. 283.

${ }^{97}$ Larenz/Wolf, BGB-AT, S. 1 f.
} 
die Übereignung nur bedingungsabhängig eintreten lassen. ${ }^{98}$ Diese Forderung trifft verschiedene Glieder der Wertezirkulationskette. Bei Sachen, die im Zeitpunkt des Vertragsschlusses noch nicht bestimmbar sind (wie z.B. herzustellende Sachen oder Gattungssachen) arbeiten die Rechtsordnungen unter Herrschaft des Einheitsprinzips über die Konstruktion der aufschiebenden Bedingung, um das logische Gebot der Bestimmtheit abzurunden. ${ }^{99}$ Danach erfolgt der Eigentumsübergang erst in dem Moment, in dem die Sache bestimmt ist. Während diese Konstruktion bei den noch zu bestimmenden Sachen aus logischer Sicht noch in erträglichem Maß hält, stellt der Kauf eines konkreten Gegenstandes unter Eigentumsvorbehalt das eigentliche dogmatische Problem dar. Hier beugt sich das Einheitsprinzip der wahren wirtschaftlichen Interessenlage der Parteien - obwohl man dies, wie wir später noch oft sehen werden, nicht offen zugibt. In Frankreich meint man, dass Art. 1138 und 1583 CC, wonach das Eigentum mit Abschluss des Kaufvertrages auf den Käufer übergeht, sobald die Parteien sich über die Sache und den Preis geeinigt haben, dispositiv sei, sodass die Parteien den Zeitpunkt des Eigentumsübergangs von der Zahlung des Kaufpreises abhängig machen können. ${ }^{100}$ In Italien gibt man dies sogar offen in Art. $1523 \mathrm{CC}$ zu. ${ }^{101}$ Das gleiche sieht man auch im angloamerikanischen Rechtskreis. Nach sec. 19 (1) S.G.A. (England) können die Parteien durch eine entsprechende Klausel den Übergang des „,property“ von der Erfüllung bestimmter Bedingungen abhängig machen (reservation of right of disposal). ${ }^{102}$ In der UCC sind die Sicherheiten einheitlich geregelt, und dort ist die Durchbrechung des Einheitsprinzips so eindeutig, so dass man von Trennungsprinzip und dinglichem Vertrag (insbes. $§ 9-203$ (b) UCC) sprechen kann. Dies werden wir erst im Zusammenhang mit dem Akzessorietätsgrundsatz erörtern.

\footnotetext{
${ }^{98}$ Huber, Savigny und das sachenrechtliche Abstraktionsprinzip, S. 502.

${ }^{99}$ Frankreich (Jeroscheg, Eigentum an beweglichen Sachen, S. 259): ... wird der Eigentumsübergang erst in jenem Moment bewirkt, in dem die Sache ... hinreichend individualisiert ist.; Italien (Patti, Codice Civile Italiano, S. 377): das gleiche Art. 1472 I CC; England (sec. 16 S.G.A. ): ...contract for ... unascertained goods no property ... transferred ... unless and until the goods are ascertained; USA: vergleichbares $\S 2-401(1)$.

${ }^{100}$ Wagemann, Grundstücksregister, S. 53; Graham-Siegenthaler, Kreditsicherungsrechte, S.310.

${ }^{101}$ Patti, Codice Civile Italiano, S. 391: nach Art. 1523 erwirbt der Käufer das Eigentum beim Teilzahlungskauf unter Eigentumsvorbehalt mit Entrichtung der letzten Kaufpreisrate.

${ }^{102}$ Eine gewisse Systemwidrigkeit spüren auch die englischen Juristen: (Bridge, The sale of goods, S. $98 \mathrm{f}$ ) the purpose of section 19 is to counter the presumptive passing of property rules in section $18, \ldots$ the darftsman might simply have left the matter to be determined by an application of the intention rule in section 17.
} 
Dogmatisch korrekt gesehen, sollen die vorstehenden Gestaltungen mit der Rechtsfigur „Bedingung“ nur als ein trügerischer Schein erachtet werden, der nur dazu dient, das Einheitsprinzip logisch abzurunden. Dieser Versuch ist meiner Meinung nach grundsätzlich fehlgeschlagen, denn in der sog. „Bedingung“ liegt die Übereinstimmung zweier auf den Eigentumsübergang (also ein dingliches Recht) bezogenen Willen, welche die Deutschen einen „dinglichen“ Vertrag nennen. Ich weiß nicht, wie man das logisch oder terminologisch anders verstehen könnte. ${ }^{103} \mathrm{Ob}$ die Franzosen, Italiener, Engländer oder Amerikaner dies als „Bedingung“ bezeichnen, ist mitnichten relevant. Die Gestaltung des Eigentumsvorbehaltes anhand der Struktur des Trennungsprinzips steht im Grunde gar nicht zur Disposition des Gesetzgebers. ${ }^{104}$ Man kann zwar zu den Namen wie „, dem dinglichen Vertrag“ oder „Trennungsprinzip“ schweigen, aber nicht zu der Struktur als solcher.

Deswegen ist die Sorge mancher deutscher Juristen, dass das Trennungsprinzip bzw. das Abstraktionsprinzip im Wege der europäischen Rechtsvereinheitlichung untergehen könnte, ${ }^{105}$ unbegründet. Wenn es wirklich „sprachlich“ dazu käme, müsste man hierzulande nur das „conditional contract“ des englisch/amerikanischen Rechts dogmatisch korrekterweise als „(dingliche) Einigung“(i.S.d. §929 BGB) übersetzen. Die Kompetenz dazu liegt allein in den Händen der Deutschen. Umgekehrt gilt das Gleiche auch für Franzosen, Italiener, Engländer oder Amerikaner usw. Sie können weiterhin „die dingliche Einigung“ als „Bedingung“ bezeichnen. Das bringt aus deutscher Sicht außer terminologischer Konfusion keine gewichtigen Nachteile mit sich.

Zusammenfassend kann man wohl feststellen, dass der Eigentumsvorbehalt den ersten unwiderlegbaren Nachweis dafür liefert, dass das sich an der Ausnahme „Hand- und Barkauf" orientierende Einheitsprinzip aus systemischer und dogmatischer Sicht dem Trennungsprinzip unterliegt.

\footnotetext{
${ }^{103}$ Vgl. Brox, BGB-AT, Rn. 117: Der wegen seiner sorgfältigen Rechtsdefinitionen renommierte Jurist Brox zieht aus dem Handkauf folgenden Schluss über das Trennungsprinzip - „Das Trennungsprinzip ist aber nicht aus logisch zwingenden Gründen das einzig Richtige“.

${ }^{104}$ Huber, Savigny und das sachenrechtliche Abstraktionsprinzip, S. 471 ff., 511.

105 Huber, Savigny und das sachenrechtliche Abstraktionsprinzip, S. 471 ff, 482; Wieling, Das Abstraktionsprinzip für Europa!, ZEuP 2001, 301 ff., 306; Aretz, das Abstraktionsprinzip - Das einzig wahre? JA 1998, 242 ff.
} 
In allen wichtigen Rechtsordnungen kommt die Notwendigkeit des Trennungsprinzips im Bereich des Immobilienrechts, wo das Planungs- und Vollzugsgeschäft in der Regel auseinander fallen, noch viel deutlicher zum Vorschein. So wurde im romanischen Rechtskreis kautelarjuristisch der rein verpflichtende Vorvertrag über den Grundstückskauf entwickelt, um in gewisser Weise Trennung und getrennte Fehlerbeurteilung zu erreichen. ${ }^{106}$ Im angloamerikanischen Recht tritt das Trennungsprinzip so deutlich in den Vordergrund, dass man von einem echten Trennungsprinzip sprechen kann:

„When title to land is transferred pursuant to a contact of sale, a time lag normally occurs between the contract execution (signing) and its consummation. A sales contract is created when the seller and buyer sign an agreement in which the seller promises to convey and the buyer promises to pay. The contract is consummated ("closed") when the seller delivers a deed to the buyer and the buyer pays the price to the seller ...... To transfer title from a property owner (the grantor) to someone else (the grantee), the grantor normally must execute and deliver an instrument that is effective to pass title... ... transferred by a written instrument. The instrument typically used for this purpose is a $\underline{\text { deed }}$, a document that states the grantor "grants," "conveys," or "quitclaims" title to the grantee... ... A quitclaim deed usually states that the grantor "quitclaims" or "releases" the property to the grantee. "107

\section{Wichtigste herkömmliche Argumente für das Abstraktionsprinzip}

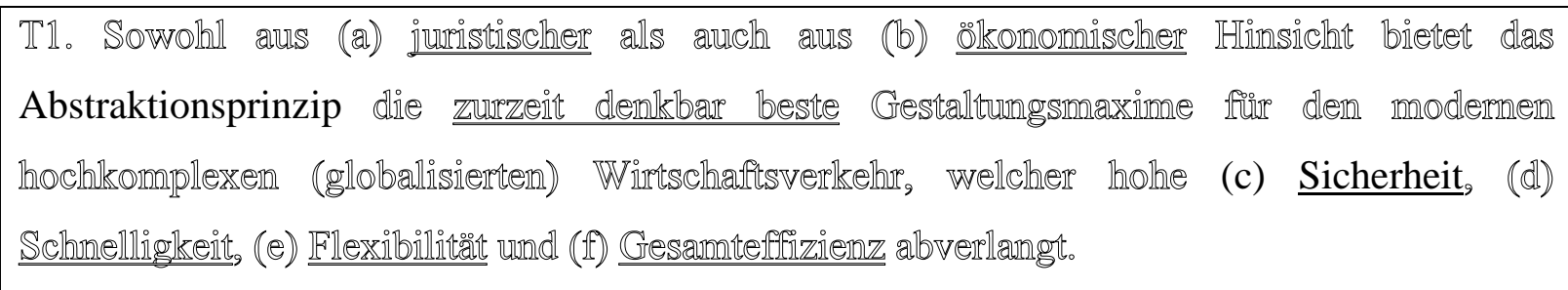

Hinsichtlich der translativen Funktion des Zivilrechts sehen die deutschen Juristen die Überlegenheit des Abstraktionsprinzips als weitere Entwicklung des Trennungsprinzips in seiner eindeutigen Zuordnungspolitik, welche die Verkehrssicherheit erhöht, indem die Wirksamkeit des Zuordnungsgeschäfts von der Fehlerquelle des Grundgeschäfts isoliert wird.

\footnotetext{
${ }^{106}$ Baur/Stürner, Sachenrecht, § 64 Rn. 13, 21, 27 und 30.

${ }^{107}$ Bernhart/Burkhart, Real Property, S. 270, 289 ff.; Wageman, Grundstücksregister, S. 54, 153.
} 
Auf Grund des Abstraktionsprinzips braucht sich der Verkehrspartner des Verfügenden (C) keine Gedanken über das vorausgegangene Grundgeschäft zwischen A und B zu machen. Vor Abschluss seines eigenen Geschäfts muss er nicht nachforschen, ob der Geschäftsgegenstand auch kondiktionsfest ist oder nicht; nach dem Geschäft kann er sofort als (endgültiger) Berechtigter den Gegenstand weiterverfügen. Bei dem Verfügenden (B) wirkt sich der (ursprüngliche oder nachträgliche) Fehler des Grundgeschäfts nur über das Bereicherungsrecht ( $\S \S 812$ ff. BGB) aus. Das Bereicherungsrecht ist, wie der Name schon sagt, Abschöpfungsrecht ( $\S 812$ I 1 1.Alt.; 818 II, III BGB); deshalb kann auch der Verfügende (B) davon ausgehen, dass er wegen seiner jetzigen Verfügung (B-C) am Ende nicht weniger vermögend sein wird als vor dem vorausgegangenen Geschäft (A-B). Rechtsökonomisch gesehen wandelt das Abstraktionsprinzip mit seiner eindeutigen Zuordnungspolitik eine Entscheidungssituation unter Unsicherheit in eine unter Sicherheit um. Diese Wirkung wird zusätzlich durch die Möglichkeit gutgläubigen Erwerbs verstärkt, denn er versperrt zusätzlich eine Rückabwicklung der dinglichen Zuordnung im Wege der Vindikation.

Indessen sieht mancher die obige Isolationswirkung sogar als Haupteinwand gegen das Abstraktionsprinzip, weil ,es die Interessen des rechtsgrundlos Verfügenden (A) nicht hinreichend schützt, wenn der Verfügungsempfänger (B) weiterveräußert oder wenn seine

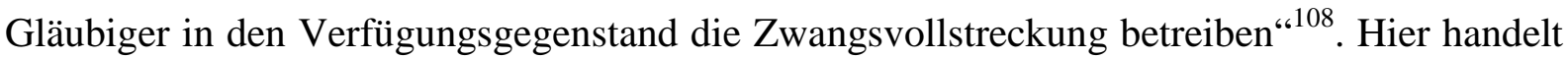
es sich im Grunde genommen um eine rechtspolitische und rechtsphilosophische Frage, die man meiner Meinung nach nicht einfach mit dem Bauchgefühl entscheiden kann. Es stimmt zwar, dass es wirklich ungerecht scheint, wenn der rechtsgrundlos Verfügende am Ende nur einen mit dem Risiko der Entreicherung behafteten „schuldrechtlichen“ Anspruch bekommt. Dieses Bauchgefühl hat wahrscheinlich jeder, weil jeder von uns Eigentümer von irgendwelchen Sachen ist. Dieses Bauchgefühl rührt von der Kategorisierung des Sachenrechts als Zuordnungsrecht her, die vor allem dessen statischen Charakter hervorhebt.

Von nicht geringerer oder sogar entscheidender Bedeutung ist aber die dynamische Seite des Sachenrechts; insbesondere im deutschen Privatrechtssystem, wo die abstrakten sachenrechtlichen Vorgänge die schuldrechtlichen stets begleiten. Die tiefgründige Herkunft

${ }^{108}$ Brox, BGB - AT, Rn. 121. 
des juristischen Konfliktes zwischen Bestands- und Verkehrsschutz stammt von dem durch die Arbeitsteilung erzeugten Spannungsfeld zwischen Leistung und Gegenleistung. In der Agrargesellschaft, wo die Bauern ihre eigenen Erzeugnisse selbst konsumieren, kann ein solcher Konflikt im Gegensatz zur Industrie- und Informationsgesellschaft im Globalisierungszeitalter gar nicht als Massenphänomen entstehen. Als Urorientierungspunkt gehören die Klarstellung des Verhältnisses zwischen Bestands- und Verkehrsschutz und die entsprechende Grundentscheidung $\mathrm{zu}$ den zentralen Aufgaben jeder Rechtsordnung. Rechtsgeschichtlich gesehen stehen zwei konträre Konzepte gegenüber: das römische Recht schützte das Bestandsinteresse des Eigentümers, indem es dem Eigentümer einen Vindikationsanspruch gegen den redlichen Erwerber gab; beim alten deutsche Recht hatte der Verkehrsschutz hingegen den Vorrang, und eine Fahrnisverfolgung bei freiwillig aus der Hand gegebenen Sachen war ausgeschlossen. ${ }^{109}$ Um eine Entscheidung für eines dieser Konzepte treffen zu können, muss man zunächst die entsprechende Grundlage schaffen, nämlich die Klarstellung der Interessenlage.

Das naheliegendste und wichtigste Interesse seitens des Eigentümers ist das Wertinteresse, welches die statische Seite des Zuordnungsrechts in Form von Stabilität und Sicherheit zum Ausdruck bringt: der Eigentümer verliert niemals ohne seinen Willen sein Recht, und niemand kann mehr Rechte auf einen anderen übertragen als er selber hat (,,nemo plus juris transferre potest, quam ipse habet“"). ${ }^{110}$ Das statische Wertinteresse gehört zu den erstrangigen Kernwerten des Privatrechts. Auf Grund des subjektiven und individualistischen Eigentumskonzeptes des Zivilrechts muss man zudem noch das Affektionsinteresse berücksichtigen, das aus der persönlichen Beziehung des Eigentümers zu seiner Sache resultiert. $^{111}$

Hinter dem Verkehrsschutz steht letztendlich die Hochachtung des Vertrauens, welches die Grundlage der interpersonellen Aktionen und damit des menschlichen Zusammenlebens ist. Dies ist wiederum auch ein erstrangiger Kernwert des (Privat)Rechts. Denn der Begriff

\footnotetext{
${ }^{109}$ Karner, Gutgläubiger Mobiliarerwerb, S. 11 ff., 74 ff., 84 ff.

${ }^{110}$ Karner, Gutgläubiger Mobiliarerwerb, S. 2, 55 f.

${ }^{111}$ Karner, Gutgläubiger Mobiliarerwerb, S. 55.
} 
„Recht“" existiert nur in Mehrpersonenverhältnissen, und Robinson Crusoe bedarf das „Rechts“ gar nicht, aber nur bis Freitag kommt.

Technische Argumente bzgl. der Handhabung dieses Interessen- und Wertekonfliktes hat Karner in seiner Habilitationsschrift hauptsächlich am Beispiel der Übereignung gut zusammengestellt: ${ }^{112}$ Für den Bestandsschutz zugunsten des Eigentümers spricht seine verfassungsrechtlich geschützte dingliche Position, die nicht im Wege eines gutgläubigen Erwerbs zum obligatorischen Anspruch degradiert werden darf. ${ }^{113}$ Dagegen sprechen jedoch der Vertrauensschutzgedanke, das auf der ökonomischen Analyse basierende Gefahrenbeherrschungsargument und die auf der Privatautonomie beruhende Rechtsscheinlehre.

Ein starkes Argument verfassungsrechtlichen Ranges findet man allerdings auch für den Verkehrsschutz, und zwar in Art. 14 Abs. 3 Satz 1 GG positiviert, wonach zum Wohle der Allgemeinheit sogar eine Enteignung zulässig ist. ${ }^{114}$ Genau diesen Rechtsgedanken sprach auch Kant an und fand den Rechtfertigungsgrund für den Verkehrsschutz auf der überindividuellen Ebene, ${ }^{115}$ der im Grunde genommen ein ökonomisches Argument ist. Der Verkehrsschutz dient der Umlauffähigkeit eines Rechtsgegenstandes, und damit nicht nur dem Verwertungsinteresse ${ }^{116}$ des Rechtsinhabers, sondern letztendlich auch seinem Mehrwertinteresse , welches in Zinstheorie fundiert. Der Schutz des Verkehrs und damit der Verkehrsfähigkeit eines Rechtsgegenstandes kommen nicht nur den Interessen der Allgemeinheit und des Erwerbers zugute, sondern auch dem Eigentümer selbst. ${ }^{117}$

Zusammenfassend lässt sich der Vorrang des Verkehrsschutzes gegenüber den Bestandsschutz feststellen. Dies bedeutet aber nicht, dass es sich hier um ein Regelkonflikt

\footnotetext{
${ }^{112}$ Karner, Gutgläubiger Mobiliarerwerb, S. 57 ff.

${ }^{113}$ Peters, Der Entzug des Eigentums durch gutgläubigen Erwerb, S. 11 f.

${ }^{114}$ Vgl. Peters, Der Entzug des Eigentums durch gutgläubigen Erwerb, S. 21, 26 ff.

${ }^{115}$ Karner, Gutgläubiger Mobiliarerwerb, S. 64 ff.

${ }^{116}$ Das Wert- bzw. Verwertungsinteresse baut meiner Meinung nach auf der Verkehrsfähigkeit auf, weil einen objektiven Wert nur die Gegenstände haben, die handelbar sind.

${ }^{117}$ Karner, Gutgläubiger Mobiliarerwerb, S. 64.
} 
handelt, der eine „Alles-oder-nichts“-Lösung fordert. Vielmehr liegt hier eine Prinzipienkollision vor, die nur mit dem Rechtsgedanke der Wesensgehaltgarantie und Verhältnismäßigkeit entschärft werden kann. Erstrebenswert ist ein modernes zeitgemäßes Sachenrechtssystem, das die durch mangelhafte Gesetzgebung und Rechtspraxis erzeugte Kollision der beiden Seiten des dinglichen Rechts wieder glättet. Das Ziel soll nicht nur im passiven Verkehrsschutz, sondern auch im aktiven Verkehrschub bestehen. Dazu können viele rechtstechnische Mittel eingesetzt werden, wie z.B. abstrakte Gestaltung der Verfügungen, kurze Verwirkungsfristen, Publizierung durch Register, Umkehr der Beweislast usw.

Um die vorausschauende Grundentscheidung der historischen Gesetzgeber zu verstehen, muss man letztendlich über sich hinaus denken, nämlich in ihre Position, der Normen vorgab, die die gesamte Wohlfahrt der Gesellschaft fördern sollen. Mit der Vindikationslösung schützt man das Eigentum m.E. nur statisch. Der Wert eines Eigentums lässt sich in fast allen Fällen nur im Wege des Verkehrs bemessen und realisieren. Aus diesem Grund geht der Verkehrsschutz i.d.R. (besonders bei der Systemgebung) dem statischen Eigentumsschutz vor, soweit dafür ein Mindestmaß an Schutz gewährleistet ist. Dies ist mit dem gutgläubigen Erwerb und der Lehre der Fehleridentität etc. sichergestellt.

Fast althergebracht gibt es immer wieder folgende Argumente gegen die abstrakte Form der Übereignung: Der abstrakten Übereignung wird vorgeworfen, dass sie einen einheitlichen Vorgang künstlich zerreiße ${ }^{118}$ und damit für das Volk lebensfremd sei. ${ }^{119}$ Alles in allem diene die Abstraktion nur dem Purismus der Rechtswissenschaftler. Es wird außerdem darauf hingewiesen, dass die Sicherheit im Rechtsverkehr, der das Abstraktionsprinzip dienen soll, durch die Vorschriften über den gutgläubigen Erwerb vom Nichtberechtigten gewährleistet sei. $^{120}$

Dem Indifferenzargument aufgrund des gutgläubigen Erwerbs kann man aber nur teilweise zustimmen. Gutgläubiger Erwerb setzt einen guten Glauben des Erwerbers voraus und die

\footnotetext{
${ }^{118}$ Dulckeit, Die Verdinglichung obligatorischer Rechte, S. 28 f, 31.

${ }^{119}$ M.w.N. Eisenhardt, Abstraktionsprinzip im 20. Jahrhundert, S. 218 f.

${ }^{120}$ Westermann, Sachenrecht, § 4 III.
} 
Möglichkeit des gutgläubigen Erwerbs, die bei einer Veräußerung nach § 933 oder $§ 934$ BGB aber nur in stark eingeschränktem Maß gegeben ist. ${ }^{121}$ Der Verkehrsschutz durch das Abstraktionsprinzip geht weiter als der von dem gutgläubigen Erwerb vermittelte und bewirkt auch heute noch einen Schutz der Rechtssicherheit überall dort, wo das Gesetz einen Gutglaubensschutz verweigert, z.B. beim Forderungskauf. ${ }^{122}$

Die Trennung des Sachenrechts vom obligatorischen Recht und die Abstrahierung des dinglichen von schuldrechtlichen Geschäft per se können aber außer der systematischen Klarheit und dogmatischen Folgerichtigkeit m.E. noch keine weiteren außergewöhnlichen Vorteile in pragmatischer Hinsicht vorweisen.

Denn die Rechtsordnungen unter dem Einheitsprinzip können das wirtschaftliche Bedürfnis nach einem Eigentumsvorbehalt oder einer gewissen Trennung beim Grundstückgeschäft, trotz terminologischer Zweifel, ohne nennenswerten Effizienzverlust mit den Konstruktionen „Bedingung“, „Vorvertrag“, „Urkunde“ ect. erfüllen. In dieser Hinsicht ist das Indifferenzargument (was das deutsche Abstraktionsprinzip kann, können die anderen Rechtsordnungen auch ohne es!) seitens des Einheitsprinzips noch nicht entkräftet.

Deshalb kommen bisher die Vorzüge des Abstraktionsprinzips gegenüber anderen Gestaltungsprinzipien aber nur so minimal zum Vorschein, dass man immer noch mit dem Indifferenzargument dagegenhalten und sagen kann: Was das Abstraktionsprinzip schafft, erreichen die anderen Gestaltungsprinzipien auch ohne nennenswerte Schwierigkeiten rechtlicher oder ökonomischer Art.

Dies ist meiner Meinung nach auch der Grund, warum der Streit rund um das Abstraktionsprinzip nach mehr als hundert Jahren immer noch nicht entschieden ist.

Um die Vorteilhaftigkeit des Abstraktionsprinzips $\mathrm{zu}$ ergründen, muss man über die Übereignung als Bezugspunkt eines Vergleichs oder einer wissenschaftlichen Auseinandersetzung hinausgehen, weil sich daraus wirklich nichts ausschlaggebendes mehr

\footnotetext{
${ }^{121}$ Wieling, Das Abstraktionsprinzip für Europa!, ZEuP 2001, 301, 304.

${ }^{122}$ Brox, BGB-AT Rn. 121.
} 
zu gewinnen ergibt (z.B. in ihrer Habilitationsschrift ist Prof. Stadler gelungen, die strukturelle Überlegenheit des Abstraktionsprinzips $\mathrm{zu}$ ergründen). ${ }^{123}$ Deshalb muss die Untersuchung noch tiefer gehen, nämlich in den Bereich der Subverfügungen, wie z.B. die Bestellung von Sicherheiten.

\section{Abstrakte Sicherheit im Vormarsch}

T1. Sowolal aus (a) juristischer als auch aus (b) ökonomischer Hinsicht bietet das Abstraktionsprinzip die zurzeit denkbar beste Gestaltungsmaxime für den modernen hochkomplexen (globalisierten) Wirtschaftsverkehr, welcher thohe (e) Sicherheit, (d)

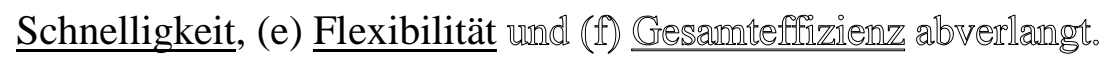

T2. Die (a) Unvollkcommentheit der gegenwarmigen Rahomenbedingungen des deutschen Zivilirechts (b) begrinstigt die (c) Entfaltung des selbstzerstörerischen Potenzials des historisch entwickelten Abstraktionsprinzips, welches zur Aufhebung der durch die Trennung zwischen Schuld- und Sachenrecht gekennzeichneten deutschen Zivilrechtsdogmatik führt.

\section{Forderungsgebundenheit der Sicherungsmittel}

Forderungsgebundenheit beschreibt die Verknüpfungsintensität zwischen der Forderung und der Sicherheit, die je nach Zielsetzung und Gestaltung unterschiedlich stark sein kann. Im Fachjargon umschreibt man die schwache Bindung zwischen der Forderung und Sicherheit mit dem Ausdruck „Nicht-Akzessorietät“ bzw. „Abstraktheit“.

Im Kreditsicherungsrecht betrachtet das BGB die Sicherungsmittel grundsätzlich als Annex der Forderung. ${ }^{124}$ Aufgrund des Abstraktionsprinzips als allgemeines Rechtsprinzip kann das

\footnotetext{
${ }^{123}$ Vgl. Wieling, Das Abstraktionsprinzip für Europa!, ZEuP 2001, S. 301 ff; Aretz, Abstraktionsprinzip, JA 1998, S. 242 ff.

${ }^{124} \S \S 1204 \mathrm{I}, 1211 \mathrm{I}, 1250 ; 1113,1137,1153,1154$ BGB.
} 
Verhältnis zwischen Forderung und Sicherheit aber auch anders gestaltet werden als die von den historischen Gesetzgebern des BGB bevorzugte Kreditsicherung durch den Gleichlauf von Forderung und Sicherheit. Danach wurde im deutschen Recht die Sicherungsübereignung oder Sicherungszession entwickelt.

Nach herrschender Meinung gilt eine Sicherheit als abstrakt bzw. nichtakzessorisch, wenn die Verbindung zwischen ihr und der $\mathrm{zu}$ sichernden Forderung nicht durch gesetzlichen Automatismus, sondern durch privatautonome Vereinbarung hergestellt ist. ${ }^{125}$

Um die abstrakte Gestaltung genauer zu verstehen, muss man zunächst sein Gegenstück, nämlich die akzessorische Konstruktion nachvollziehen. Zwar reden viele im Zusammenhang mit der Kategorisierung von Sicherheiten über die Akzessorietät, selbst bei StandardSachenrechtslehrbüchern fehlt es aber häufig an einer systematischen Stellungnahme. Dies rührt m.E. wahrscheinlich von der falschen Herangehensweise an dieses Rechtsphänomen her. Im Bürgerlichen Gesetzbuch selbst taucht nirgendwo das Wort „Akzessorietät““ auf. Der historische Gesetzgeber hat eigentlich nur Normen bereitgestellt, die einige Gemeinsamkeiten aufweisen, die im Laufe der Zeit aber von der Mehrheit der Juristen mit dem Namen „Akzessorietät“ gekürt wurden. Darunter versteht man den Gleichklang von Sicherheit und Forderung. 126 So werden Bürgschaft, Pfandrecht und Hypothek allgemein als „akzessorische“ Sicherheiten kategorisiert. ${ }^{127}$ In gewichtigen Lehrbüchern ist man eher vorsichtiger; so spricht Baur/Stürner von einer „Akzessorietät der Hypothek“, und Medicus erwähnt $§ 1138$ BGB im Zusammenhang mit der Verkehrshypothek. ${ }^{128}$

In den Augen der Altmeister des Sachenrechts ist der Begriff „Akzessorietät“ eine typische begriffsjuristische Methode, und ein allgemeiner Begriff der „Akzessorietät“ wird

\footnotetext{
${ }^{125}$ Bülow, Kreditsicherheiten, Rn. 30; Weber, Kreditsicherungsrecht, S. 11 ff.; Kessal-Wulf, Kreditsicherung, S. 408.

${ }^{126}$ Bülow, Kreditsicherheiten, Rn. 30.

${ }^{127}$ Kessal-Wulf, Kreditsicherung, S. 414; Wolf, Sachenrecht, Rn. 815, 899, 983 f.; Kropholler, Bürgerliches Gesetzbuch, § 765 Rn.1, § 1113 Rn. 2, § 1204 Rn. 2.

${ }^{128}$ Baur/Stürner, Sachenrecht, § 36 Rn. 74; Medicus, Bürgerliches Recht, Rn. 770.
} 
abgelehnt. ${ }^{129}$ Wenn man die Materie der deutschen Kodifikation genau anschaut, kommt man wirklich zu dem Ergebnis, dass eine allgemeine strenge „Akzessorietät“ bzw. ,akzessorische Sicherheit“" nicht existiert. Denn nach $§ 1204$ Abs. 2 BGB kann ein Pfandrecht auch für eine künftige oder eine bedingte Forderung bestellt werden. Im Hinblick auf den gutgläubigen Erwerb einer Verkehrshypothek gilt der $§ 1138$ BGB nach heutiger herrschender Meinung als eine Bestätigung dafür, dass die Hypothek akzessorisch ist. ${ }^{130}$ Wenn man aber die Legaldefinition der Hypothek im $\S 1113$ Abs. 1 BGB - wegen einer ihm zustehenden Forderung - genauer ansieht und pandektisch nachdenkt, kommt man zwangsläufig zu dem Ergebnis, dass das gutgläubig erworbene Grundpfandrecht eine Grundschuld ist, und zwar aus folgenden Gründen: Ausgangspunkt zur Ermittlung der Rechtsnatur des im Wege des $§ 1138$ BGB gutgläubig erworbenen Grundpfandrechts kann nur die Legaldefinition des $§ 1113$ Abs. 1 BGB sein und nicht die von Rspr. und einer Teil der Literatur ausgedachte Fiktion einer Forderung und „forderungsentkleideten Hypothek“. Der Name „forderungsentkleidete Hypothek" ist ein Widerspruch in sich selbst. Eine Hypothek ohne Forderung gibt es nicht; ein Grundpfandrecht ohne Forderung kann nur eine Grundschuld sein. ${ }^{131}$ Warum man wegen eines gesetzlich nicht verwendeten Begriffs - Akzessorietät - von den Legaldefinitionen der Hypothek und Grundschuld abweichen will, ist nicht begründet worden.

Alleine wegen der Sicherung künftiger Forderungen muss man sich schon von einem allgemeinen Begriff der „Akzessorietät“ verabschieden. Für manche fordert die Komplexität des Regelungsgegenstands eine differenzierte Lösung, nämlich den Gleichlauf von Forderung und Sicherheit in verschiedenen Phasen des Sicherungsgeschäfts; so spricht man von Entstehungs- und Erlöschensakzessorietät, Übergangsakzessorietät, Umfangsakzessorietät und Durchsetzungsakzessorietät. ${ }^{132}$ Für die andere ist eine neue Rechtsfigur nötig; so

\footnotetext{
${ }^{129}$ Heck, Sachenrecht, § 78 I 2.

${ }^{130}$ RGZ 137, 97; Palandt/Bassenge, § 1138 Rn. 6; MüKo/Eickmann, § 1138 Rn. 16.

${ }^{131}$ Wolff/Raiser, Sachenrecht, § 137 I 1, II 1 b, 3.

${ }^{132}$ Vgl. Medicus, Akzessorietät, JuS 1971, S. 497 ff.
} 
entwickelte Heck die Lehre von der Zweckgemeinschaft ${ }^{133}$ und Lübtow das Anrecht, ${ }^{134}$ die m.E. nicht zu Ende gedacht sind und systemisch gesehen zu vage bleiben.

Die Probleme, die die Akzessorietät mit sich bringt, lösen sich mit feineren Differenzierungen oder neuen Rechtsfiguren noch längst nicht auf. Der Bedarf der modernen Wirtschaft an einer sicheren und flexiblen Lösung stellt die Akzessorietät als Dogma für die Gestaltung von Sicherungsmitteln grundsätzlich in Frage, und zwar unabhängig davon, ob es um Entstehung, Erlöschen, Übergang, Umfang oder Durchsetzung der Sicherheit geht. Rechtswissenschaftliche Diskussionen innerhalb eines sicherungsrechtlichen Normensystems, dessen Strukturen und Werte in den Wirtschafts- und Sozialverhältnissen des 19. Jahrhunderts wurzeln, können nie fruchten. ${ }^{135}$ An dieser Stelle ist es meiner Meinung nach sinnvoller, über die Akzessorietät hinaus zu schauen, den Gegenstand dieses Normensystems vor dem Hintergrund der heutigen Wirtschaftsverhältnisse erneut unter die Lupe zu nehmen und sich bzgl. der Grundstruktur des privaten Vermögensrechts zeitgemäßer und genauer zu besinnen!

\section{Hauptentwicklungstendenz}

T1. Sowolnd aus (a) juristischer als auch aus (b) ökonomischer Hinsicht bietet das Abstraktionsprinzip die zurzeit denkbar beste Gestaltungsmaxime für den modernen hochkomplexen (globalisierten) Wirtschaftsverkehr, welcher hohe (c) Sicherherit, (d) Schnelligkeit, (e) Flexibilität und (I) Gesanteffizienz abverlangt.

Um die zwingende Akzessorietät der gesetzlichen Sicherheiten im BGB zu umgehen, bedienen sich die Rechtssprechung und Wissenschaft hauptsächlich zweier Instrumente des Abstraktionsprinzips und der Vertragsfreiheit. Einerseits abstrahiert man mit Hilfe des Abstraktionsprinzips die Sicherheit von der gesicherten Forderung, um Flexibilität (etwa

\footnotetext{
${ }^{133}$ Heck, Sachenrecht, $§ 78$ ff.: Die Forderung und das Pfandrecht werden durch eine Gemeinschaft verbunden, deren Zweck darin besteht, die Forderung „doppelt“ zu sichern; aus dieser Zweckgemeinschaft versuchte Heck noch die Aufhebungsgemeinschaft und Wandergemeinschaft abzuleiten.

${ }^{134}$ Lübtow, Grundpfandrecht am Vorbehaltseigentum, JuS 1963, 171: das Anrecht ist eine eigene Kategorie des subjektiven Rechts, das kein obligatorisches oder dingliches Recht ist; die Forderung und das Pfandrecht zusammen sichern das Anrecht als ein Interesse des Berechtigten, einen Gegenstand empfangen und behalten zu dürfen.

${ }^{135}$ Baur/Stürner, Sachenrecht, § 56 Rn. 9; vgl. Diskussion um das neue Bucheffektengesetz in der Schweiz in „Botschaft", 1.1 .3
} 
hinsichtlich der Bestellung der Sicherheit, des Sicherungsumfangs oder der Einwendungsmöglichkeiten usw.) zu gewinnen, andererseits stellt man die natürliche Bindung zwischen Forderung und Sicherheit, die jedem Kreditgeschäft immanent ist, durch einen inhaltlich an den Parteibedürfnissen orientierten schuldrechtlichen Vertrag (also den Sicherungsvertrag) her.

Wie oben schon erörtert (später noch ausführlicher) sind die meisten vom historischen Gesetzgeber vorgesehenen Sicherheiten im BGB den Bedürfnissen des modernen Wirtschaftsverkehrs nicht mehr gewachsen. Genau hier strahlt das Unikat der deutschen Jurisprudenz - das Abstraktionsprinzip - seine außergewöhnliche Gestaltungsflexibilität aus und zeigt eine seiner wichtigsten Existenzberechtigungen. Auch genau hier liegt m.E. das eigentliche Problem des heutigen deutschen Kreditsicherungsrechts bzw. Zivilrechts. Mit der Geburt der nichtakzessorischen Sicherheiten ergeben sich schwierige dogmatische Probleme für das deutsche Zivilrecht, die leider bisher nicht Gegenstand wissenschaftlicher Diskussionen geworden sind. Das Abstraktionsprinzip stammt ursprünglich von der Lehre der abstrakten Übereignung von Savigny. ${ }^{136}$ Ich bezweifele, ob das uneingeschränkt auf alle Verfügungsformen anwendbar ist? Wenn ja, wie soll das Verhältnis zwischen Schuld- und Sachenrecht bestimmt werden? So fragt man sich, wie weit sich das Sachenrecht mit seinem Typenzwang und seiner Typenfixierung der schuldrechtlichen Vertragsfreiheit öffnen kann, ohne seine Grundlagen aufzugeben? ${ }^{137}$ Wie wirken sich die schuldrechtlichen Vereinbarungen auf die Wirksamkeit dinglicher Geschäfte aus (Stichwort: Treuhandverhältnis, bedingte Sicherheitsübertragung, Sittenwidrigkeit, Übersicherung, Freigabeklausel)? Alle diese Fragen werden wir später im Rahmen des Sicherungsvertrags erforschen.

Unter dem Einfluss des Einheitsprinzips bzw. wegen der Abwesenheit des Abstraktionsprinzips herrscht in den anderen kodifizierten europäischen Rechtsordnungen ${ }^{138}$ offiziell immer noch das ,gesetzliche“ Akzessorietätsprinzip, wonach eine Sicherheit in ihrer Entstehung, ihrer Übertragung und ihrem Bestand bzw. Umfang von dem Vorhandsein einer

\footnotetext{
${ }^{136}$ Savigny, System III, S. 312 ff.; Obligationenrecht II, S. 256 ff.

${ }^{137}$ Wolf, Wandel im Sachenrecht, NJW 1987, 2647 ff., 2651; bzgl. des Spezialitätsgrundsatzes Baur/Stürner, § 4 Rn. 19.

${ }^{138}$ Graham-Siegenthaler, Kreditsicherungsrechte, S. 210 f. (212); 289 f. (293); $\S 888$ ff. schweizerisches ZGB; Art. 2789, 2794 C.c.it.
} 
gesicherten Forderung abhängig ist („ohne dich kann ich nicht sein!““139). In der Wirklichkeit wird dieses gesetzlich vorgeschriebene Abhängigkeitsverhältnis überall durch die kautelarjuristische Praxis aufgelockert. ${ }^{140}$ Es zeichnet sich eine Entwicklungstendenz (insbesondere in Osteuropa) ab, die Vorzüge der abstrakten Gestaltung der Sicherungsmittel anzuerkennen. ${ }^{141}$ Mancher fordert sogar die Einführung eines Sicherungssystems nach dem Art. 9 des US-amerikanischen Uniform Commercial Code. ${ }^{142}$

Der amerikanische Art. 9 UCC ist deswegen so beliebt, weil er anders als viele europäische Sicherungssysteme auf Einheit und Einfachheit setzt, indem man verschiedene Sicherungsmittel unter dem Dach des „,security interest“ vereint. In der Architektur des Art. 9 UCC sieht man die Grundstrukturen moderner Mechanismen, womit man die Bewegungsvorgänge der Vermögenswerte regulieren könnte. Zu der Idee des „security interest" zu kommen, verdankt das amerikanische Sicherungsrecht m.E. nicht unwesentlich seiner praktischen Denkweise. Während wir im Folgenden die Grundstruktur des Art. 9 UCC genauer unter die Lupe nehmen, werden wir sie mit dem Abstraktionsprinzip des deutschen Rechts vergleichen.

Wenn ein deutscher Jurist den Article 1 - 201 (35) UCC liest, fühlt er sich dogmatisch gesehen wie zuhause:

"Security interest" means an interest in personal property or fixtures which secures payment or performance of an obligation.

Denn das ,security interest“ sichert danach doch eine „Obligation“. Im Vergleich zu der deutschen Dogmatik fehlt den Amerikanern nur noch die Anerkennung bzw. Benennung des „security interest“ als dingliches Recht. Dieser Schritt wird meiner Meinung nach in dem

\footnotetext{
${ }^{139}$ Pöggeler, Akzessorietät im Zivilrecht, JA 2001, S. 65.

${ }^{140}$ Graham-Siegenthaler, Kreditsicherungsrechte, bgzl. der Sicherungsübereignung S. 221 f. (Italien), S. 303 f. (Frankreich); Baur/Stürner, Sachenrecht, § 64 Rn. 14 (in Frankreich „,hypothèque rechargeable“, Art. 2422, 2423 C.c);

141 Baur/Stürner, Sachenrecht, $\S 64$ Rn. 76; Thonabauer, Leitfadenreihe zum Kreditrisiko Kreditsicherungsrecht in - Polen (S. 49 f., 54 f.), Tschechien (S. 32 f.), Slowakei (S. 54 f., 56 f.), Kroatien (S. 61 f.), Slowenien (S. 50 f., 53 f.).

${ }^{142}$ Beale, Secured Credit in Europe, S. 375 ff. (397).
} 


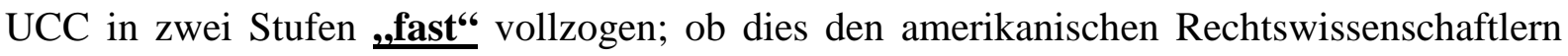
auch bewusst ist, wage ich zu bezweifeln. Als die erste Stufe dieser Entwicklung definiert Article 9 - 102 (a) (73) UCC Folgendes:

„Security agreement" means an agreement that creates or provides for a security interest.

Wenn man die Nr. 73 wörtlich übersetzt, heißt das doch: Eine Sicherheit wird aufgrund eines Sicherungsvertrags bestellt. Ob das ,security agreement“" ein schuldrechtlicher Vertrag im Sinne des deutschen Abstraktionsprinzips ist, ist leider in der Definitionsliste des UCC nicht zu finden. Erstaunlicherweise findet man in Article 9 - 401 (b) UCC eine Regelung, die sich fast direkt - zumindest aus deutscher Sicht - zur Rechtsnatur des „,security agreement“ äußert:

\section{„§ $9-401$ (b) [ Agreement does not prevent transfer.]}

An agreement between the debtor and secured party which prohibits a transfer of the debtor's rights in collateral or makes the transfer a default does not prevent the transfer from taking effect."

Danach kann ein „security agreement“ den Sicherungsgeber nicht daran hindern, über die Sicherheit rechtswirksam zu verfügen, selbst wenn es die Verfügung verbieten würde. Dieser Regelungsinhalt ist dem deutschen $\S 137$ S. 1 BGB sehr ähnlich. Der Unterschied zwischen den beiden Normen besteht darin, dass der deutsche $\S 137$ S. 1 BGB allgemein für alle Verfügungsarten und der amerikanische Article 9 - 401 (b) UCC nur für den Fall des Weiterverkaufs („transfer“143) gilt. Die Regelung des § 137 S. 1 BGB zielt in erster Linie darauf, den numerus clausus der dinglichen Rechte gegenüber privatautonomer Modifikation zu sichern; außerdem verstärkt er die Verkehrsfähigkeit der dinglichen Rechte. ${ }^{144}$ Wenn man den Article 9 - 401 (b) zusammen mit dem Article 9 - 320 (a) UCC liest, kommt man zu dem gleichen Ergebnis wie bei § 137 S. 1 BGB.

„\$ 9-320. (a) ... ..., a buyer in ordinary course of business, other than a person buying farm products from a person engaged in farming operations, takes free of a security interest

\footnotetext{
${ }^{143}$ LoPucki/Warren, Secured Credit, S. 166 ff. (168).

${ }^{144}$ MüKo, § 137 Rn. 1, 4, 7.
} 
created by the buyer's seller, even if the security interest is perfected and the buyer knows of its existence. “

Denn die Article 9 - 401 (b) und 9 - 320 (a) UCC wollen auch die Beschränkung des Verfügungsrechts des Sicherungsgebers durch einen Sicherungsvertrag verhindern. Genauso wie der $\S 137$ S. 1 BGB betrifft der Article 9 - 401 (b) UCC auch ein Verhältnis zwischen zwei Elementen, nämlich zwischen dem „,security interest“ auf der einen Seite und der Veräußerungsbefugnis des Sicherungsgebers auf der anderen Seite. Danach wird die Veräußerungsmöglichkeit gegenüber einem Verbot durch das „security interest“ rechtlich isoliert, genauer gesagt abstrahiert. Mit anderen Worten führt das Recht zur Veräußerung ein Eigenleben, das ist der typische Charakter eines dinglichen Rechts im Sinne der deutschen Zivilrechtsdogmatik. Somit kann man vorläufig annehmen, dass das ,security agreement" das Pendant des deutschen schuldrechtlichen Sicherungsvertrags im amerikanischen Recht ist. Ob das ,,security interest“ auch als die andere dingliche Hälfte mit dem schuldrechtlichen „security agreement“ ein logisch abgerundetes Ganzes bilden kann, haben die Amerikaner uns nicht direkt gesagt. Folgende Hinweise findet man in UCC und USC:

$\S 1$ - 201 (35) UCC: "Security interest" means an interest in personal property or fixtures which secures payment or performance of an obligation.

11 USC $\$ 101$ (51): “Security interest” means lien created by an agreement.

„\$ 9-102 (a) (12) UCC: Collateral means the property subject to a security interest or agricultural lien ......"

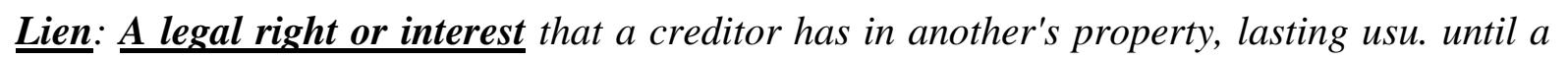
debt or duty that it secures is satisfied. ${ }^{145}$

Durch eine systematische Auslegung vorstehender Normen kann man wohl annehmen, dass das „security interest“ den deutschen dinglichen nichtakzessorischen Sicherheiten gleich

\footnotetext{
${ }^{145}$ Black's Law Dictionary, unter Stichwort „Lien“.
} 
stehen würde, wenn es ,perfektioniert“ ${ }^{146}$ wäre. Denn wenn mit „Security interest“ und „Collateral“ nicht das Gleiche gemeint ist und sich ein „Collateral“ dem „security interest“ unterzuordnen hat, passt dies genau auf das Schema „Sachen - dingliche Rechte“ (eine Einschränkung gibt es leider, das „Property“ im amerikanischen Recht ist nämlich etwas anders als die „Sachen“ im BGB; nichtsdestotrotz sind die Verständnisse beider Rechtsordnungen an dieser Stelle fast identisch). Die dogmatische Ähnlichkeit der beiden Sicherungsordnungen bzgl. der abstrakten Gestaltung von Sicherheiten wird noch deutlicher, wenn man den 11 USC § 101 (51) und den Begriff „Lien“ hinzuzieht: „Lien“ entspricht dem deutsch-rechtlichen Oberbegriff „Sicherungsrechte“ und „Security interst“ dem Unterbegriff „Abstrakte Sicherungsrechte“, weil es aufgrund eines Vertrags entsteht.

Besonders spannende Fortentwicklung der Abstraktion kann man bei schweizerischem Zivilrecht beobachten. Da das schweizerische Zivilrecht das Abstraktionsprinzip ablehnt, haben die Juristen dort eine sehr eigenartige Lösung erfunden, um in den Genuss von den Vorzügen der Abstraktion der Abstraktion zu kommen, nämlich den Schuldbrief. Im Globalisierungs- und Informationszeitalter fanden die Schweizer auch den Schuldbrief nicht mehr effizient genug und planen nunmehr die Einführung eines Register-Schuldbriefs. ${ }^{147}$ Zusammen mit dem am 1. Januar 2010 in Kraft getretenen Bucheffektengesetz soll der Register-Schuldbrief das Zeitalter der mediatisierten Rechtsverwahrung anbahnen. ${ }^{148}$

Durch die Errichtung eines Schuldbriefes wird eine neue Forderung begründet, in einem Wertpapier verbrieft und durch ein Grundpfand sichergestellt; sowohl das Wertpapier (der sog. Titel), wie auch das sichernde Grundpfandrecht wird Schuldbrief genannt. ${ }^{149}$ Durch die Verkörperung in eine Urkunde wird eine immaterielle Forderung sichtbar gemacht. Forderung und Pfandrecht können so sichtbar weitergegeben werden. Die Abstraktion geht mit Art. 854 ZGB weiter. Danach darf ein Schuldbrief weder Bedingung noch Gegenleistung

\footnotetext{
${ }^{146}$ White/Summer, Uniform Commercial Code, S. 131 ff.: „Perfection“ ist ein Vorgang, wodurch ein „,security interest" Drittwirkung erlangt. Wir werden sie im Rahmen der Publizität erörtern.

${ }^{147}$ Botschaft - ZGB, 5284 .

${ }^{148}$ Schmid-Tschirren, Papierlose Wertpapiere, S. 183 ff. (193).

${ }^{149}$ Basler Kommentar ZGB/Staehelin, Art. 842 Rn. 1.
} 
enthalten. Das Verbot des Bezugs auf ein Grundverhältnis, auf Bedingungen und auf Gegenleistungen im Titel bewirkt die Entstehung einer effektiv abstrakten neuen Forderung. ${ }^{150}$ Der Art. 855 ZGB vollendet dann die Abstraktion, indem er eine Novation verordnet: Mit der Errichtung eines Schuldbriefes wird das Schuldverhältnis, das der Errichtung zu Grunde liegt, durch Neuerung getilgt; eine andere Abrede wirkt nur unter den Vertragschließenden sowie gegenüber Dritten, die sich nicht in gutem Glauben befinden. Wenn also ein Schuldbrief besteht, dann darf man darauf vertrauen, dass eine neue reine bzw. nackte Forderung darin enthalten ist.

Die abstrahierte Forderung des Schuldbriefs (ein subjektives Recht) kann so zum flexiblen Rechtsgegenstand gemacht werden. Wer die Akzessorietät vermisst, kann den Schuldbrief nach den Regeln des Faustpfands verpfänden. Damit kann man nach Baur/Stürner „eine sehr intelligente Lösung, welche die Vorzüge der Abstraktheit und Akzessorietät zu kombinieren versucht“ 151 erreichen. In der Schweiz betrachtet man aber diese Notlösung mit Ernüchterung. ${ }^{152}$

Der Sinn und Zweck der Konstruktion des Schuldbriefs in Form eines Wertpapiers besteht darin, die Mobilisierung von Forderungen und anderen Rechten $\mathrm{zu}$ ermöglichen und den Verkehrsschutz zu verstärken; ${ }^{153}$ aber mit der Massenverbreitung der Verbriefung wird das Konzept der Verkörperung des Rechts im Hinblick auf Transport, Verwahrung und Verlustgefahr etc. zunehmend zum Hindernis des Verkehrs. Außerdem werden die meisten Wertpapiere derzeit nur noch mediatisiert verwahrt. Also kommen die Schweizer zu dem Ergebnis, dass das Wertpapierrecht in Papierform weitgehend überholt ist. ${ }^{154}$ Bisher ist die Entmaterialisierung der Wertpapiere in Europa vor allem durch den Erlass von Spezialgesetzen bewältigt worden. ${ }^{155}$ Die Entmaterialisierung läuft z.B. in Deutschland über $\S$

\footnotetext{
${ }^{150}$ Basler Kommentar ZGB/Staehelin, Art. 845 Rn. 7.

${ }^{151}$ Baur/Stürner, Sachenrecht, § 64 Rn. 60.

${ }^{152}$ Schmid-Tschirren, Papierlose Wertpapiere, S. 183 ff. (188).

${ }^{153}$ Lareida, Der Schuldbrief aus wertpapierrechtlicher Sicht, S. 6 f.

${ }^{154}$ Botschaft - BEG, $9321 \mathrm{f}$.

${ }^{155}$ Botschaft - BEG, 9333.
} 
2 Abs. $1 \mathrm{WpHG}^{156}$ i.V.m. dem DepotG, dessen Gesamtsystematik auf den Verhältnissen der 30er Jahre fußt, obwohl man längst die körperlosen Wertrechte ins Auge gefasst hat. ${ }^{157}$ Als erster Staat hat die Schweiz das Haager Wertpapierübereinkommen vom 5. Juli 2006 (HWpÜ) am 14. September 2009 ratifiziert, ${ }^{158}$ und am 1. Januar 2010 tritt das neue Bucheffektengesetz (BEG) in der Schweiz in Kraft. Die neue geschaffene Rechtsfigur Bucheffekt - lässt sich nicht in bestehende Rechtskategorien einordnen und stellt juristisches Neuland dar. ${ }^{159}$ Dieses neue Vermögensobjekt weist Merkmale sowohl einer schuldrechtlichen Forderung als auch einer Sache auf. ${ }^{160}$ Aber ein auf das Verkörperungselement verzichtendes Wertrecht hat nach der in der Schweiz herrschenden Meinung keinen dinglichen Charakter mehr, sondern stellt ein rein obligatorisches Recht dar; besonders wichtig sind dann die zessionsrechtlichen Grundsätze. ${ }^{161}$

Die gegenwärtige Veränderung des schweizerischen Zivilrechts bietet ein seltenes Zeitfenster, wodurch man eine dogmatische Revolution beobachten kann, die den Zugang zum modernen Zivilrecht eröffnet.

Nachdem wir die weltweite Entwicklungstendenz hin zu der abstrakten Gestaltung der Sicherheiten festgestellt haben, werden wir im Folgenden untersuchen, aus welchem Grund sich die nichtakzessorischen Sicherheiten von den anderen Sicherungsmitteln herausragen und was für Schwächen sie haben.

\footnotetext{
${ }^{156} \S 2$ Abs. 1 WpHG: Wertpapiere im Sinne dieses Gesetzes sind, auch wenn keine Urkunden über sie ausgestellt sind, alle Gattungen von übertragbaren Wertpapieren mit Ausnahme von Zahlungsinstrumenten, die ihrer Art nach auf den Finanzmärkten handelbar sind, insbesondere

${ }^{157}$ Brox, Wertpapierrecht, Rn. 452: Der Endpunkt dieser Entwicklung ist die Schaffung körperloser Wertrechte; es findet überhaupt keine Verbriefung mehr statt, vielmehr erfolgt nur eine Eintragung in ein besonderes Register.

${ }^{158}$ Botschaft - BEG, 9335: Eine Studiengruppe unter der Leistung von Prof. Luc Thévenoz, Universität Genf, legte im Mai 2004 den ersten Entwurf zu einem Übereinkommen über materielle Vorschriften betreffend intermediärverwahrte Wertpapiere vor.

${ }^{159}$ Botschaft - BEG, 9339: Das BEG schafft ein neues Vermögensobjekt sui generis.

${ }^{160}$ Botschaft - BEG, 9339.

${ }^{161}$ Botschaft - BEG, 9328.
} 


\section{Besorgniserregende Problemerscheinungen}

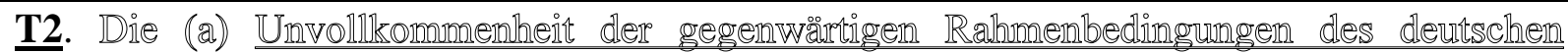
Zivillrechts (b) beginonstigt die (c) Entfaltung des selbstzerstörerischen Potenzials des historisch entwickelten Abstraktionsprinzips, welches zurie Auffhebung dere durech die

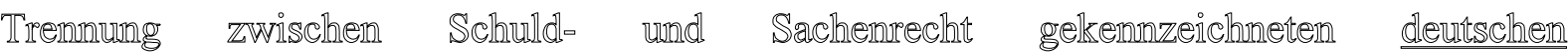
Zivillecehts dogmatik fuihart.

Medicus äußert sich über den allgemeinen Unmut über das deutsche Kreditsicherungsrecht etwa so: „Rechtspolitisch viel drängender ..... die seit etwa 30 Jahren diskutierten Argumente aus dem - Konkurs des Konkurses - : Die Zulassung ... bequemer Sicherungsrechte hatte die Aus- und Absonderungsrechte im Konkurs erheblich vermehrt. Daher blieb für die nicht gesicherten Konkursgläubiger oft nur wenig von dem übrig, was Schuldnervermögen zu sein schien.“ 162 Diese Unzufriedenheit über die geltende Rechtslage geht aber auf die Unvollkommenheit des BGB zurück, die erst im Laufe der Rechtsfortschritte sichtbar geworden ist. Dies gilt insbesondere für die schädlichen Außenwirkungen der fiduziarischen Sicherungsmittel, die mit Hilfe der fragwürdigen und als ,zulässig“ erklärten ${ }^{163}$ Kombination der Publizitätslosigkeit und des Abstraktionsgrundsatzes geschaffen worden sind. „Die Rechtsprechung und Rechtswissenschaft haben die Möglichkeit, diese Sicherungsmittel als gesetzwidrig zu verwerfen, inzwischen versäumt.“ ${ }^{164}$ Damit meint Medicus wahrscheinlich die Verdrängung der gesetzlichen Sicherheiten durch die Kautelarsicherheiten außerhalb der Kodifikation und die damit verbundenen Rechtsunsicherheiten.

Das krasse Missverhältnis zwischen der deutschen Kodifikation und Praxis berechtigt zu den Fragen, warum der BGB-Gesetzgeber damals die akzessorischen und nicht die nichtakzessorischen Sicherheiten als Erstwahl der Kreditsicherung getroffen hat. Haben Rechtssprechung und Rechtswissenschaft, wie Medicus meint, die Möglichkeit gehabt, die

\footnotetext{
${ }^{162}$ Medicus, Bürgerliches Recht, Rn. 494.

${ }^{163}$ RGZ 13, 200 ff.; RGZ 13, 298 ff.

${ }^{164}$ Medicus, Bürgerliches Recht, Rn. 494.
} 
fiduziarischen Sicherungsmittel als gesetzwidrig zu verwerfen, bevor ihre Zulässigkeit gewohnheitsrechtlich verfestigt war, ${ }^{165}$ oder doch nicht? ${ }^{166}$

Die Antwort auf diese Fragen kann man leider nicht direkt aus den historischen Quellen gewinnen. Wahrscheinlich lag es an der damaligen herrschenden Wirtschafts- und Rechtslehre ${ }^{167}$ und an dem unzulänglichen Einblick in den Nutzen der nichtakzessorischen Sicherungsmittel. ${ }^{168}$ Eine Erstickung der nichtakzessorischen Sicherungsmittel im Keim zugunsten der akzessorischen ${ }^{169}$ war und ist sowohl in wirtschaftlicher als auch juristischer Hinsicht (s.u. Vorteile der nichtakzessorischen Sicherungsmittel), wie wir später noch sehen werden, haltlos und deshalb unmöglich. ${ }^{170}$

Ausgehend vom römischen Recht und aus rechtsästhetischen Gründen haben Hugo und Savigny die Lehre der abstrakten Übereignung ins Leben gerufen. ${ }^{171}$ Dem Altmeister selbst war meiner Meinung nach nicht bewusst, welchen Raum ihre Lehre dem modernen Wirtschaftsverkehr und der Jurisprudenz im 21. Jahrhundert eröffnet.

Daher ist es die Aufgabe dieser Arbeit, im Lichte heutiger Rechtskenntnisse dahingehend zu untersuchen, was zur gegenwärtigen Verdrossenheit führt und wie sie aufgehoben werden könnte.

\footnotetext{
${ }^{165}$ Medicus, Bürgerliches Recht, Rn. 494.

${ }^{166}$ Wolf, Wandel im Sachenrecht, NJW 1987, 2647, 2650; Stavrianos, S. 46.

${ }^{167}$ Baur/Stürner, Sachenrecht, § 56 Rn. 9.

${ }^{168}$ Buchholz, Abstrakte Hypothek, S. 218: vor Inkrafttreten des BGB gab es schon in Teilen Deutschlands Vorläufer der Grundschuld; ihre praktischen Vorteile hatte der Redakteur der 1. Kommission Johow erkannt und richtig vorausgesagt, dass die Grundschuld sich auf lange Sicht gegenüber der Hypothek durchsetzen werde (Johow, beschränkte dingliche Rechte, S. 455 f.); aber die 1. Kommission lehnte die Grundschuld als allgemeine Sicherungsform ab (Motive Band 3, S. 609 f.); statt dessen gab sie sich mit einem einfachen Verweis auf die Hypothekenregelung zufrieden.

${ }^{169}$ Medicus, Bürgerliches Recht, Rn. 494.

${ }^{170}$ Vgl. Staudinger/Wolfsteiner, Vorbem zu $§ 1191$ ff., Rn 4; Wolf, NJW 1987, 2647, 2650; Kessal-Wulf, Kreditsicherung, S. 406.

${ }^{171}$ M.w.N.: Stadler, Gestaltungsfreiheit und Verkehrsschutz durch Abstraktion, S. 48.
} 
Ohne in die Details der Sicherungsrechte in den anglo-amerikanischen Systemen eingehen zu müssen, kann man in der Finanzkrise 2008, in der die durch amerikanische Vermögenswerte besicherten Finanzprodukte die Weltwirtschaft am Rande des Kollapses brachte, gravierende systemische Mängel deutlich spüren. Aus sicherungsrechtlicher Hinsicht gesehen verlangt das Phänomen, nämlich die völlige Wirkungslosigkeit der rechtlichen Sicherungsmechanismen, höchste Aufmerksamkeit.

Da die nichtakzessorischen Sicherheiten in den europäischen Rechtordnungen nicht kodifiziert sind und der Abstraktionsgedanke in den USA nicht offiziell dogmatisiert ist, führen die abstrakte Gestaltung der Sicherungsmittel und die dazu erforderlichen zeitgemäßen Grundstrukturen des Vermögensrechts ein wissenschaftliches und positives Schattendasein. Hinter den eben erwähnten Problemerscheinungen verbergen sich jedoch höchst komplexe juristische Themenkreise. Es gehört zu den wichtigsten Aufgaben der Rechtsdogmatik, die Grundelemente und -strukturen dieser Rechtsfigur herauszukristallisieren und der Globalisierung gerecht zu gestalten.

\section{Vor- und Nachteile der abstrakten Gestaltung}

T1. Sowohl aus (a) juristischer als auch aus (b) ökonomischer Hinsicht bietet das Abstraktionsprinzip die zurzeit denkbar beste Gestaltungsmaxime für den modernen hochkomplexen (globalisierten) Wirtschaftsverkehr, welcher hohe (c) Sicherheit, (d) Schnelligkeit, (e) Flexibilität und (I) Gesaminteffizienz abverlangt.

T2. Die (a) Unvollkommentheit der gegenwartigen Rahmenbedingungen des deutschen Zivillrechts (b) begionstigt die (c) Entfaltung des selbstzerstörerischen Potenzials des historisch entwickelten Abstraktionsprinzips, welches zur Aufhebung der durch die Trennung zwischen Schuld- und Sachenrecht gekennzeichneten deutschen Zivilrechtsdogmatik führt.

In diesem Abschnitt behandeln wir die spannende Frage, ob die vom dem Trennungsprinzip ausgehende dogmatische Evolution des Zivilrechts wirklich in Form der Abstraktion ihre 
„Vollendung““172 findet, und die Indifferenzargument durch Beschaffung weiteren Nutzens beseitigen kann.

\section{Der ökonomische Ansatz der Rechtsanalyse}

\section{a) Der ökonomische Blickwinkel des Rechts}

Um das Indifferenzargument (was das deutsche Abstraktionsprinzip kann, können die anderen Rechtsordnungen auch ohne es!) endgültig überwinden $\mathrm{zu}$ können, muss man meiner Meinung nach die traditionellen juristischen Argumentationslinien für die Überlegenheit und Vorteilhaftigkeit des Abstraktionsprinzips durch besondere Anstrengungen der ökonomischen Analyse des Rechts unter Beweis stellen.

Die ewige Frage der Menschheit lautet: Was ist Gerechtigkeit? ${ }^{173}$ Um diese zentrale Frage der Jurisprudenz zu beantworten, hat es zahlreiche Versuche gegeben: Ist Gerechtigkeit die Natur des Menschen, das „Glück“, Leben, die Freiheit, Gleichheit, Wahrhaftigkeit, das Wohl der Nation etc. oder einfach das Gesetz? ${ }^{174}$ Leider kann keiner von den Ansätzen eine befriedigende Antwort bieten. Wenn man nicht als „idealer Lernender“ frustriert vom Seminar zurückkehren möchte ${ }^{175}$ und den Verzicht auf den ehrgeizigen monistischen Gerechtigkeitsgedanke wagt, kann m.E. vielleicht Bentham's Formel (greatest happiness for the greatest number) zumindest im Bereich des Vermögensrechts ${ }^{176}$ abhelfen. Erst durch diese Brücke wird ein Teil der übersinnlichen „Gerechtigkeit“ endlich zu etwas Greifbarem, ${ }^{177}$ und

\footnotetext{
172 Mit „Vollendung“ meine ich die anhand der gegenwärtigen Rechtskenntnisse absehbaren Konstruktionsmöglichkeiten.

${ }^{173}$ Kelsen, Was ist Gerechtigkeit?, S. 9.

${ }^{174}$ Kelsen, Was ist Gerechtigkeit? S. 9 ff.; Haft, Juristisches Lernen, S. 70 ff.

${ }^{175}$ Haft, Juristisches Lernen, S. 45.

${ }^{176}$ Vgl. Kelly, Utilitarianism and Distributive Justice - Jeremy Bentham and the Civil Law, S. 207 f; gleiche Ansicht: Eidenmüller, Effizienz als Rechtsprinzip, S. 27.

${ }^{177}$ Kelsen, Was ist Gerechtigkeit, S. 13.
} 
der Rechtswissenschaft zugänglich. ${ }^{178}$ In dieser Hinsicht ist Jeremy Bentham der geistige Vater der Denkschule der Ökonomischen Analyse des Rechts.

Wie alle anderen Gerechtigkeitslehren geht die Ökonomische Analyse des Rechts nicht von einem logisch belegbaren Ansatz, sondern von einem empirischen Axiom als ihr ethisches Konzept aus:

„...wealth makes possible - not only or mainly luxury goods, but leusure, comfort, modern medicine, and opportunities für selfexpression and selfrealization - are major ingredients of most peoples's happiness ... “179

Obwohl der ökonomische Blickwinkel des Rechts Skepsis hervorruft, ${ }^{180}$ standen sich Recht und Ökonomie geschichtlich und ideell gesehen nicht unbedingt unversöhnt gegenüber. Das BGB ist z.B. in erster Linie ein Produkt der rechtspolitischen Reaktion auf die dramatischen Entwicklungen der politischen (Reichsgründung, 1871) und wirtschaftlichen Lage (Industrialisierung) in Deutschland am Ende des 19. Jahrhunderts. ${ }^{181}$ Von der Wirtschaftstheorie der Manchesterschule, ${ }^{182}$ die Marktwirtschaft und Freihandel befürwortete, beeinflusst und von dem normativen Individualismus ${ }^{183}$ ausgehend versuchten die Väter des BGB den vernünftigen, selbstverantwortlichen, urteilsfähigen und freien Bürgern ein technisch-instrumentales Recht $\mathrm{zu}$ schaffen, mit dem sie ihr Glück selbst schmieden

\footnotetext{
${ }^{178}$ An dieser Stelle ist es mir wohl bewusst, dass es sich hier um ein langes, tiefes philosophisches Tauziehen zwischen der angelsächsischen teleologischen und der kontinentaleuropäischen deontologischen Ethik handelt. Da sie aber den Gegenstand dieser Arbeit (vermögensrechtliche Verhältnisse) nicht unmittelbar betrifft, kann man von einer diesbezüglichen Auseinandersetzung absehen.

${ }^{179}$ Posner, Economic Analysis of Law, S. 16

${ }^{180}$ Baumann, Ökonomische Effizienzjurisprudenz, RNotZ 2007, 297, 302 f; Röver, Vergleichende Prinzipien dinglicher Sicherheiten, S. 101 ff..

${ }^{181}$ Coing/Honsell, Einleitung zum BGB, S. 4; Pohl, Deutsche Volkswirtschaft (1830 - 1880), S. 1 ff; Winkel, Wirtschaftswissenschaftliche Auffassung um die Mitte des 19. Jahrhunderts, S. 1 ff.

${ }^{182}$ Interessanterweise erschien Adam Smiths Meisterwerk - An inquiry into the nature and causes of The wealth ofnations - exakt im gleichen Jahr (1776) der Unabhängigkeitserklärung der Vereinigten Staaten von Amerika.

${ }^{183}$ Die normative Individualismus vertritt die Gegenposition des Naturrechts, nämlich der Staat soll sich nur auf die Zusammenfassung der Wünsche und Ziele der Individuen beschränken, weil nur die Mitglieder der Gesellschaft selbst am besten wissen, was für sie gut ist.
} 
können. ${ }^{184}$ Rechtstechnisch übersetzt wurden diese Werte zu Vertrags- und Eigentumsfreiheit. Spätestens seit dem bahnbrechenden Aufsatz - The Problem of Social Cost, 1960 - von Coase (Nobelpreisträger für Ökonomie, 1991) expandiert die von Adam Smith entdeckte Logik der unsichtbaren Hand im Wettbewerb des Gütermarktes auf andere gesellschaftliche Konzeptionen (der sog. ,„ökonomische Imperialismus“), ${ }^{185}$ darunter auch die Jurisprudenz. ${ }^{186}$ Das Coase-Theorem besagt: In einer Welt ohne Transaktionskosten und bei eindeutiger Zuweisung der Verfügungsrechte kann eine optimale Allokation rivalisierender Nutzungen einer knappen Ressource durch marktwirtschaftliche Verhandlungen der Beteiligten erreicht werden. ${ }^{187}$ Man muss sich dies z.B. so vorstellen: Für Nachbarn in einem Mehrfamilienmiethaus ist das Recht zum ordentlichen Wohnen nach persönlichen Bedürfnissen eine knappe Ressource. Manche jungen Bewohner möchten gerne mal ab und zu ausgiebig Spontan-Party feiern, was aber eine erhebliche Ruhestörung für andere Mieter bedeutet, die kleine Kinder oder vielleicht Frühschicht haben (die sog. reziproke Wirkung des Externer Effekte ${ }^{188}$ ). Nach dem Coase-Theorem, welches das subjektive Recht als dem Marktmechanismus unterworfenes Wirtschaftsgut versteht, müssen die Beteiligten über das Recht zum Wohnen nach Bedarf solange monetär verhandeln, bis sich eine Ausweitung bzw. Reduzierung des eigenen Rechts wirtschaftlich nicht mehr lohnt. ${ }^{189}$ Erst dann ist der optimale Nutzungsgrad dieses subjektiven Rechts erreicht. ${ }^{190}$ Die Prämisse einer Welt ohne Transaktionskosten, ${ }^{191}$ also ohne die Kosten, die potentielle Vertragspartner an Information und Koordination aufwenden müssen, um den Vertrag abzuschließen und durchzusetzen,

\footnotetext{
${ }^{184}$ MüKo/Sächer, Einl. Rn. 33

${ }^{185}$ Deffains/Demougin, Holdup-Problem und Wettbewerb der Rechtssysteme, S. $251 \mathrm{f}$.

${ }^{186}$ Posner, Economic Analysis of Law, S. 23.

${ }^{187}$ Coase, The Problem of Social Cost, S. 1 ff.; Posner, Economic Analysis of Law, S. 9: “...... basic principle of economics is that resources tend to gravitate toward their most valuable uses if voluntary exchange - a market - is permitted."

${ }^{188}$ Coase, The Problem of Social Cost , S. 1.

${ }^{189}$ Coase, The Problem of Social Cost, S. 2 ff.; genauere Beschreibung mit mathematischen Gleichungen: Helmedag, Vermarktung des Rechts, S. 57 ff.

${ }^{190}$ Vgl. Mankiw, Principles of Economics, S. 8: "prices are the instrument with which the invisible hand directs economic activity ...... guide these individual decisionmakers to reach outcomes that, in many cases, maximize the welfare of society as a whole.”; Jansen, Verfügungsrechte und Transaktionskosten, S. 102

${ }^{191}$ Schäfer/Ott, Ökonomische Analyse des Zivilrechts, S. 5.
} 
kann man freilich nicht als realitätsnah bezeichnen. ${ }^{192}$ Dennoch ist eine solche Unterstellung nach Ansicht der Ökonomen und auch nach Posners Meinung für die Analyse komplexer Phänomene hilfreich und von entscheidender Bedeutung, genauso wie Newtons Gravitationstheorie, nach der alle körperlichen Gegenstände mit gleichem Tempo zur Erde fallen würden, wenn das alles in einem luftleeren Raum passieren sollte. ${ }^{193}$ Diese Methode der Komplexitätsreduktion ist meiner Meinung nach der deutschen Jurisprudenz nicht exotisch, wenn sie nicht sogar zum Grundhandwerkszeug jedes deutschen Juristen gehört, denn die Technik der Anspruchsprüfung ist gerade eine meisterliche Methode der Rechtsfindung durch Reduktion der Komplexität des Sachverhalts auf die rechtlich relevanten Tatsachen. Allerdings bleibt die Anwendung der Komplexitätsreduktionstechnik im deutschen Recht im Gegensatz zur Naturwissenschaft oder Wirtschaftswissenschaft nur auf der Anwendungsebene und kommt nicht in Hinsicht auf die Beobachtung zum Einsatz. Bezüglich der Ökonomischen Analyse des Rechts besteht der Verdienst Coases m.E. darin, dass er die Knappheitseigenschaft des subjektiven Rechts zum Ausdruck gebracht und damit der Jurisprudenz den Zugang zum wirtschaftswissenschaftlichen Instrumentarium verschafft hat. Es ist verwunderlich, warum uns, den Juristen, so etwas nicht eingefallen ist. Könnte es sein, dass uns das Sein der Zuordnungsklarheit des subjektiven Rechts (aus Sicht der Ökonomen heißt es dann konkurrierende Nutzung) so selbstverständlich ist wie die Luft für jedermann? Wir denken schließlich auch nicht daran, dass es Luft gibt, jedes Mal wenn wir atmen. Im Hinblick auf die Knappheitshypothese bzgl. der subjektiven Rechte und vor dem Hintergrund der Globalisierung hoffen die Anhänger der Neuen Institutionenökonomik über den Wettbewerb der Rechtssysteme Institutionen zu erreichen, die die knappen (nicht nur wirtschaftlichen) Ressourcen effizient zu allokalisieren in der Lage sind; und damit ist eine neoklassisch geprägte Denkschule entstanden. ${ }^{194}$

Für die traditionellen Juristen hierzulande besteht die Hauptaufgabe der Rechtswissenschaft darin, Rechtsfragen im Rahmen und auf der Grundlage einer bestimmten, historisch

\footnotetext{
${ }^{192}$ Helmedag, Vermarktung des Rechts, S. 67.

${ }^{193}$ Mankiv, Principles of Economics, S. 21; Posner, Economic Analysis of Law, S. 17; Gegenmeinungen (m.w.N. s. Mathis, Effizienz statt Gerechtigkeit?, S. 16): die komplexitätreduzierende Methode der Ökonomischen Analyse des Rechts gefährdet die Multifunktionalität des Rechts; führt zur Wertlosigkeit

194 Deffains/Demougin,Holdup-Problem und Wettbewerb der Rechtssysteme, S. 251 ff; Posner, Economic Analysis of Law, S. 9.
} 
gewachsenen Rechtsordnung zu lösen. ${ }^{195}$ Gemeint ist damit, dass die Verfassungsmäßigkeit und die dahinter stehenden Werturteile der einzige Rechtsfertigungsgrund für Rechtsnormen sind. Der Sinn und Unsinn des Rechtspositivismus war und ist Gegenstand eines heftigen Streits ${ }^{196}$. Ohne das Gewaltenteilungsargument des Rechtspositivismus widerlegen zu müssen, beschäftigt sich die Ökonomische Analyse des Rechts mit der Frage, ob und inwieweit das analytische Instrumentarium der Wirtschaftswissenschaft zur Forschung und Lösung juristischer Probleme herangezogen werden darf. Im Zentrum dieser Bewegung steht die Frage, ob die zentrale Aufgabe der Wirtschaftswissenschaft, nämlich Effizienz zu erreichen, auch für die Jurisprudenz, insbesondere für die institutionelle Rechtsfortbildung wichtig sein könnte. ${ }^{197}$ In dieser Hinsicht gilt die ex-ante-Perspektive der Ökonomen im Gegensatz zu dem ex-post-Rechtsdenken der historischen Schule als eine besonders wertvolle Bereicherung.

\section{b) Der Effizienzbegriff}

„Effizienz“ gehört zu den wenigen fundamentalistischen Begriffen, um die herum das Theoriesystem der Wirtschaftswissenschaft aufgebaut wird. Allgemein versteht man das Wort Effizienz (v. lat. efficientia) als die Relation zwischen Nutzen und dem Aufwand, mit dem der Nutzen erzielt wird. Für die Gesetzgebung bzw. die institutionelle Rechtsfortbildung ist der Effizienzbegriff der Volkswirtschaftslehre von Bedeutung, die die Wohlfahrt aller Mitglieder der Gesellschaft maximieren will. ${ }^{198}$ Zur Bewertung dieser Zielsetzung wurden hauptsächlich folgende zwei Kriterien vorgeschlagen:

Das Paretokriterium bezeichnet einen Zustand als effizient, wenn die Besserstellung einer Person nur durch die Schlechterstellung anderer Personen $\mathrm{zu}$ erreichen ist. ${ }^{199}$ Die Einsetzbarkeit dieses Kriteriums setzt aber den funktionierenden marktwirtschaftlichen

\footnotetext{
${ }^{195}$ Larenz/Canaris, Schuldrecht - BT, S. 7.

${ }^{196}$ Eidenmüller, Effizienz als Rechtsprinzip, S. 2 ff.

${ }^{197}$ Schäfer/Ott, ökonomische Analyse des Zivilrechts, S. 1; Eidenmüller, Effizienz als Rechtsprinzip, S. 1.

${ }^{198}$ Mankiw, Principles of Economics, S. 3: "Efficiency means that society is getting the most it can from its scarce resources."

${ }^{199}$ Varian, Mikroökonomik, S. 14, Die Pareto-Effizienz ist nach dem Ökonomen und Soziologen Vilfredo Pareto (1848 - 1923) benannt, der als einer der ersten die Implikationen dieser Idee untersuchte.
} 
Wettbewerb und Preismechanismus voraus. ${ }^{200}$ Nicht für die Anhänger des Rechtspositivismus, wohl aber für Naturrechtler ist das konservative Paretokriterium deswegen unerträglich, weil es die vorhandenen wirtschaftlichen und sozialen Verständnisse billigt, ohne danach zu fragen, ob deren Zustandekommen gerechtfertigt gewesen war. ${ }^{201}$ Außerdem stößt die Anwendung des statischen Paretokriteriums als Ergebniskriterium bei der dynamischen Entwicklung der Gesellschaft an ihre Grenze, ${ }^{202}$ bei der man häufig der Frage begegnet, ob eine Maßnahme gerechtfertigt ist, wenn die Allgemeinheit davon profitiert, aber eine bestimmte Gruppe dabei benachteiligt wird. ${ }^{203}$ Infolgedessen wurde das Paretokriterium von den britischen Starökonomen Nicholas Kaldor und John R. Hicks (Nobelpreisträger für Ökonomie, 1972) dadurch modifiziert, indem sie ihm eine Gesamtbetrachtungskomponente hinzufügten: Eine gesellschaftliche Maßnahme wäre effizient, wenn dadurch der Profit der Gewinnergruppe größer als die Einbuße der Verlierergruppe wäre (potenzielle Paretoverbesserungen); ${ }^{204}$ eine tatsächliche Kompensation ist aber nicht erforderlich (sog. Hypothetische Kompensation), denn es ist nicht die Aufgabe der Ökonomen, die politische Frage der Umverteilung zu beantworten. ${ }^{205}$

Mit seiner Gesamtinteressenabwägung hat sich das Kaldor-Hicks-Kriterium zumindest in dem Bereich nützlich gemacht, in dem nur der Austauschprozess in Betracht kommt. ${ }^{206}$ Die privatvermögensrechtliche Gesetzgebung kann anhand einer Gesamtinteressenabwägung darüber entscheiden, wie bestimmte Spannungsfelder, wie z.B. Bestands- und Verkehrsschutz, geregelt werden sollen.

\footnotetext{
${ }^{200}$ Mathis, Effizienz statt Gerechtigkeit, S. 47.

${ }^{201}$ Mathias, Effizienz statt Gerechtigkeit, S. 48; einen ähnlichen Grundgedanke der Gerechtigkeit findet man bei AGB-Regelungen des BGB.

${ }^{202}$ Posner, Economic Analysis of Law, S. 13; Erlei, u.a., Neue Institutionenökonomik S. 16 f.; Eidenmüller, Effizienz als Rechtsprinzip, S. 49: Das Pareto-Kriterium gibt jedem Mitglied der Gesellschaft sozusagen ein Veto-Recht, mit dem es belastende Maßnahmen verhindern kann. Damit würden die staatlichen Handlungsspielräme sehr eingeengt. Es ist schwer, sich ein konkretes Vorhaben vorzustellen, das sich nicht mindestens für ein Individuum nachteilig auswirkt.

${ }^{203}$ Mathias, Effizienz statt Gerechtigkeit?, S. 52.

${ }^{204}$ Mathias, Effizienz statt Gerechtigkeit?, S. 52.

${ }^{205}$ Erlei, u.a., Neue Institutionenökonomik, S. 16 f.

${ }^{206}$ Es besteht erhebliche Zweifel an die generelle Einsetzbarkeit des Kaldor-Hicks-Kriterium, s. Mathias, Effizienz statt Gerechtigkeit? S. 61f.
} 
Trotz der vielen Vorteile, wie z.B. erhöhter Objektivität der Systembildung und damit verbundener Rechtssicherheit, oder effektiver Allokation subjektiver Rechte etc., die das Konzept der Ökonomischen Analyse des Rechts, genauer gesagt dessen herrschendes ${ }^{207}$ Kaldor-Hicks-Kriterium, mit sich bringt, ist es Gegenstand heftiger Kritik. Manche der Einwände sind normativer Natur, und manche sind gewichtige Sachargumente. Zunächst widmen wir unsere Aufmerksamkeit den Vorwürfen aus normativen Aspekten. Da die Entscheidungsfindung nach dem Effizienzbegriff im Sinne des Kaldor-Hicks-Kriteriums nur eine reine Kosten-Nutzen-Analyse ist, und eine Kompensation der Individuen, zu deren Last die Entscheidung fällt, nicht tatsächlich stattfindet, wird dem Kaldor-Hicks-Kriterium vorgeworfen, auf Kosten der individuellen Werte den Kollektivismus zu verbreiten; diese Art von Effizienzjurisprudenz steht möglicherweise in Konflikt mit unserer verfassungsrechtlich garantierten Freiheitsordnung ${ }^{208}$ und kann deswegen nicht konsensfähig sein. Nach der hier vertretenen Ansicht des Methoden- und Aspektenpluralismus ist diese pauschale Beanstandung so nicht richtig, denn man kann die Komplexität der sozialen Verhältnisse nicht durch ein monistisches Prinzip lösen. Im Bereich des Grundrechtsschutzes trifft der Kollektivismusvorwurf ohne weiteres zu. ${ }^{209}$ Aber jedem Mitglied der Gesellschaft ein VetoRecht gegen belastende Maßnahmen zu geben, wie es beim Pareto-Kriterium der Fall ist, ist schlechthin unmöglich; denn eine Maßnahme, die für alle vorteilhaft ist, existiert einfach nicht. ${ }^{210}$ Außerdem hängt nach dem ethischen Konzept der Ökonomischen Analyse des Rechts $^{211}$ die menschliche Freiheit zum großen Teil vom Wohlstand ab. Hinsichtlich des den Austauschprozess regulierenden Privatvermögensrechts ist m.E. das Kaldor-Hicks-Kriterium grundsätzlich einsetzbar, denn das Privatvermögensrecht stellt nur abstrakte „Spielregeln“ bereit, die für alle Verkehrsteilnehmer gleich sind. Abgesehen von einen Mindestschutz bietenden Normen, wie z.B. AGB- und Verbraucherschutzregelungen etc. besteht die Hauptaufgabe des Privatvermögensrechts darin, den „Kuchen“ so groß wie

\footnotetext{
${ }^{207}$ Eidenmüller, Effizienz als Rechtsprinzip, S. 52.

${ }^{208}$ Mathias, Effizienz statt Gerechtigkeit?, S. 61

${ }^{209}$ Vgl. Baumann, Ökonomie und Recht, RNotZ 2007, 297, 302 f.:

${ }^{210}$ Posner, Economic analysis of Law, S. 13; Eidenmüller, Effizienz als Rechtsprinzip, S. 49, 50

${ }^{211}$ Posner, Economic analysis of Law , S. 16.
} 
möglich zu machen wie und an wen dieser „Kuchen“ zu verteilen ist, ist die Aufgabe anderer Rechtsgebiete, wie etwa das Steuer-, Sozial-, Wettbewerbsrecht etc.

Die Attraktivität der Ökonomischen Analyse des Rechts besteht für viele Juristen rein instinktiv gesehen darin, dass sie gegenüber den traditionellen Techniken der Gesetzgebung und Rechtsanwendung (mit Hilfe der Auslegungen) der Beliebigkeit wenigen Raum überlässt. Genau hier greifen die Kritiker den ökonomischen Ansatz mit einer Reihe von gewichtigen Sachargumenten an, die erhöhte Aufmerksamkeit verdienen. ${ }^{212} \mathrm{Da}$ die Darstellungen der Grundbegriffe der Ökonomischen Analyse des Rechts (wie z.B. Verhandlungsmodell, Effizienz, Transaktionskosten etc.) im Schrifttum meist nicht bewusst in einer eng zusammenhängenden Relation stattfindet, müssen wir zunächst die Verhältnisse der Grundbegriffe zurechtordnen.

Nach dem Grundkonzept des Coase-Theorems führten die Verhandlungen der Inhaber subjektiver Rechte zu deren effizienten Allokation, wenn es keine Transaktionskosten gäbe; um die effiziente Allokation zu gewährleisten, muss der Staat Transaktionskosten senkende Maßnahmen ergreifen. Jetzt stellen die Kritiker folgende auf die Operationalisierbarkeit zielende Fragen:

- Frage Nr.1: Ist „Verhandeln“ die einzige Option der Beteiligten oder unterliegt sie bestimmten Vorbehalten?

- Frage Nr.2: Wie soll die Verhandlung stattfinden?

- Frage Nr.3: Wie kann man die Transaktionskosten erfassen oder berechnen?

Das Allokationsmodell des Coase-Theorems nimmt konkludent an, dass die Beteiligten verhandeln bzw. kooperieren. Ob dies generell anzunehmen ist, ist mehr als fraglich. Abgesehen von der Sonderkonstellation des Monopols ${ }^{213}$ könnten noch andere Faktoren das

\footnotetext{
${ }^{212}$ Nach dessen Befürwortern ist der ökonomische Ansatz für die Analyse aller Rechtsgebiete anwendbar (s. Posner, Economic analysis of Law, S. 3 f.; Schäfer/Ott, Ökonomische Analyse des Zivilrechts, S. 1 ff.; Eidenmüller, Effizienz als Rechtsprinzip, S. 4). Aber dessen Ursprung und der Schwerpunkt der gegenwärtigen Forschung liegt auf dem Privatrecht, genauer gesagt auf dem Privatvermögensrecht. Deshalb konzentriert diese Arbeit sich auf die diesbezüglichen Fundamentalkritiken.

${ }^{213}$ Varian, Mikroökonomik, S. 428: Ein Monopolist ist derjenige, der den Preis oder die Menge festsetzt und die Konsumenten enteiden lässt, wieviel sie zu diesem Preis kaufen oder welchen Preis sie zahlen wollen; zum Entscheidungsprozess s. Mankiw, Principles of Economices, S. $310 \mathrm{f}$.
} 
Verhandlungsmodell durchkreuzen. Nach dem mikroökonomischen Einkommenseffekt wirkt sich die durch die Veränderung des Einkommens bedingte steigende oder sinkende Kaufkraft über den Preismechanismus auf die (Angebots- und Nachfrage)Preise aus. ${ }^{214}$ Da die subjektiven vermögensrechtlichen Rechtspositionen werthaltig sind, verändert deren Zuweisung die Vermögenslage der Beteiligten. Wenn man den Einkommenseffekt und das Gesetz des Grenznutzens zusammen betrachtet, dann kommt man zu dem Ergebnis, dass sich der Angebots- und Nachfragepreis im Streitfall (also je nachdem, wem eine Rechtsposition zugewiesen wird) von einander entfernen, was das Verhandlungsmodell des Coase-Theorems in Frage stellt. ${ }^{215}$

Die tatsächliche Auswirkung dieses sog. Einkommenseffekts ist allerdings begrenzt, da er einerseits für Unternehmen, die keine Grenznutzenfunktion bzgl. zusätzlichen Einkommens besitzen, nicht gilt, und anderseits bei Konsumenten erst dann ernsthaft in Betracht gezogen werden kann, wenn er eine signifikante Größe erreicht. ${ }^{216}$ Neben dem Einkommenseffekt könnte auch der sog. „endowment effect“ (auch Besitzeffekt genannt) die potenzielle Einigung im Verhandlungsmodell gefährden. Danach schätzt der Besitzer den Wert seines Gutes höher ein als es tatsächlich der Fall ist, und das führt dazu, dass die Verkaufsbereitschaft (willingness to accept) geringer ist als die Zahlungsbereitschaft (willingness to pay). ${ }^{217}$ Dieses bisher nur durch psychologische Experimente zu spürende folgenreiche Phänomen ${ }^{218}$ werde kürzlich sogar von Neurowissenschaftlern der Stanford University durch funktionelle Magnetresonanztomograhpie nachgewiesen; ${ }^{219}$ aber außer dem Beweis der vorherigen Annahme der Verlustaversion des Menschen konnte die Studie noch keine brauchbaren Ergebnisse für die Ökonomische Analyse des Rechts liefern. Der neue neurowissenschaftliche Beweis alleine reicht meiner Meinung nach noch nicht aus, das

\footnotetext{
${ }^{214}$ Mankiw, Principles of Economices, S. $461 \mathrm{f}$.

${ }^{215}$ Eidenmüller, Effizienz als Rechtsprinzip, S. 121.

${ }^{216}$ Eidenmüller, Effizienz als Rechtsprinzip, S. 124.

${ }^{217}$ Thaler, theory of consumer choice, S. 39ff.; Shogren u.a.: Resolving Differences in Willingness to Pay and Willingness to Accept, S. 255 ff.

${ }^{218}$ Eidenmüller, Effizienz als Rechtsprinzip, S. 131.

${ }^{219}$ Knutson u.a., Neuron, Vol. 58, S. 814 ff.
} 
Verhandlungsmodell des Coase-Theorems grundsätzlich in Frage zu stellen. Denn die Studie hat sich nur auf drei Areale des Gehirns beschränkt, ${ }^{220}$ und deswegen kann noch nicht von einem Gesamtbild gesprochen werden. Empirisch gesehen kann man mit an Sicherheit grenzender Wahrscheinlichkeit behaupten, dass beim „Verhandeln“ viel mehr Elemente beteiligt sind als nur der Besitzeffekt, sonst existierte der Handel nicht. Im Ergebnis kann man das Verhandlungsmodell des Coase-Theorems vorläufig akzeptieren.

Der zweiten Frage begegnet Posner mit der sog. „hypothetischen Verhandlung“, d.h. ein subjektives Recht soll derjenige bekommen, der bereit ist, für das Recht den Höchstpreis zu bezahlen. ${ }^{221}$ Das Recht wird hypothetisch an den Meistbietenden versteigert. Die Gegenargumente des Auktionsmodells, nämlich Vortäuschung einer höheren Zahlungsbereitschaft ${ }^{222}$ und Informationsprobleme bei der Feststellung, können dadurch gemildert werden, indem man bei der Ermittlung der Zahlungsbereitschaft nicht von den Perspektiven der Beteiligten, sondern von der eines objektiven Entscheiders (Gesetzgeber oder Richter) ausgeht. ${ }^{223}$ Aber die Abstellung auf die Zahlungsbereitschaft, also auf den Nachfragepreis, wird von manchem als systematische Schlechterstellung zahlungsschwacher Konsumenten gegenüber zahlungskräftigen Unternehmen verurteilt, ohne selbst eine andere Lösung anzubieten. ${ }^{224}$ Dies ist wiederum eine Kritik normativer Art, die die Verteilungspolitik betrifft, was aber nach hier vertretener Meinung nicht die Aufgabe des privaten Vermögensrechts ist.

Die dritte Frage - wie kann man die Transaktionskosten erfassen oder berechnen - trifft genau die konzeptionelle Schwachstelle der Institutionsökonomie, nämlich die Operationalisierbarkeit der Transaktionskosten durch eine handfeste Definition. Ohne einen

\footnotetext{
${ }^{220}$ Knutson u.a., Neuron, Vol. 58, S. 814 ff.: Die drei untersuchten Hirnareale sind - der Nucleus accumbens (NAcc), der im Belohnungssystem des Gehirns eine wichtige Rolle spielt; die Inselrinde (Insula), die für die emotionale Bewertung von Ereignissen zuständig ist; der mediale präfrontale Kortex (MPFC), der die Gewinnerwartung aktualisiert.

${ }^{221}$ Posner, Utilitarianism, S. 125: “... if transaction costs are positive, the wealth maximization principle requires the initial vesting of rights in those who are likely to value them the most ...".

${ }^{222}$ Mathis, Effizienz statt Gerechtigkeit?, S. 58

${ }^{223}$ Mathis, Effizienz statt Gerechtigkeit?, S. 54.

${ }^{224}$ Eidenmüller, Effizienz als Rechtsprinzip, S. 138 f.
} 
handhabbaren Begriff der Transaktionskosten täuscht die Ökonomische Analyse des Rechts nur Scheingenauigkeit vor, und der darauf gestützten Rechtsetzung und Rechtsanwendung droht der Verlust an Redlichkeit und Überzeugungskraft. ${ }^{225}$ Gemeint ist mit dieser Kritik: Die Beantwortung der Frage, wann man zu Transaktionskosten senkenden und damit die Effizienz fördernden (staatlichen) Maßnahmen greifen soll, setzt voraus, dass man die Höhe der prohibitiven Transaktionskosten ermitteln kann. Darüber, wie kontrovers über den Begriff der Transaktionskosten in der Wirtschaftswissenschaft, welche das Instrumentarium für die Ökonomische Analyse des Rechts bereitstellt, diskutiert wird, kann man sich einen Überblick mittels des Aufsatzes von Frambach und Eissrich verschaffen. ${ }^{226}$ Sind Transaktionskosten die Kosten der Informationssuche, des Vorbereitens und Abschließens von Verträgen, der Kontrolle der Vertragsausführung etc; oder die Betriebskosten der wirtschaftlichen Aktivitäten; oder sollte man die Transaktionskosten aus der Perspektive des Individuums oder der Gesellschaft erfassen? Hilft die Klassifikation der Transaktionskosten nach Zeit, Sektor, Variabilität etc. uns weiter; sind Transaktionskosten sogar gerade diejenigen Kosten, die man nicht messen kann, die aber dennoch vorhanden sind ${ }^{227}$ Man hat den Eindruck, dass die Vielfalt der Begriffe für die Transaktionskosten die der Gerechtigkeitslehre in der Jurisprudenz übertrifft. Die Ursache dieser Vielfalt liegt in der durch die Systemoffenheit bzgl. der Transaktionskosten bedingten Schwierigkeit mit der Komplexitätsreduktion, die der Beobachtung und damit auch der Hypothesenaufstellung entgegensteht. ${ }^{228}$ Deswegen müssen spezifische und fallstudienartige Untersuchungen eine erhebliche Einschränkung hinnehmen, ${ }^{229}$ und von einem allgemein operationalisierbaren Begriff der Transaktionskosten, wenn es einen solche überhaupt gibt, ist man noch weit entfernt. Was ist nun mit den Ausgangsfragen: Also wann soll der Staat bei prohibitiven Transaktionskosten eingreifen, um die Effizienz zu fördern; wenn diese Frage unbeantwortet bleibt, soll das heißen, dass man die

\footnotetext{
${ }^{225}$ Diese harsche Kritik von Eidenmüller (Effizienz als Rechtsprinzip, S. 79) teile ich nicht, denn wenn man diese Haltung auch bei dem Gerechtigkeitsbegriff, also dem Zentralbegriff der Jurisprudenz, annehmen würde, wäre die Bildung oder Fortbildung des Rechtssystems gar nicht möglich.

${ }^{226}$ Frambach/Eissrich, Transaktionskosten, S. 43 ff.

${ }^{227}$ M.w.N.: Frambach/Eissrich, Transaktionskosten, S. 44 f.

${ }^{228}$ vgl. Jansen, Verfügungsrechte und Transaktionskosten, S. 56: „Im Vergleich zu analogen Größen der Energiephysik ist die empirische Interpretation und die Messbarkeit von ökonomischen Größen wie „Nutzen“ erheblich problematischer ...“

${ }^{229}$ M.w.N.: Frambach/Eissrich, Transaktionskosten, S. 52.
} 
ökonomische Analyse des Rechts ganz verwerfen sollte? An dieser Stelle muss zugegeben werden, dass die Ökonomische Analyse des Rechts als Hilfsmittel für die Rechtsanwendung bzw. als Entscheidungskriterium noch nicht ausgereift ist. Dies bedeutet aber längst noch nicht, dass diese junge Disziplin für die Jurisprudenz völlig unbrauchbar ist. Da niemand ernsthaft die Existenz der Transaktionskosten bestreitet, kann das Coase-Theorem als Orientierungshilfe insbesondere bei der Gesetzgebung eingesetzt werden. Mit anderen Worten heißt es, in Bereichen, wie etwa der Gesetzgebung, wo es hauptsächlich nicht um die direkte Erfassung, sondern um Einsparung von Transaktionskosten geht, ${ }^{230}$ ist das Coase-Theorem trotz der Kritik der mangelnden Messbarkeit nützlich. Dazu kann man sich vorerst mit allgemeinen oder aufzählenden Beschreibungen der Transaktionskosten zufrieden geben. Also wie z.B.: Transaktionskosten sind "costs of running the economic system"; ${ }^{231}$ oder Transaktionskosten sind Kosten der Informationssuche, Verhandlung, Durchsetzung, Ausführung, Kontrolle etc. ${ }^{232}$ Obwohl das Problem der Operationalisierbarkeit des Transaktionskostenbegriffs nicht unmittelbar im Wege dieser Arbeit steht, muss ich noch auf einen möglichen Ausweg hinweisen, nämlich dass der sog. „ordinale Nutzungsbegriff“" sowohl hinsichtlich der Rechtsanwendung als auch in Bezug auf die Gesetzgebung hilfreich sein kann. ${ }^{233}$ Insoweit lässt sich die Meinung von Eidenmüller, dass die Ökonomische Analyse des Rechts für das deutsche Rechtssystem in erster Linie eine Gesetzgebungstheorie ist, ${ }^{234}$ noch diskutieren.

Die Bedeutung der vorstehenden Erkenntnisse besteht für die Gestaltung eines der Globalisierung gerechten Kreditsicherungsrechts vor allem darin, dass man bei der Konstruktion stets auf die Senkung der Tranksaktionskosten achten muss. Ökonomisch gesehen kann die Rechtfertigung einer Veränderung bzw. einer erneuten Konstruktion eines Normensystems nur darin liegen, dass bei gleich gebliebener Rechtssicherheit das neue Normsystem bei deren Inanspruchnahme weniger kostet.

\footnotetext{
${ }^{230}$ Vgl. Frambach/Eissrich, Transaktionskosten, S. 52.

${ }^{231}$ Jansen, Verfügungsrechte und Transaktionskosten, S. 108.

${ }^{232}$ Vgl. Schäfer/Ott, Ökonomische Analyse des Zivilrechts, S. 5.

233 Baumann, Ökonomische Effizienzjurisprudenz, RNotZ 2007, 297, 298 f.: Ökonomische Analyse als konkretes Entscheidungskriterium bzgl. des Fahrlässigkeitsbegriffs.

${ }^{234}$ Eidenmüller, Effizienz als Rechtsprinzip, S. 486.
} 


\section{Vor- und Nachteile der abstrakten Gestaltung}

In diesem Abschnitt können die Vor- und Nachteile der abstrakten Gestaltung aufgrund der Komplexität des Darstellungsgegenstandes nur allgemein dargestellt werden; deren technische Umsetzung wird erst später, vor allem in der Publizität, behandelt.

\section{a) Entstehung und Erlöschen}

Im Gegensatz zu den gesetzlich akzessorischen Sicherheiten setzt die Existenz einer nichtakzessorischen Sicherheit das Vorhandensein einer zu sichernden Forderung nicht voraus. So lässt sich z.B. bei den Grundpfandrechten mit der abstrakten Bestellung einer Sicherheit ( $\$ 1196$ BGB) eine Rangsicherungsfunktion erzeugen, wodurch der Bodenwert vollständig mobilisiert werden kann. ${ }^{235}$ Bei Mobiliarsicherheiten ist die abstrakte Konstruktion m.E. der dogmatisch saubere Weg für die Besicherung künftiger Forderungen und eine Umgehung des Bestimmtheitsgrundsatzes als Verfügungsmaxime kann vermieden werden. Der weltweite Siegeszug des Eigentumsvorbehalts kann die Gestaltungsflexibilität der Abstraktion in der Entstehungsphase zusätzlich bestätigen. ${ }^{236}$

Die ökonomische Vorteilhaftigkeit der abstrakten Gestaltung der Sicherungsmittel tritt noch viel deutlicher in den Vordergrund, wenn der dynamische Kapitalfluss einen variablen Sicherungsschutz verlangt. Insbesondere für kapitalintensive, langfristige und internationale Großprojekte, die je nach aktuellen Rahmenbedingungen verschiedene Finanzierungstechniken, wie z.B. Abschnittsfinanzierung, Forderungsauswechslung wegen Neuvalutierung, Kreditaufstockung, Sicherung von Kreditrahmen ect., einsetzen müssen, bietet die Abstraktion der Sicherheit von der Forderung unermessliche Gestaltungsfreiheit und Kostensenkungsmöglichkeiten. ${ }^{237}$ Denn durch die Abstraktion schlägt die Änderung der Kapitalseite nicht auf die Sicherungsmittel durch; also mit anderen Worten - der dingliche Sicherungsmechanismus bleibt erhalten, während die schuldrechtliche Seite des Projekts

\footnotetext{
${ }^{235}$ Staudinger/Wolfsteiner, § 1196 Rn. 2: als wirtschaftlicher Zweck der Eigentümergrundschuld ist die vollständige Mobilisierung des im Grund und Boden steckenden Wertes.

${ }^{236}$ M.w.N.: Baur/Stürner, Sachenrecht, § 56 Rn. 9 - Richtlinie 2000/35/EG verpflichtet in Art. 4 Abs. 1 sogar die Mitgliedstaaten zur Einführung eines Eigentumsvorbehalts.

${ }^{237}$ Stöcker, Eurohypothek, S. 24 ff.; 230 ff.; 296.
} 
situativ verändert werden kann bzw. muss. Die für die abstrakten Sicherheiten mit Leichtigkeit gangbaren Lösungen sind für die akzessorischen Sicherheiten - zumindest ohne erheblichen Effizienzverlust - nicht möglich. Denn der Bestimmtheitsgrundsatz und die gesetzlich verordnete Erlöschensakzessorietät führen dazu, dass eine Sicherheit erlischt, wenn der Sicherungsgegenstand untergeht; damit gehen auch die mit der Bestellung der Sicherheit entstandenen Transaktionskosten (etwa die Kosten für Beurkundung, Vertragsverhandlungen usw.) verloren.

\section{b) Sicherungsumfang}

Die durch die Abstraktion gewonnene Gestaltungsfreiheit und Stabilität des Sicherungsmechanismus haben auch ihre unerwünschten externen Effekte. Einer davon ist die nachträgliche Übersicherung. Da die Abstraktion die Sicherheit auch hinsichtlich ihres Sicherungsumfangs von der Forderung isoliert, kann es bei einer nachträglichen Reduzierung des Umfangs der Forderung dazu kommen, dass der Wert der Sicherheiten den Betrag der zu sichernden Forderung nachhaltig übersteigt. ${ }^{238}$ In diesem Fall spricht das allgemeine Rechtsgefühl für den Rechtsgedanken der Umfangsakzessorietät. Eine Anpassung der Sicherheit an die Forderung ist erforderlich und bereitet der abstrakten Gestaltung der Sicherungsmittel ein schwieriges Problem, auf dessen Behandlung wir bei der sachenrechtlichen Konstruktion der Nichtakzessorietät eingehen werden.

\section{c) Mobilität}

\section{aa) Vorzüge der abstrakten Gestaltung}

Im Hinblick auf die Mobilität ist die abstrakte Gestaltung von Sicherheiten vor dem Hintergrund der Freisetzung von Sachwerten der gesetzlich vorgesehenen Übergangs- und Umfangsakzessorietät strukturell weit überlegen. Denn mit dem automatischen Gläubigerwechsel ist eine Sammelverwaltung der Forderungen unter Akzessorietät nicht mehr ohne weiteres durchführbar; außerdem macht die selbstvollziehende Variation des Wertgehalts der Sicherheit die Kalkulation der Risiken unmöglich.

\footnotetext{
${ }^{238}$ Wolters, Die Freigabeklausel im Kreditsicherungsvertrag, S. 50 f.
} 
In der modernen Marktwirtschaft beschränkt sich der Trend der Mobilisierung von Sachwerten nicht nur in Form von Briefgrundpfandrechten. Der sich immer vergrößernde Bedarf an Kredit und das damit steigende Risiko führt zu einer Charakterwandelung der Kreditinstitute vom Kreditgeber/Risikoträger zum Kredit- und Risikohändler. Die Richtlinien 2006/48/EG und 2006/49/EG (die sog. Basel II) haben durch ihre strengeren Eigenkapitalvorschriften diesen Trend noch zusätzlich verstärkt. So fordert die Finanzwelt generell, die Kreditforderungen als solche zu abstrahieren und dem Finanzverkehr zugänglich zu machen. Das dabei einsetzbare technische Mittel ist aber ein altes Instrument, nämlich die Verbriefung. ${ }^{239}$ Anhand des einheitlichen Begriffs „Security Interest“ und der vom UCC vorgesehenen abstrakten Gestaltung der Sicherheiten mit dem „Security Agreement" (Sicherungsvertrag) kann man in den USA dinglich gesicherte Kreditforderungen in allen möglichen Wirtschaftsbereichen schaffen. ${ }^{240}$ Diese Forderungen werden dann unter Article 8 UCC als „Investment Securities“ (Wertpapiere) verkleidet (ABS, MBS, CDO etc) und von „Securities Intermediary“ (Article 8 - 102 (14) UCC - Banken, Hedgefonds etc.) verwaltet.

bb) Schwäche - Risikokonzentration als die1. Ursache der Weltfinanzkrise

T2. Die (a) Unvollkommenheit der gegenwartigen Rahmenbedingungen des deutschen Zivillecehts (b) begionstigt die (c) Entfaltung des selbstzerstörerischen Potenzials des historisch entwickelten Abstraktionsprinzips, welches zure Auffhebung der durelh die Tremung zwischen Schuld- und Sachenuecht gekennzeichneten deutschen

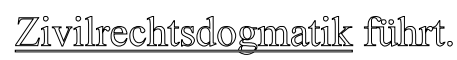

Die Ursache der Weltwirtschaftskrise ist aus juristischer Sicht deswegen besonders von Bedeutung, weil die Verbriefungstechnik deren Kern ausmacht, welche im Zuge der Finanzkrise unter heftigster Kritik steht, obwohl sie eigentlich viele wirtschaftliche Vorteile mit sich bringt. Unter „Verbriefung“ wird (weltweit) allgemein die Umwandlung von

\footnotetext{
${ }^{239}$ Brox, Wertpapierrecht, Rn. 440, 445: durch die Verbriefung wird ein privates Recht in einer Urkunde verkörpert, und dem Verkehr zugänglich gemacht.

240 Ricken, Verbriefung von Krediten und Forderungen, S. 39: MBS - private oder gewerbliche Hypothekenkredite; CDOs - Unternehmenskredite, handelbare Anleihen; ABS i.e.S. - Konsumentenkredite, Kreditkartenforderungen, Forderungen aus Lieferungen und Leistungen usw.
} 
Vermögenswerten in handelbare Wertpapiere verstanden. Traditionell sollte durch die Verbriefung der Privatrechte der Verkehr sicherer und leichter gemacht werden. ${ }^{241}$ Im Laufe der Zeit traten diese Ziele immer mehr in den Hintergrund, und die Handelbarkeit der gesicherten vermögenswerten Wertpapiere drängte sich rasch vor. Handelbare forderungsbesicherte Wertpapiere als Kapitalbeschaffungsinstrument sind an sich nicht Neues - den Grundstein für Die Verwirklichung dieser Idee hatte Friedrich der Große schon vor mehr als 240 Jahren gelegt. ${ }^{242}$ Was neu ist, sind die neuen Rahmenbedingungen des 21. Jahrhunderts und ihre Auswirkungen.

Die herrschende Wirtschaftsmacht der Angelsachsen geht aber noch viel weiter. Dort schuf man mit Hilfe von ABS (Asset Backed Securities) - also forderungsbesicherten Wertpapieren - ein „Wundermittel“, mit dem die Probleme der Finanzwelt auf einen Schlag gelöst werden sollten. Mittels fragwürdiger Vertragswerke zerstückelt und vermischt man verbriefte Forderungen, deren Risikoklassen ganz unterschiedlich sind, $\mathrm{zu}$ verschiedenen undurchsichtigen Finanzpaketen, deren Risiko nur drei spezialisierte Rating-Agenturen ${ }^{243}$ beurteilen können. Solche hoch komplexen risikobehafteten Finanzprodukte werden weltweit durch Kreditinstitute verkauft oder gekauft und anschließend zum Teil an kleine Anleger weiter veräußert. Verhängnisvoll ist aber, dass sich die Risiken der Finanzprodukte zwar mit Hilfe von Verbriefungstechnik transferieren lassen, eliminieren lassen sie sich aber nicht. Wegen der erhöhten Umlauffähigkeit konzentrieren sie sich auf wenige systemisch wichtige global agierende Finanzakteure. ${ }^{244}$ So entwickelte sich die Abkühlung der Weltwirtschaft (also Wertverfall von dinglichen Sicherheiten) im Jahre 2006 wegen der in solchen Finanzprodukten enthaltenen Informationsasymmetrie zur Vertrauenskrise und dann zur

\footnotetext{
${ }^{241}$ Brox, Wertpapierrecht, Rn. 440 ff.

${ }^{242}$ Hagen, Pfandbrief, Kreditwesen 2003, S. 652: Mit der Kabinettsordre vom 29. August 1769 legte Friedrich der Große den Grundstein für die Emission von Pfandbriefen. Er bezweckte damit, adligen Großgrundbesitzern zu billigeren landwirtschaftlichen Grundkrediten zu verhelfen, indem von sog. Landschaften auf Basis der von diesen gewährten Hypotheken Pfandbriefe emittiert werden konnten.

${ }^{243}$ Für die Bewertung der Kreditwürdigkeit hat die US-amerikanische Börsenaufsicht (SEC) bestimmte Ratingagentur zugelassen, http://www.sec.gov/divisions/marketreg/ratingagency.htm; Der Ratingmarkt wird hauptsächlich von Standard \& Poor's, Moody's und Fitch Ratings beherrscht, die nur unverbindliche,,Meinungen“ über die Kreditwürdigkeit der Wirtschaftsverkehrsteilnehmer abgeben.

${ }^{244}$ Litten/Cristea, Asset Backed Securities, WM 2003, $231 \mathrm{ff}, 213,214,217 \mathrm{f}$.
} 
Weltfinanz- und -wirtschaftskrise. ${ }^{245}$ Wenn man die mehrere hundert Seiten langen Emissionsprospekte ${ }^{246}$ (Vertragswerke) solcher Finanzprodukte ansieht, dann weiß man schon, warum der deutsche Anwaltsverein der Ansicht ist, dass das angloamerikanische Recht die Finanzkrise begünstigt hat. ${ }^{247}$

Unter deutschem Recht wurden bisher hauptsächlich Pfandbriefe und Buchgrundschuld dafür eingesetzt, um den Bodenwert für die Refinanzierung zu mobilisieren; ${ }^{248}$ die vom historischen Gesetzgeber für die Verbriefung vorgesehene Form, nämlich die Briefgrundschuld, wird von

\begin{abstract}
${ }^{245}$ Anschauliche Darstellung bei der Informationssendung des ARD „Hart aber fair“ vom 18.09.2008: Hier hat alles angefangen, auf dem US-Immobilienmarkt. Das Baugeld war billig, weil die US-Notenbank die Zinsen nach den Terroranschlägen am 11.09. immer weiter senkte, am Ende auf nur noch 1\%. Die Vertreter der Hypothekenbanken gewährten in dieser Phase beinahe jedem einen Kredit, selbst dann, wenn die Schuldner überhaupt keine Sicherheiten, nicht einen Cent Eigenkapital bieten konnten. Als Sicherheit galt nur das neue Haus. Kredite zweiter Klasse nannte man das. Offenbar war vielen Bankern klar, dass sie in Wirklichkeit faule Kredite in den Büchern hatten. Und so mischten die Hypothekenbanken gute Kredite mit schlechten zu undurchsichtigen Paketen.245 Sie verkauften die abenteuerlichen Papiere weiter, an andere Banken, die in dem Risikogeschäft große Gewinne witterten. So wanderten die kritischen Papiere immer weiter. Mehrfach umverpackt, über die ganze Welt, auch zu uns nach Deutschland. Am Ende wusste niemand mehr so genau, in wessen Safe wie viele der Risikokredite lagen. Ende 2006 dann platzte die Blase. Die Preise für die Häuser in den USA steigen nicht weiter. Sie beginnen zu sinken, eine Kettenreaktion setzt ein. Weil die Immobilien, also die Sicherheiten der Banken, jetzt weniger wert sind, erhöhen die Banken die Raten, denn sie wollen nicht auf den Risiken sitzen bleiben. Doch damit erreichen sie das Gegenteil von dem, was sie eigentlich wollen. Viele Schuldner können die teuren Raten nicht mehr leisten. Es kam zu Zwangsversteigerungen im ganzen Land. Der Immobilienmarkt geht endgültig in die Knie. Die Folge - erste Schieflagen bei den Banken; und, was noch schlimmer ist, jetzt ist das Vertrauen der Banken unter einander gestört. Sie leihen nicht so bereitwillig Geld wie früher, es kommt zu Zahlungsschwierigkeiten. Und die Probleme verschärfen sich. Weltweit müssen Banken Milliarden Kredite abschreiben. Und altehrwürdige Kreditinstitute gehen Pleite.
\end{abstract}

Wie schnell das alles gehen kann, sieht man am Beispiel Familie Otto: Sie wohnt seit ein paar Jahren im eigenen Heim, das zum großen Teil durch einen Kredit, finanziert durch der Hausbank. Herr Otto war kurzfristig arbeitslos, deshalb konnte er die Raten für das Haus nicht ganz so pünktlich bezahlen. Herr Otto findet schnell einen neuen Job, danach bedient er den Kredit normal weiter. Dann bekommt er Post, der Kredit auf das Haus ist gekündigt. 150.000 Schulden soll er jetzt auf einen Schlag zurückzahlen, und plus extra Zinsen. Sonst gibt es Zwangsvollstreckung. Jetzt würde Herr Otto gern mit seinem Berater bei der Hausbank sprechen, den er seit 20 Jahren kennt. Der nette Berater sagt, der Kredit gehört nicht mehr der Hausbank. Er ist an einen internationalen Finanzinvestor verkauft worden. In einem ganzen Paket von notleidenden Krediten, und weil Herr Otto zwei Mal die Raten nicht pünktlich bezahlt hat, kann der Finanzinvestor den Kredit kündigen und ein Ultimatum stellen. Familie Otto ist machtlos und kann natürlich nicht zahlen. Das Ende: Zwangssteigerung, und das Haus als Alterssicherung ist verloren, und damit alle Ersparnisse.

${ }^{246}$ Vgl. Prospectus von GELDILUX-TS-2008 S.A., Seite $119 \mathrm{ff}$ - the trust agreement: Da man im
angloamerikanischen Rechtskreis traditionell nicht mit Begriffsystem arbeitet, müssen die Anwälte in der
Vertragsgestaltung immer definieren, Auslegungsregeln aufstellen, verweisen usw. Im Vergleich ist es
erstaunlich zu sehen, wie effizient man mit dem deutschen Zivilrechtssystem bzw. Normsystem arbeiten kann.

${ }^{247} \mathrm{http}: / /$ rsw.beck.de/rsw/shop/default.asp?sessionid=1DA80FAAB0FD4CE9A00A38BF15226120\&docid=2896 08\&docClass=NEWS \&site=Beck\%20Aktuell $\&$ from=HP.0110

${ }^{248}$ Hies, Die Refinanzierung deutscher Hypothekenbanken, S. 29 f., 31. 
der Praxis wegen des hohen Aufwands für die Brieferstellung, den Transport oder die Aufbewahrung abgelehnt. ${ }^{249}$ Die Unternehmen hierzulande refinanzieren sich zunehmend mit CDOs nach dem angloamerikanischen Verbriefungsmodell. Damit entgeht nicht nur dem deutschen juristischen Dienstleistungssektor ein beachtlicher Anteil an Großaufträgen, sondern auch der deutschen Jurisprudenz die Opportunität für die Weiterentwicklung des Vermögensrechts. Angesichts der weitreichenden Bedeutung für die Wirtschaft hat die damalige Bundesregierung die Rahmenbedingungen für die Emission von ABS in Deutschland aufgelockert. ${ }^{250}$ In der Rechtswissenschaft selbst hat sich aber bisher nicht viel getan. $^{251}$

\section{cc) Stellungnahme und Ausblick}

Trotz der Weltfinanz- und -wirtschaftskrise ist festzuhalten, dass die Mobilisierung von Vermögenswerten durch die Verbriefung an sich die richtige Entwicklungsrichtung der globalisierten Marktwirtschaft aufweist. Der Ursprung dieser weltweiten Krise liegt m.E. nicht in der Verbriefung bzw. Abstraktion als solche, sondern in dem veralteten System der Verbriefung. Also in einem anderen komplementären Bereich der abstrakten Gestaltung, nämlich das System der Publikation.

\section{d) Durchsetzung und Bewertung des neuen § 1192 Abs. 1a BGB}

\section{T2. Die (a) Unvoll1kommenheit der gegenwartigen Rahwenbedingungen des deutschen Ziviliechats (b) beginstigt die (c) Entraltung des selbstzerstorrerischen Potenzials des historisch entwickelten Abstraktionsprinzips, welches zure Aufhebung der durch die Trennung zwischen Schuld- und Sachenrecht gekennzeichneten deutschen

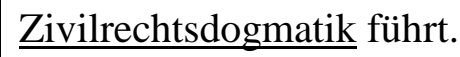

\footnotetext{
${ }^{249}$ Stöcker, Sicherungsbuchgrundschuld zur Verbriefung von Krediten, Die Bank 2004, S. 55 ff. (57); in der Schweiz ist der der Briefgrundschuld ähnliche Schuldbrief verbreitet, m.E. wahrscheinlich deswegen, weil die geographische Ausdehnung des Landes nicht so groß ist und die Transportkosten deswegen nicht so hoch sind.

${ }^{250}$ Ricken, Verbriefung von Krediten und Forderungen, S. 44 f.: Dazu gehören der Finanzmarktförderplan 2006, das Kleinunternehmerförderungsgesetz, die Einführung von Refinanzierungsregistern usw.

${ }^{251}$ Vgl. Baur/Stürner, Sachenrecht, $§ 40$ Rn. 7a; $§ 58$ 15a: Hier findet man nur die kurze Wiedergabe des „Securitization“-Modells unter angloamerikanischem Recht, aber keine eigene Antwort der deutschen Jurisprudenz auf den weltweiten Umbruch des Regelungsgehalts des Zivilrechts.
} 
Auch die Durchsetzbarkeit der abstrakten Sicherheiten hängt ganz eng mit der Umlauffähigkeit der gesicherten Forderung zusammen. Eine der Grundfunktionen des Abstraktionsprinzips ist die Stärkung des Verkehrsschutzes dadurch, dass die Einreden des Grundverhältnisses gegenüber gutgläubigen Dritterwerbern isoliert werden. ${ }^{252}$

\section{aa) „Eurohypothek“}

Diese fundamentale Funktion stellt auch die Grundbedingung für die verbreitete Inanspruchnahme der Grundschuld in der Praxis dar. Nicht ohne Grund gibt es seit langer Zeit die Diskussion über die Einführung der „Eurohypothek“ nach dem Vorbild der deutschen Grundschuld (vor der Einführung des $\S 1192$ Abs. 1a BGB) oder nach dem Modell des schweizerischen Schuldbriefes. ${ }^{253}$

Die Schaffung eines europäischen Grundpfandrechts ist das erste Gedankenspiel Europas mit der Schaffung eines einheitlichen Sicherungsrechts. Obwohl die EU die überragende Bedeutung eines einheitlichen Grundpfandrechts seit langem schon erkannt hat, ${ }^{254}$ hält sich bisher die Anstrengung und Erfolge Europas für die Einführung eines einheitlichen europäischen Sicherungsrechts bedauerlicherweise sehr in Grenzen.

Bereits in den 60er Jahren stellte eine von der EWG-Kommission eingesetzte Sachverständigengruppe unter der Leitung von Prof. Segré im Rahmen einer Untersuchung für den Ausbau der Kreditversorgungswege in dem europäischen Kapitalmarkts fest, dass die Grundschuld des deutschen Rechts (vor Einführung des § 1192 Abs. 1 a BGB) wegen ihrer „Technik“ für internationale Kreditgeschäfte von besonderem Interesse sein kann. ${ }^{255}$ Gemeint ist die ,anpassungsfähige“, „,billige“ abstrakte Gestaltung der Grundschuld - „,eine auf einem

\footnotetext{
${ }^{252}$ Huber, Savigny und das sachenrechtliche Abstraktionsprinzip, S. 501.

${ }^{253}$ Zur Entwicklungsgeschichte der Eurohypothek: Meyer, einheitliches europäisches Grundpfandrecht oder Wettbewerb der Rechtsordnungen?, EuZW 2004, 389 ff; m.w.N. Baur/Stürner, Sachenrecht, § 64 Rn. 77 ff.; Botschft - ZGB, 5298 f. - In Europa ist die nichtakzessorische Gestaltung kein Einzelfall, sie existiert auch in Spanien, Ungarn, Slowenien, Estland; in jüngster Zeit haben Experten die „Basic Gzidelines for a Europhyothec" erarbeitet.

${ }^{254}$ Segré-Bericht: Aufbau eines Europäischen Kapitalmarkts, S. 153 ff.; Weissbuch, S. 2: „das Volumen der ausstehenden Hypothekarkredite für private Wohnbauten beläuft sich auf fast 47\% des BIP der EU, womit der Hypothekarkreditmarkt zu den wichtigsten Märkten der europäischen Wirtschaft zählt. “
}

${ }^{255}$ Segré-Bericht, Aufbau eines Europäischen Kapitalmarkts, S. 159. 
Grundstück ruhende abstrakte Verpflichtung, die unabhängig von der Forderung, zu deren Sicherung sie dient, entsteht und erlischt. “256

Der Vorschlag der Segré-Gruppe - „... Angleichung der ... Rechtsvorschriften über die Grundpfandrechte sollte als eine vorrangige Aufgabe angesehen werden“‘257 bleibt bis jetzt immer noch unerfüllt. Ein Arbeitskreis für die Integration der EU-Hypothekarkreditmärkte existiert zwar immer noch und hält die von der „Segré-Gruppe“ anvisierten Ziele immer noch für sehr wichtig, ${ }^{258}$ aber konkrete Normenvorschläge hat sie leider nicht gemacht. ${ }^{259}$ Stattdessen wurde sogar vor der Immobiliencrash in den USA und Weltfinanzkrise empfohlen, den Hypothekenmarkt zu deregulieren. ${ }^{260}$ Nach der Krise kommt die Arbeit dieses Expertenkreises zum völligen Erlegen (Stand Juli 2011).

Im Zuge des Voranschreitens der globalen Wirtschaft sind jedoch auf nationaler Eben interessante Entwicklungen des Grundpfandrechts zu beobachten. Während die Schweiz nach dem Vorbild des amerikanischen UCC die abstrakte Gestaltung des Grundpfandrechts durch Einführung des Register-Schuldbriefs und der Bucheffekte noch weiter ausbaut und das eigene Model als Vorbild für die Eurohypothek empfiehlt, ${ }^{261}$ macht der deutsche Gesetzgeber meiner Meinung nach durch die Einführung des § 1192 Abs. 1a BGB einen großen Schritt zurück in die Vergangenheit und gibt nicht nur die Führungsrolle im internationalen Wettbewerb der Modellfunktion freiwillig ab, sondern verrät auch das durch den historischen Gesetzgeber mühsam aufgestellte saubere dogmatische System. ${ }^{262}$ Aus Sicht der Dogmatik

\footnotetext{
${ }^{256}$ Segré-Bericht, Aufbau eines Europäischen Kapitalmarkts, S. 159, 165, 177.

${ }^{257}$ Segré-Bericht, Aufbau eines Europäischen Kapitalmarkts, S. 177.

${ }^{258}$ Bericht der Forum-Gruppe für Hypothekarkredite (2004), S. 20
}

259 Website der EU-Kommission zur Integration der EU-Hypothekarkreditmärkte: http://ec.europa.eu/internal_market/finservices-retail/home-loans/integration_de.htm\#mortgage

${ }^{260}$ The Cost and Benifits of Integration of EU Mortgage Markets, S. 177.

${ }^{261}$ Schmid-Tschirren, Der Register-Schuldbrief, S. 17.

262 In der Literatur gibt's auch Stimme, die in $\S 1192$ Ia BGB eine Chance zur Bildung eines Einheitsgrundpfandrechts sieht (Nietsch, Der Ausschluss des gutgläubigen einredefreien Erwerbs nach § 1192 Ia BGB, NJW 2009, 3606 ff, 3609; ) und zwar über die einheitliche Herabsetzung des Maßstabs für den gutgläubigen einredefreien Erwerb auf grob fahrlässige Unkenntnis. Dieser Weg führt meiner Meinung nach zu 
gefährdet dies den guten Ruf des deutschen Zivilrechts in der Welt und sein Entwicklungspotenzial im Hinblick auf das moderne Zivilrecht. Mit dem Verlust der Modellfunktion des deutschen Rechts für die Gestaltung des Kreditgeschäftes steht Deutschland im Wettbewerb um den Finanzplatz zwangsläufig viel schlechter da. Was zu dieser Regelung geführt hat und warum sie zurückgenommen werden muss, werden wir im Folgenden erörtern.

\section{bb) Hintergründe der Einführung des § 1192 Abs. 1a BGB}

Als Hauptbeispiel wird in den Medien folgendes geschildert: „Als es deutschen Großbanken schlecht ging, begannen sie, ihre Altlasten $\mathrm{zu}$ verkaufen. So fielen Tausende Immobilienkredite still und heimlich in den Besitz ausländischer Finanzinvestoren. Für die Kunden kann das einen GAU bedeuten, denn die "Heuschrecken" wollen vor allem eines: schnell Kasse machen.“ 263 Anfang 2008 kursierten dann besonders dramatisierte Berichterstattungen über die sog. „Immobilien-Heuschrecken“ in den deutschen Medien. ${ }^{264}$ Dann brachte der Freistaat Bayern am 29.02.2008 ${ }^{265}$ den Entwurf zum „Kreditnehmerschutzgesetz“ in den Bundesrat ein, der auch fast unverändert in den Gesetzentwurf des Bundesrats eingegliedert und dem Bundestag vorgelegt wurde. ${ }^{266}$

Rechtlich gesehen stammt die in den Medien Aufsehen erregend dargestellte Gefährlichkeit der „abstrakten“ Grundschuld aus einer Konstruktion des grundschuldbesicherten Kreditgeschäfts in Zeiten, in denen die massenhafte Mobilisierung von Kreditforderungen noch kein großes Thema und das Vertragsverhältnis zwischen Kreditgeber/Sicherungsnehmer und Kreditnehmer/Sicherungsgeber deswegen relativ stabil war. So fordern die Kreditinstitute aus Kosten- und rechtlichen Gründen bei Vergabe von Immobilienkrediten die Bestellung einer Grundschuld, die nach $§ 1191$ Abs. 1 BGB unabhängig von dem Bestehen oder der

\footnotetext{
einer eindeutigen Verlust der Rechtssicherheit!! Das Fundament des guten Rufs des deutschen Grundpfandrechts wird dadurch unwiederbringlich gerüttelt bzw. gemindert.

${ }^{263}$ Der Spiegel 31/2006, S. 58 f.: Heuschrecken fressen Immobilienkredite

${ }^{264}$ Beitrag im ARD-Magazin „plusminus" vom 22.01.2008; FAZ, 23.01.2008 „Missbrauch verkaufter Hauskredite soll verhindert werden"; TAZ, 11.02.2008: Gesetz gegen Kredit-Heuschrecken.

${ }^{265}$ Am 2. März 2008 fanden die Kommunalwahlen in Bayern 2008 statt; Am 28. September 2008 fand die Landtagswahl in Bayern 2008 statt.

${ }^{266}$ BR-Drucks. 152/08, vom 29.2.2008; BT-Drucks. 16/9447, vom 6.6.2008.
} 
Veränderung der zugrunde liegenden Kreditforderung existieren kann. In dem (grds. formlosen) Sicherungsvertrag, wo die Gebundenheit der Grundschuld und Kreditforderung schuldrechtlich hergestellt werden soll, vereinbaren die Kreditinstitute im Wege der AGB, dass die Grundschuld erst bei vollständiger Tilgung der Darlehensforderung im Grundbuch gelöscht wird. Da man nach $\S \S 1191$ Abs. 1, 1192 Abs. 1 und $§ 1147$ BGB grundsätzlich erst bei Fälligkeit der gesicherten Kreditforderung im Wege der Kündigung der Grundschuld gem. $\S 1193$ Abs. 1 BGB zur Verwertung der Grundschuld übergehen darf, ${ }^{267}$ wird in der Praxis die sog. Unterwerfung unter die sofortige Zwangsvollstreckung vereinbart, ${ }^{268}$ indem man die Willeinsübereinstimmung $\quad\left(\begin{array}{llllllll}\S & 311 & \text { Abs.1 } & \text { BGB } & 269\end{array}\right), \quad$ dass sich $\operatorname{der}$ Kreditnehmer/Sicherungsgeber wegen des Grundschuldkapitals zuzüglich Zinsen der sofortigen Zwangsvollstreckung unterwirft und auf den Nachweis der Fälligkeit der Grundschuld verzichtet, in eine notarielle Urkunde aufnimmt. Unmittelbar nach ihrer Errichtung lässt man dann diese Urkunde zustellen und verwahrt sie, um sich eines Tages den Klageweg und die Zustellungsvoraussetzung im Zwangsvollstreckungsverfahren zu ersparen und im Wege der $\S \S 794$ Abs. 1 Nr. 5, 800 ZPO sofort auf den Sicherungsgegenstand zugreifen zu können. ${ }^{270}$

Im Zuge der Verbreitung des ABS-Geschäfts als Refinanzierungsmodell von den USA nach Europa verkaufen die deutschen Kreditinstitute massenhaft ihre Immobilienkredite samt dinglicher Sicherheiten an (meist angloamerikanische) „Finanzinvestoren“, die aber für das Weiterbestehen des Kreditverhältnisses keinerlei Interessen haben. ${ }^{271}$ Auf Grund der Möglichkeit eines gutgläubigen einredefreien Erwerbs der Grundschuld nach §§ 1192 Abs. 1, 1157 S. 2 BGB $^{272}$ entsteht in der vorstehenden Konstellation eine Schutzlücke für den Grundstückseigentümer, insbesondere wenn das bisherige Kreditverhältnis ungestört war. Denn sicherungsvertragliche Einreden können nach § 1157 S. 1 BGB ihren Eingang

\footnotetext{
${ }^{267}$ MüKo/Eickmann, § 1191 Rn. 101; Staudinger/Wolfsteiner, § 1147 Rn. 43.

${ }^{268}$ Vgl. Baur/Stürner, Sachenrecht, S. 993 - Anhang 4.

${ }^{269}$ Vgl. § 781 BGB: Hier wird ein Schuldverhältnis im materiellen Sinne anerkannt.

${ }^{270}$ Palandt/Bassenge, $§ 1147$ Rn. 4.

${ }^{271}$ BR-Drucks. 152/08, vom 29.2.2008: Darin sieht der Gesetzgeber die Ursache der Gefahr.

${ }^{272}$ Vgl. BGHZ 85, 388 = NJW 1983, 752.
} 
drittwirksam ins Grundbuch gem. § 1157 S. 2 BGB nur in der Konstellation finden, wenn ihr gesamter Einredetatbestand im Zeitpunkt des Erwerbs verwirklicht war. ${ }^{273}$ Für den Immobilieneigentümer bedeutet das Schutzlosigkeit gegenüber einem gutgläubigen Dritterwerber der Grundschuld (,Finanzinvestor“), der aus der Urkunde sofort in die Immobilien vollstrecken will.

Der typische Fall ist, dass ein braver Familienvater seine Kreditraten jahrelang Monat für Monat pünktlich zahlt und kurz vor vollständiger Tilgung der Kreditforderung, z.B. wegen der Finanz- und Wirtschaftskrise, arbeitslos wird; Dann geht er zu „seiner Hausbank“ und spricht mit „seinem Vermögensberater“ über die unglückliche Situation und bittet um Verständnis für die Zahlungsverzögerung. Der Bankberater sagt zu dem Familienvater, es tue ihm auch leid, aber die Kreditforderung samt Grundschuld sei an einen „Finanzinvestor“ verkauft worden, und man muss an ihn wenden. Der nur am Profit orientierte „Finanzinvestor“ will aber ohne Rücksicht auf Verluste seitens des Familienvaters sofort die Zwangsvollstreckung betreiben, was das geltende Recht ihm selbst bei völlig ungestörten Kreditverhältnissen erlaubt. Denn die Tilgung der Darlehensforderung als Einrede genießt (wie schon gesagt) keinen gutgläubigen Schutz nach § 1157 S. 2 BGB. Der beweisbelastete Immobilieneigentümer kann auch die Bösgläubigkeit des Finanzinvestors nicht nachweisen, da hier die ganz h.M. zugunsten der absoluten Zuverlässigkeit des Grundbuchs als Rechtsscheinträger eine positive Kenntnis verlangt und die bloße Kenntnis des Sicherungscharakters der Grundschuld reicht also für die Begründung der Bösgläubigkeit aber nicht aus. ${ }^{274}$

Durch die Dramatisierung solcher Fälle in der Öffentlichkeit stand der deutsche Gesetzgeber angesichts des gigantischen Volumens der Verbriefungsgeschäfte unter enormem Handlungsdruck und beschloss eine Reihe von Gesetzesänderungen, um die vorstehende unglückliche und ungerechte Konstellation zu korrigieren. Besonders deprimierend dabei ist die Einführung des $§ 1192$ Abs. 1a BGB:

\footnotetext{
${ }^{273}$ MüKo/Eickmann $§ 1157$ Rn. 8; BGHZ 85, 388 = ZIP 1983, 146.

${ }^{274}$ MüKo/Kohler, $§ 892$ Rn. 47; Palandt/Bassenge, § 892 Rn. 24; BGH LM Nr. 5; OLG Stuttgart BWNotZ 1978, 124 f.; NJW 98, 445.
} 
„Ist die Grundschuld zur Sicherung eines Anspruchs verschafft worden (Sicherungsgrundschuld), können Einreden, die dem Eigentümer auf Grund des Sicherungsvertrags mit dem bisherigen Gläubiger gegen die Grundschuld zustehen oder sich aus dem Sicherungsvertrag ergeben, auch jedem Erwerber der Grundschuld entgegengesetzt werden; § 1157 Satz 2 findet insoweit keine Anwendung. Im Übrigen bleibt $\$ 1157$ unberührt. “

\section{cc) Auswirkungen des $§ 1192$ Abs. 1a BGB}

Im Rahmen des Publizitätsgrundsatzes werden wir erörtern, warum Baur/Stürner zu Recht meint: „Ohne gründliche Vorarbeiten durch eine sachverständige Kommission sollte man im BGB und vor allem im Sachenrecht nichts ändern.، ${ }^{275}$

Mit der Legaldefinition der Sicherungsgrundschuld bewegt sich der Gesetzgeber in einer terminologisch brisanten Zone der deutschen Zivilrechtsdogmatik, wo die Balance zwischen der Kodifikation und Kautelarpraxis bisher mühsam aufrecht gehalten wird. Mit der Errichtung eines Grundbuchs will die Kodifikation dem Rechtsverkehr Schutz bieten und die Beweisführung erleichtern. Ein Dritter darf und muss sich voll und ganz auf das Grundbuch verlassen können. ${ }^{276}$ So entfaltet das Eintragungsprinzip als Teil der materiellen Publizität konstitutive Wirkung bei der Rechtsübertragung: Die materielle Wirksamkeit der rechtsgeschäftlichen Rechtsänderung wird von ihrer Eintragung abhängig gemacht; zusammen mit der Vermutungswirkung des $§ 891$ BGB will man die Übereinstimmung der wirklichen Rechtslage mit dem Buchstand erreichen. ${ }^{277}$ Da die Vermutungswirkung des $§ 891$ BGB im Falle der nachweislichen Unrichtigkeit des Grundbuchs nicht hilft, schließen $§ \S 892$, 893 BGB diese Lücke mit der Rechtsscheinwirkung. ${ }^{278}$ So gewährleisten die positive Publizität (Richtigkeitsvermutung) und die negative Publizität (Vollständigkeitsvermutung) zusammen die absolute Zuverlässigkeit des Grundbuchs; ein Erwerber darf dem Schweigen

\footnotetext{
${ }^{275}$ Baur/Stürner, Sachenrecht, § 45 Rn. 67L.

${ }^{276}$ Vgl. Baur/Stürner, Sachenrecht, § 15 Rn. 44 ff.

${ }^{277}$ Wagemann, Grundstücksregister, S. 9: Die Übertragungswirkung ist die zentrale Schnittstelle zwischen formellem und materiellem Grundstücksrecht.

${ }^{278}$ Wagemann, Grundstücksregister, S. 11.
} 
des Grundbuchs ebenso wie seinem Reden trauen. ${ }^{279}$ Aber diese Wirkung des Grundbuchs beschränkt sich nur auf dingliche Rechte. Für die Eintragung und den gutgläubigen Schutz bzgl. schuldrechtlicher Rechte wie die Einreden aus dem Sicherungsvertrag bedarf es des spezielleren $\S 1157$ S. 2 BGB. Der $\S 1157$ S. 1 BGB, welcher den Schutzumfang bestimmt, will mit dem Wortlaut „Zusteht“ aber nur solche sicherungsvertraglichen Einreden eintragungsfähig machen, die auch zur Zeit des Erwerbs schon entstanden waren. Wenn man das historische Gesetzgebungsmaterial ${ }^{280}$ anschaut - der erste Entwurf des BGB wollte eigentlich wegen der Grundentscheidung für die Trennung zwischen Schuld- und Sachenrecht dem Eigentümer keine Einreden aus einem Schuldverhältnis gegenüber dem Rechtsnachfolger eines dinglichen Rechts gewähren; diese Haltung wurde später zugunsten des Grundgedanken des § 404 BGB aufgegeben. ${ }^{281}$ - dann muss man den $§ 1157$ S. 1 BGB als einen mühsamen und fragilen Balanceakt des historischen Gesetzgebers verstehen, der versucht, sowohl dem dogmatischen System des BGB als auch dem Schutz des Eigentümers im dynamischen Rechtsverkehr gerecht zu werden. Man muss sagen, dies ist dem historischen Gesetzgeber auch gelungen, bis das Verbriefungsmodell der Angelsachsen (begleitend mit der Möglichkeit der Betreibung der sofortigen Massenzwangsvollstreckung) kam.

Durch die Einführung des $§ 1192$ Abs. 1a BGB hat der heutige Gesetzgeber dafür gesorgt, dass alle Wirkungen des schuldrechtlichen Sicherungsvertrags auf die dingliche abstrakte Grundschuld erstreckt werden. ${ }^{282}$ Diese starke Verdinglichung des Sicherungsvertrags würde dazu führen, dass man theoretisch nicht nur die bereits bestehenden Einreden aus dem Sicherungsvertrag, sondern auch den Sicherungscharakter der Grundschuld ins Grundbuch eintragen könnte; solche Eintragungen können wegen $\S 1192$ Abs. 1a S. 1 Hs. 2 BGB aber keine Gutglaubenswirkungen entfalten. ${ }^{283}$ Nach der neuen Regelung verläuft die Verdinglichung des Sicherungsvertrags außerhalb des Grundbuchs, und die dadurch bedingte Aufhebung des gutgläubigen Erwerbs entwertet die Grundschuld als sicherstes

\footnotetext{
${ }^{279}$ MüKo/Kohler, § 892 Rn. 1.

${ }^{280}$ Motive III S. 700, 701.

${ }^{281}$ Protokolle III S. 582 ff.

${ }^{282}$ Vgl. Baur/Stürner, Sachenrecht, § 45 III Rn. 67g.

${ }^{283}$ Meyer, § 1192 Abs. 1a BGB - ein Schnellschuss des Gesetzgebers, WM 2010, 58 ff. (62).
} 
Sicherungsmittel und damit ihre Umlauffähigkeit. Die Einführung der gesetzlichen Durchsetzungsakzessorietät bei der Grundschuld ist aber auch aus systematischer Sicht nicht sonderlich geglückt und enthält Wertungswidersprüche; denn der Erwerber einer akzessorischen Verkehrshypothek genießt aufgrund §§ 1138, 892 BGB Gutglaubensschutz, während diese Möglichkeit der nichtakzessorischen Grundschuld wegen §§ 1157, 1192 Abs. 1a BGB verwehrt bleibt. ${ }^{284}$ „Der Gesetzgeber hat die wahren Auswirkungen des $§ 1192$ Abs. 1a BGB verkannt und es insbesondere unterlassen, das Verkehrsinteresse an der Umlauffähigkeit der Grundschuld in seine Abwägung einzubeziehen. “ ${ }^{285}$ Angesichts der nicht verzichtbaren Vorteile der abstrakten Grundschuld wird § 1192 Abs 1a BGB meiner Meinung nach wahrscheinlich das gleiche Schicksal der weitgehenden Bedeutungslosigkeit des gesetzlichen Pfandrechts erleben und neue abstrakte Kautelbargrundpfandrechte außerhalb der Kodifikation werden sich im Laufe der Zeit wieder durchsetzen. Dies ist in Hinblick auf die deutsche Tradition der Gewährleistung der Systemklarheit durch Kodifikation höchst unerfreulich, aber denkbar, z.B. durch eine abstrahierte Hypothek: ein Darlehen in wechselnder Höhe kann durch ein abstraktes Schuldversprechen gesichert werden, welches mit dem Darlehensrïckzahlungsanspruch durch eine schuldrechtliche Sicherungsabrede mit entsprechend weiter Sicherungszweckerklärung verbunden ist; das abstrakte Schuldversprechen seinerseits wird wiederum durch eine Verkehrshypothek besichert und bleibt trotz Tilgung des Darlehensrückzahlungsanspruches bestehen. ${ }^{286}$ Diese Möglichkeit sah sogar auch der historische Gesetzgeber. ${ }^{287}$

\section{dd) Ist die abstrakte Gestaltung eines Grundpfandrechts systemisch untragbar?}

Der Preis, den § 1192 Abs. 1a BGB für den umfassenden Schutz des Immobilieneigentümers zahlt, ist unverhältnismäßig hoch. Denn geopfert wird nicht nur die Zuverlässigkeit des

\footnotetext{
${ }^{284}$ Baur/Stürner, Sachenrecht, § 45 Rn. 67 L.

${ }^{285}$ Meyer, § 1192 Abs. 1a BGB - ein Schnellschuss des Gesetzgebers, WM 2010, 58 ff. (63).

${ }^{286}$ Böttcher, Das abstrakte Schuldversprechen in der Kreditsicherung, S. 166.

${ }^{287}$ Mugdan, Sachenrecht, S. 340: „... daß die Hypothek auch für eine Forderung, welche lediglich von einem abstrakten Schuldversprechen nach Maßgabe der $\S \S 683$ und 684 getragen wird, bestellt werden könne und dass nichts entgegenstehe, einer ohne Bezeichnung einer Forderung erklärten Eintragungsbewilligung zugleich die rechtliche Bedeutung eines durch die Eintragung gültig werdenden Schuldversprechens beizulegen. ... ... Hiernach kann es sich nur fragen, ob die Grundschuld überhaupt aufgegeben werden soll. Diese Frage aber muss verneint werden. ......"
} 
Grundregisters, sondern auch die Umlauffähigkeit der Grundschuld und ihre hohe Sicherungskraft, und damit ihre Modellfunktion für die Gestaltung des modernen Privatvermögensrechts.

In der Regel veräußern die deutschen Banken bei den Verbriefungsgeschäften die Kreditforderungen samt der dazu gehörigen Sicherheit als Portfoliopaket, so dass es normalerweise nicht zu einer „gefährlichen“ Trennung kommen wird. ${ }^{288}$ Selbst wenn die Bank eine Grundschuld vor dem Eintritt des Sicherungsfalls isoliert übertragen würde, würde dies eine Gefährdung des Rückgewähranspruchs bedeuten, und sie wäre aufgrund der Interessenwahrungspflicht aus dem Sicherungsvertrag unzulässig. ${ }^{289}$ Eine dennoch vorgenommene Übertragung der Grundschuld ist zwar aufgrund der Nichtakzessorietät der Grundschuld und die Möglichkeit des gutgläubigen Erwerbs möglich, zieht aber für die übertragende Bank Schadensersatzansprüche des Sicherungsgebers nach sich. ${ }^{290}$ Hier liegt der eigentliche Beweggrund für die Einführung des $\S 1192$ Abs. 1a BGB. Fakt ist, dass ein „Finanzinvestor“ unabhängig davon, ob er eine isolierte Grundschuld in den Händen hält, ein Zwangsvollstreckungsverfahren aufgrund der Unterwerfung unter die sofortige Zwangsvollstreckung betreiben kann. So werden die als Sicherheit dienenden Immobilien im Zwangsvollstreckungsverfahren zu Schleuderpreisen versteigert, die unter normalen Umständen auf keinen Fall zustande kommen würden. Dies stellt einen maßlosen Eingriff ins Familienleben vieler „kleiner Leute“ dar, und im Extremfall landet man buchstäblich ,auf der Straße“. Ein Schadensersatzanspruch kann man aber nur mit einem jahrelangen Prozess gerichtlich geltend machen, und dies ist mit erheblichem Prozessaufwand und dem Beweisrisiko bzgl. der einzelnen Schadenspositionen verbunden. Das möchte man aber den einfachen Leuten, insbesondere wenn die sich stets vertragstreu verhalten haben, nicht zumuten.

Insoweit ist die abstrakte Gestaltung meiner Meinung nach kein systemisch, sondern ein menschliches untragbares Ergebnis des deutschen Zivilrechts.

\footnotetext{
${ }^{288}$ Baur/Stürner, Sachenrecht, $\S 45$ Rn. 67 L; Meyer, $§ 1192$ Abs. 1a BGB - ein Schnellschuss des Gesetzgebers, WM 2010, 58 ff. (60).

${ }^{289}$ MüKo/Eickmann, § 1191 Rn. 98; BGH ZIP 1991, 19, 20.

${ }^{290}$ BGH WM 1997, 13; Melzer, NJW 1997, 461 ff. (463).
} 


\section{ee) Wie ist das Risiko der Grundschuld zu begrenzen?}

An dieser Stelle stellt sich die Schlüsselfrage für die deutsche Zivilrechtsdogmatik: Ist eine völlige Beschneidung der Umlauffähigkeit der Grundschuld durch den $§ 1192$ Abs. 1a BGB unbedingt notwendig? Hier liegt m.E. eines der komplexesten Strukturprobleme im BGB. Einerseits muss das Grundbuch ein zuverlässiger Rechtsscheinträger bleiben, bei dem nur die positive Kenntnis seiner Unrichtigkeit schadet. Andererseits müssen die negativen Auswirkungen der Massengeschäfte mit der Verbriefung der durch Grundschulden besicherten Immobilienkredite gezügelt werden.

Hier ist eine feinere strukturelle Differenzierung erforderlich. Im Hinblick auf die Lösungswege sind fast keine Grenzen gesetzt! Man kann, wie der heutige Gesetzgeber es tut, eine Verdinglichung der schuldrechtlichen Elemente außerhalb des Grundbuchs (§ 1192 Abs. 1a BGB) einführen. Das greift aber massiv ins Grundregisterrecht ein und wird dazu führen, dass am Ende das Grundbuch seine Eigenschaft als zuverlässigster Rechtsscheinträger völlig verliert, wenn der heutige Gesetzgeber seine Wertung auch bei der Verkehrshypothek konsequent durchzieht. Damit verliert der deutsche Rechtsverkehr sein Glaubwürdigkeitsfundament, was mit unabsehbaren Folgen verbunden ist. Eine andere Lösung wird von Baur/Stürner aufgeworfen: „Im Falle forderungslosen Erwerbs für alle Grundpfandrechte der Maßstab der Bösgläubigkeit in $\S$ 1138, 1157 auf grobe Fahrlässigkeit herabgesetzt .....“. ${ }^{291}$ Dies ist eine mäßige Lösung, mit der man die Grundfunktion des Registers bewahren und gleichzeitig den Immobilieneigentümern helfen will, die aber gleichwohl die Zuverlässigkeit des Grundbuchs beeinträchtigt. Die Auswirkungen des Aufweichens der Rechtsscheinfunktion des Registers trifft nicht nur das Verbriefungsmodell, sondern auch jedes einzelne mit einer Grundschuld besicherte Kreditverhältnis. Die gängige Praxis der Unterwerfung unter die sofortige Zwangsvollstreckung hat auch ihre positive Seite. Durch sie erhält der Kreditgeber ein effektives Instrument, das wesentlich zur Vertragstreue des Kreditnehmers beiträgt. Außerdem erspart die Abstraktheit der Grundschuld dem Kreditgeber die Nachforschungspflicht und erhöht somit die Effizienz bei der Kreditvergabe. Im Gegenzug erhält der Kreditnehmer/Immobilieneigentümer günstigere Zinsbedingungen als bei der Hypothek. Die Praxis, die die Abstraktheit für ihre flexible Planung braucht, wird

\footnotetext{
${ }^{291}$ Baur/Stürner, Sachenrecht, § 45 Rn. 67L; das Gleiche befürwortet auch Meyer, § 1192 Abs. 1a BGB - ein Schnellschuss des Gesetzgebers, WM 2010, 60.
} 
künftig vermutlich vermehrt auf die Verkehrshypothek setzen, die aber wegen ihrer Entstehungs- und Umfangsakzessorietät Umstände bereiten wird. Man kann außerdem, wie Eickmann schon erwähnt, auf der prozessualen Ebene ansetzen, und überlegen, ob man an der sofortigen Zwangsvollstreckung etwas ändern kann. ${ }^{292}$

Das mit der Verbriefung entstandene Problem bzgl. des Eigentümerschutzes stammt meiner Meinung nach nicht aus der Grundstruktur des deutschen Privatrechts, insbesondere nicht aus der materiellen Ebene, sondern aus der Handhabung der Sicherheiten durch die ,gewerblich handelnden Aufkäufer“ von Ansprüchen aus Immobilienkrediten. ${ }^{293}$ Im Grunde genommen kann eine passende Antwort nicht über eine Einzelfalllösung hinausreichen, wenn man die Grundstrukturen des deutschen Privatrechts nicht aufgeben möchte. Dazu bietet das BGB im Rahmen des $\S 242$ BGB die Figur „Rechtsmissbrauch“, ${ }^{294}$ der der Grundgedanke zugrunde liegt, dass das Gesetz keine schrankenlose Ausübung der Rechte zulassen will. Über das Gebot der gegenseitigen Rücksichtnahme ${ }^{295}$ könnte man in der massenhaften sofortigen Zwangsversteigerung durch die Aufkäufer, insbesondere bei ungestörten Kreditverhältnissen, einen institutionellen Missbrauch erblicken, wenn die Rechtsfolgen, die sich an sich aus einem Rechtsinstitut ergeben, deshalb zurücktreten müssen, weil sie zu einem untragbaren Ergebnis führen. ${ }^{296}$ Dabei ist insbesondere das öffentliche Interesse ${ }^{297}$ daran zu berücksichtigen, dass es nicht zur massenhaften unredlichen Vereitelung der Rechtspositionen ${ }^{298}$ der sich vertragstreu verhaltenden Kreditnehmer/Immobilieneigentümer kommen darf. Diese Lösung hindert nur die Aufkäufer an dem rücksichtslosen Betreiben von Massenzwangsvollstreckungen und lässt die üblichen Geschäftsmodelle (vor allem ABS)

\footnotetext{
${ }^{292}$ Eickmann, Gefährliche Grundschuld? S. 178 f.; vgl. RGZ 83, 336, 339 („,die Härte einer rücksichtslosen Überraschung“"); „Da das BVerfG das Zustellungserfordernis dem Art. 103 GG zuordnet, gewinnt solche Praxis unter dem Blickwinkel des Grundrechtsverzichts eine besondere Dimension“.

${ }^{293}$ Gleiche Ansicht in Meyer, $§ 1192$ Abs. 1a BGB - ein Schnellschuss des Gesetzgebers, WM 2010, 58 ff, 60 , 61.

${ }^{294}$ Staudinger/Losschelders/Olzen, § 242 Rn. 214 ff.; MüKo/Roth, § 242 Rn. 14 ff.

${ }^{295}$ Staudinger/Losschelders/Olzen, § 242 Rn. 215.; MüKo/Roth, § 242 Rn. 164.

${ }^{296}$ Losschelders/Olzen, § 242 Rn. 218; Palandt/Heinrichs, § 242 Rn. 40.

${ }^{297}$ Staudinger/Losschelders/Olzen, § 242 Rn. 225; MüKo/Roth, § 242 Rn. 192.

${ }^{298}$ M.w.N.: Staudinger/Losschelders/Olzen, § 242 Rn. 246.
} 
unberührt. Eine entsprechende Rechtsprechung würde „sanften“ Druck auf die „Finanzinvestoren“ aufbauen, der zur vernünftigen Verwendung von abstrakten Sicherheiten führen würde.

In einem Urteil hat sich der BGH auch den Weg über die Auslegung des Sicherungsvertrags entschieden. Danach kann der Zessionar einer Sicherungsgrundschuld aus der Unterwerfungserklärung nur vorgehen, wenn er in den Sicherungsvertrag eintritt, weil die Unterwerfungserklärung an den Interessen der Parteien orientieren muss. ${ }^{299}$ 


\section{Typisierung des Sicherungsvertrags}

Nun gehen wir von der Hauptthese

T1. Sowohl aus (a) juristischer als auch aus (b) ökonomischer Hinsicht bietet das Abstraktionsprinzip die zurzeit denkbar beste Gestaltungsmaxime für den modernen hochkomplexen (globalisierten) Wirtschaftsverkehr, welcher hohe (c) Sicherlheit, (d)

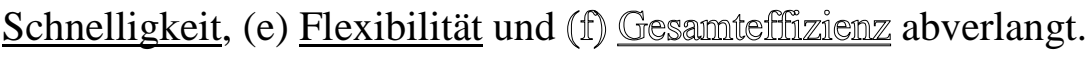

aus, konkretisiert diesen Vorzug des Trennungs- bzw. Abstraktionsprinzips und setzen uns mit der Frage auseinander, nämlich wie man die Kreditsicherung aufgrund des durch das Trennungsprinzip bzw. Abstraktionsprinzip ermöglichten schuldrechtlichen Gestaltungsraum zugunsten der Schnelligkeit und Flexibilität des modernen Wirtschaftsverkehrs besser nutzen kann.

\section{Was ist ein Sicherungsvertrag?}

\section{$\S 1$ Vertragstypische Pflichten beim Sicherungsvertrag}

(1) Durch den Sicherungsvertrag wird der Sicherungsgeber verpflichtet, dem Sicherungsnehmer eine Sicherheit für die Erfüllung einer (künftigen) Verbindlichkeit nach Maßgabe dieses Gesetzes zu bestellen.

Ein idealer Eingang in die Problematik des Verhältnisses zwischen der schuldrechtlichen Vertragsfreiheit und dem sachenrechtlichen Typenzwang stellt das Bindeglied zwischen der gesicherten Forderung und der dinglichen Sicherheit bei den nichtakzessorischen Sicherungsrechten dar, nämlich der Sicherungsvertrag.

Der Grundgedanke des Akzessorietätsprinzips ist ein elementares Gerechtigkeitsprinzip des Kreditsicherungsrechts: Die Sicherungsrechte sollen nur so weit reichen, wie ein Sicherungsbedürfnis besteht. ${ }^{300}$ Bei nichtakzessorischen Sicherheiten wird dieses Ergebnis nicht auf der dinglichen, sondern auf der schuldrechtlichen Ebene realisert, nämlich durch

\footnotetext{
300 Schnur, Wirkungsweise von Akzessorietätsprinzip und Sicherungsabrede, JA 2005, 361, 363; Lettl, Akzessorische Haftung, JA 2004, 238, 244.
} 
einen sog. Sicherungsvertrag. Auf Grund fehlender gesetzlicher Regelung herrscht sowohl in der Wissenschaft als auch in der Praxis bzgl. der Bezeichnung des hier zu untersuchenden Rechtsinstitutes eine Begriffsvielfalt (z.B. Sicherungsvertrag, Sicherungsabrede, Sicherstellungsvertrag, Zweckerklärung, Zweckvereinbarung etc.), ${ }^{301}$ die dessen dogmatische Einordnung erschwert. Die Bezeichnung dieses Rechtsinstituts als Sicherungsvertrag lässt sich am besten in den hier schon geführten Gedankengang einfügen. Erstens ist dieser „Sicherungs-“vertrag mit seinem spezifischen Inhalt mit allen anderen Typenverträgen (Kauf-, Werk-, Mietvertrag usw.) des BGB gleichrangig. Zweitens hebt die Bezeichnung als „Vertrag“ dessen Gestaltbarkeit und deren Bindungskraft deutlicher hervor.

Der hier zu behandelnde Sicherungsvertrag ist dementsprechend ein schuldrechtlicher Vertrag zwischen Sicherungsgeber und Sicherungsnehmer, durch den die Verpflichtungen der Parteien bzgl. des Sicherungsverhältnisses bestimmt werden. Dieser weiten Definition kann entnommen werden, dass alle Sicherheiten einen Sicherungsvertrag voraussetzen. Bei Personalsicherheiten, die hier in Deutschland i.d.R. gesetzlich akzessorisch gestaltet sind, fällt der Sicherungsvertrag mit der gesetzlichen Grundlage (Hauptbeispiel: der Bürgschaftsvertrag, $\S 765$ BGB) zusammen, dient lediglich als Rechtsgrund für die Sicherheitsbestellung. ${ }^{302}$ In den Vordergrund tritt der Sicherungsvertrag erst bei den nichtakzessorischen Realsicherheiten. Hier gibt es wegen des Fehlens der zwingenden Akzessorietät und des Vorhandenseins des Abstraktionsprinzips einen gestaltbaren Rechtsraum, den man durch den Sicherungsvertrag gerecht oder ungerecht ausnutzen kann. Genau dieser Rechtsraum ist Gegenstand folgender Untersuchung. ${ }^{303}$

\footnotetext{
${ }^{301}$ MüKo/Eickmann, § 1191 Rn. 13; Staudinger/Wolfsteiner, Vorbem. Zu $\S 1191$ ff. Rn. 20; Baur/Stürner, Sachenrecht, § 45 Rn. 9; Serick, Eigentumsvorbehalt und Sicherungsübertragung, Band I, § 4 II 2; : Schloz/Lwowski, Kreditsicherung, S. 97; Weber, Kreditsicherungsrecht, S. 11.

${ }^{302}$ Scholz/Lwowski, Kreditsicherung, Rn. 106; Weber, Kreditsicherungsrecht, S. 11 f.; Schnur, Wirkungsweise von Akzessorietätsprinzip und Sicherungsabrede, Jura 2005, 361, 363 ff.

${ }^{303}$ Mit „Sicherungsvertrag“ ist im Folgendem nur derjenige bzgl. der nichtakzessorischen Sicherheiten gemeint.
} 


\section{Rechtsnatur des Sicherungsvertrags}

\section{a) Treuhänderisch?}

Mit dem oben genannten gestaltbaren Rechtsraum in engem Zusammenhang steht die Eigenschaft der nichtakzessorischen Mobiliarsicherheiten als Sicherungstreuhand. ${ }^{304}$ Von einer Treuhand spricht man, wenn der Treugeber dem Treunehmer einen Überschuss an Macht bzgl. eines Rechts (i.d.R. des Eigentums oder der Inhaberschaft bei Rechten/Forderungen) in der Weise einräumt, dass der Treunehmer nach außen über die volle Rechtsstellung des Rechtsinhabers verfügt, im Innenverhältnis jedoch mehr oder weniger starken Beschränkungen im Rahmen der Zweckbindung unterworfen ist. ${ }^{305}$ Die Verselbstständigung der fiduziarischen Sicherheit von der gesicherten Forderung macht sie verkehrsfähig; der Preis dieser Flexibilität ist die Gefahr, dass der Sicherungsnehmer das schuldrechtlich wirkende Band zwischen der Sicherheit und der gesicherten Forderung zerreißt; ${ }^{306}$ der Sicherungsgeber sein gutes dingliches Recht verliert und auf einen mit Insolvenzrisiko belasteten schuldrechtlichen Schadensersatzanspruch auf Grund der Verletzung des Sicherungsvertrags gegen den im Innenverhältnis nicht verfügungsberechtigten Sicherungsnehmer verwiesen wird.

Die mit der Abstraktion verbundene Treuhandeigenschaft ist in der Tat ein Problem dieser Struktur, die man bei der späteren Gestaltung stark berücksichtigen muss. Erwähnenswert an dieser Stelle ist: ob sich die gefährliche Potenzial der Treuhand durch gewissen Mechanismus begrenzen könnte?

\section{b) Gegenseitigkeit?}

Die Tatsache, dass der Sicherungsvertrag regelmäßig im Rahmen eines Kreditgeschäfts im Hinblick auf die Sicherung einer Forderung geschlossen wird, führt den Streit herbei, ob er von der rechtlichen Struktur her ein gegenseitiger Vertrag, auf den $\S \S 320$ ff. BGB (insbes. $\S$

\footnotetext{
${ }^{304}$ Weber, Kreditsicherungsrecht, S. 171; Medicus, BR Rn. 488; Scholz/Lwowski, Kreditsicherung, Rn. 19.

${ }^{305}$ Greifelds, S. 1376: unter Stichwort „Treuhand“.

${ }^{306}$ Scholz/Lwowski, Kreditsicherung, Rn. 2.
} 
$323 \mathrm{f}$. BGB) anzuwenden sind, oder ein unvollkommen zweiseitig verpflichtender Vertrag ist, auf den teilweise das Recht der Geschäftsbesorgung angewendet wird. ${ }^{307}$

Nach der allgemeinen Vertragstheorie liegt ein gegenseitiger Vertrag i.S.d. §§ 320 ff. BGB vor, wenn der eine Vertragsteil eine Leistung gerade deshalb verspricht, weil auch der andere sich zu einer Leistung verpflichtet. ${ }^{308}$ Die Besonderheit solcher Verträge besteht in der gegenseitigen Abhängigkeit der beiderseitigen Hauptverpflichtungen zur Leistung und zur Gegenleistung. ${ }^{309}$ Die ältere Rspr. und Lit. werteten den Sicherungsvertrag als synallagmatisch, weil sie die Pflicht der Kreditgewährung und den Sicherungsvertrag als rechtlich auf einander bezogene Einheit (evtl. i.S.d. § 139 BGB) sahen ${ }^{.310}$ Im Gegensatz zu dieser Gesamtbetrachtung trennt die heute h.M. streng zwischen Kreditgewährungsvertrag und Sicherungsvertrag. Die Verpflichtung zur Kreditgewährung steht nicht der zur Sicherungsbestellung gegenüber, sonder der zur Verzinsung, ${ }^{311}$ selbst wenn die Pflicht zur Kreditgewährung in den Vertrag mit einbezogen ist. ${ }^{312}$ In dieser Hinsicht entspricht die Lösung der h.M. dem hier vertretenen Gedanken des auf Flexibilität gerichteten Abstrahierens der Sicherheit von der gesicherten Forderung mit Hilfe des Abstraktionsprinzips. Somit ist der Sicherungsvertrag kein synallagmatischer Vertrag. Zwischen Sicherungsvertrag und unvollkommen zweiseitig verpflichtendem Vertrag besteht allerdings eine gewisse Ähnlichkeit, da bei ihnen nur für einen Vertragsteil Leistungspflichten entstehen, sich unter Umständen aber auch eine Verpflichtung des anderen Vertragsteils ergeben kann. ${ }^{313}$ Im Gegensatz zum Geschäftsbesorgungsvertrag geht der Sicherungsnehmer den Sicherungsvertrag jedoch in primärem Eigeninteresse ein und ist lediglich aus dem fiduziarischen Charakter (s.u.) des Sicherungsgeschäfts auch zur Wahrung der Interessen des

\footnotetext{
${ }^{307}$ Bülow, Kreditsicherheiten, Rn 50e.

${ }^{308}$ Medicus, Bürgerliches Recht, Rn. 213 ff.; BGH NJW 06, 2773; BGHZ 15, 105; 77, 363.

${ }^{309}$ Brox/Walker, SchR-AT, § 3 I 1 a).

${ }^{310}$ Schmidt, Darlehen im Konkurs, JZ 1976, 756, 758; RG JW 1937, 2765.

${ }^{311}$ Bülow, Kreditsicherheiten, Rn. 50e; Scholz/Lwowski, Kreditsicherung, Rn. 209; BGH ZIP 1994, 1347; Palandt, § 1191 Rn. 15.

312 Jäckle, Sicherungsgrundschuld, JZ, 1982, 50.

${ }^{313}$ Brox, SchR-AT § 3, Rn 3.
} 
Sicherungsgebers verpflichtet. Der Sicherungsvertrag ist somit ein unvollkommen zweiseitig verpflichtender Vertrag atypischer Art. ${ }^{314}$

Angesichts der überragenden Bedeutung des Sicherungsgeschäfts in der modernen Marktwirtschaft und der globalen Verbreitung des Verbriefungsmodells als Refinanzierungsinstrument ist es eine Notwendigkeit, die Rechte und Pflichten der Parteien des bisher atypischen Sicherungsvertrages zu konkretisieren und zu kodifizieren.

\section{Parteien des Sicherungsvertrags}

\section{§ 9 Rückübertragungsanspruch}

(1) Nach Erledigung des Sicherungszwecks kann der Sicherungsgeber vom Sicherungsnehmer die Rückübertragung der Sicherheit an sich oder an einen Dritten verlangen.

(2) Der Rückgewähranspruch eines Dritten, der die Sicherheit zur Verfügung gestellt hat, richtet sich nach seiner Vereinbarung mit dem Sicherungsgeber. Sofern eine solche Vereinbarung nicht getroffen worden ist, kann der Dritte anstelle des Sicherungsgebers vom Sicherungsnehmer die Übertragung der Sicherheit an sich verlangen.

Die Bestimmung der Parteien des Sicherungsvertrags ist deswegen wichtig, weil nur ihnen aus dem Sicherungsvertrag Rechte zustehen oder Pflichten (insbes. Rückgewähr- und Ersatzanspruch) auferlegen können. ${ }^{315}$ Um die Parteien des Sicherungsvertrags korrekt zu bestimmen, muss man sich stets die Rechtsverhältnisse im Kreditgeschäft klar vor Augen führen. Das ist unproblematisch im Zwei-Personen-Verhältnis, in dem der Kreditgeber Sicherungsnehmer und der Kreditnehmer Sicherungsgeber ist. Verwirrung ergibt sich jedoch beim Drei-Personen-Verhältnis, in dem das Sicherungsmittel von einem Dritten zur Verfügung gestellt wird. Dann stellt sich beim Fehlen vertraglicher Vereinbarungen die Frage,

\footnotetext{
${ }^{314}$ MüKo/Eickmann, § 1191 Rn. 14.

${ }^{315}$ Brox, BGB-AT Rn. 628; MüKo/Eickmann, § 1191 Rn. 20; BGH NJW 1985, 800.
} 
ob der Dritte Sicherungsgeber ist, und ob er oder der Kreditnehmer Partei des Sicherungsvertrags ist.

Allein vom Wortlaut her spricht vieles dafür, dass nur der Dritte (tatsächlicher) Sicherungsgeber ist. Aber die Rspr. und ein Teil der Lit. qualifizieren i.d.R. den Kreditnehmer als (rechtlichen) Sicherungsgeber und Partei des Sicherungsvertrags, denn er sei zur Bereitstellung der Sicherheit verpflichtet. ${ }^{316}$ Andere verstehen unter dem Begriff des Sicherungsgebers die dritte Person, die im Rahmen des Sicherungsgeschäfts eine dingliche Rechtsposition überträgt; der Dritte schließt (konkludent) durch die Bestellung des Rechts am Sicherungsgut mit dem Sicherungsnehmer den Sicherungsvertrag ab. ${ }^{317}$ Diese Meinung versteht die Rechtsverhältnisse im Kreditgeschäft meiner Meinung nach nicht richtig. Im Kreditgeschäft stellt ein Dritter eine Sicherheit normalerweise zur Verfügung, nicht weil er in den Sicherungsvertrag eintreten will, sondern weil er eine Verpflichtung (z.B. schenkungsweise etc.) ${ }^{318}$ gegenüber dem Kreditnehmer erfüllen möchte und tritt mit dem Kreditgeber gar nicht in Kontakt. ${ }^{319}$ Aus diesem Grund ist der Kreditnehmer auch im Drittsicherungsfall der (rechtliche) Sicherungsgeber und Vertragspartei des Sicherungsvertrags, soweit nicht aus dem Sicherungsvertrag oder den Begleitumständen sich ein anderes ergibt. ${ }^{320}$

\section{Inhalt des Sicherungsvertrags}

a) Sicherungszweck bzw. Verpflichtung zur Sicherheitsbestellung

\section{$\S 1$ Vertragstypische Pflichten beim Sicherungsvertrag}

\footnotetext{
${ }^{316}$ BGH NJW-RR 1996, 234, 235; BGH NJW 1989, 1732, 1733; Scholz/Lwowski, Kreditsicherung, Rn. 34; Bülow, Kreditsicherheiten, Rn. 48 f, 980 f.

${ }^{317}$ Reinicke/Tiedtke, Kreditsicherung, Rn. 980; Rehbein, Sicherung und Sicherungszweck, S. 679.

${ }^{318}$ Roemer, Grundpfandrechte, MittRhNotK 1991, 69, 72 f.

${ }^{319}$ Bülow, Kreditsicherheiten, Rn. 48a.

${ }^{320} \mathrm{Um}$ in folgenden Ausführungen den Sprachgebrauch zu erleichtern, ist der Sicherungsgeber zugleich auch Schuldner der gesicherten Forderung, sofern nicht explizit der Fall, dass ein Dritter die Sicherheit gewährt, erwähnt wird.
} 
(1) Durch den Sicherungsvertrag wird der Sicherungsgeber verpflichtet, dem Sicherungsnehmer eine Sicherheit für die Erfüllung einer (künftigen) Verbindlichkeit nach Maßgabe dieses Gesetzes zu bestellen.

(2) Der Sicherungsnehmer ist verpflichtet, dem Sicherungsgeber die Sicherheit nach Beendigung des Sicherungsverhältnisses zurückzugewähren.

\section{§ 8 Zweckbestimmung der Leistung}

(1) Für die Zweckbestimmung der Leistung ist der erklärte Wille des Leistenden maßgebend. Sofern der Wille bei der Zahlung nicht ausdrücklich erklärt worden ist, ist er aus der Interessenlage zu entnehmen.

(2) Die Zweckbestimmung der Leistung kann nachträglich vereinbart werden.

Die im BGB geregelten Typenverträge werden als Normstrukturtypen bezeichnet; Parteivereinbarungen, die im Wirtschaftsleben vorkommen (z.B. Austausch, Herstellung oder Gebrauchsüberlassung von Wirtschaftsgütern etc.) lassen sich wegen der Vergleichbarkeit der in ihnen versprochenen Hauptleistungen unter einem Oberbegriff generalisieren. ${ }^{321}$ Typenkennzeichnender, wichtigster und unverzichtbarer Bestandteil des Sicherungsvertrags ist die (verpflichtende) Zweckerklärung, durch die sich der Sicherungsgeber dazu bereit erklärt, einen Gegenstand sicherungshalber mit dinglicher Wirkung zu belasten. ${ }^{322}$

\section{aa) Funktionen des Sicherungszwecks}

Die Zweckerklärung dient in erster Linie als kausales Element des Sicherungsvertrags; sie begründet den Anspruch des Sicherungsnehmers auf die Sicherheit und seine Befugnis, diese während des Bestehens der gesicherten Forderung(en) zu behalten und im Sicherungsfall zu seiner Befriedigung einzusetzen. ${ }^{323}$ Über die Kausalfunktion hinaus kann aus dem Zweck der Kreditsicherung gem. $\S \S 133,157$ BGB ein konturierter Typus abgeleitet werden, der zum

\footnotetext{
${ }^{321}$ Oechsler, Vertragstypen, S. 493, 502.

${ }^{322}$ Vgl. Weber, Kreditsicherungsrecht, S. 12.: hier mit dinglicher Wirkung zu übertragen.

${ }^{323}$ Kessal-Wulf, Kreditsicherung, S. 408.
} 
einen als Maßstab der Inhaltskontrolle der einzelnen Klauseln nach § 307 BGB und ggf. nach $\S 138$ BGB dienen kann (Kontrollfunktion), zum anderen Anhaltspunkte für die ergänzende Auslegung unvollständiger (z.B: Risikoverteilung bei der Verwertung) oder dynamischer (etwa bei Globalsicherung oder Sicherungsübereignung von Warenlagern) Sicherungsverhältnisse bietet (Orientierungsfunktion). ${ }^{324}$ Die praktische Handhabung dieser Funktionen des Sicherungszwecks in der Auslegung ist aber von einer Reihe sicherungsrechtlich typischer Probleme praktischer Art begleitet. Hier bemühen sich die Lehre und vor allem die Rspr. einerseits dem Bedürfnis der Kreditwirtschaft nach Flexibilität nachzukommen, andererseits die Zulässigkeit bzw. die Grenzen des Einflusses des (treuhänderischen) Schuldverhältnisses auf die dinglichen Sicherheiten (also das Sachenrecht) im Hinblick auf dessen materielle Gerechtigkeit aufzuzeichnen und zu objektivieren.

\section{bb) Bedingte Sicherungsübertragungen}

Angesichts des treuhänderischen Charakters der nichtakzessorischen Mobiliarsicherheiten und der Abstraktheit der Grundschuld hat der Sicherungsgeber regelmäßig ein Interesse daran, das Vollrecht an dem Sicherungsgut so schnell wie möglich in eigenen Rechtskreis zurückzugewinnen. Diesen beim Eigentumsvorbehalt (§ 449 BGB) gesetzlich verwirklichten Wunsch kann der Sicherungsgeber bei den anderen fiduziarischen Mobiliarsicherheiten oder Sicherheiten an Rechten nur dadurch erfüllen, indem er im Sicherungsvertrag die Befriedigung der gesicherten Forderung zur auflösenden Bedingung für die Sicherheitsübertragung macht. Mit Tilgung der Forderung soll das Sicherungsgut dann wieder an den (tatsächlichen) Sicherungsgeber zurückfallen. ${ }^{325}$ Eine solche auflösende Bedingung ist für den Sicherungsgeber in zweierlei Hinsicht vorteilhaft: Zum einen wäre ohne sie eine rechtsgeschäftliche Rückübertragung (etwa aufgrund eines durch ergänzende Auslegung des Sicherungszwecks gewonnenen vertraglichen Rückgewähranspruchs) erforderlich, zum anderen schützt den Sicherungsgeber die Bedingung über §§ 161 I, II, 936 III, 986 II BGB vor Zwischenverfügungen des Sicherungsnehmers. ${ }^{326}$ Obwohl die Parteien eines Sicherungsvertrags über großen Gestaltungsfreiraum verfügen, ist es um klarer

\footnotetext{
${ }^{324}$ Vgl. Bülow, Kreditsicherheiten, Rn. 50d; BGH NJW 1984, 1184, 1185 f; BGH NJW 2001, 1417, 1419.

${ }^{325}$ Medicus, Bürgerliches Recht, Rn. 498.

${ }^{326}$ Medicus, Bürgerliches Recht, Rn. 504.
} 
Rechtsverhältnisse willen empfehlenswert (vor allem aus Sicht des Sicherungsgebers), eine andere als die bedingte Sicherungsübertragung unter dem gegenwärtigen deutschen Mobiliarsicherungsrecht nicht zu wählen. ${ }^{327}$

Die Konstruktion der bedingten Vollrechtsübertragung und der treuhänderische Charakter der Mobiliarsicherheit sind aber sowohl aus dogmatischer als auch aus pragmatischer Sicht sehr problematisch. Hinsichtlich der gezwungenen zweckentfremdeten Verwendung des Abstraktionsprinzips zur gekünstelten Konstruktion der treuhänderischen Mobiliarsicherheit darf ich auf die Ausführungen bzgl. des Abstraktionsprinzips und des Publizitätsgrundsatzes verweisen. Da die fiduziarischen Mobiliarsicherheiten nirgendwo publiziert sind, wird der Schutz des $\S 161$ BGB in der Praxis durch die Möglichkeit eines gutgläubigen lastenfreien Erwerbs gem. § 936 BGB ausgehöhlt, weil die Banken den durch Eintritt der auflösenden Bedingung bedingten automatischen Rückfall der Sicherheit an den Sicherungsgeber durch Vereinbarung einer Rückübertragungspflicht modifizieren. ${ }^{328}$ Die Publizitätslosigkeit der fiduziarischen Mobiliarsicherheit hindert zudem ihren Einsatz als Refinanzierungsinstrument mit Hilfe der Verbriefungstechnik und die Wertfreisetzung des Mobiliars. Deshalb gibt es bei der Gestaltung einer neuen einheitlichen Sicherheit für diese Konstruktion keinen Platz.

\section{cc) Regulierung der Leistungsstörungen anhand des Sicherungszwecks}

In dem aus mehreren Rechtsgeschäften bestehenden Kreditgeschäft ${ }^{329}$ können leicht Störungen auf verschiedenen Weise entstehen. So kann die Valutierung wegen Unwirksamkeit des Kreditgewährungsvertrags ausbleiben oder der Sicherungsvertrag unwirksam sein usw.

Komplikationen ergeben sich bei der Nichtvalutierung, also wenn der Sicherungsnehmer den Kredit nicht auszahlt, obwohl der Sicherungsvertrag wirksam ist und der Sicherungsgeber die Sicherheit bestellt hat. Hier besteht Einigkeit darüber, dass der Sicherungsgeber die Sicherheit

\footnotetext{
${ }^{327}$ Warum das so wichtig ist s. Medicus, Bürgerliches Recht Rn. 498: Nach einer vordringenden Ansicht soll die Sichungsübereigung im Zweifel auflösend bedingt sein. Die Bankpraxis vereinbart aber häufig eine Pflicht zur Rückübertragung.

${ }^{328}$ Vgl. Medicus, Bürgerliches Recht, Rn. 498.

${ }^{329}$ s.o. A III 3: Rechtsverhältnisse im Grundfall des Kreditgeschäfts.
} 
zurückzugewähren hat. Die Wege dorthin sind aber höchst unterschiedlich. Eine Rückabwicklung der Sicherheit über $\S \S 326,346$ ff $\mathrm{BGB}^{330}$ kommt nach der hier vertretenen Ansicht nicht in Betracht. ${ }^{331}$ Ausgehend von den (Kausal- oder Orientierungs-)Funktionen des Sicherungszwecks lässt sich der Sicherheitenrückabwicklungsanspruch evtl. über das Bereicherungsrecht ( $§ 812$ Abs. 1 Alt. 1 BGB) oder ergänzende Vertragsauslegung ( $§ 133$, 157 BGB) begründen.

Den bereicherungsrechtlichen Weg begründen manche damit, dass der Kreditgewährungsund der Sicherungsvertrag eine rechtliche Einheit i.S.d. § 139 BGB seien; die Nichtigkeit des Kreditgewährungsvertrags, somit die des Sicherungsvertrags (Rechtsgrund der Sicherheitsbestellung) nach sich ziehe. ${ }^{332}$ Diese den Akzessorietätsgrundsatz reflektierende Lösung verwischt die durch das Abstraktionsprinzip hergestellte Grenze zwischen der Forderung und der Sicherheit beim nichtakzessorischen Sicherungsverhältnis. ${ }^{333}$ Richtiger ist m.E. der Weg über einen Rückgriff auf den Sicherungszweck durch ergänzende Vertragsauslegung, um einen vertraglichen Rückgewähranspruch zu gewinnen, soweit die Parteien keine vorsorgliche Regelung getroffen haben (Vertragslücke). ${ }^{334}$ Der Einwand der Anhänger des bereicherungsrechtlichen Weges, dass eine für die ergänzende Vertragsauslegung erforderliche Voraussetzung, nämlich der hypothetische Parteiwille, angesichts der zuwiderlaufenden Interessen gar nicht vorhanden sei, ${ }^{335}$ ist nicht zutreffend. Wie oben schon erwähnt, hat der Sicherungszweck als der wichtigste und unverzichtbare Teil des oft unvollständigen Sicherungsvertrags eine Orientierungsfunktion. Diese Funktion darf ihm nicht durch einfache Unterstellungen abgesprochen werden. Die hypothetischen Parteieninteressen im Falle der Nichtigkeit des Kreditgewährungsvertrags sprechen für den Weg der ergänzenden Vertragsauslegung. Auf Seiten des Sicherungsgebers ist sein Interesse an der Rückgewähr der Sicherheit direkt aus der Zweckerklärung zu entnehmen. Besteht die

\footnotetext{
${ }^{330}$ Medicus, Bürgerliches Recht, Rn. 496.

${ }^{331}$ s. C, IV, 3, 4.

${ }^{332}$ Bülow, Kreditsicherheiten, Rn. 979; Serick, Band I, § 4 II 3.

${ }^{333}$ s.o. A, III, 2.

${ }^{334}$ Buchholz, ZIP 1987, 891, 898; Becker-Eberhard, S. 380 ff.

${ }^{335}$ Weber, AcP 169, 237, 243; Jäckle, JZ 1982, 50.
} 
zu sichernde Forderung nicht, dann ist auch auf Seiten des Sicherungsnehmers kein Grund ersichtlich, warum er die Sicherheit noch behalten will; vor allem wenn man an die mit dieser verbundenen Verpflichtungen denkt (etwa Schadensersatzansprüche aus Nebenpflichtverletzungen). ${ }^{336}$

Bei einer Störung in Form eines nichtigen Sicherungsvertrages besteht die Schwierigkeit mit dem Abstraktionsprinzip nicht. Im Gegenteil erleichtert es die Problemlösung. Ohne einen wirksamen Sicherungsvertrag als Rechtsgrund ( $\$ 812$ Abs. 1 Alt. 1 BGB) darf der Sicherungsgeber die Sicherheit nicht behalten. ${ }^{337}$ Etwas heikler ist es, wenn die Sicherheit schon vor Abschluss des Sicherungsvertrags bestellt wurde, um dessen Abschluss zu fördern. Hier löst man das Problem über die seltene Alternative $§ 812$ Abs. 2 Alt. 2 BGB. ${ }^{338}$

\section{dd) Zweckwidrige Verfügung über Forderung und/oder Sicherungsgut}

Aus Sicht des Sicherungsgebers ist die gefährlichste Schwäche der treuhänderischen Sicherheiten der Überschuss an Rechtsmacht des Sicherungsnehmers, den dieser über das Innenverhältnis (Sicherungsvertrag) hinaus i.d.R. drittwirksam ausüben kann. ${ }^{339}$ Denn diese vertragliche Verfügungsbeschränkung hat nach § 137 BGB keine dingliche Wirkung; der Sicherungsnehmer macht sich allenfalls wegen Verletzung des Sicherungsvertrags schadensersatzpflichtig. ${ }^{340}$ Der Schutz der Verfügungsfreiheit und Handlungsfähigkeit des Vollberechtigten (hier des Sicherungsnehmers) geht so weit, dass die Verfügung des Sicherungsnehmers auch dann wirksam ist, wenn die Überschreitung des Innenverhältnisses dem Dritten evident ist. ${ }^{341}$ Ein Systemwiderspruch zwischen Bevollmächtigung und Treumacht besteht hier nicht, da der Treuhänder im eigenen Namen über ein eigenes Recht

\footnotetext{
${ }^{336}$ Becker-Eberhard, Forderungsgebundenheit, S. 390, 402 ff.

${ }^{337}$ Medicus, Bürgerliches Recht, Rn. 495.

${ }^{338}$ Medicus, a.a.O.

${ }^{339}$ Medicus, Bürgerliches Recht, Rn. 502.

${ }^{340}$ Palandt/Heinrichs, $§ 137$ Rn. 3, 6.

${ }^{341}$ BGH NJW 1968, 1471.
} 
verfügt. ${ }^{342}$ Im Ergebnis überwiegt die vertragliche Verfügungsbeschränkung die Sicherheit des Rechtsverkehrs nicht. ${ }^{343}$

In den meisten Fällen der nichtakzessorischen Mobiliarsicherheiten oder Sicherheiten an Rechten wirkt sich diese Gefährlichkeit halb so schlimm aus wie befürchtet, weil die Sicherheiten i.d.R. (aufschiebend oder auflösend) bedingt übertragen werden. Die $\S \S 161$ I, II, 936 III, 986 II BGB bieten schon ausreichenden Schutz gegen Zwischenverfügungen. Ungünstig für den Sicherungsgeber wird es erst dann, wenn die Sicherheitsübertragung unbedingt erfolgt (z.B. Sicherungsübereignung mit Rückübertragungsklausel). ${ }^{344}$ In solchen Konstellationen greift der Schutz des $§ 161$ BGB nicht. Der Sicherungsgeber ist nur auf die Möglichkeit verwiesen, den Sicherungsnehmer aus der Verletzung des Sicherungsvertrags in Anspruch zu nehmen. Aus diesem Grund ist es ratsam den Weg der bedingten Übereignung zu wählen, wenn man sich nichtakzessorischer Mobiliarsicherheiten bedient; dies dürfte wegen der Verwendung der Allgemeinen Geschäftsbedingungen durch die Banken aber schwierig werden.

Kritischer ist die Situation auch bei der Sicherungsgrundschuld. Hier bestellt der Sicherungsgeber dem Sicherungsnehmer (zugunsten der Klarheit des Grundbuchs) unbedingt eine Grundschuld zur Sicherung einer Forderung; folgerichtig kommt $\S 161$ BGB nicht in Betracht. Die Verbindung zwischen gesicherter Forderung und Grundschuld erfolgt nur durch den schuldrechtlichen Sicherungsvertrag, der bekannterweise die Verfügungsbefugnis des Sicherungsnehmers nicht drittwirksam einschränkt. ${ }^{345}$ Somit ist hier die Gefahr einer doppelten Inanspruchnahme des Sicherungsgebers gegeben, wenn der Sicherungsnehmer vor dem Sicherungsfall die gesicherte Forderung unbefugt von der Sicherungsgrundschuld trennt. Diese sog. isolierte Abtretung erfolgt etwa zu Refinanzierungszwecken, ${ }^{346}$ z.B.: tritt der Sicherungsnehmer die Forderung an A und die Sicherungsgrundschuld an B ab. Nach h.M. ist

\footnotetext{
${ }^{342}$ Medicus, Bürgerliches Recht, Rn. 502; Schlosser, rechtsgeschäftliche Treuhand, NJW 1970, 681 ff.

${ }^{343}$ BGHZ 134, 182, 186.

${ }^{344}$ Medicus, Bürgerliches Recht, Rn. 504.

${ }^{345}$ BGH NJW 1972, 1463.

${ }^{346}$ Wolf, Sachenrecht, Rn. 966; Döring, Risikobegrenzung bei der Sicherungsgrundschuld, S. 115 ff.
} 
die Zweckerklärung i.d.R. kein Abtretungsverbot i.S.d. § 399 BGB; ${ }^{347}$ als vertragliche Verfügungsbeschränkung entfaltet sie wegen $\S 137$ BGB keine dingliche Wirkung. ${ }^{348}$ Also kann A vom Sicherungsgeber Zahlung verlangen und B den Anspruch aus § 1147 BGB erheben.

Um diese Gefahr zu vermeiden, ist versucht worden, den Akzessorietätsgrundsatz im Bereich der Sicherungsgrundschuld in der Weise einzuführen, dass man mit Hilfe analoger Anwendung des $\S 1157$ S. 2 BGB den Sicherungsvertrag bzw. Sicherungszweck im Grundbuch eintragen und später gegen den Erwerber verwenden darf. ${ }^{349}$ Diesen Weg lehnt die h.M. zu Recht ab. ${ }^{350}$ Würde der Sicherungszweck als Einrede qualifiziert, so könnten über diese Brücke alle Gegenrechte, die sich aus der Forderung ergeben, unmittelbar der Grundschuld entgegengesetzt werden; das ist aber mit $\S 1192$ BGB nicht vereinbar; für den öffentlichen Glauben des Grundbuchs wäre es unerträglich, wenn der Umfang einer dinglich wirkenden Einrede hinsichtlich so gravierender Fragen im Unklaren bliebe; ${ }^{351}$ der Erwerber der Sicherungsgrundschuld würde einen derart unsicheren Erwerb vernünftigerweise ablehnen. Damit wäre die Sicherungsgrundschuld weitgehend verkehrsunfähig. ${ }^{352}$ Mit dem nichtakzessorischen Charakter der Sicherungsgrundschuld unvereinbar ist außerdem die Einheitstheorie, nach der die Grundschuld im Wege der entsprechenden Anwendung der $\S \S$ 401 I, 1153 I, 1250 II BGB der abgetretenen Forderung automatisch folgen soll. ${ }^{353}$

Nach h.M. ist der Sicherungsgeber in folgender Weise gegen die doppelte Inanspruchnahme geschützt: Gegen den Zessionar kommen dem Sicherungsgeber § 273 BGB und § 404 BGB zugute. Danach muss er die Forderung nur erfüllen, wenn der Zessionar seine Verpflichtung

\footnotetext{
${ }^{347}$ BGH NJW 1982, 2768; BGH NJW-RR 1987, 139; Hoepner, Zweckerklärung, BKR 2002, 1025, 1031.

${ }^{348}$ BGHZ 134, 182, 186; Palandt/Hinrichs, § 137 Rn. 1, 3

${ }^{349}$ Neef, Eintragungsfähigkeit sicherungsvertraglicher Einreden, S. 134 ff.

${ }^{350}$ MüKo/Eickmann, § 1191 Rn. 83; Bamberger/Roth/Rohe, § 1192 Rn. 53.

${ }^{351}$ Gaberdiel, Eintragungsfähigkeit sicherungsvertraglicher Einreden, DNotZ 2005, 718.

${ }^{352}$ Medicus, Bürgerliches Recht, Rn. 507.

${ }^{353}$ Bülow, Kreditsicherheiten, Rn. 1005.
} 
der Rückgewähr der Sicherungsgrundschuld aus dem Sicherungsvertrag erfüllt. ${ }^{354}$ Gegen den dinglichen Gläubiger hat der Sicherungsgeber aber schlechte Karten. Da der Rückgewähranspruch des Sicherungsgebers beim Erwerb der Sicherungsgrundschuld durch den Dritten noch nicht entstanden war, kann der Sicherungsgeber diesen Anspruch nicht nach $\S 1157$ BGB gegen ihn einwenden, ${ }^{355}$ und muss die Inanspruchnahme durch den dinglichen Gläubiger dulden.

\section{ee) Ordnungsmäßige Erledigung des Sicherungszwecks}

Sobald die gesicherte Forderung getilgt ist, erledigt sich der Sicherungszweck und die Sicherheit muss zurückgewährt werden. Anders als der automatische Rückfall bei bedingt übertragenen Mobiliarsicherheiten oder Sicherheiten an Rechten ${ }^{356}$ erfolgt die Rückgewährung bei deren unbedingter Übertragung dann über die Kausalfunktion des Sicherungszwecks (§ 812 Abs. 1 Alt. 1. BGB). ${ }^{357}$

Bei der Sicherungsgrundschuld stellt der Gesetzgeber ausreichende Regelungen zur Verfügung, die zu den der Sicherheitsrückgewährung gleichwertigen Ergebnissen führen. Zahlt der Sicherungsgeber auf die Forderung und die Sicherungsgrundschuld, dann erlischt die Forderung nach $\S 362$ I BGB, die Sicherungsgrundschuld wird zur Eigentümergrundschuld ( $\S 1142,1143$ BGB, h.M.), und der Sicherungsgeber kann nach $\S$ 894 BGB Grundbuchberichtigung verlangen. ${ }^{358}$ Wenn der Sicherungsgeber nur auf die Forderung zahlt, so erlischt diese ( $\$ 362$ I BGB). Die Grundschuld bleibt zunächst bestehen, aber der Sicherungsgeber hat aus dem Sicherungsvertrag einen Anspruch auf Rückgewähr. Drei Optionen stehen ihm zur Verfügung: Rückübertragung entsprechend § 1154 BGB, Verzicht entsprechend $\S 1169$ BGB (mit der Folge des $\S 1168$ BGB) oder Aufhebung nach $\S$

\footnotetext{
${ }^{354}$ Wolf, Sachenrecht, Rn. 967; BGH NJW 1982, 2768.

${ }^{355}$ Medicus, Bürgerliches Recht, Rn. 508; zu Sonderproblem zur Teilleistung auf die Forderung: Medicus, Bürgerliches Recht, Rn. 508; Wolf, Sachenrecht, Rn. 970.

${ }^{356}$ s. C, IV, 4, a), bb).

${ }^{357}$ MüKo/Lieb, § 812 Rn. 347; Palandt/Sprau, § 812 Rn. 18.

${ }^{358}$ Baur/Stürner, Sachenrecht, § 44 Rn. 23 ff.; Medicus, Bürgerliches Recht, Rn. 499.
} 
875 BGB. ${ }^{359}$ Da die Zahlung häufig konkludent erfolgt, stellt sich die Frage, worauf gezahlt wird. Dabei entscheidet in erster Linie der Wille des leistenden Sicherungsgebers. In der Bankpraxis wird i.d.R. Zahlung nur auf die Foderung vereinbart. ${ }^{360}$ Beim Fehlen eines solchen ausdrücklich erklärten Willens muss man ihn über das Interessen des Zahlenden und die Begleitumstände herausfinden. ${ }^{361}$

\section{b) Sicherungsumfang}

\section{$\S 5$ Sicherungsumfang}

Sofern nicht aus dem Sicherungsvertrag sich ein anderes ergibt, haftet der Sicherungsgegenstand für den Bestand der Hauptverbindlichkeit, Zinsen sowie Kosten, die im Zusammenhang mit der Befriedigung aus dem Sicherungsgegenstand anfallen.

Der Sicherungsumfang ist insoweit ein verlängertes Problemfeld des Sicherungszwecks, als hier (anders als bei den gesetzlichen akzessorischen Sicherungsrechten) auf Grund der Abwesenheit gesetzlicher Regelungen ein gestaltbarer Rechtsraum vorhanden ist. ${ }^{362}$

\section{aa) Üblicher Haftungsumfang}

Das Risiko einer unzureichenden Bezeichnung der gesicherten Forderung darf nicht unterschätzt werden, wenn nur einzelne oder nur einige von mehreren gleichartigen Forderungen durch die Sicherheit gedeckt werden sollen (sog. Spezialsicherheiten). ${ }^{363}$ Ohne zusätzliche Vertragsvereinbarungen ist der Haftungsumfang aus der Zweckerklärung zu entnehmen. Auf jeden Fall ist die Hauptforderung von der Sicherheit erfasst.

Über die Frage, ob noch weitere vertragliche Nebenforderungen (wie z.B. Zinsen, Provision, Kosten etc.) auch ohne weiteres durch die Sicherheit miterfasst werden, besteht Unklarheit.

\footnotetext{
${ }^{359}$ Palandt/Bassenge, $§ 1191$ Rn. 26.

${ }^{360}$ Medicus, Bürgerliches Recht, Rn. 501.

${ }^{361}$ Vgl. Baur/Stürner, Sachenrecht, § 45 Rn. 43 ff.

${ }^{362}$ Kessal-Wulf, Kreditsicherung, S. 406, 408 f., 439 f.

${ }^{363}$ Blaurock, Kreditsicherungsrecht, S. 3.
} 
Bei gesetzlichen akzessorischen Sicherheiten ist der jeweilige Bestand der Hauptverbindlichkeit für den Sicherungsumfang maßgebend (§§ 767 I S.1; 1118, 1210 II 1. Hs. BGB). ${ }^{364}$ Bei den nichtakzessorischen Sicherheiten sollte es m.E. nicht anders sein. Eine Umkehrung nach dem Akzessorietätsgrundsatz lässt sich nicht befürchten. Die Parteien können durch die über das Abstraktionsprinzip gewonnene Gestaltungsfreiheit den Haftungsumfang ihren Bedürfnissen nach anpassen, indem sie durch die Zweckerklärung verschiedene Nebenforderungen in den Sicherungsverband einbeziehen.

Für andere Forderungen, wie z.B. Vorfälligkeitsentschädigung, Verwertungskosten, Schadensersatzansprüche wegen Nichterfüllung der ursprünglich gesicherten Verbindlichkeit, Ansprüche aus $\S 812$ ff. BGB etc, die im Laufe der Abwicklung des Kreditgeschäfts wegen Realisierung der Sicherheit oder an Stelle der gesicherten Forderung entstehen, sollte man sich nach der Orientierungsfunktion des Sicherungszwecks richten: Gesichert werden soll das überlassene Kapital, nicht eine bestimmte Anspruchsbeziehung. ${ }^{365}$ Mit anderen Worten haftet die Sicherheit für die Ersatzansprüche der Hauptforderung, soweit sie mit dem ursprünglichen Anspruch wirtschaftlich identisch sind. ${ }^{366}$ Rechtstechnisch gesehen steht dieser Weg meiner Meinung nach dem Grundgedanken des $§ 285$ BGB sehr nahe. ${ }^{367}$

\section{bb) Formularmäßige Erweiterung des Sicherungszwecks/-umfangs}

Im bankenmäßigen Geschäftsverkehr werden häufig Sicherungsverträge unter Einbeziehung von AGB geschlossen. ${ }^{368}$ Die entsprechenden Formulare der Kreditinstitute sehen i.d.R. vor, dass die nichtakzessorischen Sicherheiten zur Sicherung aller gegenwärtigen und künftigen Forderungen des Sicherungsnehmers gegen den (tatsächlichen) Sicherungsgeber (Eigentümer oder Rechtsinhaber) aus der bestehenden Geschäftsverbindung dienen sollen. ${ }^{369}$ Nach

\footnotetext{
${ }^{364}$ Lettl, Akzessorische Haftung, JA 2004, 238, 239.

${ }^{365}$ BGHZ 114, 57, 73; BGH NJW 2003, 885, 886; Clemente, Sicherungsgrundschuld, Rn. 295

${ }^{366}$ MüKo/Quack Anh. §§ 929-936 Rn. 37; BGH NJW 1991, 1746; BGH NJW 1999, 3708 = JuS 2000, 401.

${ }^{367}$ Palandt, § 285 Rn. 1; BGH NJW 88, 2345, BGH NJW-RR 05, 241.

${ }^{368}$ Scholz/Lwowski, Kreditsicherungsrecht, Rn. 108

369 BGHZ 114, 9, 13; Hoepner, Zweckerklärung, BKR 2002, 1025, 1026; Blaurock, S. 10; Roemer, Rundpfandrechte, MittRhNotK 1991, 69; in folgender Ausführung wird die dritte Person, die im Rahmen des
} 
anfänglichem Zögern hat der BGH die Zulässigkeit einer solchen sog. erweiterten Sicherungszweckerklärung bejaht. ${ }^{370}$ Anders als in Zweipersonenverhältnissen (wenn der Sicherungsgeber zugleich der Schuldner der gesicherten Verbindlichkeit ist, dann hat er die Entwicklung der Hauptverbindlichkeit unter Kontrolle und wird daher durch den Umfang der Haftung nicht überrascht) ${ }^{371}$ ergibt sich in den Drittsicherungsfällen das Problem, dass die Gefahr einer Inanspruchnahme des Sicherungsgebers deshalb erheblich größer ist, weil er nach dem Abschluss des Sicherungsvertrags (also nach der Einbeziehung der erweiterten Zweckerklärung) den Sicherungsumfang beeinflussende Handlungen des Kreditnehmers nicht verhindern kann. Deshalb hat der BGH in seiner Grundsatzentscheidung vom 09.01.1982 klargestellt, dass der Sicherungsgeber (hier ein Landwirt) i.d.R. mit einer formularmäßigen Erweiterung des Sicherungsumfangs nicht zu rechnen braucht, wenn die Sicherheit anlässlich einer konkreten Verbindlichkeit gewährt wurde (sog. Anlassrechtsprechung). ${ }^{372}$ Trotz dieser Entscheidung sehen die Kreditinstitute mit dem Hinweis darauf, dass dies eine Einzelfallentscheidung sei, keinen Anlass, generell auf formularmäßige Erweiterungen des Sicherungsumfangs $\mathrm{zu}$ verzichten. ${ }^{373}$ Tatsächlich ließ der BGH in einem Fall eine formularmäßige weite Zweckerklärung zu, bei dem eine $\mathrm{GmbH}$ eine Sicherungsgrundschuld bestellte. ${ }^{374}$ Die Literatur sieht die Qualifizierung der formularmäßigen Erweiterung des Sicherungsumfangs zu einer überraschenden Klausel i.S.d. § 305c BGB als Ausdruck des Grundsatzes von Treu und Glauben ( $§ 242$ BGB). ${ }^{375}$ Insgesamt ist das Risiko einer formularmäßigen Erweiterung des Sicherungsumfangs bei Drittsicherungsfällen so groß, dass man es in der Praxis nicht eingehen sollte.

\footnotetext{
Sicherungsgeschäfts eine dingliche Rechtsposition überträgt in Abweichung von genannt, um die Darstellung zu vereinfachen.

${ }^{370}$ BGH NJW 1987, 1636; BGH NJW 1991, 1677.

${ }^{371}$ BGH NJW 2000, $2675=$ JuS 2000, 1121.

${ }^{372}$ BGHZ 83, 56 = ZIP 1982, $290=$ DNotZ 1982, $314=$ NJW 1982, 1035; BGHZ 126, 174 = NJW 1994, 2145.

${ }^{373}$ Blaurock, Kreditsicherungsrecht, S. 11.

${ }^{374}$ BGH ZIP 1987, 695 f. = WM 1987, 586 = DB 1987, $1298=$ NJW 1987, 1885.

${ }^{375}$ Clemente, Sicherungsabrede, ZIP 1985, 193 ff.; Blaurock, Kreditsicherungsrecht, S. 13. 


\section{cc) Sittenwidrigkeit, Übersicherung und Freigabeklausel}

\section{§ 6 Anspruch des Sicherungsgebers auf Freigabe}

Der Sicherungsgeber kann vom Sicherungsnehmer die Teilfreigabe der Sicherheit verlangen, wenn der Verkehrswert der Sicherheit $150 \%$ des Betrags der gesicherten Forderung überschreitet. Lässt sich ein Verkehrswert nicht ermitteln, so kann der Anschaffungswert der Sicherheit herangezogen werden.

Im Kern geht es hier um die umfassende Angemessenheitsbeurteilung darüber, ob und wie der Inhalt schuldrechtlicher Vereinbarungen die Wirksamkeit der dinglichen Geschäfte beeinflusst bzw. beeinflussen darf. In jedem Fall stehen schuld- und sachenrechtliches Geschäft für die Angemessenheitsbeurteilung in einer gegenseitigen Abhängigkeit, die die Geltung des Abstraktionsgrundsatzes im eigentlichen Sinn zwar nicht beeinträchtigt, aber doch $\mathrm{zu}$ neuen Verbindungen zwischen Schuld- und Sachenrecht führt. ${ }^{376}$ Trotz der Heranziehung des $\S 237$ S.1 BGB (so betonen mehrere BGH-Senate im Hinblick auf die Praxis die Wichtigkeit der Objektivierung der Deckungsgrenze ${ }^{377}$ ) ist die genauere Bestimmung dieses Verhältnisses angesichts der Gestaltungsvielfalt in der Praxis und der einzelfallorientierten Anstrengungen der Rspr. und Lehre ohne neue Ideen extrem schwierig. An dieser Stelle stößt die Vernunft an ihre Grenze. Diese Arbeit begnügt sich mit einer einfachen Zusammenstellung der wichtigsten von Rspr. und Lehre entwickelten Lösungsansätze.

Häufig führt das konkurrenzbedingte Streben des Sicherungsnehmers nach möglichst umfassenden Sicherheiten dazu, dass er sich Sicherheiten versprechen lässt, die in auffälligem Missverhältnis $\mathrm{zu}$ dem Sicherungszweck stehen (sog. anfängliche Übersicherung). ${ }^{378} \mathrm{Im}$ Interessenkonflikt zwischen Sicherungsgeber und Sicherungsnehmer erfüllt die Sittenwidrigkeit gem. $\S 138$ Abs. 1 BGB eine Begrenzungs- und

\footnotetext{
${ }^{376}$ Wolf, Wandel im Sachenrecht, NJW 1987, 2647, 2651.

${ }^{377}$ BGH ZIP 1996, 1426; BGH ZIP 1996, 1429; BGH NJW 1998, 671, 675.

${ }^{378}$ Kessal-Wulf, Kreditsicherung, S.438.
} 
Kontrollfunktion. ${ }^{379} \mathrm{Ob}$ der Sicherungsvertrag und auch das Verfügungsgeschäft im Einzelfall sittenwidrig und damit nichtig sind, lässt sich nicht mit Hilfe einer festen objektiven Grenze ermitteln. ${ }^{380}$ Darüber besteht allerdings Uneinigkeit. Der BGH verneinte die Lösung der Übertragung der Deckungsgrenze (etwa 150\%) bei der nachträglichen Übersicherung (s.u.), ohne eine feste Grenze gezogen zu haben. ${ }^{381}$ Deshalb bleibt nichts anderes übrig als eine Einzelfallbeurteilung der Sittenwidrigkeit nach dem gesamten Charakter des Sicherungsgeschäfts. ${ }^{382}$ Nach einer Literaturmeinung genügt es auf jeden Fall für den sittenwidrigen Charakter, wenn der Wert der Sicherheiten das Doppelte des anerkennenswerten Sicherungsbedürfnisses erreicht.

Viel problematischer ist die Situation bei der sog. nachträglichen Übersicherung. Die durch das Abstrahieren der Sicherheit von der Forderung gewonnene, für den Sicherungsgeber vorteilhafte Flexibilität und Dynamik der nichtakzessorischen Sicherungsmittel kann sich zu Lasten des Sicherungsgebers auswirken, wenn die dem Gläubiger zur Verfügung gestellten Sicherheiten in ihrem Wert oder Bestand unverändert bleiben oder sogar anwachsen, während die gesicherte Forderung durch die Erbringung von Tilgungsleistungen abnimmt. ${ }^{383}$ Diese Gefahr besteht insbesondere bei der Sicherungsübereignung von Warenlagern mit wechselndem Bestand oder bei Globalsicherungsabtretungen, sog. revolvierende Globalsicherheiten. Die frühere Rspr. erklärt die Sicherungsverträge wegen Verstoss gegen $\S \S$ 138 Abs. 1, 307 BGB für nichtig, wenn die Parteien keine Vorkehrungen gegen nachträgliche Übersicherung getroffen haben. ${ }^{384}$ Viele Diskussionen ${ }^{385}$ über diese unbefriedigende Lösung des BGH führten am Ende zu der Entscheidung des Großen Zivilsenats des BGH, dass das Fehlen einer Freigabeklausel oder deren Einschränkung nicht mehr zur Unwirksamkeit der

\footnotetext{
${ }^{379}$ MüKo/Armbrüster, § 138 Rn. 101; Wiegand/Brunner, Übersicherung und Freigabeanspruch, NJW 1995, 2513.

${ }^{380}$ BGH NJW 1991, 353, 354; Ganter, Übersicherung, WM 2001, 1 ff.

${ }^{381}$ BGH NJW 1998, 2047.

${ }^{382}$ M.w.N.: MüKo/Armbrüster, $\S 139$ Rn. 101.

${ }^{383}$ Kessal-Wulf, Kreditsicherung, S. 439.

${ }^{384}$ BGHZ 98, 303 = BGH NJW 1987, 487; BGHZ 109, 240 = BGH NJW 1990, 716.

${ }^{385}$ M.w.N.: Baur/Stürner, Sachenrecht, $§ 57$ Rn. 20 ff.
} 
gesamten Sicherungsvereinbarung führt; vielmehr soll es einen ermessensunabhängigen, aus der fiduziarischen Natur des Sicherungsvertrags abzuleitenden Freigabeanspruch geben. ${ }^{386}$

Trotz dieser Grundsatzentscheidung bleiben noch Einzelheiten im Unklaren. Nicht eindeutig ist zunächst die Rechtsnatur des ermessensunabhängigen Freigabeanspruchs. Der Große Zivilsenat des BGH geht von der Treuhandnatur des Sicherungsvertrages aus und gelangt über eine ergänzende Auslegung des Sicherungszwecks zur Pflicht des Sicherungsnehmers, die Sicherheit schon vor Beendigung des Vertrags zurückzugewähren, wenn und soweit diese endgültig nicht mehr benötigt wird. ${ }^{387}$ In der Literatur wird zum Teil eine gewohnheitsrechtliche Grundlage für den Anspruch gesehen. ${ }^{388}$ Die praktischen Unterschiede zwischen den beiden Anspruchsgrundlagen dürften aber unerheblich sein. ${ }^{389}$ Um Streit dieser Art zu vermeiden, kann man im Wege der Neugestaltung des Registerpfandrechts diesen ermessensunabhängigen Freigabeanspruch dann normieren.

Folgenschwerer ist hingegen der Streit über die Höhe der Deckungsgrenze, also das zulässige Maß der nachträglichen Übersicherung. Enthält der Sicherungsvertrag keine ausdrückliche oder eine unangemessene Deckungsgrenze, dann geht der BGH, unter Berücksichtigung der Kosten für Verwaltung und Verwertung der Sicherheit, von einer festen Deckungsgrenze von $110 \%$ des Werts der gesicherten Forderung aus. ${ }^{390}$ Diese Grenze bezieht sich nur auf den realisierbaren Wert des Sicherungsgutes. Da dieser aber regelmäßig deutlich unter dem Nennwert liegt, ergänzt der BGH die Deckungsgrenze mit einer widerleglichen Vermutung (,,...regelmäßig ...“) nach dem Vorbild des § 237 S. 1 BGB, wonach der Freigabeanspruch entsteht, wenn der Nennwert der Sicherheit $150 \%$ des Betrags der gesicherten Forderung überschreitet. Im Gegensatz zu dem Verallgemeinern der Deckungsgrenze des BGH wird in

\footnotetext{
${ }^{386}$ BGHZ 137, 212 = NJW 1998, 671.

${ }^{387}$ BGH NJW 1998, 671, 672; BGHZ 124, 371 = BGH NJW 1994, 861.

${ }^{388}$ Serick, Freigabeklauseln, Deckungsgrenze und Haftobergrenze, NJW 1997, 1529.

389 Serick, Freigabeklauseln, Deckungsgrenze und Haftobergrenze, WM 1997, 345 ff.: Der gewohnheitsrechtliche Charakter bedeute etwa in Zweifelsfragen komme das BGB nur zur Anwendung, wenn das Gewohnheitsrecht keine Lösung anbiete. Bülow, JZ 1997, 500, 503: aber es sei schwer feststellbar, welche Inhalte des Sicherungsvertrags sich gewohnheitsrechtlich durchgesetzt haben und welche noch der freien Parteivereinbarung unterliegen.
}

${ }^{390}$ BGHZ 137, 212 = NJW 1998, 671, 674. 
der Literatur eine einzelfallorientierte Bestimmung favorisiert. Die Deckungsgrenze soll nach dem Verhältnis zu bestimmen sein, das die Parteien des Sicherungsvertrags zu Beginn zugrunde gelegt haben. ${ }^{391}$ Durch eine solche sich aus dem jeweiligen Sicherungsvertrag ergebende Deckungsgrenze soll das paradoxe Ergebnis verhindert werden, dass z.B. bei einem Nennwert des Sicherungsguts von $160 \%$ der gesicherten Forderung - angesichts der Bewertungsrisiken liegt kein auffälliges Missverhältnis vor - zwar keine Sittenwidrigkeit wegen anfänglicher Übersicherung eintritt, aber doch von Beginn an ein Freigabeanspruch wegen „,nachträglicher“ Übersicherung besteht. ${ }^{392}$

Auf obige Weise wandelt sich ein dinglicher Anspruch auf Rückgabe der Sicherheit auf Grund des Abstraktionsprinzips in einen schuldrechtlichen Anspruch auf Freigabe der Sicherheit um: Auf den ersten Blick widerspricht diese „Degradierung“ dem Gerechtigkeitsgefühl. Sie hat aber ihre guten Gründe: 1. Die Entscheidung der Kreditgeber für die Gewährung des Kredits wird erleichtert; 2. Der Sicherungsgeber profitiert selbst von dieser Gestaltung; 3. Das „Degradieren“ klingt viel dramatischer als es tatsächlich der Fall ist, weil der Sicherungsgeber ausreichend geschützt werden können; 4. Hohe Flexibilität für mehrperiodische Großprojekte. (Bülow, S. 377, Otten, S. 381 - Sicherungsvertrag)

\section{c) Sonstige Pflichten und Rechte aus dem Sicherungsvertrag}

Neben der Sicherheitenbestellungspflicht des Sicherungsgebers als Hauptleistungspflicht und der Pflicht des Sicherungsnehmers zur Freigabe bei Übersicherung enthält der Sicherungsvertrag evtl. noch Nebenleistungspflichten, und über die leistungsbezogenen Pflichten hinaus können noch Rücksichtnahmepflichten i.S.d. § 242 BGB in Verbindung mit dem Sicherungsvertrag abgeleitet werden.

\section{aa) Sonstige Pflichten des Sicherungsgebers}

\section{§ 3 Wertwahrungspflicht des Sicherungsgebers}

\footnotetext{
${ }^{391}$ Canaris, Deckungsgrenze und Freigabeanspruch, ZIP 1996, 1577 ff; Anspruch auf Freigabe von Globalsicherheiten, ZIP 1997, 813 ff.

392 Canaris, Deckungsgrenze und Freigabeanspruch, ZIP 1996, 1577 ff; Anspruch auf Freigabe von Globalsicherheiten, ZIP 1997, 813 ff.; Bülow, Freigabeklausel, JZ 1997, 500, 502.
} 
(1) Der Sicherungsgeber darf den Wert des Sicherungsgegenstandes während der Dauer des Sicherungsvertrages nicht beeinträchtigen. Darüber hinaus ist der Sicherungsgeber nicht verpflichtet, den Wert des Sicherungsgegenstandes beständig zu erhalten, wenn er sich nach der Übertragung der Sicherheit verringert, soweit nicht aus dem Sicherungsvertrag sich ein anderes ergibt.

(2) Tritt im Laufe des Sicherungsverhältnisses ein Ereignis ein, das den Wert des Sicherungsgegenstandes gefährdet oder beeinträchtigt, so hat der Sicherungsgeber geeignete Maßnahmen zu treffen und dies dem Sicherungsnehmer unverzüglich anzuzeigen.

\section{(1) Nachsicherungspflicht}

Für die umgekehrte Situation der nachträglichen Übersicherung, nämlich dass nach dem Vertragsschluss der Wert der Sicherheit sich verringert oder das Ausfallrisiko sich vergrößert (schwierig zu bestimmen), ${ }^{393}$ können die Parteien die zusätzliche Verpflichtung des Sicherungsgebers vereinbaren, dass er seine Sicherheit zu verstärken hat. ${ }^{394} \mathrm{Im}$ bankmäßigen Verkehr geschieht dies regelmäßig durch AGB-Einbeziehung. 395 Ohne diese Zusatzvereinbarung kann ein solcher Nachsicherungsanspruch nicht etwa durch ergänzende Auslegung des Sicherungszwecks gewonnen werden, denn der Sicherungszweck erfasst zwar die Sicherung des überlassenen Kapitals, er ist allerdings auf das übertragene Sicherungsgut beschränkt. $^{396}$

\section{(2) Pflichten zur Werterhaltung des Sicherungsguts}

Die Sicherungsübereignung als nichtakzessorisches Sicherungsmittel ermöglicht dem Sicherungsgeber die parallele Nutzung der Gebrauchs- und Wertelemente eines Mobiliars durch das Belassen der unmittelbaren Sachherrschaft bei dem Sicherungsgeber. Im Gegenzug

\footnotetext{
${ }^{393}$ Wenzel, Der Anspruch auf Verstärkung von Sicherheiten, WiB 1994, 596 f.

${ }^{394}$ Bülow, Kreditsicherheiten, Rn. 50h; Wenzel, Der Anspruch auf Verstärkung von Sicherheiten, WiB 1994, 596 f.; OLG München BB 1997, 435.

${ }^{395} \mathrm{Nr} 19$ Abs 3 aE AGB-Banken idF vom 1.4.2002; Nr 26 Abs 2 lit b AGB-Sparkassen idF vom 1.4.2002: mit Kündigungsmöglichkeit der Bank, wenn der Kreditnehmer dem Nachsicherungsverlangen der Bank nicht nachkommt.

${ }^{396}$ BGH ZIP 1990, 31.
} 
muss der Sicherungsgeber im Rahmen des Sicherungsvertrags (ohne ausdrückliche Vereinbarung dürften solche Pflichten aus dem Sicherungszweck zu entnehmen sein) zur Werterhaltung des Sicherungsguts (Erhaltungspflicht bzgl. sachgemäßen Gebrauchs, notwendiger Reparatur, Wartung oder Versicherungspflicht etc. ${ }^{397}$ ) verpflichtet sein. ${ }^{398}$ Die Pflicht zur Werterhaltung kann auch in Form von Garantien oder ordnungsmäßiger Buchführung (etwa bei wechselndem Bestand) bestehen. ${ }^{399}$

\section{bb) Pflichten des Sicherungsnehmers}

\section{(1) Zweckmäßige Verwendung der Sicherheit}

Wegen der Rechtsnatur des Sicherungsvertrags als unvollkommen zweiseitig verpflichtender Vertrag atypischer $\mathrm{Art}^{400}$ kann teilweise das Recht der Geschätsbesorgung und über $\S 675$ Abs. 1 BGB das Auftragsrecht angewandt werden. ${ }^{401}$ Danach ist der Sicherungsnehmer zur sorgfältigen Ausführung des ihm übertragenen Geschäfts, also zur Verwendung der Sicherheit nach Maßgabe des Sicherungszwecks, verpflichtet (entsprechend $\S 662$ BGB). ${ }^{402}$ Diese Pflicht wird i.d.R. dadurch verletzt, dass der Sicherungsnehmer vor Eintritt des Sicherungsfalls unberechtigt über die Sicherheit verfügt. ${ }^{403}$

\footnotetext{
397 Scholz/Lwowski, Kreditsicherung, Rn. 613 ff; Beck’sches Formularbuch/Meyer-Sparenberg, Sicherungsübereignungsvertrag, § 4 .

${ }^{398}$ Baur/Stürner, Sachenrecht, § 57 III Rn. 15.

${ }^{399}$ Beck’sches Formularbuch/Meyer-Sparenberg, Sicherungsübereignungsvertrag, $§ \S 4,5$.

${ }^{400}$ s. C, IV, 2 f.

${ }^{401}$ MüKo/Eickmann, § 1191 Rn. 14.

${ }^{402}$ Vgl. Brox/Walker, SchR-BT $§ 29$, Rn. 11.

${ }^{403}$ s. C, IV, 4, a), dd).
} 


\section{(2) Rückübertragungspflicht}

Die Pflicht zur (teilweisen) Rückübertragung der Sicherheit ergibt sich entweder wenn sich der Sicherungszweck ordnungsmäßig erledigt hat ${ }^{404}$ oder im Falle nachträglicher Übersicherung. ${ }^{405}$

Ohne ausdrückliche Vereinbarung ist die Frage problematisch, wer beim Drittsicherungsfall bzgl. der Sicherheitsrückübertragung anspruchsberechtigt ist: Der rechtliche oder tatsächliche Sicherungsgeber? Hier kann auf die Überlegung der Bestimmung der Parteien des Sicherungsvertrags zurückgegriffen werden. Wenn sowohl hinsichtlich des Rückübertragungsanspruchs als auch hinsichtlich der Parteien des Sicherungsvertrags keine Regelungen getroffen werden, dann sollte der Kreditnehmer (rechtlicher Sicherungsgeber) anspruchsberechtigt sein, weil der Sicherungsnehmer i.d.R. keinen Kontakt mit dem Dritten aufnimmt; er kennt nur seinen Vertragspartner, also den Kreditnehmer. ${ }^{406}$

\section{cc) Kündigungsrecht?}

\section{§ 7 Sonderkündigungsrecht}

Der Sicherungsvertrag kann nur aufgrund einer ausdrücklichen Regelung im Sicherungsvertrag gekündigt werden.

In der Rspr. und Lit. ist es im Dunkeln, ob und unter welchen Voraussetzungen dem Sicherungsgeber einer nichtakzessorischen Sicherheit ein Kündigungsrecht zusteht. Nach einer Ansicht gibt es für die Kündbarkeit des Sicherungsvertrags keinen Grund, weil durch die begrenzte Sachhaftung das Haftungsrisiko bei den nichtakzessorischen Sicherungsmitteln für den Sicherungsgeber beim Vertragsschluss überschaubar ist. ${ }^{407}$ Eine andere Meinung leitet

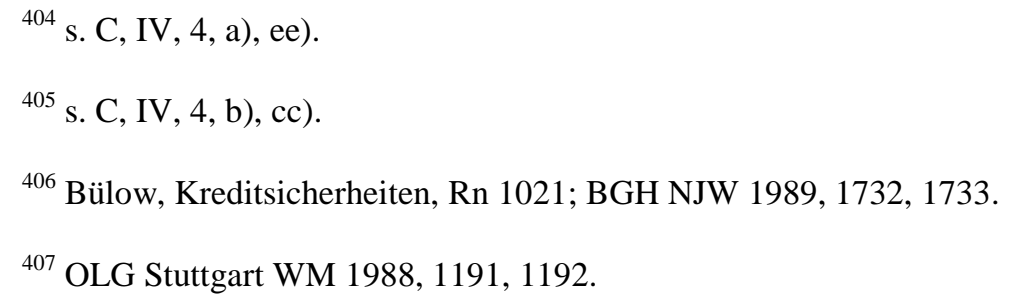


die Kündbarkeit des Sicherungsvertrags anhand von Grundsätzen ab, die eigentlich für die Bürgschaft entwickelt worden sind. ${ }^{408}$

Angesichts des dynamischen Verhältnisses bei den nichtakzessorischen Sicherungsmitteln könnte es ein Kündigungsrecht des Sicherungsgebers geben, wenn der Sicherungsvertrag ein Dauerschuldverhältnis i.S.d. § 314 Abs. 1 BGB wäre, für die es aber keine Legaldefinition gibt. Ein Dauerschuldverhältnis ist dadurch gekennzeichnet, dass aus ihm während der Laufzeit ständig neue Leistungs- und Schutzpflichten entstehen und dem Zeitelement eine wesentliche Bedeutung zukommt. ${ }^{409}$ Ein dem Dauerschuldverhältnis ähnliches Zeitelement enthält der Sicherungsvertrag, weil sich dieser nicht in einer einmaligen Erfüllungshandlung erschöpft, sondern eine Verpflichtung zu einem andauernden Tun, Dulden oder Unterlassen begründet (s.o. Werterhaltungspflicht, Nachsicherungspflicht). In einer Einzelfallentscheidung hat der BGH das Kündigungsrecht eines Drittsicherungsgebers bejaht, aber nicht weil der Sicherungsvertrag ein Dauerschuldverhältnis sei, sondern weil die Kündigung nach dem Grundsatz von Treu und Glauben ( $\$ 242$ BGB) gerechtfertigt sei. ${ }^{410}$ Außer dieser ist insoweit keine andere höchstrichterliche Entscheidung bekannt, die die Kündbarkeit des Sicherungsvertrags bei einer nichtakzessorischen Sicherheit bestätigt. Trotz seines dauerschuldverhältnisähnlichen Zeitelementes ist m.E. § 314 BGB nicht entsprechend anzuwenden, und für ein Kündigungsrecht des (Dritt)Sicherungsgebers besteht auch kein sachlicher Grund. Erstens steht in dem Sicherungsverhältnis als atypischem Dauerschuldverhältnis dessen Stabilität im Vordergrund. Das Bindeglied zwischen der gesicherten Forderung und der Sicherheit sollte meiner Meinung nach nicht unter ein Kündigungsrecht (also ein einseitig eingreifendes Gestaltungsrecht) des Sicherungsgebers gestellt werden, sonst wird die Sicherungskraft massiv geschwächt! Zweitens hält die Sachhaftung der nichtakzessorischen Sicherheit das Risiko für den Sicherungsgeber in Grenzen. ${ }^{411}$ Schließlich bietet außer $\S \S 138$ Abs. 1, 307, 242 BGB die Rechtsfortbildung durch die Rspr. und Lehre ausreichenden Schutz für den Sicherungsgeber. Er kann z.B. bei

\footnotetext{
${ }^{408}$ Erman/Wenzel, § 1191 Rn. 44; BGH NJW 1951, 836.

${ }^{409}$ Palandt/Grüneberg, § 314 Rn. 2.

${ }^{410}$ BGH NJW-RR 1993, 944, 945.

${ }^{411}$ OLG Stuttgart WM 1988, 1191, 1192.
} 
Übersicherung Freigabe seiner Sicherheit verlangen; bei zweckwidriger Zwischenverfügung des Sicherungsnehmers hat er im schlimmsten Fall einen Schadensersatzanspruch wegen Verletzung des Sicherungsvertrags, bei Zweckerledigung einen Anspruch auf Rückübertragung etc.

\section{d) Wichtige Sicherungsmodalitäten}

\section{aa) Voraussetzungen für die Verwertungsreife}

\section{§ 10 Sicherungsfall und Verwertungsreife}

(1) Der Sicherungsnehmer kann die Verwertungsphase einleiten, wenn die gesicherten Forderungen (Sicherungszweck) trotz Fälligkeit nicht befriedigt werden.

(2) Der Sicherungsnehmer hat dem Sicherungsgeber die Verwertung der Sicherheit vorher anzudrohen. Die Androhung darf unterbleiben, wenn sie untunlich ist. Ist die Androhung untunlich, so wird der Monat von dem Eintritt der Verwertungsberechtigung an berechnet.

(3) Die Verwertung darf nicht vor dem Ablauf eines Monats nach der Androhung beginnen, wenn der Wertverfall der Sicherheit nach ihrer Eigenschaft nicht zu befürchten ist. Sofern der Wertverfall der Sicherheit zu befürchten ist, hat der Sicherungsnehmer dem Sicherungsgeber eine angemessene Frist anzudrohen.

Wichtiger Bestandteil eines Sicherungsvertrags sind die Regelungen darüber, ab welchem Zeitpunkt und wie die Sicherheit zu verwerten ist, sofern hierfür nicht ohnehin gesetzliche Regelungen bestehen. Als Grundvoraussetzung der Verwertung tritt ein solcher sog. „Sicherungsfall“ regelmäßig ein, wenn der Kreditnehmer bei Fälligkeit der gesicherten Forderung nicht zahlt. ${ }^{412}$ In einem allgemeinen Sicherungsvertrag soll sich der Sicherungsfall grundsätzlich an dem Sicherungszweck orientieren, damit auch die Nebenforderungen erfasst werden.

\footnotetext{
${ }^{412}$ Bülow, Kreditsicherheiten, Rn. 50c.
} 
Von dem Eintritt des Sicherungsfalls bis zur tatsächlichen Verwertung (also Verwertungsreife) müssen i.d.R. noch weitere Voraussetzungen vorliegen. Häufig vereinbaren die Parteien bei Sicherheitsbereitstellung durch einen Dritten nach dem Vorbild des $§ 771$ BGB, dass der Sicherungsnehmer zuerst gegen den Kreditnehmer vorgehen muss. Ob über das Erfordernis des Sicherungsfalls hinaus für die Verwertungsreife noch andere Umstände erforderlich sind, ist umstritten. So wird diskutiert, ob Verzug zu den Voraussetzungen für die Verwertungsreife gehört; insbesondere in der Konstellation, in der der Kreditnehmer nach Fälligkeit der Forderung nicht leistet, weil ihm eine Einrede gegen den Kreditgeber zusteht. Eine Literaturmeinung befürwortet den Verzug aus den Voraussetzungen auszunehmen, allerdings ohne eine Begründung zu geben. ${ }^{413}$ Demgegenüber sieht die h.M. den Verzug und damit auch die Einredefreiheit als Voraussetzung der Verwertungsreife. ${ }^{414}$ Der h.M. ist m.E. Recht zu geben, denn wenn der Schuldner (Kreditnehmer) seine Leistung verweigern darf, auch wenn ihm die Einrede bloß zusteht ohne dass diese ausgeübt wird, darf die als ultima ratio konzipierte, mit Kosten verbundene und nicht rückgängig zu machende Verwertung nicht beginnen.

Wenn die oben genannten Voraussetzungen (Sicherungsfall, Verzug und Einredefreiheit) vorliegen, dann tritt nach h.M. die Verwertungsreife nach Ablauf einer dem Sicherungsmittel nach angemessenen Frist ein, nachdem der Sicherungsnehmer dem Sicherungsgeber die Verwertung angedroht hat (entsprechend $\S 1234$ BGB). ${ }^{415}$

\section{bb) Schutzpflicht aus § 242 BGB}

In der Verwertungsphase obliegt dem Sicherungsnehmer die Schutzpflicht aus $§ 242$ BGB zur bestmöglichen (also schonend, zügig etc.) Verwertung der Sicherheit. ${ }^{416}$ Verletzt er diese Pflicht schuldhaft, ist er dem Sicherungsgeber aus § 280 BGB (pFV) zum Ersatz des

\footnotetext{
${ }^{413}$ Palandt/Bassenge, $§ 903$ Rn. 30.

414 Bülow, Kreditsicherheiten, Rn. 987, 1035; Scholz/Lwowski, Kreditsicherung, Rn. 247, 249; Palandt/Heinrichs, § 286 Rn. 12; Bamberger/Roth/Kindl, § 930 Rn. 36; BGHZ 48, 250; BGHZ 104, 11.

${ }^{415}$ Bülow, Kreditsicherung, Rn. 1040; Palandt/Bassenge, § 930 Rn. 30.

${ }^{416}$ BGH NJW 2000, 352; BGH NJW 2000, 3273; BGH NJW 1997, 1063; Bülow, Kreditsicherung, Rn. 1043; m.w.N.: Pallas, Rechtsstellung des Sicherungsgebers bei der Verwertung, Rn. 261 ff.
} 
Mindererlöses verpflichtet; der Schadensersatzanspruch kann dann im Wege der Aufrechnung auf die gesicherte Forderung angerechnet werden.

\section{cc) Art der Verwertung}

\section{$\S 11$ Pflicht des Sicherungsnehmers zur bestmöglichen Verwertung}

Der Sicherungsnehmer hat für die bestmögliche Verwertung hinsichtlich des Verwertungserlöses Sorge zu tragen. Die Erfüllung dieser Anforderung wird vermutet, soweit der Sicherungsnehmer das elektronische Verwertungsverfahren der Zentralregisterstelle in Anspruch genommen hat.

Die Art der Verwertung bestimmt sich nach den Vereinbarungen der Parteien bzw. nach der jeweiligen Art der Sicherheit, wenn keine ausdrücklichen Vereinbarungen getroffen wurden. Als Verwertungsart kommen freihändiger Verkauf, Zwangsvollstreckung aufgrund eines Zahlungstitels, Einziehung der abgetretenen Forderung, Zwangsversteigerung und Selbsteintritt durch den Sicherungsnehmer etc. in Betracht. ${ }^{417}$

Obwohl das Spektrum der Verwertungsoptionen sehr groß ist, schränkt die vom BGH auferlegte Pflicht des Sicherungsnehmers zur bestmöglichen Verwertung der Sicherheit seine Wahl jedoch erheblich ein. ${ }^{418} \mathrm{Im}$ Folgenden wird nur auf die problematischen Verwertungsarten eingegangen.

\section{(1) Verfallklausel bei Sicherungsübereignung}

So sind bei Mobiliarsicherheiten oder Sicherheiten an Rechten schnelle, flexible Verwertungsarten (etwa freihändiger Verkauf, Forderungseinziehung usw.) gefragt, die situativ auf den Markt sachgerecht reagieren können. ${ }^{419}$ Verwertungsarten wie z.B. Pfandverkauf, Zwangsversteigerung etc., die ursprünglich als objektiver Schutzmechanismus

\footnotetext{
${ }^{417}$ M.w.N.: Weber, Kreditsicherungsrecht, S. 180, 203, 248, 319; Scholz/Lwowski, Kreditsicherung, Rn. 780 f.; Bülow, Kreditsicherheiten, Rn. 326 ff.; 1039 ff.; 1046 ff.; Baur/Stürner, Sachenrecht, § 44 Rn. 14.

${ }^{418}$ BGH NJW 2000, 352.

${ }^{419}$ Weber, Kreditsicherungsrecht, S. 180.
} 
gedacht waren, ${ }^{420}$ erweisen sich hingegen als bürokratisch und kostenintensiv. Besonders streitig ist die Zulässigkeit der sog. Verfallklauseln bei der Sicherungsübereignung, durch die das Eigentum bei Eintritt des Sicherungsfalls dem Sicherungsnehmr „,verfällt“, d.h. zum Volleigentum ohne treuhänderische Bindung wird, ${ }^{421}$ da im Fahrnispfandrecht gem. $§ 1229$ BGB eine Vereinbarung nichtig ist, in der vor dem Eintritt der Verkaufsberechtigung festgelegt wird, dass dem Pfandgläubiger das Eigentum an der Sache zufallen oder übertragen werden soll, wenn er nicht oder nicht rechtzeitig befriedigt wird. ${ }^{422}$ Die Meinungen in der Rspr. und Lit. sind keinesfalls beständig, und bisher liegt noch keine Entscheidung des Großen Zivilsenats vor. Das RG betrachtete den Verfall zu Eigentum als wesentlichen Bestandteil des Sicherungsvertrags. ${ }^{423}$ In einer älteren Entscheidung sprach sich der BGH auch für die Zulässigkeit aus, ${ }^{424}$ aber neuerlich hat er das Gegenteil getan. ${ }^{425}$ Geht man von dem Schutzgedanken des $§ 1229$ BGB aus, und will man den Sicherungsgeber dadurch schützen, dass man den Sicherungsnehmer dazu zwingt, das Sicherungseigentum im Sicherungsfall nach den gesetzlich bestimmten Möglichkeiten zu verwerten, dann kommt man zur Unzulässigkeit der Verfallklausel. ${ }^{426}$ Dieser Schutzgedanke greift bei dem künftigen Registerpfandrecht aber nicht unbedingt ein, weil die Sach- und Interessenlage hier anders ist als beim Faustpfandrecht. Bei einem Registerpfandrecht behält der Sicherungsgeber den unmittelbaren Besitz der Sachen, und der Sicherungsnehmer muss auch beim Vorliegen einer Verfallvereinbarung vor der Verwertung der Sache diese herausverlangen. Gegen dieses Herausverlangen kann sich der Schuldner nach § 273 BGB zur Wehr setzen, falls ihm ein Anspruch auf eine ordnungsgemäße Verrechnung des Sachwerts mit der offenen Forderung (Verrechnungsklausel) zusteht. Fehlt es an einer solchen Verrechnungsklausel, so liegt die

\footnotetext{
${ }^{420}$ Gerhardt, Mobiliarsicherheiten, JZ 1986, 672, 679; Schreiber, Sicherungseigentum und seine Verwertung, JR $1984,485,488$.

421 Weber, Kreditsicherungsrecht, S. 181; Bülow, Kreditsicherheiten, Rn. 1046; Zur Rechtsnatur der Verfallklausel s. Serick, Verwertung von Sicherungseigentum, BB 1970, 550 f..

${ }^{422}$ Weber, Kreditsicherungsrecht, S. 155.

${ }^{423}$ RG, DJZ 1902, 485; RGZ 83, 50, 53; zur Entwicklung der Rspr. Gaul, AcP 168, 362 ff.

${ }^{424}$ BGH NJW 1980, 226.

${ }^{425}$ BGHZ 130, 101 = BGH NJW 1995, 2635.

${ }^{426}$ Baur/Stürner, Sachenrecht, § 57 Rn. 16; BGHZ 130, 101.
} 
Sittenwidrigkeit ( $§ 138$ Abs. 1 BGB) bzw. unangemessene Benachteiligung des Schuldners nahe, da dann die Interessenlage der des $§ 1129$ BGB entspricht. ${ }^{427}$

\section{(2) Verwertung durch freihändigen Verkauf?}

Der BGB-Gesetzgeber hat für die Verwertung der gesetzlichen Sicherheiten ausführliche objektivierte (d.h. die Parteien können den Verwertungsvorgang nicht beeinflussen) Regelungen (etwa durch öffentliche Versteigerung, § 1235 BGB) getroffen, die dem Gedanken der bestmöglichen Wahrung der Interessen des Sicherungsgebers Rechnung tragen (sollen). ${ }^{428}$ Ohne vertragliche Vereinbarung ist die Verwertung durch freihändigen Verkauf bei einem Faustpfandrecht (wegen $\S 1233$ Abs. 1, 1235 Abs. 1 BGB) und einem Pfandrecht an Rechten (wegen $\S 1273$ Abs. 2 BGB) nicht möglich. So stellt sich sowohl bei den gesetzlich nicht geregelten nichtakzessorischen Sicherheiten (Sicherungsübereignung, Sicherungsabtretung) als auch bei der Sicherungsgrundschuld die Frage, ob die gesetzlichen Verwertungsregeln entsprechend anzuwenden sind. Wer mehr Rechtssicherheit und Gerechtigkeit (vor allem für den Sicherungsgeber) für wichtiger hält, tendiert zur entsprechenden Anwendbarkeit der gesetzlichen Verwertungsvorschriften. ${ }^{429}$ Diese auf den ersten Blick vernünftig erscheinende Meinung passt m.E. aber überhaupt nicht in die Entstehungsgeschichte und das System der nichtakzessorischen Sicherungsmittel, durch welche man mit Hilfe flexibler Gestaltung den Kapital- und Warenverkehr zu fördern versucht. Die verobjektivierten langwierigen gesetzlichen Verwertungsarten sind nicht nur zeit- und kostenintensiv; ihnen fehlt auch die Möglichkeit, jederzeit marktgerecht zu reagieren. Deswegen befürwortet eine starke Ansicht, den freihändigen Verkauf (auch ohne vertragliche Vereinbarung) als Standardverwertungsart zu qualifizieren. ${ }^{430}$ Der Sicherungsgeber ist schon durch die Voraussetzungen der Verwertungsreife und die Pflicht des Sicherungsnehmers zur bestmöglichen Verwertung ausreichend geschützt.

\footnotetext{
${ }^{427}$ Palandt/Bassenge, § 930 Rn. 33; Weber, Kreditsicherungsrecht, S. 181; Bülow, Recht der Kreditsicherheiten, Rn. 1046.

${ }^{428}$ Vgl. Staudinger/Wolfsteiner, Vorbem zu $§ 1191$ ff. Rn. 93.

${ }^{429}$ Staudinger/Wolfsteiner, Vorbem zu $§ 1191 \mathrm{ff} ;$ Schreiber, Sicherungseigentum und seine Verwertung, JR 1984, 485, 488; Gerhardt, Die neuere Rechtsprechung zu den Mobiliarsicherheiten, JZ 1986, 672.

${ }^{430}$ Palandt/Bassenge, § 930 Rn. 31; Weber, Kreditsicherungsrecht, S. 18; § 1191 Rn. 33; RG JW 1928, 2784; RG JW 1936, 2310; BGH NJW-RR 1987, 1291; RGZ 143, 116.
} 
Im Kern geht es bei diesem Streit um die richtige Rechtspolitik, den Interessenkonflikt zwischen Sicherungsgebern und Sicherungsnehmern im Endstadium der Sicherungsmechanismus zu entschärfen. Dafür müssen neue rechtliche und technische Rahmenbedingungen geschaffen werden. ${ }^{431}$

\section{dd) Bewertung der einzelnen Sicherheiten}

\section{§ 4 Bewertung der Sicherheit}

Soweit sich aus dem Sicherungsvertrag nicht ein anderes ergibt, richtet sich die Bewertung der Sicherheit nach dem Richtwert, der durch die Zentralregisterstelle zur Zeit der Sicherheitsfreigabe zur Verfügung gestellt wird. Sofern ein solcher Richtwert nicht vorhanden ist, ist der objektive Verkehrswert maßgebend.

Für die nichtakzessorischen Mobiliarsicherheiten spielt die Bewertung der einzelnen Sicherheiten eine besonders wichtige Rolle, weil sich die Sicherungsgüter im dynamischen Wirtschaftsverkehr (z.B. Warenlager, Geschäftsforderungen) befinden. Nach Sicherstellung von Waren, die starken Preis- und Umsatzschwankungen unterliegen (z.B. Halbfabrikate), deren Absatz durch die stetigen Fortschritte in der Technik gefährdet erscheint (z.B. Computer), oder bei denen es sich um Modeartikel handelt (z.B. Kleidung, Handys) usw., könnte es nach dem Vertragsschluss passieren, dass wegen Wertminderung oder -zuwachses Nachsicherungs- oder Freigabeansprüche entstehen. ${ }^{432}$ Folgerichtig sollte eine Risikoverteilung zwischen Sicherungsgeber und Sicherungsnehmer für den Fall getroffen werden, dass das Sicherungsgut nicht zum angenommenen Wert oder sogar überhaupt nicht verwertet werden kann. Dabei scheint ein Abstellen auf den Zeitpunkt, in dem der Sicherungsnehmer die Freigabe oder der Sicherungsgeber die Aufstockung des Sicherungsguts verlangt, ausgewogen zu sein und auch der Kontrolle der $\S \S 138$ Abs. 1, 307

431 Durch dieses Problem wird die Schlussfolgerung in D, I, 2, a), aa), (1), die man aus der Transformationskurve zieht, deutlich, nämlich: unter unveränderten Rahmenbedingungen ist die gleichzeitige Befriedigung des Sicherungsgeberinteresses an objektiver Verwertung und des Sicherungsnehmerinteresses an flexibler Verwertung nicht möglich. Dazu braucht man meiner Meinung nach ein elektronisches Verwertungsmechanismus. Genauer s. D, II, 4, b).

${ }^{432}$ Scholz/Lwowski, Kreditsicherung, $281 \mathrm{ff}$. 
BGB standzuhalten. ${ }^{433}$ Außerdem sollte die Echtzeit-Bewertungsfunktion des Zentralregisters für die Bestimmung des Wertes herangezogen werden. Dies ist meiner Meinung nach der bestmögliche Ermittlungsweg.

\section{e) Formbedürftigkeit des Sicherungsvertrags}

\section{§ 2 Form der Sicherungserklärung}

Zur Gültigkeit des Sicherungsvertrags ist die schriftliche Erteilung der Sicherungserklärung erforderlich. Die Erteilung der Sicherungserklärung kann auch in elektronischer Form erfolgen, wenn sie mit qualifizierten digitalen Signaturen der Parteien versehen ist.

Da die im BGB geregelten Sicherungsmittel zum Teil Formerfordernisse (§§ 518 Abs. 1 S.1, 766 S.1; 780 I S.1 BGB) voraussetzen, stellt sich für die künftig gesetzlich zu regelnden nichtakzessorischen Sicherungsmittel (vor allem die Sicherungsabtretung, das Registerpfandrecht) die Frage, ob der Sicherungsvertrag auch unter Formzwang gestellt werden sollte.

Die bisher herrschende Meinung verneint dies unter Hinweis auf die Vertragsfreiheit; das Gesetz erleichtert mit der Formfreiheit den Rechtsverkehr und trägt den Gegebenheiten des modernen Wirtschaftsverkehrs Rechnung; der Sicherungsvertrag kann somit mündlich oder auch konkludent zustande kommen. ${ }^{434}$ Dieser pauschalen Haltung ist m.E. entgegenzuhalten. Gerade wegen des Fehlens gesetzlicher (Form-)Vorschriften für die nichtakzessorischen Sicherungsmittel und der damit verbundenen Unsicherheit sollte man sich mit dem Sinn und Zweck eines Formzwangs auseinandersetzen.

\section{aa) Zweck der Formvorschriften}

\section{(1) Funktionen der Formvorschriften bei den gesetzlichen Sicherheiten}

Soweit das Gesetz den Grundsatz der Formfreiheit einschränkt, verfolgt es damit bestimmte Zwecke. Das wichtigste Ziel, das der BGB-Gesetzgeber mit den $§ § 518$ Abs. 1 S.1, 766 S.1;

\footnotetext{
${ }^{433}$ Beck’sches Formularbuch/Meyer-Sparenberg, Sicherungsübereignungsvertrag $§ 10$.

${ }^{434}$ Palandt/Bassenge, § 930 Rn. 305; BGH NJW-RR 91, 305; BGH WM 1956, 667 f; BGH WM 1966, $113,114$.
} 
780 Abs. 1 S.1 BGB erreichen will, ist der Schutz der sich einseitig verpflichtenden Partei (also des Sicherungsgebers) vor übereiltem Vertragsschluss, denn eine ausschließlich berechtigte Partei hat kein Interesse daran, den Vertragsschluss erneut zu überdenken. ${ }^{435}$ Diese Warnfunktion geht sogar so weit, dass der Gesetzgeber in $\S 7766$ S.2, 780 S.2 BGB die eigentlich durch $\S 126$ Abs. 3 BGB der Schriftform gleichgestellte elektronische Form wieder ausnimmt, weil die Schriftform wegen ihrer langen Tradition und Verankerung im Bewusstsein der Menschen besser vor übereilten Entscheidungen schützen kann als eine digitale Signatur. ${ }^{436}$ Neben der Warnfunktion sollen die oben genannten Formvorschriften noch Identitäts- und Perpetuierungsfunktionen leisten. Durch die eigenhändige Unterschrift wird der Aussteller der Urkunde erkennbar gemacht und klargestellt, mit welchem Inhalt das Geschäft zustande gekommen ist. ${ }^{437}$

\section{(2) Interessenlage bei den nichtakzessorischen Sicherungsmitteln}

Eine vergleichbare Interessenlage findet man auch bei den nichtakzessorischen Sicherungsmitteln, bei denen der Sicherungsgeber ebenfalls ohne Gegenleistung seine Pflicht zur Sicherheitsübertragung erfüllen muss. Wegen des fehlenden Schutzes durch den Akzessorietätsgrundsatz scheint hier das Bedürfnis nach Übereilungsschutz noch dringender als bei den gesetzlich geregelten Sicherheiten. Das Gleiche gilt auch für die Identitäts- und Perpetuierungsfunktion.

\section{bb) Folgenabwägung}

Die Einführung eines Formzwangs bei den nichtakzessorischen Sicherheiten bedarf angesichts des Grundsatzes der Formfreiheit und der schweren Rechtsfolgen, die die Nichteinhaltung der Form auslöst, einer hinreichenden Folgenabwägung, durch die die Vorund Nachteile, die ein Formzwang mit sich bringt, für die Entscheidung sichtbar gemacht

\footnotetext{
${ }^{435}$ Rimmelspracher, Kreditsicherungsrecht, Rn. 309, 564; BGHZ 132, 119.

${ }^{436}$ Teil B, zu Artikel 1 Nr.9 bis 11 der Begründung des Gesetzesentwurfs zur Anpassung der Formvorschriften des Privatrechts und anderer Vorschriften an den modernen Rechtsgeschäftsverkehr v. 6.9. 2000, BRDrucksache 535/00 v. 20.10.2000.

${ }^{437}$ Vgl. Palandt/Heinrichs, § 125 Rn. 2 f.
} 
werden. ${ }^{438}$ Ein Formzwang schafft Abschlussklarheit, schützt den Sicherungsgeber vor übereilter Entscheidung, lässt die Vertragsparteien und die Vertragsinhalte erkennen. Allerdings gehen solche Vorteile bzgl. der Verkehrssicherheit auf Kosten der Flexibilität des Geschäfts und verursachen zusätzlichen Material- und Zeitaufwand. Insgesamt überwiegen die Vorteile, die eine Einführung des Formzwangs mit sich bringt, wenn die Zusatzkosten in Grenzen gehalten werden können. Das dürfte durch eine angemessene Auswahl bestimmter Formerfordernisse zu erreichen sein.

\footnotetext{
${ }^{438}$ Häsemeyer, Form im Privatrecht, JuS 1980, 1 ff.
} 


\section{Komplettierende Mechanismen bei der Sicherheitsbestellung}

T3. Die (a) dogmatische Unvollkommenheit des Abstraktionsprinzips und des deutschen Zivilrechts kann (b) durch Hinzufügen fehlender komplettierender Reglungsmechanismen (zentrales elektronisches Registersystem), behoben werden.

In der gegenwärtigen Praxis kann man deutlich beobachten, dass das deutsche Kreditsicherungsrecht ihrer Aufgaben nicht mehr gewachsen ist. Man beschwert sich massiv über Kreditklemme, Wertverlust der Kreditsicherheiten und ruft sogar den Niedergang der Kreditsicherheiten aus. ${ }^{439}$

„Das Vertrauen in die Rechtsbeständigkeit dieser Sicherheiten war durch den lange andauernden Schlingerkurs der Gerichte nachhaltig erschüttert. Bankmitarbeiter fragten sich, ob der hohe Aufwand für die Bestellung und Überwachung von Sicherheiten angesichts der Unwägbarkeit der Rechtsprechung überhaupt noch sinnvoll sei oder ob man Kredite, die nur mit Hilfe von Sicherheiten vertretbar sind, überhaupt noch vergeben soll. Die Kreditnehmer wehrten sich gegen die Forderung nach Sicherheiten mit ähnlichen Argumenten, auch für sie schien das Verhältnis von Aufwand und Beschränkung ihrer Bewegungsfreiheit zu dem angestrebten Erfolg gestört. “440

In diesem Abschnitt werden wir durch institutionelle Analyse folgendem Phänomen auf den Grund gehen.

\section{Probleme des gegenwärtigen Bestimmtheits- und Publizitätsgrundsatzes}

T3. Die (a) dogmatische Unvollkommenheit des Abstraktionsprinzips und des deutschen Zivilrechts Kamn (b) dureh IHimzurfugen fehlender Komplettierender Reglungsmechamismen (zentrales elekbromisches Registersystem), behoben werden.

\footnotetext{
${ }^{439}$ Obermüller, Niedergang der Kreditsicherheiten, NZI 2010, 201 ff, 201.

${ }^{440}$ Obermüller, Niedergang der Kreditsicherheiten, NZI 2010, 201 ff, 203.
} 


\section{Bestimmtheitsgrundsatz}

\section{a) Allgemeines Verständnis im deutschen Recht}

Nach den Standardlehrbüchern des deutschen Sachenrechts gilt für das Verfügungsgeschäft das Spezialitätsprinzip, d.h.:

\section{„Das Verfügungsgeschäft $\underline{\text { muss }}$ sich $\underline{\text { immer }}$ auf die $\underline{\text { einzelnen }}$ Vermögensbestandteile beziehen. “441}

Die Bestellung einer Sicherheit ist unstreitig ein Unterfall des Verfügungsgeschäfts. Nach der Doktrin der deutschen Verfügungslehre müssen sich Sicherungsgeschäfte dann eigentlich immer auf die einzelnen Sicherungsgegenstände beziehen. Der Regelfall im deutschen Sicherungsrecht ist dies aber gerade nicht! Das Wort „Bestimmtheit“ taucht im Kreditsicherungsrecht in verschiedenen Kontexten auf; so ist z.B. oft wegen unzureichender Konkretisierung von der Bestimmung des Haftungsumfangs oder des Sicherungsmittels die Rede. Mangels ausdrücklicher Vereinbarungen muss der Sicherungsumfang der abstrakten Sicherheiten (etwa ob Zinsen, Vorfälligkeitsentschädigung, Ansprüche aus §§ 812 ff. BGB oder Schadensersatz etc. in den Sicherungsverband des Sicherungsguts fallen) mittels Auslegung der Zweckerklärung des Sicherungsvertrags bestimmt werden. Strukturell findet der Bestimmtheitsgrundsatz ${ }^{442}$ nur auf die Bestimmtheit des Sicherungsmittels Anwendung und nicht auf die Bestimmung des Sicherungsumfangs. Die Bestimmtheit (i.d.R. bzgl. der Sicherungsübereignung und Sicherungsabtretung, nicht aber der Sicherungsgrundschuld oder Hypothek; dort gewährleistet das Grundbuch dieses Erfordernis) ist insoweit eher ein Problem des gesamten Sicherungsrechts in praktischer Hinsicht, weil einerseits der Sicherungsnehmer nach umfassenden Sicherheiten strebt, andererseits der BGH hohe Anforderungen stellt. Hierzu gibt es eine umfangreiche und nicht immer konsequente Rspr. ${ }^{443}$ Mit drei Stichwörtern lassen sich die unübersichtlichen Konturen des Bestimmtheitsgrundsatzes bzgl. der Sicherungsübereignung aufzeichnen, auf die man in der Praxis stets achten muss:

\footnotetext{
${ }^{441}$ Baur/Stürner, Sachenrecht, § 5 - Übersicht 3; Wolf, Sachenrecht, Rn. 28: insoweit ist keine Ausnahme vorgesehen.

${ }^{442}$ Wolf, Sachenrecht, Rn. 26; BGHZ 73, 253.

${ }^{443}$ M.w.N.: Medicus, Bürgerliches Recht, Rn. 52.
} 
Individualisiert $^{444}$, äußerlich erkennbar ${ }^{445}$ und - wenn unzweckmäßig oder unzureichend dann ,Raumsicherung““. ${ }^{446}$

Rechtstechnisch gesehen beginnt die verzwickte Lage des geltenden Kreditsicherungsrechts mit der bequemen ungedachten Zulassung der antizipierten Abtretung, die eigentlich gegen den Bestimmtheitsgrundsatz verstößt. Anders als das RG, das sich in der Anfangszeit des BGB noch an den Bestimmtheitsgrundsatz hielt, ${ }^{447}$ lässt der $\mathrm{BGH}$ anstelle der (gegenstandsbezogenen) Bestimmtheit schon die Bestimmbarkeit der abgetretenen Forderung(en) genügen, um die Vorauszession zu ermöglichen. ${ }^{448}$ Nach einhelliger Meinung im deutschen Rechts hat diese weite Fassung in der Regel keine Schwierigkeiten mit dem Bestimmtheitsgrundsatz. ${ }^{449}$ Genau hier liegt die Quelle des Chaos des deutschen Kreditsicherungsrechts. Das Bestimmbarkeitskriterium ist zwar „punktuell logisch“ richtig, wenn man verlangt, dass „die abgetretenen Forderungen spätestens zur Zeit ihrer Entstehung nach Höhe, Schuldner und Gegenstand zu individualisieren sein müssen““450. Es hat aber, (zumindest) ohne komplementierende Regelungsmechanismen, ${ }^{451}$ verheerende Auswirkungen. Denn von ihrer Rechtsnatur her ist die Abtretung ein Verfügungsvertrag, der unmittelbar die

\footnotetext{
444 Allgemeine Definition: BGHZ 73, 253; Lwowsik, Sicherungsübereignung, ZIP 1980, 953; Blaurock, Kreditsicherungsrecht, S. 117: In Bezug auf die Sicherungsübereignung heißt das, dass die zu übereignende Sache so gekennzeichnet wird, dass sie sich von allen anderen gleichartigen Sachen des Sicherungsgebers einwandfrei unterscheiden lässt.

${ }^{445}$ BGH NJW 1984, 803 f.; BGH NJW 1992, 1161 f.; BGH WM 1988, 346; OLG München NJW 1987, 1896, nicht ausreichend sind z.B.: „,des halben Lagers“; „Handbibliothek Kunst“; „die Gegenstänade, die nicht der Unpfändbarkeit gem. $\S 808$ ff. ZPO unterliegen“.

${ }^{446}$ Vortmann, Raumsicherungsübereignung, ZIP 1988, 626.

${ }^{447}$ RGZ 155, 26 ff.: In der Anfangszeit des BGB hat das RG versucht, den „abstrakten“ Bestimmtheitsgrundsatz als Zessionsmaßstab zu nehmen, und nicht die einzelfallorientierte Bestimmbarkeit. So ist die Konstruktion des verlängerten Eigentumsvorbehalts zumindest in der Hinsicht fraglich, weil er in Kombination mit der Verarbeitungsklausel unscharf sein kann, worauf sich die Abtretung bezieht, auch wenn sich ein verlängerter Eigentumsvorbehalt im Einzelfall nur auf die konkret bestimmbaren Forderungen aus dem Weiterverkauf bezieht: Im Jahre 1903 hat auch das RG kapituliert und die Vorausabtretung für zulässig erklärt (RGZ 55, 334, 335.

${ }^{448}$ BGHZ 7, 365; BGH NJW 1974, 1130; 1995, 1668; 00, 276.

${ }^{449}$ Palandt, § 389, Rn. 14.

${ }^{450}$ Kropholler, Bürgerliches Gesetzbuch, § 398, Rn. 17.

${ }^{451}$ Was für harmonierende Regelungsmechanismen es gibt, werden wir i.R.d. Rechtsgestaltung diskutieren.
} 
Rechtsänderung, nämlich den Übergang der Forderung bewirkt. ${ }^{452}$ „Solange eine Forderung aber noch nicht besteht, kann ihre Zuständigkeit noch nicht geändert werden, sondern erst mit ihrer Entstehung. “453

An dieser Stelle wird die Grundmaterie des Rechts tangiert, nämlich die Frage danach, ob, inwieweit und wie das subjektive Recht von seinem Gegenstand distanzieren darf.

Auf diese Fragen werden wir später im Rahmen der Gestaltung des Sicherungsrechts eingehen. Zunächst sehen wir uns das Problem der Sicherungskollision als direkte schädliche Wirkung des Bestimmbarkeitskriteriums genauer an. Seine andere mittelbare negative Folge, nämlich die „Übersicherung“, ist m.E. als eine direkte Konsequenz der abstrakten Gestaltung des Sicherungsrechts zu betrachten.

\section{b) Sicherungskollisionen}

Aus spieltheoretisch-ökonomischer Sicht ist die Grundkonstellation des Mobiliarsicherungsrechts als Nullsummenspiel zu bezeichnen, in dem sich die Auszahlungen über alle Spieler zu Null addieren. ${ }^{454}$ Das heißt: Der Gewinn eines Spielers führt zwangsläufig zu einem Verlust in gleicher Höhe bei einem anderen Mitspieler. Anders als die Theorie, wonach keine Überschneidungen existieren, sieht das in der Realität des deutschen Kreditsicherungsrechts ganz anders aus: jeder Kreditgeber versucht, seinen vergebenen Kredit möglichst umfangreich zu sichern, und zwar durch den begrenzten Wert des Mobiliars des Kreditnehmers. Auf Grund der Unvollkommenheit des Normensystems und der Rechtsprechung kann es aber dazu kommen, dass ein und dasselbe Sicherungsobjekt unabhängig voneinander als Sicherheit für verschiedene Kreditgläubiger bestellt wird. Dadurch entstehen sog. Sicherungskollisionen, die beachtlichen unproduktiven und unvorhersehbaren Prozesskosten verschlingen, die zur Steigerung der Gesamtwohlfahrt der Gesellschaft hätten eingespart werden können. Deshalb stellt sich die Analyse der

\footnotetext{
${ }^{452}$ Bülow, Kreditsicherheiten, Rn. 1368.

${ }^{453}$ Bülow, Kreditsicherheiten, Rn. 1672.

${ }^{454}$ Rieck, Spieltheorie, S. 283.
} 
Sicherungskollision als ein wichtiger Eingang in die Problematik des Mobiliarsicherungsrechts dar.

Das Problem der Sicherungskollision ${ }^{455}$ kann in zwei Subprobleme aufgeteilt werden, nämlich Sicherungskonkurrenz und Sicherungskonflikt: Bei der Sicherungskonkurrenz geht es um die Frage, wie der begrenzte Wert des Mobiliars zwischen mehreren Sicherungsnehmern aufgeteilt wird, und beim Sicherungskonflikt handelt es sich um den Verdrängungskampf der verschiedenen Sicherheiten. ${ }^{456}$ Ausgangspunkt der Problematik ist der allgemeine Prioritätsgrundsatz, wonach das früher entstandene Recht dem späteren im Rang vorgeht (sog. vertikale Aufteilung); entscheidend ist also der Entstehungszeitpunkt. ${ }^{457}$ Schwierig wird es aber mit diesem Prinzip, wenn die Sicherungsrechte verschiedener Kreditgläubiger zum selben Zeitpunkt (z.B. bei Verarbeitungsklauseln gem. §947 Abs. 1 BGB) entstehen und die Sicherungsnehmer dabei versuchen, die Konkurrenten durch ausschließende Vertragsbestimmungen zu verdrängen und die Sicherheit für sich allein zu beanspruchen. Im Herrschaftsbereich der abstrakten Mobiliarsicherheiten ist diese Konstellation leider der Regelfall der dinglichen Sicherung des Flusses der Produktions- oder Finanzierungsmittel.

So bieten z.B. mehrere Lieferanten (Vorbehaltsverkäufer) unabhängig voneinander ihre Produktionsmittel nur unter der (AGB-)Bedingung an, dass die Verarbeitung des Vorbehaltskäufers für sie erfolgen muss, damit er über $§ 950$ I BGB das Eigentum an der hergestellten Sache erwirbt. ${ }^{458}$ Der BGH hat sich über den zwingenden Charakter der $\S \S 946$

\footnotetext{
${ }^{455}$ Die Sicherungskollisionen im deutschen Kreditsicherungsrecht sind vielfältig. Ihre vollständige Aufzählung und Darstellung ist nicht Aufgabe dieser Arbeit. Wichtiger ist die Auseinandersetzung mit den problematischen Sicherungskonflikten und den dahinter stehenden strukturellen Mängeln des Systems. So werden z.B. die Konflikte zwischen (verlängertem) Eigentumsvorbehalt/ Sicherungsübereignung des Warenlieferanten und Raumsicherung/ Globalzession der Banken als Subproblem der Vertragsbruchtheorie betrachtet und nicht weiter diskutiert.

${ }^{456}$ Bülow, Kreditsicherheiten, Rn. 1633 ff.

${ }^{457}$ Baur/Stürner, Sachenrecht, § 59 B V Rn. 53 f.

${ }^{458}$ Weber, Kreditsicherungsrecht, S. 202.
} 
ff. BGB hinweggesetzt und einen solchen Verarbeitungsvorbehalt zugelassen. ${ }^{459}$ Dieser Lösungsweg steht aber dem sachenrechtlichen Publizitätsgedanke entgegen. Andere schlagen dem Lieferant die antizipierte Sicherungsübereignung vor, ${ }^{460}$ was nach der hier vertretenen Meinung dogmatisch nicht ganz sauber ist. Egal welcher Meinung man am Ende folgt, man muss die kollidierenden Willen und Interessen der Lieferanten entweder über $\S 947$ Abs. 1 BGB analog oder über $\S \S 133,157,140,947$ I BGB wieder bestmöglich in Einklang bringen, und zwar durch Aufteilung der Sicherheit nach dem Verhältnis des Werts der verarbeiteten Sachen (sog. Anteilserwerb). ${ }^{461}$

Angesichts des begrenzten Wertes der Sicherheit und der Schutzwürdigkeit der am Kreditgeschäft beteiligten Parteien stellt der Anteilserwerb, also der Rechtsgedanke des $\S 947$ I BGB durchaus die zweckmäßigste Lösung dar, die für Sicherungskollisionen allgemein gültig sein soll. Dies ist aber unter dem gegenwärtigen deutschen Kreditsicherungsrecht nicht ohne weiteres möglich. ${ }^{462}$

In engem Zusammenhang mit der formularmäßigen weiten Bestimmung der gesicherten Forderungen steht auch das Problem des Interessenkonfliktes zwischen Geld- und Warenkreditgeber im Bereich der Mobiliarsicherheiten oder Sicherheiten an Rechten, weil jeder von ihnen die mehrfach abgetretenen Kaufpreisforderungen mit Hilfe von Globalzessionen (z.B. Sicherungsabtretung, verlängerter Eigentumsvorbehalt oder Factoring) an sich zu ziehen versucht. Häufig gewähren Kreditinstitute Darlehen nur unter der formularmäßigen Bedingung der Abtretung aller künftigen Ansprüche des Sicherungsgebers, der mit diesem Kredit seine Handels- oder Produktionsgüter im Wege eines verlängerten Eigentumsvorbehalts beim Warenlieferant besorgt. In Rahmen des verlängerten Eigentumsvorbehalts tritt der Sicherungsgeber die künftigen Forderungen ab, die er aus dem

\footnotetext{
${ }^{459}$ BGHZ 20, 159, 163 f.; vgl. BGHZ 46, 117: Auch die Vereinbarung eines bestimmten Miteigentumsanteils zugunsten des Lieferanten ist zulässig; BGH NJW 1989, 3213 f.: Die Verarbeitungsklausel ist nur außer Kraft, wenn der Vorbehaltskäufer äußerlich erkennbar von der vereinbarten Art der Verarbeitung abweicht.

${ }^{460}$ Westermann, Sachenrecht, § 53 III 2d; Medicus, Bürgerliches Recht, Rd. 519.

${ }^{461}$ Bülow, Kreditsicherungsrecht, Rn. 1639.

${ }^{462}$ Der Grund liegt in der Schwierigkeit der Bestimmung der Anteile, s. D, I, 1, d).
} 
Weiterverkauf erlangen wird. ${ }^{463}$ Damit kommen die Kreditinstitute den Warenlieferanten zeitlich immer zuvor. Der BGH hat aber die zeitlich vorangehende, nach dem Prioritätsprinzip begründete Forderungsinhaberschaft des Geldkreditgebers mit der Begründung der Sittenwidrigkeit ( $\$ 138$ I BGB) aberkannt: Durch die totale Beanspruchung aller Forderungen des Kreditnehmers seitens der Bank wird dieser notwendig dazu gedrängt, seine Lieferanten, die nur unter verlängertem Eigentumsvorbehalt liefern möchten, darüber zu täuschen, dass die künftigen Forderungen noch nicht abgetreten sind. Denn andernfalls könnte er nicht mit Belieferung rechnen (sog. Vertragsbruchtheorie). ${ }^{464}$ Argumente gegen den BGH haben sich nicht durchgesetzt. ${ }^{465}$ Ein schrittweises Nachgeben der Kreditinstitute (etwa mittels Verpflichtungsklausel, schuldrechtlicher Verzichtsklausel) führte am Ende zu dem Ergebnis, dass die bankenmäßige Globalzession dem Vorwurf des § 138 I BGB nur mit einer dinglichen Verzichtsklausel entgehen kann. Also muss die Bank von vornherein auf die Abtretung von Forderungen verzichten, die im Rahmen einer anderweitigen Globalzession (i.d.R. einem verlängerten Eigentumsvorbehalt) abgetreten wurden, so dass die Abtretung erst mit der Tilgung der Schuld gegenüber dem Vorbehaltslieferanten wirksam werden soll. ${ }^{466}$ Für das von $\S 138$ I BGB geforderte subjektive Element, dass der vorangehende Sicherungsnehmer (i.d.R. Geldkreditgeber) den nachfolgenden Sicherungsnehmer (i.d.R. Warenkreditgeber) schädigen will, genügt nach dem BGH, dass die Bank von der Sachlage (etwa der Branchenüblichkeit des verlängerten Eigentumsvorbehalts) weiß. ${ }^{467}$

Die herrschende Vertragsbruchlehre des BGH schützt meiner Meinung nach parteiisch den Warenkreditgeber, auch wenn dieser im Vergleich zum Geldkreditgeber der Forderung aus dem Weiterverkauf näher steht. ${ }^{468}$ Insbesondere verletzt das Argument des Näheprinzips massiv das einfache Rechtsgefühl jedes besonnenen Menschen, denn ohne den Kredit der

\footnotetext{
${ }^{463}$ Palandt/Grüneberg, § 398 Rn. 24 f.; Kessal-Wulf, Kreditsicherung, S. 438.

${ }^{464}$ Kollision zwischen Sicherungsabtretung und verlängertem Eigentumsvorbehalt: BGHZ 30, 149 ff.; BGHZ 72 , 308, 310; BGH NJW 1999, 940; krit. hierzu Canaris NJW 1981, 249; Kollision zwischen mehreren verlängerten Eigentumsvorbehalten: BGH NJW 1999, 2588.

${ }^{465}$ Piker, Die Schlacht der Kreditoren, JuS 1988, 375, 378; m.w.N.: Medicus, Bürgerliches Recht, Rn. 527.

${ }^{466}$ BGH NJW 1999, 940; krit. Medicus, Bürgerliches Recht, Rn. 526 f.

${ }^{467}$ Vgl. BGH NJW 1999, 940.

${ }^{468}$ M.w.N.: Bülow, Kreditsicherungsrecht, Rn. 1665.
} 
Geldinstitute hätte der Kreditnehmer gar nicht in sein Geschäft einsteigen können. Mit der Vertragsbruchtheorie will der BGH wahrscheinlich die verhandlungsschwachen Mittelständler schützen. Leider hat er sich dabei keine Gedanken über die hinter den Kreditgeschäften stehenden Wirtschaftsverhältnisse gemacht und übersieht, dass in der modernen Marktwirtschaft die Warenkredite der meisten Lieferanten gleichermaßen durch Banken finanziert sind; wirtschaftlich gesehen bleibt im Grunde genommen nur der Konflikt der Bank des Lieferanten mit der Bank des Vorbehaltskäufers übrig. ${ }^{469}$ Darüber, wer von den beiden der „bessere“ Sicherungsnehmer ist und vor allem aus welchem Grund, hat der BGH aber kein Wort verloren.

Auch bei der Sicherungsübereignung hat das Bestimmbarkeitskriterium des BGH erhebliche Probleme. Der Hauptanwendungsfall ist die Sicherungsübereignung von Warenlagern mit wechselndem Bestand für einen Kontokorrentkredit. ${ }^{470}$ Hier sieht man, wie schwierig die dingliche Sicherung schuldrechtlicher Bewegungsvorgänge im Rahmen das gegenwärtigen statischen Sachenrechtssystems sein kann. Die Probleme mit dem Publizitätsgrundsatz erörtern wir erst später. An dieser Stelle setzen wir uns zunächst mit dem Bestimmbarkeitskriterium vor. Im Hinblick auf die Willenseinigung bzgl. einer Raumsicherung mit wechselndem Bestand stellen sich folgende Fragen: Bezieht sich die Raumsicherung auf das ganze Warenlager oder nur einen bestimmten Teil davon? Wie und mit welcher Genauigkeit hat die räumliche Abgrenzung zu erfolgen? Fallen auch Anwartschaftsrechte unter die Raumsicherung? ${ }^{471}$

Die gegenwärtige Rechtsprechung verlangt, dass man anhand der Sicherungsabrede und äußerer Kriterien ohne weiteres erkennen kann, welche individuell bestimmten Sachen übereignet worden sind. ${ }^{472}$ Nach den Einzelrechtsprechungen sind z.B. kennzeichnende Schilder oder Markierungen ausreichend. ${ }^{473}$ Bei wechselndem Bestand ist das

\footnotetext{
${ }^{469}$ M.w.N.: Bülow, Kreditsicherheiten, Rn. 1665.

${ }^{470}$ Baur/Stürner, Sachenrecht, § 51, Rn. 31.

${ }^{471}$ Baur/Stürner, Sachenrecht, § 57, Rn. 13.

${ }^{472}$ BGH NJW 1992, 1161; 1995, 2350; 1996, 2654.

${ }^{473}$ Was das ganz konkret bedeutet - m.w.N.: Baur/Stürner, Sachenrecht, § 57, 13.
} 
Bestimmbarkeitskriterium des BGH kein ex ante handhabbares Merkmal und damit ein Rechtsunsicherheitsfaktor sowohl bei der Vertragsgestaltung als auch bei der Sachverwaltung, der zur rechtlichen oder faktischen Unwirksamkeit der Sicherungsübereignung führen kann.

\section{c) Einfluss des Bestimmbarkeitskriteriums auf die Sicherungskraft}

Aus Sicht der Kreditinstitute entzieht der BGH durch seine Vertragsbruchtheorie praktisch die ökonomische Grundlage der Globalzession. Denn angesichts der Branchenüblichkeit des (verlängerten) Eigentumsvorbehalts- bzw. Verarbeitungsklausel muss ein kreditgebendes Geldinstitut immer damit rechnen, dass es seine Globalzession im Ernstfall (Insolvenz) gerichtlich nicht durchsetzen kann. ${ }^{474}$ Außerdem schwächt nicht nur die Rechtsprechung zur Vertragsbruchtheorie, sondern auch das System selbst die Zession als Sicherungsmittel, denn auf Grund der fehlenden Formbedürftigkeit der Abtretung kann der Kreditnehmer durch betrügerische Umdatierungen die Sicherungszession „faktisch“ beeinträchtigen.

Für die Sicherungsübereignung ist, was die Schwächung der Sicherungskraft anbelangt, neben der Unsicherheit und Unvorhersehbarkeit der Einzelfallrechtsprechung bzgl. des Bestimmbarkeitskriteriums ${ }^{475}$ noch die viel problematischere Publizitätslosigkeit zu erwähnen.

Die Frage, Warum die Sicherungszession und die Sicherungsübereignung trotz ihrer schwachen Sicherungskraft in der Praxis paradoxerweise immer noch sehr verbreitet sind, hat Adams am Beispiel der Sicherungsübereignung dargestellt. ${ }^{476}$ Der geringe Anstieg des Nutzens der Sicherungsübereignung oder Globalzession steht aber fast kostenloser (formularmäßigen) Bestellung gegenüber.

${ }^{474}$ Deshalb wird die Globalzession für die Kreditvergabeentscheidung keine (große) Rolle spielen, s. Tabelle in D, II, 2, a), aa), (2); das gleiche gilt auch für Sicherungsübereignung.

${ }^{475}$ M.w.N.: Melsheimer, Sicherungsübereignung oder Registerpfandrecht - eine politologische Studie, S. 6: Seit langem beschwert man sich über die fehlende Rechtssicherheit.

476 Adams, Ökonomische Analyse der Sicherungsrechte, S. 123 ff, 126, : „... ein Rechtsinstut von den Wirtschaftssubjekten dann benutzt wird, wenn die internalisierten Kosten die internalisierten Erträge nicht übertreffen. ... Da stets einige der sicherungsübereigneten Güter auch im Konkursfalle noch aufzufinden sind ... bedeutet eine Sicherungsübereignung eine Ertragssteigerung für den Kreditgeber. Geht man davon aus ..., dass die Konkursrate $0,5 \%$ beträgt und die Sicherungsübereignung $11 \%$ eines Kredites im Fall des Konkurses verlässlich deckt, dann ergibt sich eine Steigerung des Erwartungswertes der Verzinsung um 0,55\% als Ertrag der Sicherung. “ 


\section{d) Anteilserwerb als Lösung des Konflikts?}

Wie oben schon erwähnt, läuft die Lösung des Sicherungskonflikts im Ergebnis auf einen Anteilserwerb hinaus. Es wurde versucht, diesen Weg auch dogmatisch zu begründen. Hier verwirft man das Bestimmbarkeitskriterium des BGH und kehrt zum Bestimmtheitsgrundsatz des BGB zurück; für die Wirksamkeit einer Zession (Verfügung) genügt die Entstehungsmöglichkeit einer Forderung nicht und die Verfügung wird nur in dem Zeitpunkt wirksam, in dem die Forderung (Verfügungsgegenstand) auch tatsächlich entstanden ist; wenn sich verschiedene auf die gleiche Forderung zielende Sicherungszessionen widersprechen, dann sind sie aufgrund einander ausschließender Verfügungserklärungen insgesamt unwirksam; somit kehrt man zur anteilmäßigen Aufteilung des Sicherungsobjekts zurück; am Ende geht es nur noch darum, die richtigen Anteile für die Sicherungsnehmer herauszufinden. ${ }^{477}$ Wer diese Lösung für ansprechend hält, kann sie anhand konkreter Rechenbeispiele mit Zahlen im Bülows Standardwerk - Recht der Kreditsicherheiten - (Rn. 1667) nachvollziehen.

Dieser per se richtige und wichtige Ansatz zur Konfliktlösung hat einen unerfreulichen Haken. Seine Gegner wenden ein:

Die anteilsmäßige Aufteilung der Sicherungsmasse setzt voraus, dass man sämtliche Sicherungsnehmer kennt;

der Warenlieferant, der die Weiterverkaufsforderung beansprucht, kennt aber in aller Regel weder die kreditgebende Bank noch andere Zulieferer. Selbst wenn nur noch einer der Sicherungsnehmer nicht $\mathrm{zu}$ ermitteln ist, kann man keine richtige Quote herausfinden; prozessual scheitert diese Lösung an den hohen Anforderungen des $\S 253$ Abs. 2 Nr. 2 $\mathrm{ZPO}^{478}$

An dieser Stelle ist man innerhalb des gegenwärtigen deutschen Zivilrechtssystems mit seinem Latein am Ende. Auch wenn manche wie Bülow berechtigterweise folgende dogmatische Frage stellen:

\footnotetext{
${ }^{477}$ Lange, Eigentumstradition, NJW 1950, 565 f.; m.w.N. Bülow, Kreditsicherheiten, Rn. 1666.

${ }^{478} \mathrm{vgl}$. BGHZ 32, $361(364)$.
} 
„Bleibt die Frage offen, ob ihr (Teilungslehre) Ausgangspunkt richtig ist, dass nämlich mehrere antizipierte Abtretungen nicht zur Priorität einer der Abtretungen führen, weil die Entstehung des Verfügungsobjekts, der Weiterverkaufsforderung, nicht vorweggenommen werden könne. “479

Meines Erachtens ist die Teilungslehre dogmatisch richtig, und ihr Problem liegt außerhalb des Systems. Im Grunde genommen ist dies ein Problem der Informationsasymmetrie und nicht der falschen Dogmatik. ${ }^{480}$

Das Prioritätsprinzip besagt, dass das früher entstandene Recht dem späteren im Rang vorgeht; entscheidend ist also der Zeitpunkt der Entstehung. ${ }^{481}$ Die Teilungslehre ist die logische Konsequenz, wenn die Rechte zum gleichen Zeitpunkt entstehen bzw. wenn sich ihre Entstehungszeitpunkte nicht ermitteln lassen. Es fehlt dem gegenwärtigen System des (deutschen) Zivilrechts ein dogmatisches Puzzleteil, um dem Argument bzw. Problem der Informationsasymmetrie entgegenzuwirken. Hier liegt der Übergang zu einem anderen problematischen Rahmenbedingung gebenden Grundsatz, nämlich dem Publizitätsprinzip, womit ich mich an einer anderen Stelle auseinandersetzen möchte.

\section{e) Kann es das „Case-Law“ besser?}

Im deutschen Recht hat sich der Bestimmtheitsgrundsatz im Laufe der Zeit zum Bestimmbarkeitskriterium, in Kombination mit der Einzelfalllösung entwickelt. Dieses Modell der Konfliktlösung ist typisch „Case-Law“. Deshalb ist es höchst anregend, sich das vergleichbare Rechtsgebiet des anglo-amerikanischen Sicherungsrechts vor Augen zu führen.

In Großbritannien gibt es vielfältige Sicherungsrechte, wie z.B. mortgages, charges, pledes und liens. Wie es überall auf der Welt der Fall ist, wird verbreitet nicht das Besitzpfandrecht

\footnotetext{
${ }^{479}$ Bülow, Kreditsicherheiten, Rn. 1671.
}

${ }^{480}$ Dieses Problem der Informationsasymmetrie kann durch die Einführung der elektronischen Zentralregister mit Echtzeitfunktion gelöst werden (s. D, II, 4, a) und b).

${ }^{481}$ Greifelds, S. 1062: unter Stichwort „Prioritätsprinzip“. 
wie pledes oder liens in Anspruch genommen, sondern die besitzlose floating charge, ${ }^{482}$ was im Hinblick auf den Bestimmtheitsgrundsatz interessant erscheint. An der Verdrängung der fixed charge durch die floating charge sieht man auch im angelsächsischen Sicherungsrecht die Tendenz der Auflockerung des Bestimmtheitsgrundsatzes im Zuge der industriellen Revolution. ${ }^{483}$ Die floating charge verfolgt das gleiche Ziel wie die deutsche Globalzession oder verlängerte Sicherungsübereignung, nämlich eine möglichst umfassende Kreditsicherung durch das Gesamtvermögen des Kreditnehmers. Mit einer floating charge wird ein Unternehmen mit seinem gegenwärtigen oder künftigen Vermögen als Kreditsicherheit bestellt. ${ }^{484}$ Anders als die Deutschen, die begrifflich gegenstandbezogen denken, versucht man sich hier bzgl. des Kasus der Bestimmtheit nicht schon bei der Vertragsgestaltung festzulegen, sondern erst bei der Abwicklung - das heißt: Man verzichtet weitestgehend auf den Bestimmtheitsgrundsatz oder sogar auf das Bestimmbarkeitskriterium. Konkretisiert wird erst bei der sog. „crystallisation“ (Sicherungsfall). Davor schwebt die floating charge wie ein Fangnetz über dem Unternehmensvermögen. Ab der „crystallisation“ wandelt sich die floating charge in eine fixed charge um, welche die Vermögenswerte des Unternehmens mit dinglicher Wirkung erfasst. ${ }^{485}$ Zwei entscheidende Vorteile bringt diese spezielle Konstruktion des englischen Sicherungsrechts mit sich: erstens entfallen die dogmatischen Schwierigkeiten mit dem Bestimmtheitsgrundsatz bei der Vertragsgestaltung und der Sicherungskollision und es werden damit verbundene Transaktionskosten eingespart, weil man im Vergleich zum deutschen Kreditsicherungsrecht für die Verpfändung des ganzen Vermögens eines Unternehmens keine Kombination von verschiedenen Sicherungsmitteln braucht; noch wichtiger behält das kreditnehmende Unternehmen durch die floating charge die Verfügungsfreiheit über seine Vermögenswerte bei. ${ }^{486}$

Der essenzielle Mangel der floating charge mit ihrem (völligen) Verzicht auf die Bestimmtheit bzw. Bestimmbarkeit liegt darin, dass ihre Sicherungskraft relativ schwach ist.

\footnotetext{
${ }^{482}$ Bernstorff, Englisches Recht, S. 130 ff.

${ }^{483}$ McCormack, Registration of Company Charges, S. $46 \mathrm{f}$.

${ }^{484}$ Von Bernstorff, Englisches Recht, S. 134.

${ }^{485}$ Hofmann, Mortgage und Charge, S. 58.

${ }^{486}$ McCormack, Registration of Company Charges, S. 48 f.; Hofmann, Mortgage und Charge, S. 58 f., S. 162.
} 
Denn das Unternehmen kann über seine Vermögensgegenstände im Wege der gewöhnlichen Geschäftstätigkeit verfügen. ${ }^{487}$ Das bedeutet, ein lastenfreier Erwerb durch die Geschäftspartner des Unternehmers oder die floating charge geht im Rang jeder bestimmten Sicherheit nach, wenn sie vor der crystallisation bestellt ist. ${ }^{488}$

Aus diesem Grund lehnte das ,pre-Article 9“ US-Kreditsicherungsrecht die floating charge als „quasi-security“ mit der Begründung ab, dass sie mit der Rechtsnatur einer Sicherheit unvereinbar sei, weil der Sicherungsgeber letztendlich nicht die Herrschaft über bestimmte Vermögensgegenstände habe. ${ }^{489}$ Ähnlich wie das RG in Deutschland verteidigte auch das US Supreme Court in den 20er Jahren des letzten Jahrhunderts den Bestimmtheitsgrundsatz im Sicherungsrecht: ${ }^{490}$

„Under the law of New York a transfer of property as security which reserves to the transferor the right to dispose of the same, or to apply the proceeds thereof, for his own uses is, as to creditors, fraudulent in law and void“"

Im Laufe der Industrialisierung und mit dem zunehmenden Bedarf an Kapital lockerte sich das US-Kreditsicherungsrecht im Hinblick auf den Bestimmtheitsgrundsatz auf. Nun sehen wir uns den von vielen europäischen Sicherungsrechtlern überschwänglich empfohlenen amerikanischen Article 9 UCC genauer an. ${ }^{491}$ Durch Article 9 UCC ${ }^{492}$ wollten seine Verfasser die Zersplitterung des amerikanischen Sicherungsrechts mit der einheitlichen Rechtsfigur „Security Interest“" auf einen Schlag bezwingen: ${ }^{493}$

\footnotetext{
${ }^{487}$ Hofmann, Mortgage und Charge, S. 58.

${ }^{488}$ Hofmann, Mortgage und Charge, S. 146.

${ }^{489}$ McCormack, Registration of Company Charges, S. 50.

${ }^{490}$ M.w.N.: McCormack, Registration of Company Charges, S. 74.

${ }^{491}$ M.w.N.: Kieninger, Reform des Mobiliarsicherungsrechts, WM 2005, 2305 ff.; McCormack, Registration of Company Charges, S. 64 ff.

${ }^{492}$ Den Gesetzestexten des UCC (Uniform Commercial Code) liegt die Version von 2005 zugrunde.

${ }^{493}$ Article 1 - 103 (a) (1) UCC; speziell für Sicherungsrechte: Gilmore, S. 288.
} 
,$\S 9-109$ (a) ....., this article applies to: ... ... a transaction, regardless of its form, that creates a security interest in personal property or fixtures by contract ... ..."

In rechtsphilosophischer Hinsicht ist dies eine ausgezeichnete Idee, von der eigentlich jeder Sicherungsrechtler träumen, sie aber nicht auszusprechen vermag! Denn wenn man die vielfältigen Kreditsicherungssysteme der verschiedenen Rechtsordnungen ansieht, fragt man sich immer, warum so viele unterschiedliche Rechtsgestalten erforderliche sind, wenn das ökonomische Ziel der „Sicherung“"srechte immer das gleiche ist?

Nach Article 1 - 201 (35) UCC wird das ,security interest” lehrbuchartig allgemein definiert:

"Security interest" means an interest in personal property or fixtures which secures payment or performance of an obligation ${ }^{494}$. "Security interest" includes any interest of a consignor and a buyer of accounts, chattel paper, a payment intangible, or a promissory note in a transaction that is subject to Article 9. ......

Die Entstehungsvoraussetzungen eines besitzlosen „security interest“ (Regelfall) werden in Article 9 - 203 UCC geregelt, wonach der verfügungsberechtigte Schuldner (2) einen Sicherungsvertrag - sog. Security Agreement - (b 3 A $)^{495}$ mit dem Gläubiger schließen muss, der den Kredit auch valutiert (1). ${ }^{496}$

Im Hinblick auf die Bestimmtheit verlangt Article 9 - 203 (b) (3) (A) UCC, dass die Parteien eine Beschreibung des Sicherungsgegenstands (description of the collateral) in dem Sicherungsvertrag (security agreement) aufnehmen müssen. An dieser sowohl dogmatisch als auch technisch höchst heiklen Stelle kann es das amerikanische Sicherungsrecht nicht besser

\footnotetext{
${ }^{494}$ Diese Definition der Sicherheit zeigt, je mehr das amerikanische Recht mit Begriffen oder Normen arbeitet, desto mehr nähert sich sein Rechtsverständnis bzgl. der deutschrechtlichen Trennung zwischen Schuld- und Sachenrecht. Dies werden wir im Rahmen der „Abstraktheit“ noch deutlicher sehen.

495 Article 9 - 102 (73): "Security agreement" means an agreement that creates or provides for a security interest. M.E.: Wenn man Article 1 - 201 (35) und Article 9 - 102 (73) zusammen liest, kommt man strukturell nicht zu einem anderen Ergebnis als zur Trennung zwischen schuldrechtlicher Verpflichtung und dinglicher Sicherung; ob den amerikanischen Rechtswissenschaftlern diese auf Grund der begrifflichen bzw. pandektischen Denkweise entstandene Unterscheidung auch bewusst ist, ist eine andere Frage!!!

${ }^{496}$ White/Summers, Uniform Commercial Code, S. 97 ff.
} 
als sein Kollege im deutschen Recht. Dafür wie man den Sicherungsgegenstand beschreiben soll, bietet der Article 9 - 108 (a) und (b) UCC eine inhaltsleere Formel: ${ }^{497}$

„(a) ...... a description of personal or real property is sufficient, whether or not it is specific, if it reasonably identifies what is described.

(b) [Examples of reasonable identification.] ...... a description of collateral reasonably identifies the collateral if it identifies the collateral by:

(1) specific listing;

(2) category;

(4) quantity;

(5) computational or allocational formula or procedure; or

(6) ...... if the identity of the collateral is objectively determinable.

Mit dieser Formel steht der UCC nicht wirklich besser da als das verzweifelte deutsche Sicherungsrecht. Auch hier diskutieren die amerikanischen Sicherungsrechtler intensiv darüber, was „Sufficiency of Description“ (zu Deutsch: Bestimmtheit) ist. Ähnlich wie die deutschen Spruchkörper ${ }^{498}$ verlangen die US-Gerichte zwar nicht die präzise Individualisierung des Sicherungsgegenstands z.B. per Seriennummer; aber die Beschreibung muss es schon einem Dritten ermöglichen, das Sicherungsgut vernünftig zu identifizieren; ${ }^{499}$

\footnotetext{
${ }^{497}$ Vgl. White/Summers, Uniform Commercial Code, Vol. 4, S. 164 f.

${ }^{498}$ BGH WM 83, 1409: Die übereignete Sache muss im Übereignungsvertrag durch einfache äußere Merkmale so bestimmt bezeichnet sein, dass jeder Kenner des Vertrags sie zu dem Zeitpunkt, in dem das Eigentum übergehen soll, unschwer von anderen unterscheiden kann.

${ }^{499}$ Z.B. das US-Berufungsgericht für den 10. Bezirk (Mitchell v. Shepherd Mall State Bank, 458 F. 2d 700,703 $-10^{\text {th }}$ Cir. $\left.1972-\right)$ verlangt: ,in order for a security agreement to be effective it must contain language which specifically creates or grants a security interest in the collateral described“"
} 
Summa summarum unterscheiden sich die deutschen und amerikanischen Gerichte in ihrem Einzelfalllösungsweg bzgl. des Bestimmtheitsgrundsatzes kaum voneinander. ${ }^{500}$

Im Hinblick auf die Bestimmtheit bzgl. der Sicherungsgegenstände, die der Sicherungsgeber erst nach Abschluss des Sicherungsvertrags (security agreement) erwirbt (sog. ,,after-acquired property“), hat der UCC interessanterweise die ursprüngliche Blockadehaltung des amerikanischen Sicherungsrechts gegenüber der englischen „floating charge“ aufgegeben und die Erstreckung des Sicherungsvertrags darauf zugelassen.

\section{„§9-204. (a) [After-acquired collateral.]}

... ..., a security agreement may create or provide for a security interest in after-acquired collateral. “

Auch hier zeichnet sich die deutliche Tendenz ab, mit unklaren Termini wie z.B. „all inventory“ den Bestimmtheitsgrundsatz aufzulockern: „to enable the security interest to float on collateral. “501

Das fehlende Bewusstsein des amerikanischen (Sicherungs)Rechts von der Unterscheidung zwischen Schuld- und Sachenrecht führt zu einem problematischen Regelungskomplex von Sicherungssurrogationen, dessen Anwendungsbereich seit 1962 kontinuierlich erweitert worden ist. $^{502}$ Article 9 - 102 (a) (64) UCC definiert die Surrogation eines Sicherungsgutes (,Proceeds“) sehr allgemein:

„Proceeds, ....., means the following property:

(A) whatever is acquired upon the sale, lease, license, exchange, or other disposition of collateral; .......

(C) rights arising out of collateral;

\footnotetext{
${ }^{500}$ M.w.N. LoPucki/Warren, S. 151 ff.: Z.B. „all merchandise“ ist zu allgemein; „laundry equipment“ reicht hingegen aus.

${ }^{501}$ LoPucki/Warren, Secured Credit, S. 156.

${ }^{502}$ White/Summer, Uniform Commercial Code, Bd. 4, S. 202 f.
} 
(D) to the extent of the value of collateral, claims arising out of the loss, nonconformity, or interference with the use of, defects or infringement of rights in, or damage to, the collateral; or

(E) to the extent of the value of collateral and to the extent payable to the debtor or the secured party, insurance payable by reason of the loss or nonconformity of, defects or infringement of rights in, or damage to, the collateral. “

Anders als bei der vertraglichen Einbeziehung des ,after-acquired-property“ fingiert der Article 9 - 315 (a) (1) UCC ausdrücklich den Übergang des Sicherungsrechts auf die Surrogate, wenn der Sicherungsnehmer die Transaktion autorisiert hat; bei zweckwidriger Verfügung über den Sicherungsgegenstands dehnt sich das Sicherungsrecht über Article 9 102 (a) (12), (64) und 9 - 315 (a) UCC usätzlich auf das Surrogat aus. ${ }^{503}$ Der Hintergrund dieser Paragraphenkette ist Article 9 - 401 (b) und 9 - 320 (a) - zwei Normen, die mich in Erstaunen versetzen. Obwohl diese Vorschriften zum Thema „Abstraktion“ gehörten, müssen sie schon in diesem Zusammenhang erwähnt werden.

\section{„§9-401 (b) [Agreement does not prevent transfer.]}

An agreement between the debtor and secured party which prohibits a transfer of the debtor's rights in collateral or makes the transfer a default does not prevent the transfer from taking effect."

„\$ 9-320. (a) ... ..., a buyer in ordinary course of business, other than a person buying farm products from a person engaged in farming operations, takes free of a security interest created by the buyer's seller, even if the security interest is perfected and the buyer knows of its existence. “

Mit diesem der Anschauung des Alltagslebens entsprechenden Mechanismus (,tracing of the value of the collateral") wollen die Verfasser des UCC offensichtlich die Sicherungskraft des „security interest“ stärken. Infolge des Article 9 - 320 (a), der den handelsüblichen gutgläubigen Erwerb zulässt, hat der an sich gute Wille des Gesetzesgebers allerdings einen

\footnotetext{
${ }^{503}$ LoPucki/Warren, Secured Credit, S. 169.
} 
technischen Haken, nämlich: Das nach Article 9 - 102 (a) (12), (64) und 9 - 315 (a) UCC per se sowohl durch das originale Sicherungsgut als auch durch das Surrogat besicherte „security interest" besteht praktisch in der Konstellation des Article 9 - 320 (a) UCC nur in dem Surrogat. Bei Surrogaten stellt sich immer die Frage nach deren Identifizierbarkeit, die leider im UCC nur fragmentarisch geregelt ist, z.B. in:

\section{„§9-315 (a) (2) a security interest attaches to any identifiable proceeds of collateral."}

Die häufigsten und problematischsten Fälle sind die, in denen das Surrogat in Bargeld, Schecks oder Guthaben besteht. ${ }^{504}$ Für die Konstellation der Einzahlung auf ein Konto des Sicherungsgebers gilt die von der Rechtsprechung entwickelte Methode der „lowest intermediate balance“, die sich jetzt auch in Article $9-315$ (b) (2) wieder finden lässt. ${ }^{505}$ Für die anderen Konstellationen wie z.B. wenn der Sicherungsgeber das ersatzweise enthaltene Bargeld verpufft hat oder wenn der Erwerber nicht im guten Glauben war und das Sicherungsgut aber nicht mehr herauszufinden ist, bleibt der Sicherungsnehmer auf seinem „security interest“ sitzen. ${ }^{506}$

Zusammenfassend lässt sich in Bezug auf die Bestimmtheit auf Grund des immer steigernden Bedarfs der modernen Wirtschaft an flexiblem Kapitalmanagement die Tendenz feststellen, dass der Bestimmtheitsgrundsatz immer mehr zugunsten des Bestimmbarkeitskriteriums aufgelockert wird. Dadurch entstehen tote Winkel der rechtlichen oder tatsächlichen Art, die leider letztendlich nur durch Einzelfallentscheidungen gerettet werden können. Dies ist aber im Hinblick auf die von der Globalisierung verlangte flexible und effiziente Gestaltung des Kapitalflusses keine befriedigende Antwort und gefährdet damit die Friedensfunktion des Rechts.

\footnotetext{
${ }^{504}$ White/Summer, Uniform Commercial Code, Bd. 4, S. 204.

${ }^{505}$ White/Summer, Uniform Commercial Code, Bd. 4, S. 205: "lowest intermediate balance." Assume a secured creditor could prove the debtor had deposited $\$ 10,000$ of proceeds into its bank account. Assume also that thereafter the lowest balance in the account was $\$ 8,000$. In that case, the lowest intermediate balance fiction would treat the remaining $\$ 8,000$ as identifiable proceeds of the secured creditor.

${ }^{506}$ LoPucki/Warren, Secured Credit, S. 168.
} 
Die obige Auseinandersetzung lässt aber keine Lösung erkennen. Ganz im Gegenteil wirft sie mehr Fragen auf als Antworten. M.E. liegt der goldene Schlüssel nicht im, sondern außerhalb des Blickwinkels „Bestimmtheitsgrundsatz“.

\section{Die Publizität der Mobiliarsicherheiten}

Auch hinsichtlich der Publizität kann man die Übereignungsprinzipien in zwei Gruppen aufteilen. Nach dem reinen Konsensprinzip geht das Eigentum mit dem Vertragsschluss, also der Willenseinigung, über. Dafür ist kein Publizitätsakt erforderlich. Ganz im Geist des römischen Rechts ${ }^{507}$ verlangen die meisten kontinentaleuropäischen Rechtsordnungen im Gegensatz zu dem publizitätslosen Übereignungsmodell des Konsensprinzips die Übergabe (traditio) bzw. ein Übergabesurrogat als eines der Kernelemente des Übereignungsprinzips. ${ }^{508}$ Dieses Modell der publizierten Übereignung steht im Einklang mit dem Absolutheitsgrundsatz des Zuordnungsrechts, wonach die Veränderungen der jedermann gegenüber wirksamen dinglichen Rechtsstellungen um Rechtsklarheit und - sicherheit willen möglichst weitgehend nach außen hin offen gelegt werden sollen. ${ }^{509}$

Der Publizitätsgrundsatz gehört $\mathrm{zu}$ den von den neuen Gegebenheiten der Informationsgesellschaft und Globalisierung am stärksten betroffenen Fundamenten des Zuordnungsrechts, weil heutzutage die altehrwürdigen Werte Rechtssicherheit und -klarheit immer häufiger in Konflikt mit den Bedürfnissen des modernen Rechtsverkehrs nach Schnelligkeit, Flexibilität, Praktikabilität und Diskretion (d.h. Einschränkung der Informationspreisgabe über die Parteien des Rechtsgeschäfts) geraten.

Ein besonders geeigneter Zugang zu diesem sowohl in rechtpolitischer als auch in rechtstechnischer Hinsicht äußerst brisanten Problem findet man bei den Publizitätsmitteln des Mobiliarsicherungsrechts, da sich der wirtschaftliche Wert der Mobiliarsicherheit und das das Grundgeschäft begleitende Sicherungsverhältnis in einem dynamischen Umfeld befinden. Wie schon erwähnt, haben die Verfügungsprinzipien in ihren jeweiligen Einflussbereichen

\footnotetext{
${ }^{507}$ Kaser/Knütel, Römisches Privatrecht, § 24, S. 119 ff: Nach justinianischem Recht wurde das Eigentum (an Grundstücken und an beweglichen Sachen) durch Übergabe (traditio) übertragen.

508 s. Tabelle der Übereignungsmechanismen, C, I, 1.

${ }^{509}$ Seiler, Sachenrecht, S. 896.
} 
großen Einfluss auf die Rechtsentwicklung und -gestaltung. Dies gilt für die Mittel der Publizität aber nur auf technischer Ebene. In institutioneller Hinsicht ist das Offenkundigkeitsprinzip der absoluten Rechte als allgemein anerkannte Maxime noch viel essenzieller; es gibt praktisch einen der zentralen Normzwecke vor, an denen sich die unterschiedlichen Gestaltungen der verschiedenen Rechtsordnungen wegen des Bedürfnisses der gegenseitigen Anerkennung im internationalen Verkehr orientieren müssen.

\section{a) Deutschland}

\section{aa) Probleme des gegenwärtigen Publizitätsgrundsatzes}

\section{(1) Besitz als Publizitätsmittel}

Die Begründung einer Sicherheit durch Inbesitznahme der Pfandsache gehört zu den ältesten und geläufigsten Bestellungsarten. ${ }^{510}$ Wo das Offenkundigkeitsprinzip in Form des Traditionsprinzips herrscht, findet man seine Durchführung mit dem sog. Faustpfandrecht, bei dem der Besitz die Publizitätsfunktion übernimmt. ${ }^{511}$ Anders als viele europäische Rechtsordnungen, die neben dem Faustpfandrecht auch ein besitzloses Pfandrecht mit Hilfe eines Registers zulassen, betrachtete der deutsche historische Gesetzgeber das besitzlose (also geheime) Pfandrecht (Mobiliarhypothek) als Gefahr für den Rechtsverkehr ${ }^{512}$ und versuchte deswegen den Rechtsgedanken des Traditionsprinzips auch bei der Gestaltung des Fahrnispfandrechts konsequent durchzuführen. Um ein besitzloses Pfandrecht auszuschließen, verlangt § 1205 Abs. 1 BGB zur Bestellung des Pfandrechts an beweglichen Sachen, dass der Eigentümer die Sache dem Gläubiger übergibt; d.h. der Gläubiger muss den unmittelbaren Besitz erlangen. ${ }^{513}$ Die systematische Vorgehensweise des Gesetzgebers führt außerdem dazu, dass bei der Verpfändung einer Forderung der Gläubiger sie dem Schuldner anzeigt ( $\$ 1280$ BGB). Mit dem Erfordernis der Übergabe schoss der historische Gesetzgeber in systematischer Hinsicht ein wenig über das eigentliche Ziel hinaus. Denn damit werden beim Pfandrecht, das zu den beschränkten dinglichen Rechten zählt, höhere Anforderungen gestellt

\footnotetext{
510 M.w.N. Staudinger/Wiegand, Vorbem zu $§ § 1204$ ff. Rn. 3 ff.

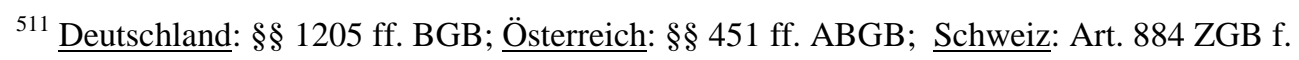

${ }^{512}$ Motive III S. 801, II S. 340

${ }^{513}$ Palandt, § 1205 Rn. 3; § 929 Rn. 12, 21.
} 
als etwa beim Vollrecht - Eigentum. ${ }^{514}$ Diese marginale Systemwidrigkeit führte im Laufe der Zeit $\mathrm{zu}$ erheblichen dogmatischen und praktischen Schwierigkeiten für das deutsche Mobiliarsicherungsrecht.

Offenbar sahen die BGB-Väter in der Gestaltung des Mobiliarpfandrechts in einer sog. „trade-off“-Konstellation zwischen der durch Inbesitznahme zu realisierenden Nutzung und dem Forderungsschutz. Um dies und die spätere Lösung dieses Problems besser zu verstehen ist es hilfsreich einige mikroökonomische Instrumente für Darstellungszwecke heranzuziehen.

Als das erste Grundprinzip der Wirtschaftswissenschaft hat N. Gregory Mankiw, derzeit einflussreichster Ökonom in den USA, in seinem Werk „Principles of Microeconomics“ die Knappheit der Ressourcen (people face trade-offs) genannt, also „There ist no such thing as a free lunch, ...... Making decisions requires trading off one goal against another." ${ }^{515}$ Man begegnet zwangsläufig diesem Problem überall dort, wo der menschliche Bedarf ins Spiel kommt, wie z.B. zwischen: Produktion und Konsum, Effizienz und Gerechtigkeit, Rechtssicherheit und Flexibilität, Effizienz etc. Anhand Mankiws Beispiel von Möglichkeiten der Produktion von Autos und Computer (s. Abb. 3) ${ }^{516}$ können wir die Bedeutung dieser Wirtschaftstheorie für die Analyse des Rechts viel besser begreifen. Wir nehmen an, dass alle (begrenzten) Ressourcen für die Produktion von Autos und Computern verwendet werden. Dann kann man im Idealfall maximal „1000 Autos und 0 Computer“ oder „,0 Auto und 3000 Computer“ produzieren. Zwischen den beiden Extrempositionen liegen Produktionsmöglichkeiten durch die Aufteilungen der Ressourcen.

\footnotetext{
${ }^{514}$ M.w.N.: Kneiff, Registerpfandrecht, S. 7; Hromadka, Faustpfandprinzip, S. 1.

${ }^{515}$ Mankiw, Principles of Economics, S. 2.

${ }^{516}$ Mankiw, Principles of Economics, S. 23, 25
} 
Abb. 2 - Transformationskurve der Produktionsmöglichkeiten ${ }^{517}$

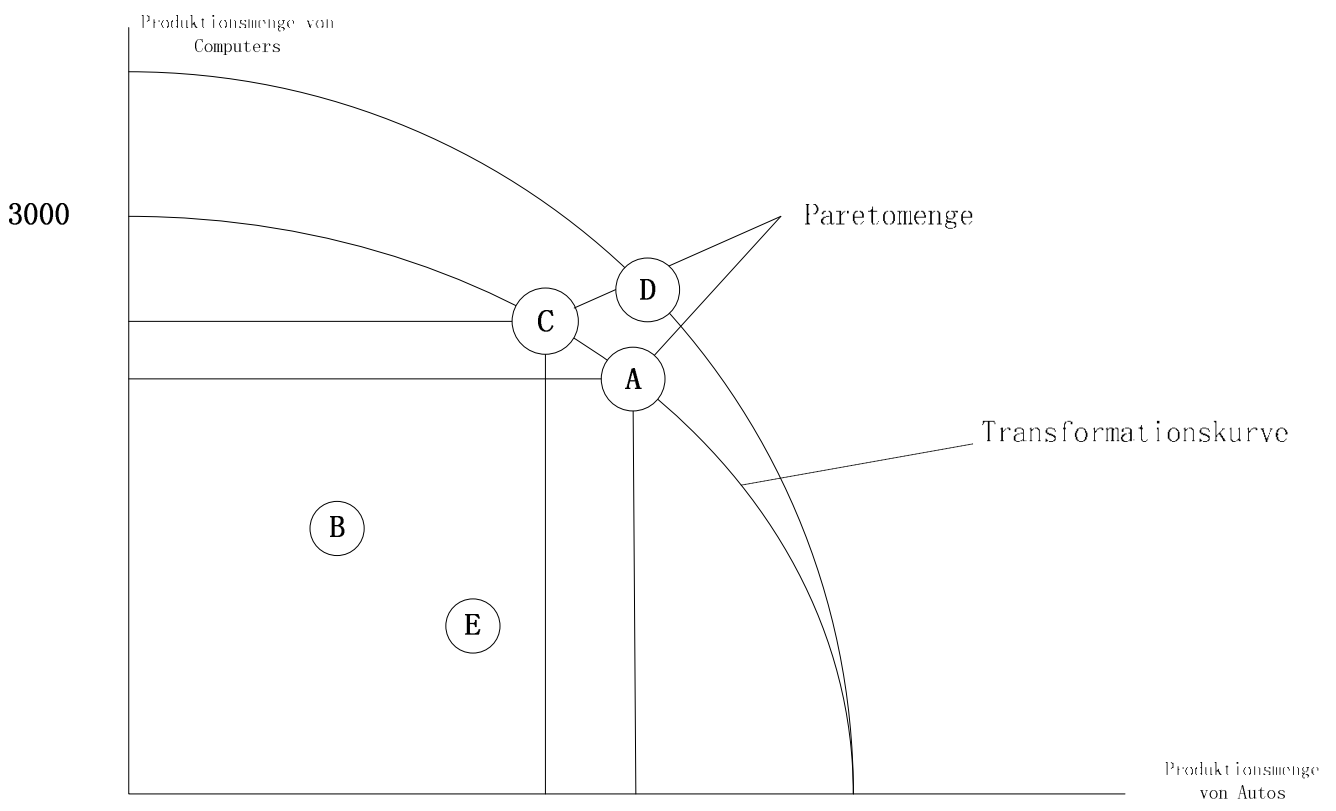

Das vorher im Zusammenhang der sozialen Gerechtigkeit erörterte Paretokriterium kann man sehr gut anhand der Transformationskurve veranschaulichen. Effizient ist eine Produktion, wenn sich ihre Erzeugnisse auf der Kurve befinden, wie z.B. die Punkte A, C etc; d.h. also wenn die Steigerung der Anzahl eines Produktes (z.B. Computer) nur durch Senkung der Anzahl des anderen (z.B. Autos) erreicht werden kann.

Die wichtigste Schlussfolgerung, die man aus der Transformationskurve ziehen kann, ist: Eine Produktion außerhalb der Kurve (Punkt D) ist unter der unveränderten Bedingung der Ressourcenknappheit nicht möglich. ${ }^{518}$

\footnotetext{
${ }^{517}$ Mankiw, Principles of Economics, S. 23, 25; Varian, Mikroökonomik, S. 591: Die Transformationskurve gibt die mögliche Menge an Outputs bei gegebener Technologie und gegebenen Inputmengen an. Die Form der Transformationskurve hängt vor der Art der zu Grunde liegenden Technologien ab.
} 
Im Gegensatz dazu sind Produktionen innerhalb der Kurve (Punkt B oder E) nicht nur möglich, sondern der Regelfall. Eine Produktion innerhalb der Kurve bedeutet Effizienzverluste, die vielfältige Ursachen, wie etwa fehlgeschlagene Forschungsversuche, Energieverluste, Ausfälle der Arbeitskräfte wegen Krankheit etc., haben können. Der wichtigste zu den Effizienzverlusten führende Faktor besteht in den Tranksaktionskosten, also z.B. den Kosten für die Informationssuche, Verhandlung, Kontrolle der die Produktion koordinierenden Verträge usw. Wenn man sich die Schwierigkeit der Messbarkeitsproblems oder der Begriffsvereinheitlichung der Transaktionskosten vergegenwärtigen möchte, muss man nur einen Blick auf den Bereich innerhalb der Kurve werfen.

Die Transformationskurve bietet nur eine Momentaufnahme der Produktion, also das Paretokriterium.

Trotz der Bedingung der Ressourcenknappheit ist eine Produktion außerhalb der Kurve (d.h. das Kaldor-Hicks-Kriterium) wünschenswert, und diese kann nur mittels einer Steigerung der Effizienz bzw. Senkung der Transaktionskosten erreicht werden.

In Abb. 2 ist zu sehen, dass die Produktivität durch die technologische Weiterentwicklung der Computerindustrie gestiegen ist und sich die Transformationskurve nach außen bewegt. Im Ergebnis kann die Gesellschaft sowohl mehr Computer als auch mehr Autos genießen. Auch bei der Gestaltung des (Kreditsicherungs)Rechts herrscht Ressourcenknappheit (vor allem bzgl. des Wertes der Sicherungsgegenstände) und mit der „Tradeoff-Situation“ konfrontiert man insbesondere beim Bestimmen das Verhältnis zwischen Verkehrs- und Bestandschutz, als dessen Subprobleme die Ermittlungen der bestmöglichen Handhabungen der Rechtsprinzipien bzgl. Publizität, Bestimmtheit, Forderungsgebundenheit etc. in Erwägung gezogen werden müssen. Auf Einzelheiten wollen wir nicht eingehen, und als wichtigste Erkenntnis reicht an dieser Stelle vorerst das, dass man trotz Ressourcenknappheit durch Einsatz von Effizienz fördernden (technischen) Mitteln oder durch effektive Umgestaltung der Produktionsstrukturen mehr Erzeugnisse erwirtschaften kann.

${ }^{518}$ Was für Bedeutungen diese Schlussfolgerung für die Rechtsgestaltung haben kann, s. C, IV, 4, d), cc), (2). 
Warum die Väter des BGB das Faustpfandrecht (Besitzpfandrecht) in Form des $§ 1205$ I BGB gewählt haben, ist nicht ganz klar und auch nicht überzeugend begründet worden. Eines kann man mit Sicherheit ausschließen, dass ihnen die rechtliche Konstruktion des besitzlosen Pfandrechts unbekannt war. ${ }^{519}$ Die historischen Quellen der BGB-Gesetzgebung und die Literatur über die Entstehung des Faustpfandrechts gewähren nur einen unvollständigen Einblick. Ursprünglich (auch heute noch) dient das Faustpfandrecht dazu, dem Gläubiger Schutz vor Beschädigung, Verschlechterung des Haftungsgegenstandes oder Verwertungsschwierigkeiten in ganz direkter Weise zu gewähren, nämlich indem er die tatsächliche Sachgewalt über das Pfand erhält (,trade-off“ zwischen Gläubigerschutz und Besitz). ${ }^{520}$ Indem es die verpfändete Sache aus dem sichtbaren Vermögen des Schuldners herausnimmt, schützt das Faustpfand außerdem noch den Drittgläubiger oder potentiellen zweiten Pfandnehmer vor dem Erwerb und der Pfandnahme einer belasteten Sache. ${ }^{521}$ Diese Funktion verliert durch die Anerkennung des Pfandrechts als Recht und den Ausbau des Verfahrensrechts immer mehr an Bedeutung.

Eine genauere Auseinandersetzung mit Wert oder Unwert des Faustpfandprinzips fand innerhalb der Kommission leider nicht statt. Dementsprechend hagelte es vor und nach dem Inkrafttreten des BGB Kritik an dem Faustpfandrecht aus allen Richtungen. ${ }^{522}$ Rechtspolitisch wurde dem Faustpfandrecht vorgeworfen, dass es den Besitzbürger bevorzuge. ${ }^{523}$ Nur dieser sei in der Lage, eine Sache zu verpfänden, indem er sie aus seinem Besitz weggebe. ${ }^{524}$ Müsse

\footnotetext{
${ }^{519}$ Melscheimer, Sicherungsübereignung oder Registerpfandrecht - eine politologische Studie, S. 15: Schon auf dem 15. Deutschen Juristentag im Jahr 1880 erörterte man die Frage, inwieweit eine Übereignung mittels constitutum possessorium zu Sicherungszwecken als Umgehung des Faustpfandprinzips anzusehen sei. Der Berichterstatter, der den Gutachten zustimmte, dass das Faustpfand in keiner Weise geeignet sei, den modernen Kreditbedürfnissen zu entsprechen, glaubte daher, die Existenzberechtigung der Sicherungsübereignung nicht verneinen zu dürfen.

${ }^{520}$ Protokolle III S. 4168 ff.; Kaser/Knütel, Römisches Privatrecht, § 250 III, S. 227 f.

${ }^{521}$ Motive III, S. 801; Protokolle II, S. 364.

${ }^{522}$ Leonhard, Beseitigung der Verpfändung beweglicher Sachen, S. 219; Leist, Sicherungsübereignung, S. 8; Gierke, Entwurf des BGB, S. 389; Wieacker, Privatrechtsgeschichte, S. 383; Hromadka, Faustpfandprinzip, S. 140; Weber, Kreditsicherungsrecht, S. 164.

${ }^{523}$ Heftigste Kritik (Hromadka, Faustpfandprinzip, S. 140): ,der Gesetzgeber, der Adelige ... . ... möglicherweise selbst Geld ausleiht und auf Sicherheit bedacht ist, den entscheidenden Einfluss auf die Gesetzgebung auszuüben."

${ }^{524}$ Weber, Kreditsicherungsrecht, S. 164.
} 
der Kreditnehmer die finanzierten Sachen herausgeben, um den Kredit zu bekommen, bedürfe es des Kredits erst gar nicht. ${ }^{525}$ Der kleine Mann, der auf seine Produktions- oder Lebensunterhaltungsmittel angewiesen sei, werde praktisch vom Kreditmarkt ausgeschlossen, oder er müsse zu hohen Zinsen einen Personalkredit aufnehmen. ${ }^{526}$ Selbst aus Sicht des Gläubigers ist das Faustpfandrecht nicht immer vorteilhaft, weil ihn gem. § 1215 BGB die Verwahrungspflicht trifft, was Arbeit und Verantwortung bedeutet.

Aus Sicht der ökonomischen Analyse des Rechts meinen die vorstehenden Argumente gegen das Faustpfandrecht den Verstoß gegen das Ertragsgesetz und das Gesetz des abnehmenden Grenznutzens, welche in engem Zusammenhang mit dem die Produktionsergebnisse bewertenden Kaldor-Hicks-Kriterium stehen.

Abb.3 - Klassisches Ertragsgesetz ${ }^{527}$

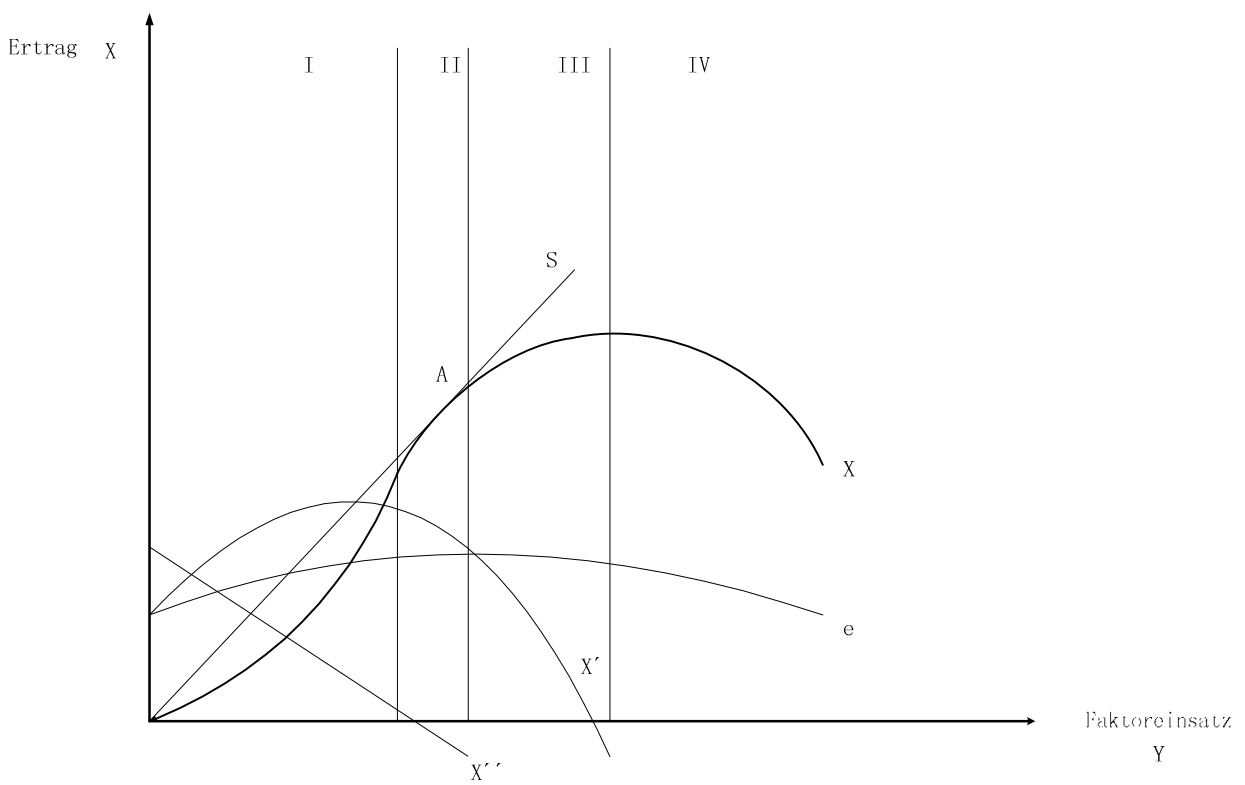

\footnotetext{
${ }^{525}$ Bülow, Kreditsicherheiten, Rn. 467 ff.

${ }^{526}$ Leonhard, Beseitigung der Verpfändung beweglicher Sachen, S. 219.

${ }^{527}$ Abbildung von Bloech u.a., Produktion, S. 24.
} 
Abb. 3 beschreibt die sog. partielle Faktorvariation, bei der ein Produktionsfaktor variiert wird, während alle anderen konstant gehalten werden. ${ }^{528}$ Hier kann man deutlich die vier Bereiche der Ertragssituation erkennen: ${ }^{529}$

\begin{tabular}{|c|c|c|c|c|c|}
\hline Bereich & $\begin{array}{l}\text { Gesamtertrag } \\
\text { (X) }\end{array}$ & $\begin{array}{l}\text { Durchschnittsertrag } \\
\text { e }\end{array}$ & $\begin{array}{l}\text { Grenzertrag } \\
X^{\prime}\end{array}$ & $\begin{array}{l}\text { Steigungsmaß der } \\
\text { Grenzertragskurve } \\
X^{\prime \prime}\end{array}$ & Endpunkte \\
\hline I & $\begin{array}{l}\text { positiv, } \\
\text { progressiv steigend }\end{array}$ & $\begin{array}{l}\text { positiv, degressiv } \\
\text { steigend }\end{array}$ & $\begin{array}{l}\text { positiv, degressiv } \\
\text { steigend bis Max. }\end{array}$ & $\begin{array}{l}\text { positiv, konstant } \\
\text { fallend bis Null }\end{array}$ & $\begin{array}{l}\text { Wendepunkt } \\
X^{\prime}=\text { max. } \\
X^{\prime \prime}=0\end{array}$ \\
\hline II & $\begin{array}{l}\text { positiv, degressiv } \\
\text { steigend }\end{array}$ & $\begin{array}{l}\text { positiv, degressiv } \\
\text { steigend bis Max. }\end{array}$ & $\begin{array}{l}\text { Positiv, progressiv } \\
\text { fallend } X^{\prime}>\mathrm{e}\end{array}$ & $\begin{array}{l}\text { negativ, konstant } \\
\text { fallend }\end{array}$ & $\begin{array}{l}\mathrm{e}=\max \\
\mathrm{e}=\mathrm{X}^{\prime} \\
\mathrm{E}^{\prime}=0\end{array}$ \\
\hline III & $\begin{array}{l}\text { positiv, degressiv } \\
\text { steigend }\end{array}$ & $\begin{array}{l}\text { positiv, progressiv } \\
\text { fallend }\end{array}$ & $\begin{array}{l}\text { positiv, progressiv } \\
\text { fallend bis Null } \\
\mathrm{X}^{\prime}<\mathrm{e}\end{array}$ & $\begin{array}{l}\text { negativ, konstant } \\
\text { fallend }\end{array}$ & $\begin{array}{l}X=\max \\
X^{\prime}=0\end{array}$ \\
\hline IV & $\begin{array}{l}\text { positiv, progressiv } \\
\text { fallend }\end{array}$ & $\begin{array}{l}\text { positiv, progressiv } \\
\text { fallend }\end{array}$ & $\begin{array}{l}\text { negativ, progressiv } \\
\text { fallend }\end{array}$ & $\begin{array}{l}\text { negativ, konstant } \\
\text { fallend }\end{array}$ & - \\
\hline
\end{tabular}

Die Gesamtertragskurve zeigt, dass es so etwas wie einen „optimalen Faktoreinsatz“ im Sinne von maximalem Ertrag je eingesetzten Faktor gibt, nämlich im Bereich II, genauer gesagt auf Punkt A (Maximum der Grenzproduktivität).

Abb. 4 - Gesetz des abnehmenden Grenznutzens ${ }^{530}$

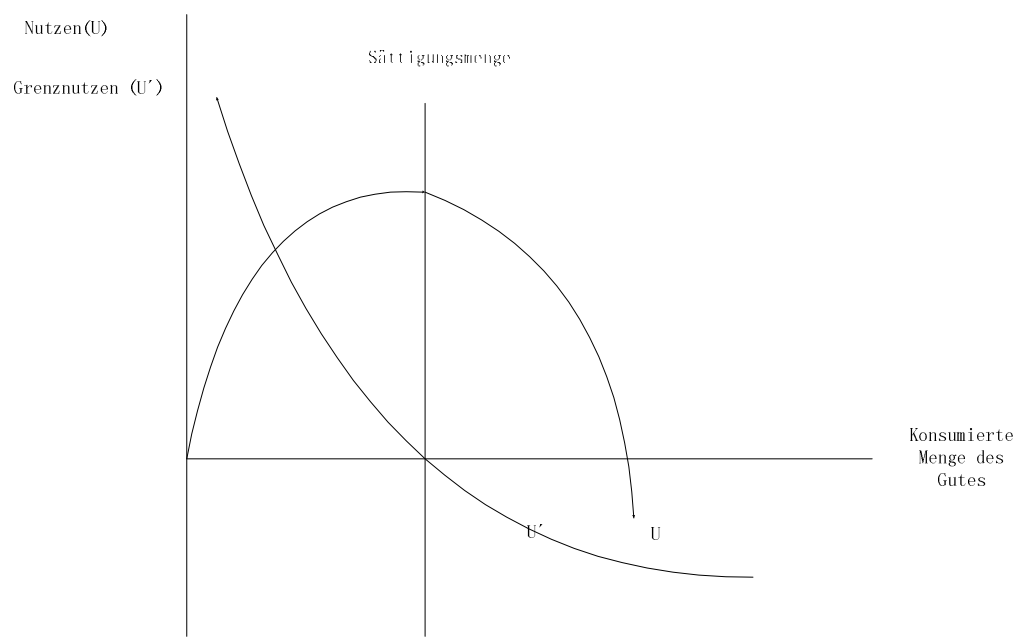

\footnotetext{
${ }^{528}$ Bloech, Produktion, S. 22 f.: „Obwohl das Ertragsgesetz für den landwirtschaftlichen Bereich entwickelt wurde, eignet es sich prinzipiell auch zur Analyse von Fragestellungen in anderen Bereichen.“; Beispiel: Auf mehreren Feldern wurde nur die Menge des Saatgutes variiert, und alle anderen Faktoren wie etwa Feldgröße, Düngereinsatz etc. wurden konstant gehalten.

${ }^{529}$ Tabelle von Bloech, Produktion, S. 26.

${ }^{530}$ Zum Zweck der kommenden Rechtsanalyse können Nutzen und Grenznutzen hier im Gegensatz zur Standardabbildung des ersten Gossenschen Gesetzes in der Mikroökonomie auch im Minusbereich sein.
} 
Das Gesetz des abnehmenden Grenznutzens besagt, dass der Nutzen, den ein Gut dem Subjekt stiftet, mit jeder zusätzlich konsumierten Einheit ständig abnimmt, bis Sättigung eintritt. ${ }^{531}$ Dieser zusätzlich gestiftete Nutzen wird auch Grenznutzen genannt.

Als wichtigste Erkenntnisse sollten wir hier zum einen festhalten, dass es auch so etwas wie einen „optimalen Verbrauch“ im Sinne von maximalem Nutzen je Konsumeinheit gibt, zum anderen, dass exzessiver Verbrauch schädlich sein kann.

Die Handhabung der Publizität des BGB im Faustpfandrecht verstößt meiner Meinung nach das Ertragsgesetz: Wenn man den Publizitätsgrundsatz genauer unter die Lupe nimmt, dann scheint dies aber nicht zwingend. Allgemein wird die Publizität der Offenkundigkeit gleichgesetzt; dabei ist auch immer von der Erkennbarkeit der dinglichen Rechtslage die Rede. ${ }^{532}$ Scheinbar logischerweise kommt man beim Pfandrecht zu der Lösung der Wegnahme des unmittelbaren Besitzes vom Verpfänder, damit er „erkennbar“ nicht mehr zur Doppelverpfändung oder Veräußerung in der Lage sein kann. Genau hier ist höchste Aufmerksamkeit geboten. Die drei Begriffe „Publizität, Offenkundigkeit und Erkennbarkeit“" stehen beim Mobiliarpfandrecht nicht auf gleicher Ebene. Hier sollte man die Unterbegriffe der Publizität - die Offenkundigkeit und Erkennbarkeit - so verstehen, dass die Offenkundigkeit (also die positive Publizität) die absolute dingliche Rechtslage gegenüber jedermann demonstriert, und die Erkennbarkeit (die negative Publizität) den Drittgläubiger oder den potenziellen Erwerber vor unbefugter Verfügung schützt, weil der Verpfänder die Sache nicht vorzeigen kann. ${ }^{533}$ Die negative Publizität nimmt dem Verpfänder mit dem unmittelbaren Besitz auch die Nutzungsmöglichkeit, auf die (z.B. Kraftfahrzeuge eines Transportunternehmens, Warenlager eines Ladens - sog. Betriebsmittel usw.) der „kleine Mann“ aber nicht verzichten kann; sie schließt ihn damit aus dem Realkreditmarkt aus.

Rechtstechnisch kann der Besitz auch keine hundertprozentige Sicherheit für den Drittgläubiger bieten. Denn niemand darf sich darauf verlassen, dass alle im Besitz des

\footnotetext{
${ }^{531}$ Varian, Mikroökonomik, S. 52 f.

${ }^{532}$ Baur/Stürner, Sachenrecht, § 4 II; Wolf, Sachenrecht, Rn. 25.

${ }^{533}$ Melsheimer, Sicherungsübereignung oder Registerpfandrecht - eine politologische Studie, S. 4; Hromadka, Faustpfandprinzip, S. 10.
} 
Schuldners befindlichen Sachen diesem auch gehören. ${ }^{534}$ Trotzdem werden beim Pfandrecht Anforderungen an die Übergabe gestellt, die noch strenger sind als bei der Übereignung. ${ }^{535}$

Die vom Gesetz verordnete Publizität der Verpfändung, egal ob durch Besitz oder Anzeige, stört die Dispositionen des Kreditschuldners. ${ }^{536}$ Das wahre Wirtschaftsleben lässt sich aber nicht von der Wunschvorstellung des historischen Gesetzgebers aufhalten.

„Das wirtschaftliche Bedürfnis nach einem Kreditsicherungsmittel ohne Besitzübertragung jedenfalls war stärker als alle Bedenken begriffjuristischer Konstruktion. “537

Infolgedessen hat die Kautelarjurisprudenz schnell Möglichkeiten gefunden, die lästige Publizitätsanforderung des BGB zu umgehen, und schuf mit Hilfe des Abstraktionsprinzips und der Vertragsfreiheit neue Sicherungsinstrumente, nämlich die Sicherungsübereignung und Sicherungsabtretung. Mit dem Modell der Vollrechtsübertragung zum Sicherungszweck ist ein neuer Typus dinglicher Sicherheiten entstanden, der anders ist als das gesetzlich vorgesehene Modell - „,beschränktes dingliches“ Recht. Damit ist im Grunde genommen ein Tabu des kontinentaleuropäischen Sachenrechts gebrochen, nämlich der numerus clausus und damit letztendlich der Absolutheitsgrundsatz.

Diese durch das Abstraktionsprinzip ermöglichte Systemwidrigkeit trifft das dogmatische Herz des deutschen Pandektensystems besonders hart: Man fragt sich, wo ist nun die durch das Trennungsprinzip definierte Grenze zwischen Schuld- und Sachenrecht? Und wo ist die Grenze der Privatautonomie? Mit welchen Konstruktionen kann man das bedrohliche Entfaltungspotenzial der bisher nicht allgemein erkannten selbstzerstörerischen Seite des

\footnotetext{
${ }^{534}$ Hromadka, Faustpfandprinzip, S. 188.

${ }^{535}$ Baur/Stürner, Sachenrecht, § 55 A I 3 b.

${ }^{536}$ Bülow, Kreditsicherheiten, Rn. 1092.

${ }^{537}$ Melsheimer, Sicherungsübereignung oder Registerpfandrecht - eine politologische Studie, S. 5.
} 


\begin{tabular}{|l} 
Abstraktionsprinzips entschärfen und das Pandektensystem dogmatisch wieder \\
harmonisieren?
\end{tabular}

Eine überzeugende Antwort auf die Frage, warum der Wächter des BGB (also das RG) nach anfänglichem Zögern die Sicherungstreuhand doch akzeptiert hat, ${ }^{539}$ ist in der juristischen Literatur nicht $\mathrm{zu}$ finden. Wenn man die Argumente für die Zulässigkeit der Sicherungstreuhand ansieht, findet man den besten Beweis dafür, dass jede Rechtsordnung versucht, ihr eigenes System logisch abgrunden. Man versucht die Zulässigkeit der Sicherungstreuhand mit folgenden Argumenten zu begründen:

- (kein Institutionsmissbrauch) ..... ist die Übereignung ...... abstrahiert, sofern ihre Voraussetzungen vollständig eingehalten werden, haben die Handelnden Anspruch auf Anerkennung durch die Rechtsordnung. ...... Hat das Gesetz das besitzlose oder sonst publizitätslose Pfandrecht nicht vorgesehen, so ist es doch nicht ausgeschlossen, andere Rechtsformen für Kreditsicherungszwecke $\mathrm{zu}$ verwenden, wenn nur deren Anforderungen (gemeint ist das Abstraktionsprinzip) erfüllt sind. ${ }^{540}$

- (gesetzlicher Hinweis) In $\S 216$ II (früher: $§ 223$ II) ...., ein Recht zur Sicherung eines Anspruchs zu übertragen, vorausgesetzt. ..... Damit ist nicht ausdrücklich die Sicherungsübereignung durch Besitzkonstitut gem. § 930 anerkannt, ..... aber auch nicht ausdrücklich untersagt worden. Die Rspr. hätte in den Fällen des $§ 216$ II in analoger Anwendung des $\S 1205$ das Besitzkonstitut für unzulässig erklären können, ...... dies hat sie nicht getan.

${ }^{538}$ Die Lösung dieser Systemunvollkommenheit erfordert tiefe Eingriff in das gegenwärtige System, weil sie alle Eckpfeile des deutschen Sachenrechts tangiert, s. vor allem: zur Problembeschreibung - C, III, 2, c) und d) / D, I, 1, c) / D, I, 2, a), aa), 2) / D, II, 2, a), aa), (2); zur Problemlösung - D, II, 2, b) und 3.

${ }^{539}$ Wiegand, Staudinger Anh. zu $\S \S 929$ ff, Rn. 52 f.: (1) Unmittelbar nach Erlass des BGB wurde die Sicherungsübereignung als unzulässig angesehen, weil sie mit dem Faustpfandprinzip unvereinbar sei; (2) Nach eher marginalen Bemerkungen in RGZ 5, 181 hat das Reichsgericht in RGZ 13, 200 seinen Standpunkt grundlegend fixiert: „... die rechtliche Möglichkeit eines in dieser Weise bedingten constitutum possessorium ist nicht zu beanstanden ...“(3) Die Bedenken gegen die Zulässigkeit der Sicherungsübereignung sind seitdem praktisch verstummt; sie wurde allgemein als Ergebnis richterlicher Rechtsfortbildung anerkannt und zunehmend als Gewohnheitsrecht betrachtet.

${ }^{540}$ Bülow, Kreditsicherheiten, Rn. 1100. 
Obwohl die vorstehenden Argumente auf gar keinen Fall überzeugend sind, gibt es aber für solche Fälle bedauerlicherweise oft kein handfestes institutionelles Sanktionsmittel. ${ }^{541}$ Das Problem der Gesetzesumgehung war den römischen Juristen schon bekannt; die methodische Grenze zwischen Gesetzesumgehung und Gesetzesauslegung war und ist aber immer noch fließend!

„Das Gesetz umgeht, wer ohne Verstoß gegen den Wortlaut des Gesetzes den $\underline{\text { Sinn }}$ des Gesetzes hintergeht (Contra legem facit, qui id facit quod lex prohibet; in fraudem vero, qui salvis verbis legis sententiam eius circumvenit, Paul. Dig. 1, 3, 29, ähnlich Ulp. Dig. 1,3, 30) “542

Der eigentliche Grund für die gegenwärtige Rechtslage bzgl. der abstrakten Fahrnissicherheiten dürfte ein wirtschaftlicher sein, nämlich der durch die negative Publizität herbeigeführte Effizienzverlust bei den gesetzlich vorgesehenen Sicherheiten. Wie bei der Ökonomischen Analyse des Rechts schon erwähnt: Die effizientere Institution gewinnt den Kampf, und es ist nicht selbstverständlich, dass sich die Parteien immer für den Weg der „Absicherung des Geschäfts durch das Rechtssystem“ entscheiden; Die in Betracht kommenden Institutionen dürfen nicht mehr Transaktionskosten verschlingen als die Risikoprämie; Wer diese rote Linie überschreitet, wird von einem rationalen Entscheider gar nicht als Handlungsoption wahrgenommen. ${ }^{543}$ Unter dem Druck der Institutionenökonomik knickte die deutsche Judikatur als erster ein, und anschließend kapitulierte auch die machtlose Lehre vor der dogmatisch unsauberen Sicherungstreuhand. ${ }^{544}$

Meines Erachtens ist die publizitätslose Sicherheit, gerade im deutschen Recht, ein Verrat an sich selbst. Denn wegen des fehlenden logischen Gegenstücks - der

\footnotetext{
${ }^{541}$ Die entscheidende Frage ist, ob die einvernehmliche systemwidrige (aus Sicht des historischen Gesetzgebers) Auslegung durch die Juristen als Gesetzesumgehung oder Rechtsfortbildung zu werten ist. Wer entscheidet über diese Frage? Die Juristen selbst. Um die Tradition der Kodifikation und die dahinter stehenden Ideen zu wahren, müssen sie ihre Meinung ebenfalls durch Kodifikation äußern. In diesem Sinne ist der Weg des Gewohnheitsrechts suboptimal!

${ }^{542}$ Medicus, BGB-AT, Rn. 660.

${ }^{543}$ Entscheidungstheoretische Hintergründe s. D, II, 2, a), aa) und bb).

${ }^{544}$ M.w.N.: Wiegand, Staudinger Anh. Zu $§ 929$ ff, Rn. 52 f.:
} 
„äußeren“ Kundbarmachung - löst sich das von den Vätern des BGB mit höchster Weitsicht und Vorsicht designierte Dogma, nämlich die scharfe Betonung des „,inneren“ „Einigseins“ des Vollzugsgeschäfts, in Luft auf, und zwar mit verheerenden Folgen.

Für das deutsche Mobiliarsicherungsrecht geht es deshalb im Kern also darum, befriedigende Formen der Kreditsicherung $\mathrm{zu}$ finden und $\mathrm{zu}$ kodifizieren, die sowohl das (bisher vom historischen Gesetzgeber einseitig geschützte) Sicherungsinteresse des Gläubigers als auch den Bedarf des Schuldners nach Nutzungsmöglichkeit und Diskretion zufrieden stellen. Nur so ist die absurde Diskrepanz zwischen den gesetzlich geregelten und tatsächlich angewendeten Sicherungstypen zu beseitigen.

Die gezwungene logische Abrundung des publizitätslosen besitzlosen Mobiliarpfandrechts kann das Gewohnheitsrecht als seinen Existenzgrund zwar innerhalb Deutschlands präsentieren. Die Entgleisung aus dem Offenkundigkeitsprinzip wird jedoch im Internationalen Kontext hart bestraft. Die deutsche Sicherungsübereignung steht mit ihrer Publizitätslosigkeit international isoliert da und führt dazu, dass der Sicherungsnehmer seine Sicherheit verliert, sobald das Sicherungsgut die deutsche Grenze überschreitet. ${ }^{545}$

\section{(2) Publizitätslosigkeit in Deutschland}

In Deutschland führt der strenge Zivilcode zur Entstehung zahlreicher geheimer Sicherungsrechte außerhalb der Kodifikation. Wertungswidersprüche in solchen Konstellationen sind vorprogrammiert; die Konsequenz ist der herbe Verlust von Rechtssicherheit, Effizienz und Sicherungskraft. ${ }^{546}$ Insoweit darf ich auf die vorangegangenen Ausführungen verweisen. Insgesamt dürfte man sagen, dass die gegenwärtige Publizitätslosigkeit des deutschen Kreditsicherungsrechts vor dem Hintergrund der globalisierten Marktwirtschaft nicht mehr hinzunehmen ist. Eine Gesamtrevision und Neupositionierung der Externalisierung des sicherungsrechtlichen Verhältnisses ist daher dringend erforderlich.

\footnotetext{
${ }^{545}$ m.w.N.: Kieninger, Reform des Mobiliarsicherungsrechts, WM 2005, 2305 ff., 2305.

${ }^{546}$ Bekannt war dieses Defizit schon sehr lange; geändert ist die Rechtslage bis heute noch nicht: Feilner, Sicherungsübereignung oder Registerpfand?, S. 69: in den 20er Jahren war man schon der Meinung - ,... Sicherungsübereignungen leicht zu missbräuchlichen oder gar zu betrügerischen Handlungen des Übereigners, wie auch des sicherungsnehmers führen können. ..."; Hellmund, Sicherungsübereignung und Registerpfandrecht, S. $52 \mathrm{ff}$.
} 


\section{bb) Register als Publizitätsmittel und Die große Diskussion in den 20er Jahren}

Nach einer nicht neuen, aber im Vordringen befindlichen Meinung soll das unbefriedigende Ergebnis der Kodifikation der Fahrnissicherheiten durch die Einführung des international gängigen Registerpfandrechts korrigiert werden, ${ }^{547}$ Ein Pfandregister soll also die Funktion der negativen Publizität übernehmen. Zurzeit brodeln sowohl auf nationaler als auch internationaler Ebene Reformbewegungen in Richtung der Registrierung der Mobiliarsicherheiten. ${ }^{548}$ In Osteuropa ist das Registerpfandrecht schon reihenweise eingeführt. $^{549} \mathrm{Ob}$ dies der richtige und gangbare Weg für die Harmonisierung des Interessenkonflikts zwischen Gläubiger und Schuldner ist, werden wir im Folgenden untersuchen. Dabei ist es von entscheidender Bedeutung, dass neben der Befriedigung der wirtschaftlichen Bedürfnisse nach Freisetzung der Werte des Mobiliars und Gewährleistung der Verkehrssicherheit zugleich die dogmatische Systemfolgerichtigkeit sichergestellt wird.

Seit dem Inkrafttreten des BGB vor mehr als hundert Jahren ist die Reform der Mobiliarsicherheiten nicht nur zu einem Standardthema der Juristentage geworden, sie bildet auch den Gegenstand zahlreicher Monographien und Stellungnahmen. ${ }^{550}$ Bislang haben solche Diskussionen trotz großer Bemühungen nicht gefruchtet. Die obige Erörterung bzgl. des Faustpfandrechts kann man durchaus als dogmatische, ideelle und deswegen akademische Auseinandersetzung bezeichnen, die alleine keine ausreichende Begründung für eine tiefgehende systemische Revision der Kreditsicherungsinstitution hierzulande bietet. Vielmehr muss man die komplexe Interessenlage des Kreditsicherungsgeschäftes richtig verstehen. Dies stellt eine der unerlässlichen Grundbedingungen für die Vermeidung ewig zirkulierender fruchtloser Reformdiskussionen dar.

\footnotetext{
${ }^{547}$ Schon während des Gesetzgebungsverfahrens wurde um das richtige Konzept für die Mobiliarsicherheiten heftig gerungen (m.w.N.: Kneiff, Registerpfandrecht, S. 6, 8 ff; Wiegand, Staudinger Anh. zu §§ 929 ff., Rn. 34 ff.). In den 30er Jahren erschienen zahlreiche Dissertationen und Beiträge, die sich für ein Registerpfandrecht aussprachen. Vor dem Hintergrund der Globalisierung ist diese Forderung immer lauter geworden (Kieninger, Reform des Mobiliarsicherungsrechts, WM 2005, 2305, 2307; 2353, 2358).

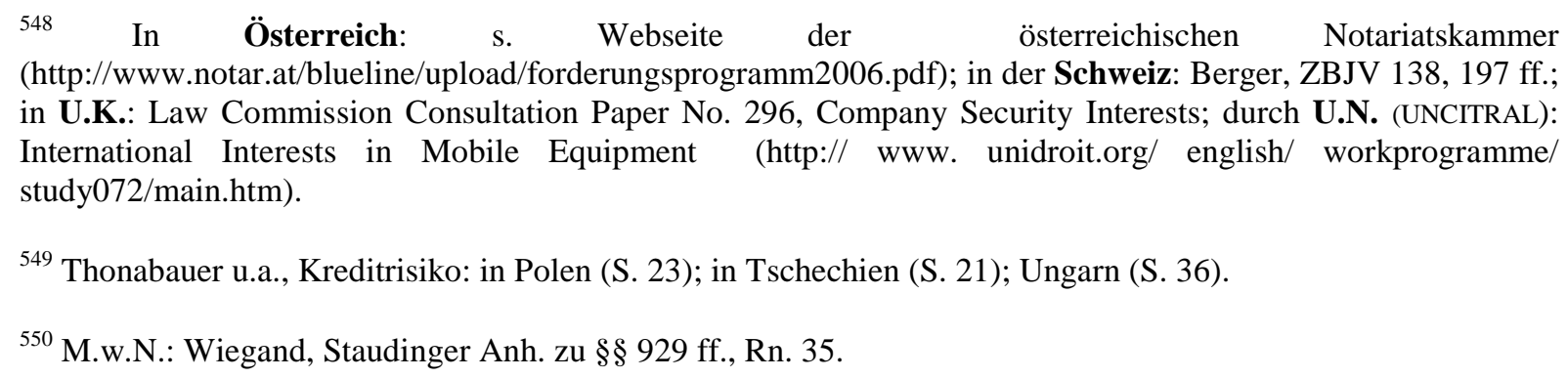
(http://www.notar.at/blueline/upload/forderungsprogramm2006.pdf); in der Schweiz: Berger, ZBJV 138, 197 ff.; in U.K.: Law Commission Consultation Paper No. 296, Company Security Interests; durch U.N. (UNCITRAL): International Interests in Mobile Equipment (http:// www. unidroit.org/ english/ workprogramme/ study072/main.htm).

${ }^{549}$ Thonabauer u.a., Kreditrisiko: in Polen (S. 23); in Tschechien (S. 21); Ungarn (S. 36).

${ }^{550}$ M.w.N.: Wiegand, Staudinger Anh. zu $§ § 929$ ff., Rn. 35. 
Für das Verständnis der gegenwärtigen Rechtslage des deutschen Mobiliarpfandrechts stellt die Abhandlung von Melsheimer - Sicherungsübereignung oder Registerpfandrecht - ein rechtsgeschichtliches Fossil zur Verfügung, das die wichtigsten historischen Stoffe über die Interessenkämpfe zusammengestellt hat. Es ist für die Gestaltung eines neuen Sicherungssystems in der Hinsicht von großer Bedeutung, dass man nicht in verwirrenden Interessenkämpfen die Orientierung verlieren darf und rechtspolitisch besonders rücksichtsvoll arbeiten muss.

In Deutschland war die Diskussion um das Publizitätserfordernis stets vom Kampf verschiedener Interessengruppen um die für sie günstigsten Sicherungsinstrumente begleitet. ${ }^{551}$ Dies erschwert die Herausbildung eines dogmatisch sauberen und fundierten Sicherungssystems sehr, und infolgedessen muss sich die Praxis mit Einzelfallentscheidungen des BGH herumschlagen. Am 14. Juni 1910 forderte der deutsche Handelstag Vertreter von Banken, Börsen, Großhandel etc. auf, sich zur Sicherungsübereignung zu äußern; im Oktober 1910 nahmen 30 Handelskammern teils ausführlich Stellung, und fast alle sprachen sich für die Einführung des Registerpfandrechts aus; bis auf die älteste Kaufmannschaft - die Berliner Handelskammer, die auf folgende schlagkräftige Argumentation hinwies:

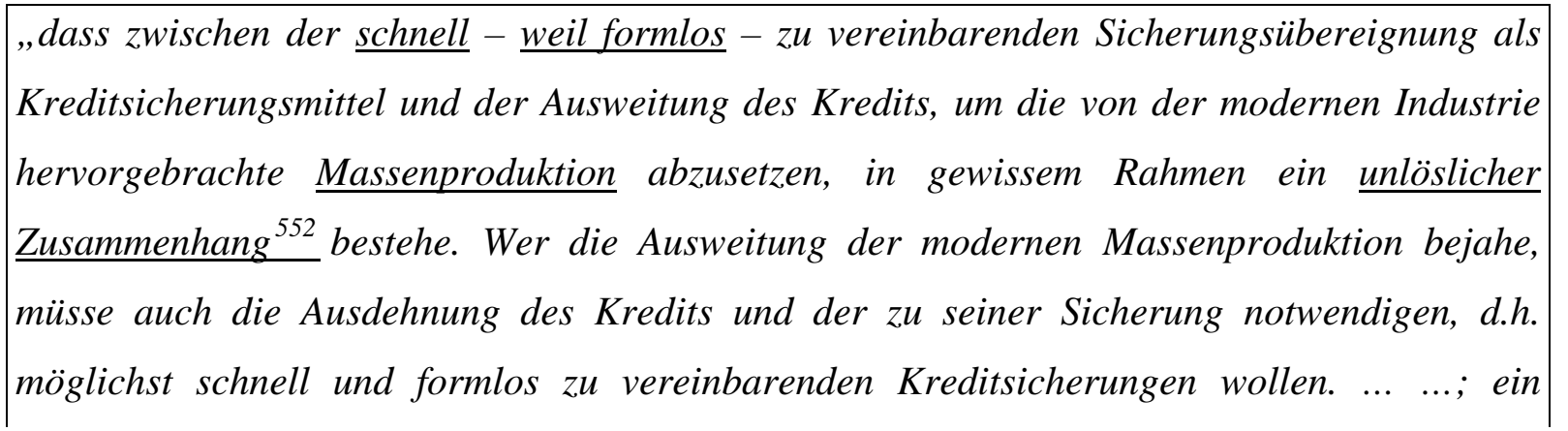

\begin{abstract}
${ }^{551}$ Melsheimer, Sicherungsübereignung oder Registerpfandrecht - eine politologische Studie, S. 15 ff, 19 ff., 33 ff.: Schon auf dem 15. Deutschen Juristentag im Jahr 1880 erörterte man die Problematik der Umgehung des Faustpfandprinzips durch die Sicherungsübereignung; im Jahr 1910 begannen die ersten Vorstöße von Wirtschaftsverbänden, wie z.B. Verein der Großhändler in Hamburg oder der Vereinigung Deutscher Zuckerwaren- und Schokoladenfabrikanten e.V., die auf eine Beseitigung der Sicherungsübereignung abzielten; an dieser Diskussion teilgenommen haben noch Interessengruppen - Haus- und Grundbesitzervereine, Wasserleitungsbrache, Mittelstand, Kleinkaufleute, Handwerker etc.
\end{abstract}

\footnotetext{
${ }^{552}$ Diese Argumentation der Berliner Handelskammer war unter Berücksichtigung der damaligen technischen Rahmenbedingung zutreffen und entsprach dem Gesetz der Transformationskurve (s. D, I, 2, a), aa), (1); sie greift nach unter dem Einsatz der RFID-Technik (s. D, II, 3, a), aa)) nicht mehr, weil diese Technik Massengeschäftsverkehr mit Schnelligkeit, Leichtigkeit und vor allem Sicherheit sehr kostengünstig bewältigen kann.
} 
Register für Sicherungsübereignungen würde die schon sehr große Zahl der mannigfaltigsten Register noch vermehren und dazu führen, dass alle diese Register praktisch gar nicht mehr eingesehen werden könnten. “553

Bei der Verhandlung auf dem 31. Deutschen Juristentag im Jahre 1912 wurde der Antrag bzgl. der Einführung des Registerpfandrechts bei Stimmengleichheit abgelehnt. ${ }^{554}$

Nach dem ersten Weltkrieg nahm Keinath als Vertreter des Großhandels den Kampf um die Publizität von Kreditsicherungen wieder auf und brachte am 29.01.1926 einen Gesetzentwurf bzgl. der Einführung des Registerpfandrechts im Reichstag ein. ${ }^{555}$ Aber sein Vorhaben wurde von Bankenvertretern mit dem Argument torpediert, dass ein öffentliches Pfandbuch zu teuer und die Preisgabe der Beweglichkeit in der Kreditsicherung für die Publizität viel zu hoch sei. ${ }^{556}$ Außerdem sei eine Registereinsicht beim modernen Geschäftsverkehr weitgehend illusorisch, weil sie oft fernmündlich stattfinde, ganz abgesehen von der Scheu der Geschäftswelt, ihr Kreditbedürfnis in einem Register offenkundig zu machen. ${ }^{557}$ Wer für die Einführung der Registerpflicht für die Sicherungsübereignung sei, müsse auch andere Sicherungsformen wie z.B. den Eigentumsvorbehalt etc. einbeziehen; das sei aber mit einer Vergrößerung und Verteuerung des Behördenapparates verbunden. ${ }^{558}$ Es ist den Banken gelungen, die Industrieverbände, die sich für den Eigentumsvorbehalt interessierten, als Verbündete im Kampf gegen die Einführung der Registerpflicht für die Sicherungsübereignung zu gewinnen; schließlich lief auch der Einzelhandel auf die Seite der Banken über. ${ }^{559}$

\footnotetext{
${ }^{553}$ Melsheimer, Sicherungsübereignung oder Registerpfandrecht - eine politologische Studie, S. 25 f., 29 f.

${ }^{554}$ Melsheimer, Sicherungsübereignung oder Registerpfandrecht - eine politologische Studie, S. 40.

${ }^{555}$ Drucksachen des Reichstags III, Wahlperiode 1924/26 Nr. 1811. (abgedruckt im Zentralblatt für Handelsrecht, 1926, S. 99 - 101).

${ }^{556}$ Verhandlungen des Deutschen Industrie- und Handelstages, 1926, Heft 1, S. 14.

${ }^{557}$ Verhandlungen des Deutschen Industrie- und Handelstages, 1926, Heft 1, S. 19.

${ }^{558}$ Verhandlungen des Deutschen Industrie- und Handelstages, 1926, Heft 1, S. 19 f.

${ }^{559}$ Verhandlungen des Deutschen Industrie- und Handelstages, 1926, Heft 1, S. 34 f., 41 f.
} 
Mit dem Konjunkturaufschwung im Jahre 1926 kühlte die Diskussion über die Kreditsicherungsreform ab und geriet zeitweise in Vergessenheit. Vor dem neuen Hintergrund der Globalisierung und des immer wachsenden Bedarfs an Kredit gewinnt die Reformbewegung nach der Finanz- und Wirtschaftskrise wieder an Fahrt. Man muss die Interessen und Argumente, die die große Diskussion in den 20er Jahren geliefert hat, im Lichte der neuen Gegebenheiten des modernen Verkehrs neu evaluieren.

\section{b) Reformbewegung für ein europäisches Mobiliarkreditsicherungsrecht}

Die rasante Beschleunigung des globalen grenzüberschreitenden Warenverkehrs und deren Verlangen nach Rechtssicherheit schlagen sich auch in der Diskussion über die Einführung eines möglichen europäischen Mobiliarkreditsicherungsrechts nieder. ${ }^{560} \mathrm{Im}$ Zuge der Diskussionen innerhalb dieser Reformbewegung sind verschiedene Ansätze vorhanden, die für die Bildung eines einheitlichen Sicherungsrechts von Nutzen sein kann.

Im Gegensatz zur stagnierenden Diskussion über das einheitliche europäische Grundpfandrecht ${ }^{561}$ ist die Reformbewegung bzgl. des europäischen Mobiliarpfandrechts viel lebhafter und konkrete, nicht zuletzt, weil hierfür auf internationaler Ebene schon fertige Modelgesetze vorhanden sind. ${ }^{562}$ Alle drei Modelgesetze stammen mehr oder weniger aus dem angelsächsischen Rechtskreis, mit dessen Rechtstradition.

\section{aa) Reale Probleme in der EU und für den Welthandel}

Zutreffend schildert Prof. Krimphove ${ }^{563}$ in seinem Meisterwerk „Das europäische Sachenrecht" die gegenwärtige Rechtslage in der EU so:

\footnotetext{
${ }^{560}$ Pospiech, The Future of Secured Credit in Europe ,WM 2007, $1950 \mathrm{f}$.

${ }^{561} \mathrm{C}$, III, 2, d), aa).

${ }^{562}$ UNCITRAL - Legislative Guide on Secured Transactions; EBRD - Model Law on Secured Transactions; USA - Article 9 Uniform Commercial Code.

${ }^{563}$ Meiner Meinung nach hat Prof. Krimphove die besten Voraussetzungen (Studium in Rechtswissenschaft, Volkswirtschaftslehre, Theologie; Beherrschung von Deutsch, Englisch, Französisch, Italienisch, und Spanisch; Dr. jur. mit summa cum laude!) um den Themenkomplex „europäisches Sachenrecht“, mit allen dazu gehörenden juristischen, ökonomischen und philosophischen Tiefen, zu analysieren und Reformvorschläge abzugeben!
} 
„Die europäischen Gemeinschaften und ihre Mitgliedsländer befinden sich zurzeit in einer rechtshistorisch entscheidenden Phase ihres Zusammenwachsens. Historisch gleicht die aktuelle geschichtliche Situation der Bildung eines europäischen Binnenmarktes dem Zusammenwachsen der im Deutschen Bund nur lose verbundenen, rechtlich selbständigen 35 Fürstentümer und vier freien Städte zu dem einheitlichen Wirtschaftsgebiet des Deutschen Reiches im ausgehenden I9ten Jahrhundert: Auch hier erforderte die politische/ökonomische Integration die Schaffung eines einheitlichen Rechtssystems. “564

Besonders wird die unsichere Rechtslage am Beispiel der Sicherungsübereignung des deutschen Rechts deutlich: eine deutsche Bank, die einen Reisebus zur Sicherung des Kaufpreisdarlehens übereignet bekommt, muss feststellen, dass sie in Spanien gegen die Beschlagnahme im Wege des einstweiligen Rechtsschutzes aufgrund einer offenen Forderung des spanischer Hoteliers gegen das deutsche Reiseunternehmen nichts unternehmen kann, weil das spanische Recht nur Registerpfandrecht kennt. ${ }^{565}$ Das gleiche Schicksal erlebt auch der publizitätslose verlängerte Eigentumsvorbehalt, wenn das Sicherungsgut den Geltungsbereicht des deutschen Rechts verlässt. ${ }^{566}$

Theorietisch könnte zwar die Nichtanerkennung einer Sicherheit aus anderen Mitgliedstaaten aufgrund des Typenzwangs nationaler Sachenrechtsordnung nach einhelliger Literaturmeinung eine Einschränkung der Warenverkehrsfreiheit (Art. $28 \mathrm{EGV)} \mathrm{sein.}{ }^{567}$ In der Praxis dürften die nationalen Gerichte wohl aber anders entscheiden.

\section{bb) Übernahme des Article 9 UCC oder Schaffung eigenen Systems?}

Bei der Suche nach der richtigen Lösung für die vorstehenden Probleme des Kreditsicherungsrechts ist man sich einigt, dass sie nicht kollisionensrechtlich gelöst werden kann (vor allem deswegen, weil es bei nicht registrierten Sachen wegen der lex rei sitae-Regel keinen objektiven Anknüpfungspunkt gibt); der richtigere Weg für die EU sollte nach einer

\footnotetext{
${ }^{564}$ Krimphove, das europäische Sachenrecht, S. 12.

${ }^{565}$ Kieninger, Europäisches Mobiliarkreditsicherungsrecht, S. 109 ff, 115.

${ }^{566}$ Kieninger, Europäisches Mobiliarkreditsicherungsrecht, S. 109 ff, 115.

${ }^{567}$ M.w.N.: Roth, Secured Credit and the Internal Market, S. $36 \mathrm{ff}, 54 \mathrm{f}$.
} 
im Vordringen befindlichen Meinung die Harmonisierung der Sachenrechtsordnung durch die Einführung eines Registerpfandrechts sein. ${ }^{568}$

Der von Prof. Kieninger ${ }^{569}$ vertretene Reformkreis tendiert dazu, ein Sicherungssystem nach dem us-amerikanischen Model des Article $9 \mathrm{UCC}^{570} \mathrm{zu}$ schaffen. Bei der Diskussion werden zusätzlich strukturell ähnliche Modelgesetze von der Kommission der Vereinten Nationen für internationales Handelsrecht (UNCITRAL) und von der europäischen Bank für Wiederaufbau und Entwicklung (EBRD) herangezogen. ${ }^{571}$

Art. 9 UCC (1999) will durch das Konzept der Vereinheitlichung aller Sicherungsinstrumente unter dem Begriff „Security Interest“ die Rechtssicherheit und Benutzerfreundlichkeit erhöhen und dieses Konzept begeistert nicht nur Gesetzgeber in eigenem Rechtskreis (Kanada, Neuseeland, Indien etc.), sondern auch die kontinentaleuropäischen Sicherungsrechtlicher (zentral- und mitteleuropäische Staaten). ${ }^{572}$ Allerdings bei näherem Zusehen erheben die kontinentaleuropäischen Juristen, nicht zuletzt wegen Verteidigung eigener Rechtstradition, doch viele berechtigte (zum Teil systemische) Fragen.

Zunächst misstraut man die zweistufige Sicherungsbestellung des UCC/UNCITRAL Legislative Guide on Secured Transactions, wonach die Sicherheit zunächst durch einen Sicherungsvertag ${ }^{573}$ innerparteilich wirksam und erst später durch einen weiteren Akt (i.d.R.

\footnotetext{
${ }^{568}$ Krimphove, das europäische Sachenrecht, 483 f.; Graham-Siegenthaler, Kreditsicherungsrechte, S. 9 f.; Kieninger, Europäisches Mobiliarkreditsicherungsrecht, S. 109 ff, 120 f; Stürner, Perfection and Priority, S. 165.

${ }^{569}$ Kieninger, Reform des Mobiliarsicherungsrechts, WM 2005, 2305 ff., 2353 ff., 2357: „Gemeinsames Vorbild aller Reforbestrebungen ist - mit durchaus unterschiedlicher Akzentsetzung und Ausprägung - Art. 9 UCC; Europäisches Mobiliarkreditsicherungsrecht, in: Kreditsicherheiten, S. 109 ff, 132; differenzierte Ansicht: Veneziano, Attachment/Creation of a Security Interest, S. $113 \mathrm{ff}$.

${ }^{570}$ Drobnig, Mobiliarsicherheiten, S. 36 ff., 40.: die Schaffung eine einheitliche Europäische Mobiliarsicherheit nach dem amerikanischen Art. 9 UCC ist gar nicht neu; Bereits im Jahr 1990 hat Kreuzer dies schon vorgeschlagen; dem gegenüber war Drobnig skeptisch und hat nur vorgeschlagen, dass die EG-Kommission prüfen sollte, ob und inwieweit dafür ein praktisches Bedürfnis besteht. Diese Vorschlage ist nicht umgesetzt worden.

${ }^{571}$ Graham-Siegenthaler, S. 518; Veneziano, Attachment/Creation of a Security Interest, S. 113 ff.; Kieninger, Reform des Mobiliarsicherungsrechts, WM 2005, 2305 ff., 2353 ff.

${ }^{572}$ Graham-Siegenthaler, Kreditsicherungsrechte, S. 515 ff, 517; Lukas, Attachment/Creation, S. 135 ff, 136.

573 Unter § 903-203 UCC heißt es „Attachment“ und beim UNCITRAL Legislative Guide on Secured Transactions wird dieser Schritt „Creation“ genannt (S. 65 ff.).
} 
Registrieren) ${ }^{574}$ drittwirksam wird. ${ }^{575}$ Hier prallen zwei verschiedene Rechts- und Philosophiewelten zusammen! Der angelsächsische Rechtskreis kennt den Begriff dingliches Rechts und seine Absolutheit nicht; ${ }^{576}$ für ihn ist die zweistufige Konstruktion selbstverständlich. Die kontinentaleuropäischen Juristen bestehen auf eine „konstitutive“ Regelung, die eindeutig besagt, wann eine Sicherheit bzw. ein subjektives Recht (drittwirksam) entstanden ist; für sie ist ein Recht, das zweistufig bzw. allmählich entsteht, sehr schwer vorstellbar. ${ }^{577}$

Heftigere Widerstände leisten die Altmeister des deutschen Sachen- bzw. Kreditsicherungsrechts. Prof. Stürner meint, dass die deutsche Wirtschaft auch ohne „perfection and publicity“ überlebt und in der Praxis das Mobiliarsicherungsrecht in internationalem Wirtschaftsverkehr erfahrungsgemäß keine Rolle spielt. ${ }^{578}$ Bei allem Respekt greifen diese Argumente von Prof. Stürner meiner Meinung nach nicht. Denn die Tatsache, dass Prof. Stürner in seinem 25 jährigen Laufbahn als Richter am OLG Stuttgart und Karlsruhe (Spezialsenat für Auslandssachen) keinen einzigen Fall gehabt hat, wo Konflikte grenzüberschreitender Sicherheiten eine entscheidende Rolle gespielt hat, ${ }^{579}$ bedeutet aber nicht, dass man bei der Harmonisierung bzw. Vereinheitlichung der Mobiliarsicherheit auf den Holzweg ist. Wie Prof. Stürner selbst schon erwähnt (als Beleg für die Bedeutungslosigkeit des Mobiliarsicherungsrechts im Internationalen Warenverkehr), dass die vorsichtigen Kaufmänner in internationalem oder intereuropäischem Warenhandeln nicht etwa das Mobiliarsicherungsrecht, sondern Bankgarantien bevorzugen. ${ }^{580}$ Dies ist meiner Meinung nach gerade kein Nachweis dafür, dass das Mobiliarsicherungsrecht für den internationalen Warenverkehr bedeutungslos ist. Umgekehrt ist hier der Fall! Gerade wegen

\footnotetext{
${ }^{574}$ § 9-308 ff. UCC; UNCITRAL Legislative Guide on Secured Transactions (S. 103 ff.).

${ }^{575}$ Veneziano, Attachment/Creation of a Security Interest S. 128.

${ }^{576} \mathrm{C}, \mathrm{I}, 1$.

577 Veneziano, Attachment/Creation of a Security Interest, S. 128; Lukas, Attachment/Creation, „The Guide merely contains soft law, ... There is no need to follow all recommendations “, S. 135 f. 141.

${ }^{578}$ Stürner, Perfection and Priority, S. 166 ff, 168, 172, 173.

${ }^{579}$ Stürner, Perfection and Priority, S. 166 ff, 173.

${ }^{580}$ Stürner, Perfection and Priority, S. 166 ff, 172.
} 
der Wirkungslosigkeit der europäischen nationalen Mobiliarsicherheiten im Ausland sind die vorsichtigen Kaufmänner gezwungen, teuere Bankengarantien als Ersatzsicherungsinstrumente in Anspruch zu nehmen und gerade wegen der völligen Abwesenheit des Mobiliarsicherungsrechts im europäischen bzw. internationalen Warenverkehr bekommen die nationalen Gerichte auch selten Fälle vorgelegt. In dieser Hinsicht hat das Recht als Institution der Koordination des internationalen Warenverkehrs völlig versagt und dieses Versagen darf nicht als Argument gegen die Anstrengung für Aufhebung dieses Versagens verwendet werden!

Andere Argumente der Altmeister, die auf die systemischen Schwächen des Art. 9 UCC zielen, scheinen mir allerdings zutreffend. $\mathrm{Zu}$ Recht moniert Prof. Stürner die Unvollkommenheit des Registersystems des UCC wegen Zulassung von zahlreichen Ausnahmen von der Registerpflicht, weil dadurch die Funktion des Registers entwertet wird. ${ }^{581}$ Aus Sicht eines deutschen Sicherungsrechtlers findet Prof. Lwowski die gegenwärtige deutsche Mobiliarsicherheit gerade wegen des fehlenden Registrierungserfordernisses dem Filing-System des Art. 9 UCC gegenüber hinsichtlich des Kostens rechtpolitisch sogar vorteilhafter. ${ }^{582}$

Obwohl die Diskussionsteilnehmer innerhalb der Reformdiskussion über ein mögliches europäisches Mobiliarsicherungsrecht es für sehr wichtig halten, dass die Effizienz eines Sicherungssystems von entscheidender Bedeutung ist, ${ }^{583}$ einen konkreten Reformvorschlag, der die (scheinbare) Rechtsicherheit des Filing-Systems des Art. 9 UCC und die europäische sachenrechtliche Grundordnung harmonisierend in einer konkreten und effizienten Gestaltung zusammenbringt, sucht man leider vergeblich!

Durch akribischen ökonomisch-institutionellen Vergleich der europäischen Sachrechtsordnungen kommt Prof. Krimphove, der sich (noch nicht) aktiv an der Reformdiskussion teilgenommen hat, zur folgenden konkret brauchbaren Lösungsansätze für

\footnotetext{
${ }^{581}$ Stürner, Perfection and Priority, S. 166 ff, 171.

${ }^{582}$ Lwowski, „Quiet““ Creation of Security Interest, S. 174 ff, 175, 177, 178.

${ }^{583}$ Brinkmann, The Position of Secured Creditors in Insolvency, S. 248 ff, 249; Eidenmüller, Secured Creditors in Insolvency Proceedings, S. 273 ff, 283; Sigman, Perfection and Priority, S. 143 ff, 158; Stürner, Perfection and Priority , S. 166 ff, 169; Lwowski, ,Quiet“ Creation of Security Interest, S. 174 ff, 177.
} 
die Gestaltung eines künftigen europäisches Kreditsicherungsrecht. In seinem Meisterwerk (das europäische Sachenrecht) schlägt er die Kombination zwischen Abstraktionsprinzip als Verfügungsprinzip und (elektronischer) Registrierung als dessen (Haupt-)Manifestierung vor, weil im Vergleich zu anderen Gestaltungen nur diese Konstellation das höchste Maß an Rechtssicherheit und Effizienz bietet. ${ }^{584}$

\section{cc) Zusammenfassung}

Obwohl Art. 9 UCC sich mit dem Konzept der Vereinheitlichung der Sicherungsinstrumente klaren Beifall verdient, seine Konkretisierung befindet sich jedoch doch in einem unsicheren Anfangsstadium und ist für die künftige Kodifikation des europäischen sowohl hinsichtlich der Rechtssicherheit, als auch hinsichtlich der Rechtstradition nur sehr begrenzt übernehmbar. ${ }^{585}$ Deshalb ist den (insbesondere deutschen) Reformisten zu raten, sich bei der Konstruktion des künftigen europäischen Kreditsicherungsrechts mehr Hochachtung für die Stärke eigener dogmatischer Überlegenheit zum Ausdruck zu bringen, weil sie den Schlüssel zum sicheren und effizienteren Vermögensrecht in sich trägt.

\section{c) USA - Informationsasymmetrie als die 2. Ursache der Weltfinanzkrise}

Hinsichtlich der Publizität hat selbst das von vielen Fachleuten befürwortete treffliche Vorbild aus den Vereinigten Staaten seine Schattenseite, weil das herrliche und mächtige Gebäude des einheitlichen „Security Interest“ auf sandigem Fundament fußt. ${ }^{586}$

\section{aa) Problem Nr. 1 - Filing-System Disaster}

Vorne im Zusammenhang mit dem Spezialitätsgrundsatz wurde die Schwäche des Art. 9 UCC bzgl. der Bestimmung des Sicherungsgegenstands schon erörtert. Nicht nur auf der Rechtsobjektseite, sondern auch auf der Rechtssubjektseite lässt Art. 9 UCC Wünsche offen.

\footnotetext{
${ }^{584}$ Krimphove, das europäische Sachenrecht, Teil III 2.3 ff, 4.1 ff., 6.1 ff. (insbes. 2.3.4, 4.2.1.1, 4.4.3.3, 6.1.1)
}

585 Über die systemischen Schwäche des Art. 9 UCC wegen der verheerenden Kombination der Verbriefungstechnik und des lückenhaften Publizitätssystems s. C, III, 2, c), bb) und D, 2, c); Hinsichtlich der unterschiedlichen Rechtstradition s. C, I, 1.

\footnotetext{
${ }^{586}$ Alces, Abolisch the Article 9 Filing System, S. 679 ff, 683 f: obwohl man sich schon im Jahr 1995 über viele Probleme (hinsichtlich Struktur, Verarbeitungsgeschwindigkeit, Zuverlässigkeit, Kosten etc.) des Article 9 Filing Systems beschwert hat. Größere Verbesserung ist bis heute nicht eingetreten.
} 
In seinem Aufsatz „The Spearing Tool Filing System Disaster“ hat Prof. LoPucki durch einen dramatischen Fall gezeigt, zu welchen katastrophalen Folgen das unsichere Kopfzerbrechen bereitende Rechtssubjekt-Filing führen könnte. Gem. § 9-308 i.V.m. § 9-310 (a) UCC gewinnt eine Sicherheit i.d.R. die Drittwirkung, erst wenn das ,financing statement“ (nicht das security agreement bzw. Sicherungsvertrag) registriert ist. Bei der Registrierung des „financing statement“ taucht häufig das ewige Problem mit den sog. „debtor name errors“ auf, das die amerikanischen Juristen verzweifeln lässt. ${ }^{587}$

Im „Spearing Tool“-Fall führt ein „debtor name error“ zur bizarren Entscheidung: ${ }^{588}$ Crestmark Financial Corp. (Crestmark) schließt mit Spearing Tool Manufacturing Co. (Spearing Tool) einen Sicherungsvertrag und registriert im April 1998 und 2001 im financing statement mit dem exakten Namen des Schuldners. Im October 2001 wurde das Vermögen des Spearing Tolls durch Registrierung einer Steuerforderung belastet und zwar mit falschem Namen des Spearing Tools. Nach § 26 U.S.C. § 6323 (d) verliert eine „,normale“ Forderung seinen Vorrang gegenüber einer Steuerforderung, wenn sie 45 Tage nach der Registrierung der Steuerforderung ausgezahlt wird. Crestmark erfüllt diese Anforderung, und hat alle 45 Tage kontrolliert, ob Steuerforderung im Register vorkommt. Da bei der Registrierung der Steuerforderung falschen Namen des Spearing Tolls verwendet wurde, hat Crestmark diese Belastung nicht bemerkt und verlor dadurch seine registrierte drittwirksame Sicherheit. Das Berufungsgericht (Court of Appeals for the Sixth Circuit) meinte, dass einmalige Kontrolle mit dem exakten Namen des Schuldners der Sorgfaltspflicht nicht genügt. Durch diese Entscheidung werden die Transaktionskosten der normalen Sicherungsnehmer ins Unermessliche gesteigert. ${ }^{589}$

Bei genauerem Zusehen werden die strukturellen Rechtsunsicherheit des „Filing System“ des Art. 9 UCC noch deutlicher. Das amerikanische Publizitätssystem ist ein sog. ,notice filing system“, das vor allem darauf abzielt, Hinweise für die Existenz einer Belastung zu geben und

\footnotetext{
${ }^{587}$ LoPucki, Filing System disaster, S. 281, 288.

${ }^{588}$ Alces/Lloyd, Reform of the Article 9 Filing System, S. 99; Sigman, Article 9 UCC Filing System, S. 459; LoPucki, Filing System disaster, S. 295 f..

${ }^{589}$ Um die präzise Bestimmung auf der Rechtssubjektseite zu erreichen, braucht man Zusatzmechanismus wie z.B. Identifizierung durch elektronische Personalausweis oder Steuer-ID etc., s. D, II, 3, a), bb), (1).
} 
die Prioritätsverhältnisse zu bestimmen. ${ }^{590}$ Um über das genauere Sicherungsverhältnis zu erfahren, muss man anhand der Information des „finaning statment“ den „security agreement“ (Sicherungsvertrag) finden und studieren. Nur dort sind die echten Sicherungsverhältnisse (unpubliziert) geregelt. ${ }^{591}$

\section{bb) Problem Nr. 2 - dezentralisiertes Registerwesen}

Nach Article 9 - 308 (a) und 9-310 (a) UCC entfaltet das „Security Interest“, abgesehen von den gesetzlichen Ausnahmen, grundsätzlich erst eine Drittwirkung, wenn das „Financing Statement“ in ein Register eingetragen ist (sog. „Perfection“). ${ }^{592}$ Problematisch dabei ist, dass das Registerwesen in den USA, zum Teil wegen des Bundesstaatsprinzips, zum Teil wegen Sonderinteressen bestimmter Gruppen, nicht zentral, sondern dezentralisiert organisiert ist; selbst innerhalb eines Bundesstaates existieren verschiedene Register für unterschiedliche Wirtschaftsgüter. ${ }^{593}$ Die Folge dieses dezentralisierten Registersystems ist im Grunde genommen katastrophal:

„The theory of the filing system has suffered considerably in implementation, ... ..., filing system are highly imprecise and difficult and expensive to use...... Even if a filter and searcher got to the same filing system, that may still not be sufficient to ensure that the message is received. ... ... For the message to be received, the filer must not only leave it in the right system, the filer must leave it in the right place in that system. “594

Die Registrierung ist so kompliziert, dass nur Banken und Fachantwälte sich damit auskennen; für einfache Leute bleibt nur der Gang zu speziellen „severice companies“ übrig, die eine hohe Gegenleistung verlangen. Es ist erstaunlich, wieviel Transaktionskosten das Registerwesen in den USA verschlingt! Die einmalige Recherche nach einem Namen des Vertragspartners/Schuldners kostet den Gläubiger zwei Gebühren, und eine Gebühr beträgt 50

\footnotetext{
${ }^{590}$ Sigman, Perfection and Priority, S. 143 ff, 151.

${ }^{591}$ Sigman, Perfection and Priority, S. 152.

${ }^{592}$ White/Summers, Uniform Commercial Code, Vol. 4, S. 131 f., 182 ff.

${ }^{593}$ LoPucki/Warren, Secured Credit, S. 276 ff.

${ }^{594}$ LoPucki/Warren, Secured Credit, S. 277, 290.
} 
US-Dollar; wenn man z.B. außer nach dem Familiennamen auch nach dem Vornamen des Vertragspartners/Schuldners recherchieren will, zahlt man das Doppelte. Nicht nur das Recherchieren selbst kostet, sondern auch wenn man das Ergebnis ausstellen lassen möchte: jede Seite Kopie kostet 1 US-Dollar; Papiere können extra abgerechnet werden; für „Overnight“" Versendung zahlt man extra; nicht nur die Registereinsicht kostet, sondern auch die Eintragung: die „service company“ verlangt ca. 15 US-Dollar und das „filing office“ fordert ca. 25 US-Dollar pro Eintragung. ${ }^{595}$

Wenn jemand die vorstehenden Gebühren, Anwaltskosten etc. ausgibt, sollte er davon ausgehen können, dass er dem Rechercheergebnis aus dem Registersystem auch blind vertrauen darf. Unter dem UCC ist dies offensichtlich nicht der Fall. Eine dem positiven und negativen Publizitätsgrundsatz des deutschen Grundregisters entsprechende Konstruktion zugunsten des Gutglaubeschutzes sucht man im amerikanischen Registerrecht vergeblich! Das System ist so mangelhaft organisiert, dass selbst die Profis sich ihrer Sache nicht sicher sein können. Um die drohende Haftung und Folgeschäden wegen fehlerhafter Eintragungen oder Einsichtsergebnisse abzufangen, brauchen alle Beteiligten eines Kreditsicherungsgeschäfts (Schuldner, Gläubiger, Bank, Service Company, Anwälte) die sog. „UCC Insurance“. 596

Die hohen Transaktionskosten sind nur eine der negativen Seiten des dezentralisierten Registerwesens in den USA. Systemisch gesehen verhängnisvoller ist meiner Meinung nach die dadurch verursachte Intransparenz der Sicherungsverhältnisse. Ohne die Verbriefungsinstrumente des Article 8 UCC war dies wahrscheinlich noch nicht so offensichtlich. Erst durch die Finanzkrise kann man den auf das fehlerhafte Registerwesen zurückzuführenden Systemfehler des UCC nicht mehr leugnen. Denn die dadurch bedingte Informationsasymmetrie ist eine der Hauptursachen für den Zusammenbruch des Vertrauens im Interbankenverkehr.

\footnotetext{
${ }^{595}$ LoPucki/Warren, Secured Credit, S. 286 f.

${ }^{596}$ LoPucki/Warren, Secured Credit, S. 317 f.
} 
Insoweit steht die hohe Rechtssicherheit des UCC nur auf dem Papier. Die faktische Wirkung des objektiven Registerrechts des UCC ist viel schwächer als die des deutschen Grundbuchs mit seinem subjektiven Maßstab im Wege der Gutgläubigkeit.

Auf dieses systemische Defizit des UCC wurde bisher in der Diskussion über die Einführung einer einheitlichen „europäischen Sicherheit“ noch nicht hingewiesen bzw. verschwiegen.

\section{d) Lösungsansatz aus der Spieltheorie}

Für die Analyse der Ursache und Prozessen der Weltfinanzkrise reichen meiner Meinung nach die traditionellen Instrumente der ökonomischen Analyse des Rechts nicht aus, weil in diesen Prozessen Entscheidungssubjekte sehr stark in den Vordergrund treten, deren Verhalten sich nicht quantifizieren lässt. dafür benötigt man neue analytische Werkzeuge.

Richard Posner, der wichtigste Vertreter der Ökonomischen Analyse des Rechts, leitet den Paradigmenwechsel mit folgender Überzeugung ab: „Economics is the science of rational choice in a world - our world - in which resources are limited ..... The concept of man as a rational maximizer of his self-interest implies that he could increase his satisfactions by altering his behavior, he will do so.“597 Damit meint er das „Homo-oeconomicus-Modell“ der neuen Institutionenökonomik, dessen Kern besagt, dass die den Anreizen oder Restriktionen ausgesetzten Individuen unter Anwendung des Kosten-Nutzen-Kalküls ihre Handlungsmöglichkeiten bewerten, um sich dann gemäß dem relativen Vorteil zu entscheiden. ${ }^{598}$ Dies ist auch der Ausgangspunkt eines relativ neuen Instruments der Ökonomischen Analyse des Rechts, nämlich der Spieltheorie. In Bezug auf das menschliche Verhalten basiert die traditionelle Ökonomik auf dem Anreizmodell. ${ }^{599}$ Danach werden die Menschen als anonyme „Price-Taker“ angesehen, und entscheidend sind nur die Lage des Angebots und der Nachfrage, also der Markt. Diese Grundhaltung der Chicago-Schule wird auch von der traditionellen Ökonomischen Analyse des Rechts übernommen. Man versucht z.B. Strafe als Preis des Verbrechens darzustellen; oder Vertrag, Schaden, Prozess etc. mit

\footnotetext{
${ }^{597}$ Posner, Economic Analysis of Law, S. 3 f.

${ }^{598}$ Erlei u.a., Neue Institutionenökonomik, S. 4.

${ }^{599}$ Vgl. Mankiw, Principles of Economics, S. 5: "People respond to incentives. When the price of an apple rises, people decide to eat more pears and fewer apples."
} 
Hilfe von Marktmechanismen zu analysieren usw. ${ }^{600}$ Dabei ergeben sich viele heikle Probleme, wie etwa die Messbarkeit der Transaktionskosten, Kooperationsbereitschaft der Parteien, asymmetrische Informationen etc. Aber in vielen Bereichen des Rechts (insbes. Gesetzgebung, Vertragsverhandlung oder Prozessführung), ${ }^{601}$ reagieren die Akteure nicht (nur) auf Reize, sie agieren strategisch und wissen genau, dass Aktion Reaktion erzeugt, und versuchen deswegen gezielt nutzenmaximierend $\mathrm{zu}$ handeln. In dieser Hinsicht ist die Spieltheorie eine Theorie sozialer Interaktion und beschäftigt sich mit solchem strategischen Verhalten; im Hinblick auf den für die Gestaltung des Kreditsicherungsrechts essenziellen Institutionszweck werden wir am Beispiel der Kreditfinanzierung mit diesem faszinierenden Instrument darstellen, aus welchen ökonomischen Gründen Rechtssysteme (darunter auch die Kreditsicherheiten) überhaupt existieren. ${ }^{602}$

Ein zentraler Bestandteil der Spieltheorie ist das Gefangenendilemma, und dabei handelt es sich vielleicht um das wichtigste Vorkommnis der menschlichen Gesellschaft - das Zusammenspiel von individuellen Interessen. In der wunderbaren Welt des Adam Smith lenkt eine unsichtbare Hand die individuellen Interessen und Leidenschaften der Menschen in die Richtung, die den Interessen der Gesellschaft als Ganzes entspricht. Paradoxerweise existiert zugleich auch das Phänomen, dass für alle Beteiligten vorteilhafte Kooperationen wegen Interessenkonflikten scheitern, wie z.B. bei Nutzung öffentlicher Güter, Klimaschutz, Rüstungswettbewerb, Überfischung usw. Die tausendfach geschilderte, juristisch allerdings

\footnotetext{
${ }^{600}$ Vgl. Posner, Economic Analysis of Law, S. 167 f, 215 f.

${ }^{601}$ Ayres, Playing Games with the Law, S. 1294: "the advances in modeling imperfect and asymmetric information that have made game theory a dominant methodology in microeconomics are even more central to the analysis of legal issues. Asymmetric information and strategic behavior are at the core of a large number of legal policy issues."

${ }^{602}$ Brandenburger/Nalebuff, the right game, S. 57 f.; Erlei u.a., Neue Institutionenökonomik, S. 76: Die Spieltheorie war ursprünglich nur ein reines mathematisches Werkzeug für die Analyse der Interaktionen mehrerer Akteure in einem System. Nach dem bahnbrechenden Buch (Theory of Games and Economic Behavior) von Neumann und Morgenstern wurde die Spieltheorie zum wichtigsten Instrument der Ökonomischen Analyse. Für spieltheoretische Arbeiten wurden bisher insgesamt 8 Wirtschaftsnobelpreise vergeben. Für die Ökonomische Analyse des Rechts ist das von Jensen und Meckling hervorgehobene „Agency Problem" besonders interessant.
} 
nicht korrekte Standardversion des Gefangenendilemmas (one-shot simultaneous situation) sieht folgendermaßen aus: ${ }^{603}$

Kurz vor Weihnachten werden die zwei bewaffneten Bankräuber Pech und Leid, die ihr gesamtes Vermögen wegen der Pleite gegangenen amerikanischen L-Bank verloren haben, festgenommen. Sofort verhört der Polizeikommissar Kniff, ,vermutlich einer der ersten Spieltheoretiker“, die Verdächtigen, und zwar getrennt, so dass eine Absprache zwischen den beiden nicht möglich ist. Da der Kommissar den beiden den Raub nicht nachweisen kann, bietet er jedem folgenden Deal an: Die beiden können entweder gestehen oder schweigen. Wenn sie schweigen, kann ihnen der Raub zwar nicht nachgewiesen werden, aber sie werden wegen unerlaubten Waffenbesitzes zwei Jahre ins Gefängnis gehen müssen. Gesteht nur einer, dann gilt für ihn die Kronzeugenregelung und er kommt ungestraft davon; der andere erhält eine Strafe von 15 Jahren. Gestehen beide, so bekommt jeder 10 Jahre. Die folgende Tabelle enthält die Auszahlungen von dem Deal:

\begin{tabular}{|l|l|l|l|}
\hline \multicolumn{2}{|c|}{} & \multicolumn{2}{|l|}{ Leid } \\
\cline { 3 - 4 } \multicolumn{2}{|c|}{$(\mathrm{s})$ chweigen } & $(\mathrm{g})$ estehen \\
\hline \multirow{2}{*}{ Pech } & $(\mathrm{s})$ chweigen & $(2,2)$ & $(0,15)$ \\
\cline { 2 - 4 } & (g)estehen & $(15,0)$ & $(10,10)$ \\
\hline
\end{tabular}

Das Dilemma besteht darin: Obwohl Pech und Leid wissen, dass es für sie besser wäre, gemeinsam zu schweigen (s-s), ist dieses Strategiepaar äußerst instabil; denn ohne verbindliche Abmachung hat jeder von ihnen einen starken Anreiz (g-s und straffrei davon kommen) davon abzuweichen. Angetrieben von diesem Anreiz (0,15) und der Angst vor der Strategie $\mathrm{g}-\mathrm{s}(15,0)$ des anderen wählen die beiden die streng dominante suboptimale Strategie „gestehen“ $(10,10)$, und zwar ganz unabhängig davon, was der andere tun würde. Am Ende kommt das schlechteste Ergebnis für die beiden zustande, d.h. die kollektive Rationalität wird von der individuellen Rationalität zerstört. Trotz seiner klaren Struktur ist das Gefangendilemma keiner einfachen Lösung zugänglich; in diesem Sinne widersetzt sich das Dilemma bis zu einem gewissen Grade dem rational denkenden Verstand. ${ }^{604}$

\footnotetext{
${ }^{603}$ Vgl. Rieck, Spieltheorie, S. 44 ff.; Petersen, Das Gefangenendilemma, S. 500 ff.

${ }^{604}$ Langerfeldt, Das Gefangenendilemma, WiSt 2003, S. 226.
} 
Um das Gefangenendilemma besser verstehen zu können müssen wir noch einen weiteren Kernbegriff der Spieltheorie vorstellen, nämlich das Nash-Gleichgewicht. Abstrakt kann man ein Strategienpaar als Nash-Gleichgewicht bezeichnen, wenn A's Entscheidung für die gegebene Entscheidung von B optimal ist, und B's Entscheidung für die gegebene Entscheidung von A optimal ist. ${ }^{605}$ Andere formulieren das Nash-Gleichgewicht so: Im NashGleichgewicht kann kein Spieler seine Auszahlung erhöhen, indem er alleine von der Gleichgewichtskombination abweicht. ${ }^{606}$ Über das Nash-Gleichgewicht gibt es in der Literatur viele konkrete Beispiele. Am anschaulichsten (finde ich persönlich) ist die Abbildung von Varian, ${ }^{607}$ die eigentlich das Cournot-Gleichgewicht (Vorläufer des NashGleichgewichts) beschreibt und die ich hier zum Zweck der Erklärung des NashGleichgewichts modifiziert und verallgemeinert habe.

\begin{tabular}{|c|c|c|c|c|}
\hline \multicolumn{5}{|c|}{${ }^{606}$ Rieck, Spieltheorie, S. 31.} \\
\hline \multicolumn{5}{|c|}{$\begin{array}{l}{ }^{607} \text { Die Abbildung hier verzichtet auf die mathematischen Beschreibungen. Wer sich dafür interessiert, s. Varian, } \\
\text { Mikroökonomik, S. 581; eine andere Art von Beispielen ist die Entscheidungsmatrix, z.B. Rieck, Spieltheorie, S } \\
\text { 30: das Nash-Gleichgewicht eines Kartells. }\end{array}$} \\
\hline \multirow{3}{*}{$\begin{array}{c}\text { Engagement auf } \\
\text { dem Markt }\end{array}$} & & \multicolumn{3}{|c|}{ Die andere } \\
\hline & & A (gering) & B (mittel) & C (stark) \\
\hline & 1 (gering) & $(18,18)$ & $(15,19)$ & $(9,21)$ \\
\hline \multirow[t]{2}{*}{ Wir } & 2 (mittel) & $(19,15)$ & $(16,16)$ & $(11,15)$ \\
\hline & 2 (stark) & $(21,9)$ & $(15,11)$ & $(9,9)$ \\
\hline
\end{tabular}


Abb. 5 - Nash-Gleichgewicht

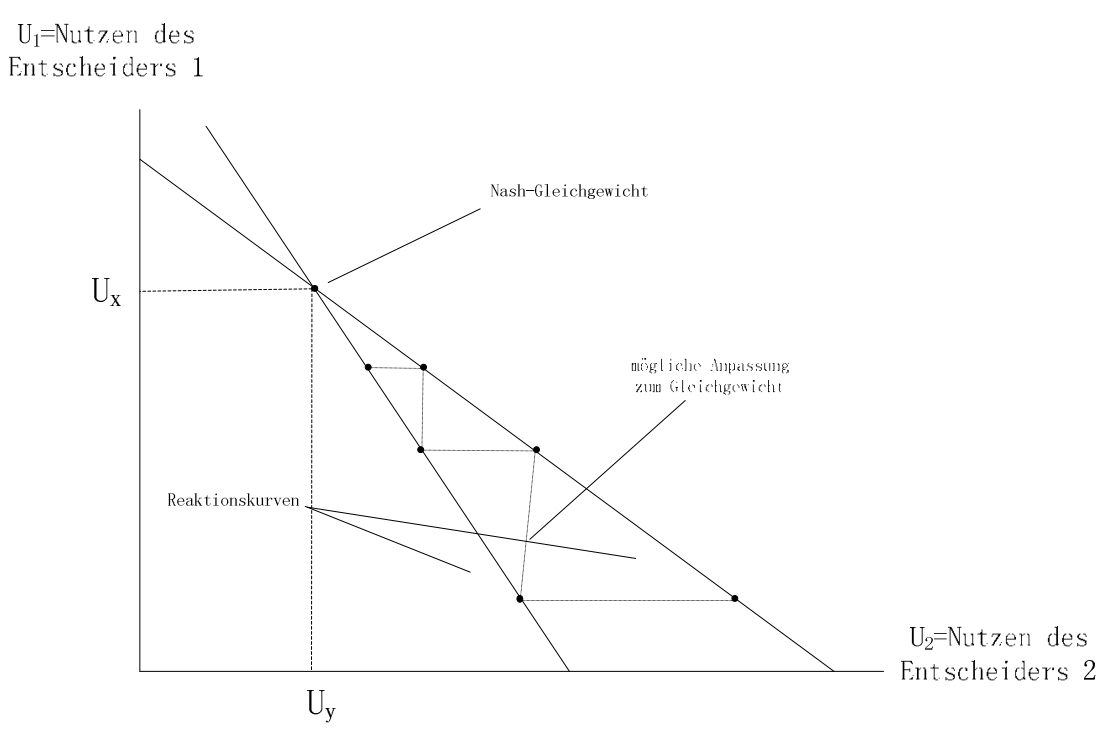

In Abbildung 5 verbindet die punktierte Linie die Strategienpaare, die sich auf Grund opportunistischen Verhaltens der Spieler dynamisch verändern, bis das Nash-Gleichgewicht erreicht ist. Die Linie ist deswegen punktiert, weil im Vergleich zum tatsächlichen, durch einen Abstimmungsprozess erreichten Gleichgewicht, wie z.B. ein Gleichgewicht zwischen Angebot und Nachfrage, ein Nash-Gleichgewicht nur ein durch Gedankenspiel (unter den Annahmen von Rationalität, gemeinsamem Wissen und statischer Interpretation) erreichtes Gleichgewicht ist. Im Nash-Gleichgewicht hat keiner der Spieler einen Anreiz, von dem Strategienpaar abzuweichen, da die Spieler gemeinsam ihre Gewinne maximieren können. Rieck hat diesen Charakter des (Nash-),,Gleichgewichts“ hervorragend erklärt, ${ }^{608}$ obwohl der Gedanke ursprünglich aus der klassischen Mechanik kommt:

„Befindet sich ein System im Gleichgewicht, so entwickelt es keine Kräfte aus sich selbst heraus, um den Systemzustand zu ändern. Daher wird ein System einen Gleichgewichtszustand beibehalten, solange keine ändernden Kräfte von außen auftreten, das heißt, solange sich die Rahmenbedingungen nicht ändern. “

Für Pech und Leid könnte die „Lösung“ ihres Dilemmas so aussehen: Sie wissen, dass sie nur über das konstruktive Strategiepaar s - s ,gemeinsam“ besser wegkommen können als über

${ }^{608}$ Rieck, Spieltheorie, S. 33. 
andere destruktive Strategiepaare wie z.B. g - s oder g - g; ,parallel“ wissen sie auch, dass sie beide Nutzenmaximierer sind und die Struktur und Auszahlungen des Spielbaums auskennen. Durch den Wechsel von der individuellen zur kollektiven Sichtweise könnte es auch in der „one-shot simultaneous situation“ für nutzenmaximierende Akteure rational sein, sich kooperativ zu verhalten, weil dies die einzige Möglichkeit zur gemeinsamen Nutzenmaximierung ist. ${ }^{609}$

Das Paradox des Gefangenenparadoxes ist: Je nach dem (gemeinsamen) Blickwinkel der Spieler könnten zwei Nash-Gleichgewichte entstehen, und zwar die „lose-lose“-Situation wegen der individuellen Rationalität oder die „win-win“-Situation auf Grund der kollektiven Rationalität. Ob die individuelle Rationalität die dominante Sichtweise ist, wie ihre Anhänger behaupten, ${ }^{610}$ lässt sich nicht nachweisen. Während die Dominanz der individuellen Rationalität eher nur für das laborartige einmalige Gedankenspiel gilt, spricht in der Realität vieles für die kollektive Rationalität, wo viele andere Faktoren, wie z.B. Gewissen, Reputation, wiederholte Interaktion oder Gesetz etc., ins Spiel kommen. Nach dem allgemeinen Verständnis über das Gleichgewicht können sie (insbesondere das Gesetz) das Zünglein an der Waage sein, die Entfaltung des selbstzerstörerischen Potenzials der individuellen Rationalität verhindern und die kollektive Rationalität stärken. Fest steht, dass die Spieltheorie bzw. Wirtschaftswissenschaft ein eindeutiges Konzept nicht zur Verfügung stellen kann. Deswegen werden wir im Folgenden die vorstehenden Erkenntnisse in der Analyse des Effizienzkampfs zwischen Vertrauen und Zivilrecht um den Ordnungsraum der Wertschöpfung einsetzen.

Eine der Voraussetzungen für die Entstehung eines Gefangenendilemmas ist die Informationsintransparenz zwischen der Akteuren, welche vereinfach gesagt zum Zusammenbruch des Vertrauens führt, der wiederum die Kooperationsbereitschaft der Beteiligten eliminieret. Genau diese Voraussetzung liefert auch das amerikanische Recht mit seinem Registersystem und Rechtspraxis! Das dezentralisierte Registersystem kann keine zuverlässige Quelle bzgl. der Belastung liefern. Statt diesen Mangel durch die Konstruktion

\footnotetext{
${ }^{609}$ M.w.N.: Langerfeldt, Das Gefangenendilemma, WiSt, 2003, S. 229 f; ausführliche Erörterung der Rationalen Kooperation in ,one-shot simultaneous PD-Situations“ s. Heiner, S. 1 ff.

${ }^{610}$ Langerfeldt, Das Gefangenendilemma, WiSt, 2003, S. 229.
} 
der positiven und negativen Publizität im Sinne des deutschen Grundregisterrechts aufzufangen wählt man lieber den einfachen, aber kostenintensiven Weg der Versicherung. Diese aus dem Registersystem selbst stammende Unsicherheit wird durch abenteuerliche Vertragsgestaltung verkompliziert bis völlige Informationsintransparenz herrscht. Während der Finanzkrise hörte man öfter den Satz „es blickt niemand mehr durch“. Wenn Finanzakteure wie Banken den Wert der Finanzprodukte ihrer Verkehrspartner, genauer gesagt den Wert der Sicherheit der Finanzprodukte ihrer Verkehrspartner, nicht mehr durchblicken und abschätzen können, dann befinden sie sich in einem Gefangendilemma, dessen Ausgang der Zusammenbruch des Interbankenverkehrs bedeutet.

Hinter dieser kurzen Problembeschreibung verbergen sich höchstkomplexe Nutzensberechnungen, welche erst bei der Konstruktion des neuen Registers dargestellt werden, ${ }^{611}$ weil man nur so die Feinheiten der Gestaltung besser verstehen kann.

\section{e) Zusammenfassung}

Das Problem des Publizitätsgrundsatzes liegt in der Diskrepanz zwischen der starren gesetzlichen Strukturen und dynamischer wirtschaftlicher Entwicklung. Die in den vergangenen hundert Jahren nahezu unveränderte Grundstruktur der Publizität ist dem modernen Verkehr im Informations- und Globalisierungszeitalter nicht mehr gewachsen, weil sie gegen bestimmte Gesetze der Wirtschaftlichkeit verstößt und die Kooperation der Einzelnen hindert! Deshalb ist der heutige Publizitätsgrundsatz nicht nur ineffizient (Faustpfandrecht), er verursacht zusätzliche Rechtsunsicherheit in Form von Sicherungskollision oder Informationsasymmetrie etc.

Nach der Transformationskurve kann man dieses Problem nur durch Hinzufügen effizienterer Komponente lösen. 


\section{Zentrales elektronisches Register als Lösung}

T3. Die (a) dogmatische Unvollkommenheit des Abstraktionsprinzips und des deutschen Zivilrechts kann (b) durch Hinzufügen fehlender komplettierender Reglungsmechanismen (zentrales elektronisches Registersystem), behoben werden.

\section{$\S 13$ Sicherheitsbestellung}

(1) Ein Sicherungsgut kann in der Weise belastet werden, dass an denjenigen, zu dessen Gunsten die Belastung erfolgt, eine bestimmte Geldsumme aus dem Sicherungsgut zu zahlen ist.

(2) Die Sicherheit kann auch für eine zukünftige oder bedingte Forderung bestellt werden. ${ }^{612}$

\section{Institutioneller Hintergrund für den Bedarf eines Zentralregisters}

So beschwert sich Strange über die Verwendung des Schlagwortes „Globalisierung““: 613

"a term ......(too often) used by a lot of woolly thinkers who lump together all sorts of superficially converging trends ...... and call it globalization without trying to distinguish what is important from what is trivial, either in causes or in consequences."

Wie wir den schwammigen Begriff „Globalisierung“ im Hinblick auf die kommende Analyse $\mathrm{zu}$ verstehen haben, möchte ich anhand eines konkreten Gegenstands demonstrieren, nämlich dem Symbol des Globalisierungszeitalters - Computer. Um dieser Frage nachzugehen, habe ich das Gehäuse meines Dell-Desktopcomputers aufgemacht und mich über dessen Innenleben schlau gemacht; anschließend noch über „yahoo - finance“ einen Blick auf die Aktien von Dell Inc. geworfen: Mein Computer ist ein übliches Modell, das man über den

\footnotetext{
${ }^{612}$ Hier liegt eine wirtschaftlich notwendige Durchbrechung des Bestimmheitsgrundsatzes.

${ }^{613}$ Dicken, Global Shift, S. 4.
} 
Online-Vertrieb Dells überall auf der Welt bestellen kann. Zusammengebaut wurde der Computer in Irland, und zwar mit Gehäuse und Mainboard aus China, CPU aus den USA, Festplatte aus Japan, DVD-Laufwerk aus Südkorea usw. Einen dreijährigen Vor-Ort-SupportService und eine Unfallversicherung gibt's noch dazu. Die US-Firma Dell ist an der New Yorker Börse Nasdaq 100 notiert; ihre meisten Aktien sind im Besitz von institutionellen Investoren und der Rest kann von jedermann, auch über Internet-EBS (Electronic Broking Service), erworben werden. ${ }^{614}$

Durch den Computer sehen wir eine total vernetzte Welt, von Nachfrage, Produktion, Logistik, Service, bis hin zu Finanzierung und Management. Die Organisation der sensibel verflochtenen Faktoren der internationalen Transaktionen ist auf Grund der geografischen Entfernung, unterschiedlicher Sprachen, Kulturen, politischer und rechtlicher Rahmenbedingungen äußerst komplex und kompliziert. Grundsätzlich gilt das Prinzip: Je größer die geografische Entfernung, je mehrstufiger und zeitaufwendiger die Transaktion, je heterogener die kulturellen, politischen oder rechtlichen Umfelder sind, desto komplexer, zeit-, kosten-, und risikointensiver wird das Geschäft. Für die Institutionen, ${ }^{615}$ die den Kreislauf des modernen Wirtschaftsverkehrs regulieren, besteht die Aufgabe darin, das durch die Arbeitsteilung und Spezialisierung erzeugte Potential an Leistungsstörungen zu mildern und abzubauen. Im Zeitalter der Globalisierung gilt das Motto: Schneller, flexibler, effizienter, (gerechter, nachhaltiger) ${ }^{616}$ und vor allem sicherer. All das ist leichter gesagt als getan. Diesbezüglich werden wir die Mechanismen des Vertrauens und Vertrages miteinander vergleichen.

\footnotetext{
${ }^{614}$ Die Geschichte des weltweit zweitgrößten Computerherstellers Dell ist ein trefflicher Spiegel der Globalisierung. Die Firma wurde im Jahr 1984 von Michael Dell gegründet, und zwar mit 1000 US-Dollar. 1987 expandierte das Unternehmen in das U.K., 1988 in die BRD. Seit 1996 kann man Dell-Produkte über das Internet bestellen. Vor dem Zusammenbruch der UdSSR im Jahr 1991 verlief der Kurs von Dell-Aktien nur mäßig. Im Dez. 2008 belief sich der Unternehmenswert (trotz der Finanzkrise immerhin) auf ca. 15 Mrd. USDollar. Ein Wertzuwachs von unglaublichen 1500.000.000.000\%

${ }^{615}$ Ripperger, Vertrauensmechanismus bei der Organisation internationaler Transaktion, S. 259 f.: Viele formelle oder informelle Institutionen, wie z.B. internationales Wirtschaftsrecht, Schiedsgerichtswesen, Mediation, internationaler Konzern, Wirtschaftsverband etc., können zur Verringerung von Risiken und zur Regelung von Leistungsstörungen bei internationalen Transaktionen beitragen; sie weisen aber unterschiedliche Schwachstellen auf.

${ }^{616}$ Wie schon erwähnt, die Problematik des Wertekonflikts zwischen gegenwärtigem Wohlstand und Gerechtigkeit/Nachhaltigkeit in der Globalisierung, obwohl sie sehr wichtig ist, nicht Gegenstand dieser Arbeit.
} 
Die Kampfansage seitens des Vertrauens sieht so aus:

Verträge sind in einem internationalen Kontext regelmäßig unvollständiger, in geringerem Maße durchsetzbar, kostenintensiver und weniger in der Lage, dem erhöhten Erfordernis nach Flexibilität gerecht zu werden als im binnenwirtschaftlichen Bereich. ...... Indem explizite Verträge als Organisationsmechanismus bei internationalen Transaktionen deutlich an Effizienz verlieren, steigt der Bedarf an Vertrauen. ...... “617

Mit folgenden Kostenkurven kann man den Kern dieser Aussage veranschaulichen:

Abb. 6 - Durchschnittskostenkurven ${ }^{618}$ und Effizienz von Vertrauen/Verträgen ${ }^{619}$

DK

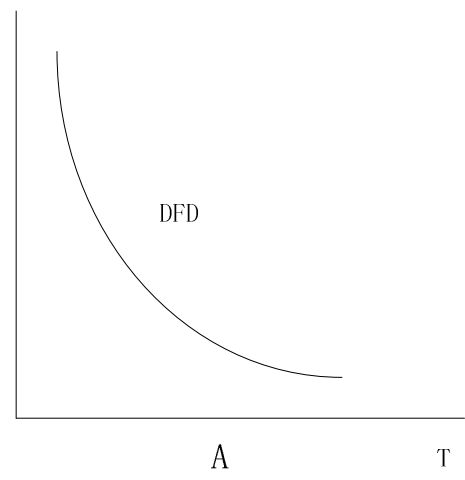

Hitiziont

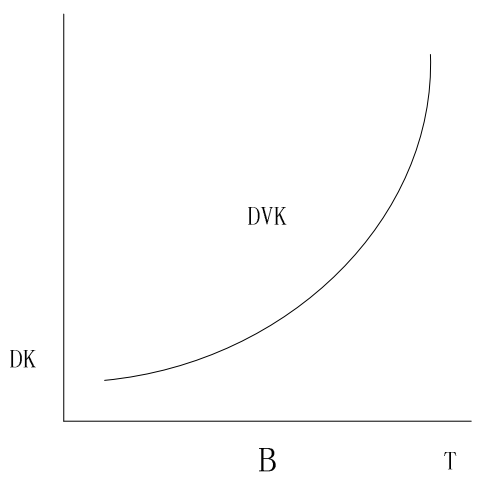

B
DK

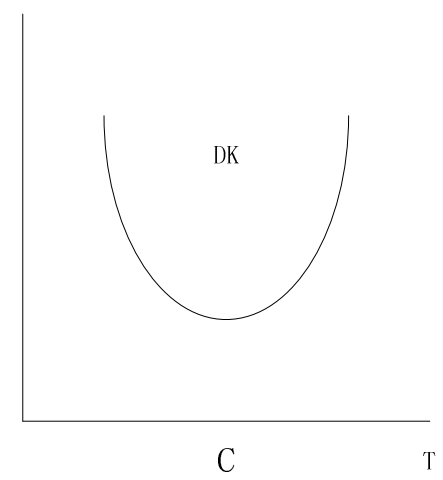

Explizilo Vorluge im

internat jonkt lon

Kontext

\footnotetext{
${ }^{617}$ Ripperger, Vertrauensmechanismus bei der Organisation internationaler Transaktionen, S. 288.

${ }^{618}$ Vgl. Varian, Mikroökonomik, S. 436.

${ }^{619}$ Ripperger, Vertrauensmechanismus bei der Organisation internationaler Transaktionen, S. 278.
} 
Nach Ripperger sind die Kosten des Vertrauens in Form von Informations- und Anreizkosten zum überwiegenden Teil einmalig wegen des Aufbaus von Vertrauen anfallende SetupKosten (Fixkosten), deren durchschnittliche Höhe mit jeder zusätzlichen Transaktion innerhalb einer bestehenden Vertrauensbeziehung fällt, also in der Situation A. ${ }^{620}$ Die Transaktionskosten des Rechts, wie z.B. Kosten für Rechtsberatung, Vertragsverhandlungen und -gestaltungen, Rechtsdurchsetzung etc., sind hingegen variable Kosten (Abbildung B), deren Durchschnitt mit steigenden Transaktionen aufwärts geht. ${ }^{621}$ Nach der Kostenlehre der Mikroökonomik sind aber für die Effizienzbewertung nicht etwa die durchschnittlichen Fixkosen oder variablen Kosten entscheidend, sondern die Gesamtdurchschnittskosten der entsprechenden Unternehmung (Abbildung C). ${ }^{622}$ Außerdem gehören Anreizkosten in Form von Treueprämien eindeutig nicht zu den Fixkosten; sie fallen mit jeder neuen Transaktion erneut an. An dieser Stelle ist es voreilig zu behaupten, dass mit einer erhöhten (erfolgreichen) Anzahl von Transaktionen das Vertrauen das Recht ersetzen kann. Vielmehr muss man die Mechanismen des Vertrauens und Rechts genauer untersuchen, indem man ihre „Performance“ im Lichte der Anforderungen des modernen (globalen) Verkehrs gegenüberstellt.

Die fünf Hauptansprüche des modernen (globalen) Verkehrs - Einfachheit, Schnelligkeit, Flexibilität, Effizienz und Sicherheit - überlagern sich und sind eng miteinander verflochten. Effizienz stellt das oberste Ziel dar. Danach soll der Nutzen (einer bestimmten Gruppe ${ }^{623}$ ) mit geringstem Aufwand maximiert werden. Einfachheit, Schnelligkeit und Flexibilität sind die technischen Mittel, die zur Erreichung dieses Zieles dienen, und Sicherheit bildet das stabilisierende Gegengewicht in der Wertzirkulation.

Hinsichtlich der Schnelligkeit zeichnen sich Vertrauen und Recht durch unterschiedliche Wirkungsweisen aus. In der Anfangsphase einer Geschäftsbeziehung verhindern das mit der

\footnotetext{
${ }^{620}$ Ripperger, Vertrauensmechanismus bei der Organisation internationaler Transaktionen, S. 275 f., 288.

${ }^{621}$ Ripperger, Vertrauensmechanismus bei der Organisation internationaler Transaktionen, S. 259 ff.

${ }^{622}$ Varian, Mikroökonomik, S. 435 ff., 419 ff.: Das Ziel ist Minimierung der Gesamtdurchschnittskosten.

${ }^{623}$ Wer zu dieser bestimmten Gruppe gehört, ist eine heikle Frage. Die Gruppe kann aus bestimmten Firmen, Staaten sein; kann aber auch die Erdbevölkerung sein. Hierdurch sieht man, dass die Grenze zwischen internationalem Privatrecht und öffentlichem Recht fließend ist.
} 
Spielsumme überproportional steigende Risiko ${ }^{624}$ und das Vertrauensdilemma eine Kooperation auf hohem Niveau. Der Vertrauensgeber ist gezwungen, die Vertrauenswürdigkeit des Vertrauensnehmers zu ermitteln, indem er ein Großprojekt aufspaltet und kleine Aufträge je nach Erfolg schrittweise vergibt. In Bezug auf die Kreditfinanzierung von Großprojekten kann das dazu führen, dass die kapitalintensiven Großprojekte wegen Kreditmangel ganz scheitern oder zumindest die Aufbauphase sich erheblich verlangsamt. Im Gegensatz zu der langsamen Aufbauphase des Vertrauens kann das (internationale) Recht, welches abstrakte Regeln für abstrakte Verkehrsteilnehmer bereitstellt, ein relativ schnelles Zustandekommen der Kooperationen herbeiführen. Vereinfacht gesagt heißt das: „man muss nur unterschreiben.“

Sobald das Vertrauensverhältnis sich etabliert hat, kann das Vertrauen dann seine wahre Stärke voll entfalten, da in einem Vertrauensspiel keine externen Einschränkungen existieren, die die Handlungsspielräume der Beteiligten einschränken. Die Parteien können jederzeit, wenn nötig auch ohne Absprache, den veränderten oder sogar sich verändernden Umweltzuständen entsprechend die Kooperation anpassen. Der Preis für diesen hohen Grad an Flexibilität ist das Fehlen an Sicherheit in zweifacher Hinsicht: Erstens bleibt das Vertrauensdilemma beim „End Game“ ungelöst; zweitens bietet das personenbezogene Vertrauen keine Sicherheit gegen sich verschlechternde Umweltzustände, die außerhalb des Einflussbereichs des Partners liegen. Für das zwingende Recht ergeben sich zwar diese zwei Probleme nicht, ihm fehlt aber wegen der Unvollständigkeit und öffentlichen Förmlichkeit die Flexibilität.

Hinsichtlich der Effizienz als wichtigstes Kriterium in der Institutionenökonomik haben wir vorher schon das Hauptorientierungsmerkmal herausgearbeitet, nämlich die Risikoprämie. In der Entscheidungstheorie wird sie folgendermaßen interpretiert: „Eine riskante Maßnahme kann im Vergleich zu einer sicheren Alternative nur dann vorteilhaft sein, wenn sie im Urteil des Entscheiders gegenüber der sicheren alternative eine „Risikoprämie“ bietet, die höher ist als der Risikoabschlag. Stimmt die Risikoprämie mit dem Risikoabschlag überein, ist der

\footnotetext{
${ }^{624}$ s. D, II, 2, a), aa).
} 
Entscheider indifferent zwischen der riskanten und der sicheren Alternative. “625 In einer konkreten Entscheidungssituation stellt die Höhe der Risikoprämie den Richtwert der höchst tragbaren Transaktionskosten dar. Die in Betracht kommenden Institutionen dürfen nicht mehr Transaktionskosten verschlingen als die Risikoprämie. Wer diese rote Linie überschreitet, wird von einem rationalen Entscheider gar nicht als Handlungsoption wahrgenommen. Für den Rest gewinnen nur diejenigen Institutionen bzw. Kombinationen von Institutionen, die die Gesamteffizienzrechnung des Entscheiders überstehen können.

\section{Das „entsprechende“ Konzept eines allgemeinen Zentralregisters}

\section{a) Nutzensstrukturen der Akteure als Regelungsgegenstand}

Im Vorwort dieser Arbeit wurde das durch die Arbeitsteilung erzeugte Spannungsfeld zwischen Leistung und Gegenleistung als Grundproblem der menschlichen Gesellschaft genannt. Obwohl der bahnbrechende Beitrag von Jensen und Meckling - Theory of the Firm: Managerial Behavior, Agency Costs and Ownership Structure - sich nur auf das vertragliche Vermögensmanagement bezieht, ${ }^{626}$ hat er eine der Erscheinungsformen dieses Grundproblems angesprochen, nämlich das Vorhandensein des durch die Trennung von Eigentum und Management verursachten „Agency Problems“. Allgemein kann man von „Agency Relationship“ sprechen, wenn der Profit des Vertretenen (Prinzipals) von dem Handeln des Vertreters (Agent) abhängt und der Prinzipal Schwierigkeiten hat, die Handlungen des Agenten zu beobachten. ${ }^{627}$ Auf Grund dieser Informationsasymmetrie besteht für den Prinzipal ständig das Risiko, dass der Agent nicht im Interesse des Prinzipals handelt, wie es vereinbart wurde. Die dadurch entstehenden Effizienzverluste für den Prinzipal werden als „Agency Costs“ bezeichnet. Nach Jensen und Meckling kann das Prinzipal-AgentenProblem dadurch gemildert werden, indem man durch eine effizientere Gestaltung der relevanten Gesetze und Verträge die zu den Transaktionskosten gehörenden Agenturkosten senkt. ${ }^{628}$ Aus Sicht der Institutionenökonomik gilt das Rechtssystem aber nur als eine der

\footnotetext{
${ }^{625}$ Laux, Entscheidungstheorie, S. 216.

${ }^{626}$ Jensen/Meckling, Theory of the Firm, S. 309 f.

${ }^{627}$ Posner, Agency Models in Law and Economics, S. $47 \mathrm{f}$.

${ }^{628}$ Jensen/Meckling, Theory of the Firm, S. $376 \mathrm{f}$.
} 
funktional äquivalenten Strategien bzw. Mechanismen zur Verringerung von Transaktionskosten. Ein anderer komplementär einsetzbarer Mechanismus ist das Vertrauen, der dem Gegenstand dieser Arbeit - dem Kreditsicherungsrecht - besonders nah steht. Obwohl es ein wenig paradox klingt, basiert das Rechtssystem jedoch in gewissem Maße auf dem Vertrauen in die Funktionalität des Staatswesens und das Vertrauen wird dadurch von der zwischenmenschlichen Ebene auf die funktionale Systemebene verlagert; durch diese Verlagerung verwandelt sich die Aufgabenstellung von Verstärkung des Vertrauens in die Gewährleistung der Funktionalität des Rechtssystems; umgekehrt stellt die Rechtsordnung Reihen von Instrumenten für die Verstärkung des Vertrauens zur Verfügung. ${ }^{629}$

Der wichtigste Grund dafür, warum wir uns mit Hilfe der Spieltheorie ausführlich damit beschäftigen werden, auf welche Art und Weise sich die beiden Institutionen (Vertrauen und Recht) auf das „Agency Problem“ auswirken, liegt darin, dass das Nutzenkalkül in einem schrankenlosen Vertrauensspiel die Urstrukturen und Fundamente der Kooperation enthält. Die daraus gewonnenen Erkenntnisse werden dann in der Rechtsvergleichungs- und Rechtsgestaltungsphase als entsprechende Orientierungshilfe dienen. Die anderen „Agency Costs“ senkenden Methoden werden nur einzelfallbezogen angesprochen, wie z.B. der Mechanismus der Anreize oder der bürokratischen Kontrolle im Zusammenhang mit dem Refinanzierungssystem durch sekundäre Immobiliensicherheiten und der Weltfinanzkrise.

\footnotetext{
${ }^{629}$ Ripperger, Okonomik des Vertrauens, S. 52 ff.
} 
Abb. 7 Prinzipal - Agenten - Problem ${ }^{630}$

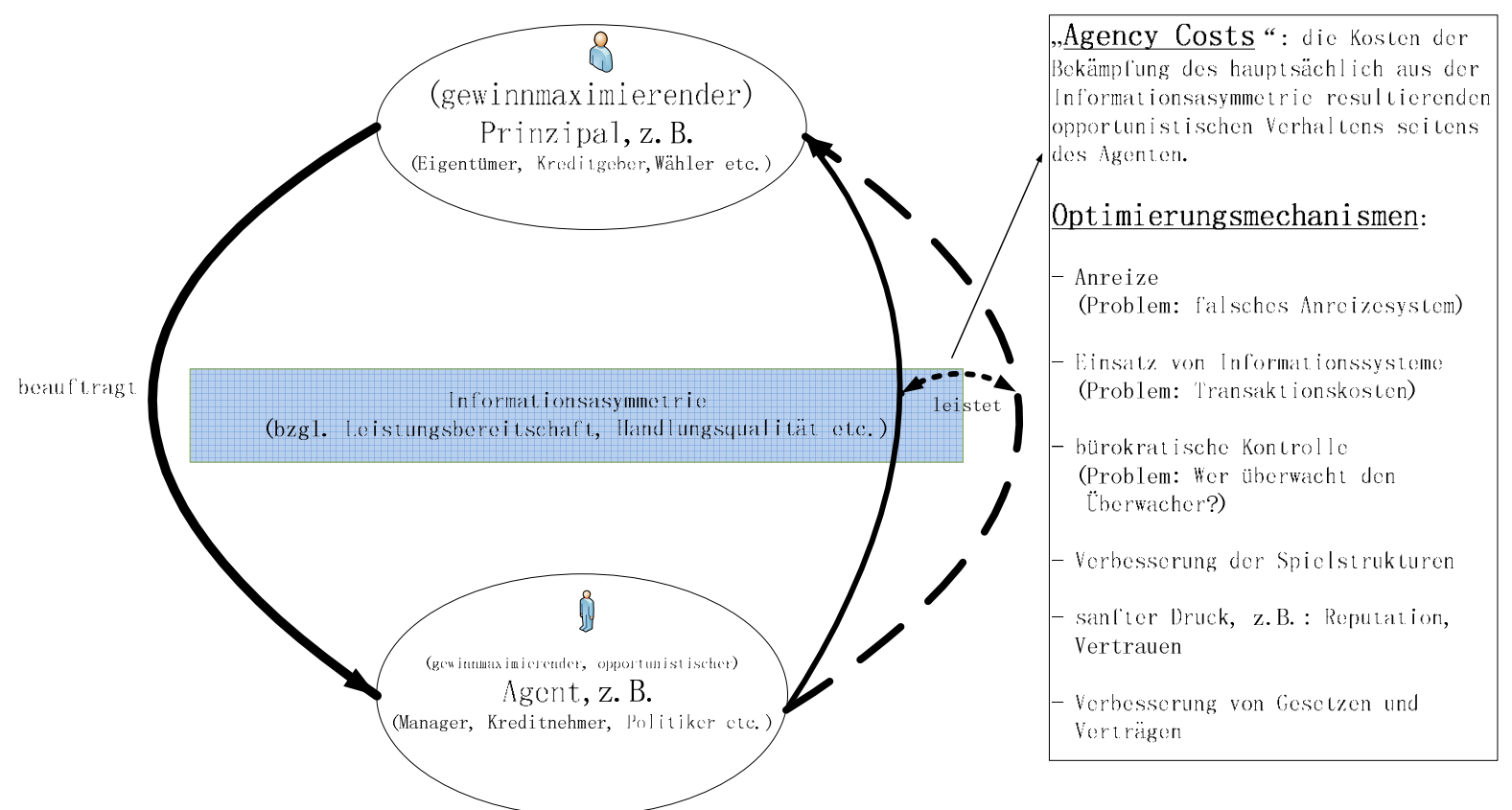

Eine der Stärken der Spieltheorie liegt in der Analyse der mit Informationsasymmetrie behafteten Interaktionen zwischen den Homo oeconomicus. Im Folgenden versuchen wir mit diesem Instrument das Prinzipal-Agenten-Problem des (Kreditsicherungs)Rechts schrittweise zu analysieren. Zunächst fangen wir mit dem „Spiel“ der Kreditfinanzierung (Vorleistung nichtkooperatives Spiel) in der vereinfachten Zwei-Personen-Form an; zum Zweck der Rechtsanalyse wird dieses „Spiel“ im Laufe dieser Arbeit durch Hinzukommen weiterer realitätsnaher Elemente und Mechanismen immer komplexer. Das Grundverhaltensmuster jedes Spiels ist die sog. Rückwärtsinduktion: um die Reaktion des Gegenspielers herauszufinden, muss der strategisch handelnde Akteur versuchen (ex ante), so weit wie möglich in die Kombinationen der Handlungsmöglichkeiten aller Beteiligten (einschließlich der eigenen) des Spiels zu sehen, dann rechnet er von dem Wunschergebnis bis zur

\footnotetext{
${ }^{630}$ Vgl. die Erzählungen in: Erlei u.a., Neue Institutionenökonomik, S. 70 f.; Posner, Agency Models in Law and Economics, S. 47 f.
} 
gegenwärtigen bestmöglichen Entscheidung zurück. ${ }^{631}$ Durch das Freilegen und Verändern der Spielstrukturen kann illustriert werden, wie sich Vertrauen und (mögliche) gesetzliche Regelungen (,shadow of the law“) auf das Verhalten des Homo oeconomicus auswirken. ${ }^{632}$ Die daraus gewonnenen Ergebnisse dienen dann als Normzwecke der Rechtsgestaltung. Im Laufe dieser Analyse werden wir noch einem Grundprinzip der Ökonomik begegnen: „Trade can make everyone better of" ${ }^{633}$ was als das Fundament des globalen freien Handels und der Vertragsfreiheit gilt. Aber die spannende Frage lautet: wie soll eine Kooperation zwischen Egoisten entstehen?

\section{aa) Das Nutzenkalkül des Prinzipals}

\section{(1) allgemeine Modellierung}

Nehmen wir an, dass das Kreditfinanzierungsspiel zwischen zwei Spielern, also dem Kreditgeber (Gläubiger - Prinzipal) und Kreditnehmer (Schuldner - Agent), eine Art von „freewheeling game“ ist, d.h. die Spieler interagieren ohne irgendwelche externen Anreize oder Restriktionen wie etwa Boni, Verträge oder Sicherheiten. ${ }^{634}$ Die Geschichte könnte folgendermaßen aussehen: Der junge Physiker Doktor U, der aufgrund seiner Forschung ein Patent im Wert von $\mathrm{X}$ für eine Art besonders einfacher und kostengünstiger Herstellung von hocheffizienten Foliensolarzellen besitzt, will angesichts der hohen Energiepreise und anderer günstiger Bedingungen ( $\mathrm{N}_{1-\mathrm{n}}$ - Natur) erfolgreicher Unternehmer werden, kommt zur Bank B und möchte einen Kredit in Höhe von Y für das Projekt „Solar-GmbH“ aufnehmen. Der Einfachheit halber wird der Zeitraum des Projekts auf 5 Jahre begrenzt, und bis dahin sollen die Kreditsumme und der Wert des Patentes vollständig amortisiert und auf die Produkte übergegangen sein. Am Ende kann die $\mathrm{GmbH}$ eine Produktionsmenge im Wert von E

\footnotetext{
${ }^{631}$ Rieck, Spieltheorie, S. 224.

${ }^{632}$ Ayres, Playing Games with the Law, S. 1291, 1309.

${ }^{633}$ Mankiw, Principles of Economics, S. 6.

${ }^{634}$ Dieser Name ist aus Brandenburger/Nalebuff, the right game, S. 57 f. entnommen. Obwohl er inhaltlich deckungsgleich mit dem „nichtkooperativen Spiel“, er aber ist weniger verwirrender; Rieck, Spieltheorie, S. 34 ff.: „,in der Spieltheorie gibt es eine für Anfänger verwirrende Kategorisierung zwischen kooperativem und nichtkooperativem Spiel. Es ist nicht so, dass in einem nichtkooperativen Spiel keine Kooperation existiert. Der Unterschied besteht darin, dass in einem kooperativen Spiel Kooperation als auf jeden Fall gegeben vorausgesetzt wird, wogegen in einem nichtkooperativen Spiel Kooperation nur als Resultat von Entscheidungen der Spieler entstehen kann.“.
} 
erbringen, womit eine zusätzliche Wertschöpfung von $G$ verbunden ist. U verspricht der B hohe Zinsen in Gesamthöhe von Z. Offensichtlich sind das Zustandekommen und erfolgreiche Unternehmen dieses Geschäfts nicht nur für die Beteiligten, sondern auch für die ganze Gesellschaft vorteilhaft, weil alle durch die Zusammenfügung des Kapitals des Kreditgebers und der Produktivität des Kreditnehmers von vermehrtem Reichtum profitieren. Deswegen soll die Erfolgsaussicht dieser Transaktion gefördert werden. In diesem „KreditfinanzierungsFreewheeling-Game“ hängt das Zustandekommen der Kooperation zunächst von der Erstentscheidung der Bank ab, ob sie das Geschäft eingehen will; mit anderen Worten heißt das, woraus besteht das rationale Entscheidungskalkül der Bank? Der Ausgangspunkt (aller vermögensbezogenen Austauschverträge) ist klar: die Bank will durch das Geschäft ihren Nutzen maximieren. In der Entscheidungstheorie nennt man das als „Entscheidung bei Risiko und einem Ziel“. ${ }^{635}$ Ohne externe Anreize oder Restriktionen wandelt sich das Kreditfinanzierungsspiel zu einem Vertrauensspiel. Die vorleistende Bank muss darüber entscheiden, ob sie darauf vertrauen darf, dass sie am Ende die Kreditsumme nebst Zinsen zurückbekommen wird (Wahrscheinlichkeit p - probability). Diese scheinbar simple Frage überfordert den Menschen mit seinem sogenannten gesunden Menschenverstand. Nichtsdestotrotz wollen wir die Entscheidungssituation in einer Welt der Informationsasymmetrie mit Hilfe der Rückwärtsinduktion unter die Lupe nehmen, weil sich dahinter die institutionellen Normzwecke des (Kreditsicherungs)Rechts verbergen.

In der Entscheidungslehre gibt es hauptsächlich drei Kriterien für die Entscheidungssituation bei Risiko: Die $\mu$-Regel, das $(\mu, \sigma)$-Prinzip und das Bernoulli-Prinzip. ${ }^{636}$ Anhand der $\mu$-Regel hat Michael Adams in seiner Dissertationsschrift die Verhältnisse zwischen Kreditsumme, Zinssatz, Konkursrisiken und Auszahlungsquote analysiert. ${ }^{637}$ Nach der $\mu$-Regel ist diejenige Entscheidung die optimale, die den Erwartungswert der Zielgröße (z.B. monetärer Nutzen) maximiert. Sie überlässt dem Entscheider aber keinen Raum für subjektive Wertschätzungen und berücksichtigt auch nicht seine die Risikoeinstellungen. Das Bernoulli-Prinzip wird erst

\footnotetext{
${ }^{635}$ Nach meinem Verständnis ist die Spieltheorie ein Teilbereich der Entscheidungstheorie mit der Besonderheit, dass das Ergebnis des Spiels von der dynamischen Korrelation der an den Auszahlungen orientierten Mitspieler bestimmt ist.

${ }^{636}$ Ausführlich: Laux, Entscheidungstheorie, S. 146 ff, 146, 153, 167, 170.

${ }^{637}$ Adams, Ökonomische Analyse der Sicherungsrechte, S. 47 ff.
} 
dann zu einer Entscheidungsregel, wenn die entsprechende Nutzenfunktion festgelegt ist; dazu muss jedoch die Indifferenzwahrscheinlichkeit ${ }^{638}$ eines konkreten Entscheiders durch Befragung ermittelt werden. Aus den genannten Gründen eignen sich die $\mu$-Regel und das Bernoulli-Prinzip nicht unmittelbar zur ökonomischen Analyse der Institutionen. In dieser Hinsicht steht das $(\mu, \sigma)$-Prinzip, ${ }^{639}$ das sowohl den Erwartungswert der Zielgröße als auch das begleitende Risiko erfasst, besser da.

Zurück zu unserer nutzenmaximierenden Bank: Sie würde dem U den Kredit gewähren (Vertrauenshandlung), wenn der potentielle Gewinn des Geschäfts höher als der potentielle

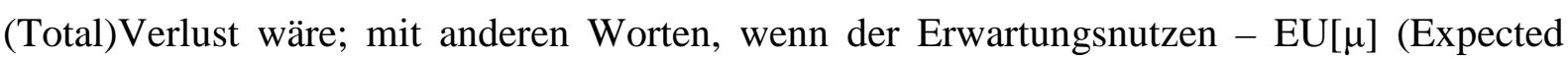
Utility) ${ }^{640}$ - größer als Null wäre, also wenn folgende Vertrauensungleichung (NeumanMorganstern-Nutzenfunktion) gilt: ${ }^{641}$

(1) $\mathrm{EU}[\mu]=\mathrm{Z} * \mathrm{p}-(-\mathrm{Y}) *(1-\mathrm{p})>0$ oder $\frac{\mathrm{p}}{1-\mathrm{p}}>\frac{\mathrm{Y}}{\mathrm{Z}}$ wobei $\mathrm{Z}>0$ und $-\mathrm{Y}<0^{642}$

Da sich die Bank (Vertrauensgeber) wegen fehlender externer Restriktionen unter Unsicherheit darüber, ob U (Vertrauensnehmer) im Erfolgsfall die Kreditsumme nebst Zinsen zurückzahlen wird (Vertrauenswürdigkeit), entscheidet, muss sie grundsätzlich von einer „Hold-Up-Situation“ ausgehen. Das bedeutet: Ihre Vorleistung an den U konstituiert eine irreversible Investition, die sie in ein einseitiges Abhängigkeitsverhältnis von U bringt. ${ }^{643}$ Auch wenn es genug objektive Beweise $\left(\mathrm{A}_{1-n}\right)$ für die Vertrauenswürdigkeit gäbe und die von

\footnotetext{
${ }^{638}$ Laux, Entscheidungstheorie, S. 167, 170: Der Entscheider muss angeben, bei welcher Wahrscheinlichkeit er indifferent ist zwischen dem (sicherem) Ergebnis (z.B. $20.000 €$ ) und der Lotterie (z.B. möglicher Gewinn 100.000 oder -50.000$)$

${ }^{639}$ Laux, Entscheidungstheorie, S. 146, 155: $\mu$ ist der Erwartungswert der Zielgröße; $\sigma$ ist das Maß dafür, wie stark die möglichen Zielgrößenwerte um den Erwartungswert der Zielgröße gestreut sind.

${ }^{640}$ Varian, Mikroökonomik, S. 261; Eisenführ/Weber, S. 207, 211 f.: die Erwartungsnutzentheorie wurde durch Neumann und Morgenstern (Gründer der modernen Spieltheorie) entwickelt und gilt als Grundlage rationalen Handelns für Entscheidungen bei Risiko.

${ }^{641}$ Vgl. Ripperger, Ökonomik des Vertrauens, S. 118 ff.: In ihrer Dissertationsschrift hat Ripperger die bis dahin noch nicht genau erforschten ökonomischen Mechanismen des Vertrauens modelliert. Zusammen mit der Entscheidungstheorie bildet die ökonomische Analyse des Vertrauens eine der Grundlagen für die Rechtsgestaltung in dieser Arbeit.

${ }^{642}$ Einfachheitshalber wird bei Verlusten der entgangene Gewinn der Bank nicht einkalkuliert.

${ }^{643}$ Ripperger, Ökonomik des Vertrauens, S. 74.
} 
B subjektiv wahrgenommene Vertrauenswürdigkeit des U (Vertrauenserwartung) der Bank p ${ }^{\mathrm{A}}$ gleich Eins, d.h. voll vertrauenswürdig, wäre, wird B noch mit dem Problem „Moral-HazardSituation“ ${ }^{644}$ konfrontieren: Der Prinzipal kann nie ein eindeutiges Urteil darüber fällen, inwieweit die Handlung des Agenten und nicht exogene Faktoren zum Erfolg oder Misserfolg des Geschäfts geführt hat. Deswegen muss die B die Umweltfaktoren $\mathrm{N}_{1-n}$ (z.B. diverse Marktsituationen), ${ }^{645}$ die die Leistungsfähigkeit des $U$ nach der Kreditgewährung beeinträchtigen könnten, mit in ihr Nutzenmaximierungskalkül einbeziehen $\left(\mathrm{p}^{\mathrm{N}}\right)$. Jetzt können wir die von $\mathrm{B}$ wahrgenommene subjektive ${ }^{646}$ Eintrittswahrscheinlichkeit (p) der Nutzenmaximierung (Rückzahlung der Kreditsumme nebst Zinsen) so ausdrücken:

(2) $p=p^{A} * p^{N}$

Damit ist (1) äquivalent zu:

(3) $\mathrm{EU}[\mu]=\mathrm{Z} * \mathrm{p}^{\mathrm{A}} * \mathrm{p}^{\mathrm{N}}-(-\mathrm{Y}) *\left(1-\mathrm{p}^{\mathrm{A}} * \mathrm{p}^{\mathrm{N}}\right)>0$

Nach dem $(\mu, \sigma)$-Prinzip muss die Bank (Prinzipal) noch das mit der Kreditgewährung (Vertrauenshandlung) verbundene Risiko berücksichtigen. Als Maßstab für das Risiko wird in vielen ökonomischen Modellen die Varianz der Zielgröße herangezogen; allgemein ist die Varianz $\sigma^{2}(\mu)$ einer Zufallsgröße $\mu$ als der Erwartungswert der quadratischen Abweichung der Zufallsgröße von ihrem Erwartungswert definiert: ${ }^{647}$

\footnotetext{
${ }^{644}$ Ripperger, Ökonomik des Vertrauens, S. 75.

${ }^{645}$ Laux, Entscheidungstheorie, S. 130; Ripperger, Ökonomik des Vertrauens, S. 116: Hier beträgt die Summe der Eintrittswahrscheinlichkeiten von A1-n und N1-n (sich ausschließender Ereignisse) Eins.

${ }^{646}$ Bzgl. der Variable $\mathrm{p}^{\mathrm{N}}$ hat Ripperger nicht immer eine beständige Ansicht: In „Ökonomik des Vertrauens“, S. 120 geht sie von einem subjektiven Charakter aus; aber in „Die Effizienz des Vertrauensmechanismus“, S. 271 ist $\mathrm{p}^{\mathrm{N}}$,die tatsächliche Wahrscheinlichkeit“. In der Entscheidungstheorie muss man von Subjektivität ausgehen; einen anderen Weg gibt es nicht: Eisenführ/Weber, Rationales Entscheiden, S. 151 ff: nach der ökonomischer Entscheidungstheorie sind Wahrscheinlichkeiten - zumindest in den Entscheidungssituationen - subjektiver Natur und können nicht objektiv festgestellt werden. Die in den Naturwissenschaften herrschende frequentistische Wahrscheinlichkeitsinterpretation ist in vielen schwierigen Entscheidungssituationen unbrauchbar, da es sich um neuartige Situationen handelt - keine zwei Würfe der Roulettekugel geschehen unter völlig identischen Bedingungen. Andernfalls würde immer dasselbe Ergebnis dabei herauskommen. Methoden für eine verbesserte Modellierung der Unsicherheit sind z.B.: Auflistung aller Pro- und Contra-Argumente, Erstellung von Ursachenbäumen, Kreation optimistischer und pessimistischer Szenarien etc.
}

${ }^{647}$ Laux, Entscheidungstheorie, S. 135 
$\sigma^{2}(\mu)=\operatorname{EU}\left[(\mu-\operatorname{EU}[\mu])^{2}\right]$

Da die Größe des mit der Kreditgewährung verbundenen Risikos nicht nur vom Verhältnis zwischen potentiellen Schaden und Nutzen abhängt, sondern mit deren Größe wächst, ergibt sie sich also aus: $:^{648}$

(4) $\sigma^{2}(\mu)=(\mathrm{Z}-\mathrm{EU}[\mu])^{2} * \mathrm{p}+((-\mathrm{Y})-\mathrm{EU}[\mu])^{2} *(1-\mathrm{p})$

Jetzt begegnen wir den für die institutionelle Analyse wichtigen Elementen in einem Entscheidungsprozess. Bis hierhin haben wir uns nur mit der subjektiven Einschätzung des Entscheiders auseinander gesetzt. Wie der Entscheider anhand seiner Einschätzungen seine Handlung bestimmt, hängt noch von seiner persönlichen Risikoeinstellung (r) $a b$; in einer Entscheidungssituation bei Risiko könnte er risikoscheu ( $\mu$-Rs), risikoneutral ( $\mu$-Rn) oder risikofreudig ( $\mu$-Rf) sein. Der Grundbegriff bei der Risikobewertung ist das Sicherheitsäquivalent (SÄ) - also der Risikoabschlag. Er bezeichnet diejenige sichere Konsequenz, bei der ein Entscheider indifferent zwischen diesem Betrag SÄ (a) und der zu beurteilenden Lotterie a ist, also z.B. zwischen sicheren $400 €$ und einer Lotterie (1000 €, 0,5; $0 €, 0,5)^{649}$

$\mathrm{EU}[\mathrm{SÄ}(\mathrm{a})]=\mathrm{EU}[\mathrm{a}]$

\footnotetext{
${ }^{648}$ Ripperger, Ökonomik des Vertrauens, S. 121.

${ }^{649}$ Eisenführ/Weber, Rationales Entscheiden, S. 222.
} 
Abb. 8 Risikoeinstellungen und Sicherheitsprämien in der RNF

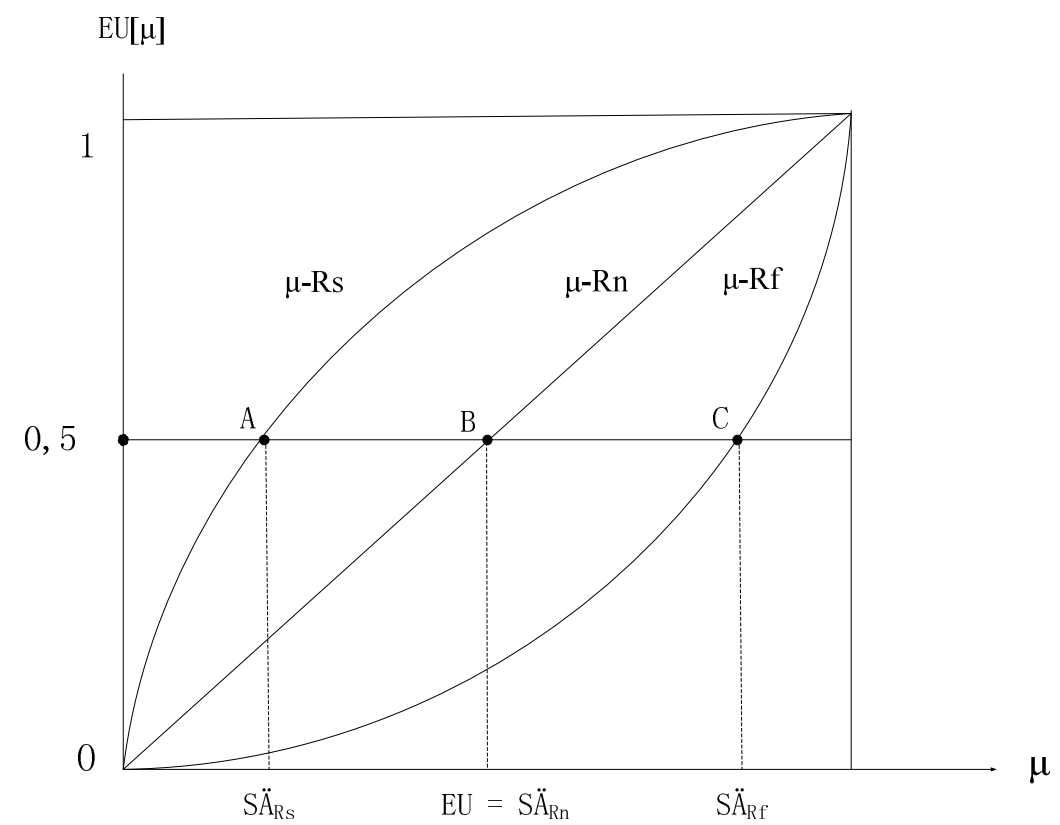

In der obigen grafischen Darstellung der Risiko-Nutzen-Funktion (RNF) kann man deutlich erkennen, dass die Risikoeinstellung des Entscheiders die Krümmung der Nutzenfunktion bestimmt. Bei Risikoaversion ist das Sicherheitsäquivalent jeder beliebigen Lotterie bzw. Entscheidungssituation kleiner als der entsprechende Erwartungswert, und deswegen ist die RNF streng konkav; bei Risikofreude hingegen ist sie konvex und bei Risikoneutralität linear. ${ }^{650}$ Diese Kategorisierung der Risikoeinstellungen ist für viele Zwecke aber zu grob. Deshalb entwickelten Arrow und Pratt folgende Maßzahl für die Quantifizierung der absoluten und von den Konsequenzen der Lotterie unabhängigen Risikoeinstellung: ${ }^{651}$

$\mathrm{r}(\mathrm{x})=-\frac{u^{\prime \prime}(x)}{u^{\prime}(x)}$

\footnotetext{
${ }^{650}$ Laux, Entscheidungstheorie, S. $216 \mathrm{ff}$.

${ }^{651}$ Eisenführ/Weber, Rationales Entscheiden, S. 225.
} 
Durch Multiplikation mit der jeweiligen Konsequenz x erhält man das Maß für die relative Risikoeinstellung: ${ }^{652}$

$\mathrm{r}^{*}(\mathrm{x})=-\frac{u^{\prime \prime}(x)}{u^{\prime}(x)} \cdot \mathrm{x}$

Anhand der beiden Formeln weiß man, dass sich die Risikoeinstellung in der Stärke und der Art der Krümmung der Nutzenfunktion exakt widerspiegelt. Dies möchten wir als Zwischenergebnis festhalten. Für die Beschreibung der Risikoeinstellung eines Entscheiders wird weiterhin der wichtige Begriff „Risikoprämie (RP)“ herangezogen, der sich aus der Differenz zwischen dem Sicherheitsäquivalent und dem Erwartungswert der Lotterie ergibt: ${ }^{653}$

(5) $\mathrm{RP}(\mu)=\mathrm{EU}[\mu]-\mathrm{SÄ}[\mu]$

Da bei Risikoaversion ein beliebiges Sicherheitsäquivalent kleiner als der entsprechende Erwartungswert ist, $\mathrm{RP}_{\mathrm{Rs}}$ (a) $>0$; bei Risikoneutralität $\mathrm{RP}_{\mathrm{Rn}}(\mathrm{a})=0$; bei Risikofreude $\mathrm{RP}_{\mathrm{Rf}}(\mathrm{a})$ < 0. Im Zusammenhang mit dem Vertrauensspiel kann „Risikoprämie“ als der Preis angesehen werden, der ein Vertrauensgeber $\mathrm{zu}$ zahlen bereit wäre, um die entscheidungsrelevanten Unsicherheiten zu beseitigen. ${ }^{654}$ Anhand des Arrow-PrattschenRisikoeinstellungsmaßes kann folgende Formel zur Schätzung des Sicherheitsäquivalents verwendet werden: ${ }^{655}$

(6) $\mathrm{S} \ddot{\mathrm{A}}=\mathrm{EU}[\mu]-\frac{1}{2} \mathrm{r} \sigma^{2} \mathrm{EU}[\mu]$

Die nutzenmaximierende Bank würde dem U den Kredit nur gewähren, wenn (1) der Erwartungsnutzen und (2) das Sicherheitsäquivalent positiv ist, also seine Risikoprämie

\footnotetext{
${ }^{652}$ Eisenführ/Weber, Rationales Entscheiden, S. 225.

${ }^{653}$ Eisenführ/Weber, Rationales Entscheiden, S. 223.

${ }^{654}$ Ripperger, Ökonomik des Vertrauens, S. 122.

${ }^{655}$ Ripperger, Ökonomik des Vertrauens, S. 122; Eisenführ/Weber, Rationales Entscheiden, S. 225 f., 226 ; ausführlich Laux, Entscheidungstheorie, S. 199, 208, 227 ff.
} 
seinen erwarteten Nutzen nicht übersteigt, d.h. wenn folgende Ungleichungen erfüllt wären: ${ }^{656}$

(I) $\mathrm{EU}[\mu]=\mathrm{Z} * \mathrm{p}^{\mathrm{A}} * \mathrm{p}^{\mathrm{N}}-(-\mathrm{Y}) *\left(1-\mathrm{p}^{\mathrm{A}} * \mathrm{p}^{\mathrm{N}}\right)>0$

(II) $\mathrm{EU}[\mu]-\frac{1}{2} \mathrm{r} \sigma^{2} \mathrm{EU}[\mu]>0$

Die Frage lautet: Was für Konsequenzen können wir aus diesen Ungleichungen für die institutionelle (Rechts)Analyse ziehen? Diese Frage kann am besten beantwortet werden, indem man das Kreditfinanzierungsspiel z.B. mit verschiedenen konkreten Zahlen versieht. Wir betrachten die Spiele zunächst aus Sicht der Bank (Prinzipal, Vertrauensgeber). Um sich auf das Wesentliche zu konzentrieren, werden die Unweltfaktoren $\left(\mathrm{p}^{\mathrm{N}}\right)$ an dieser Stelle nicht berücksichtigt (d.h. $\mathrm{p}^{\mathrm{N}}=1$; Stichwort: Energiekrise), und die von $\mathrm{B}$ subjektiv wahrgenommene Vertrauenswürdigkeit des $\mathrm{U}\left(\mathrm{P}^{\mathrm{A}}\right)$ auf einheitliche 0.85 gesetzt.

\begin{tabular}{|c|c|c|c|c|c|c|c|}
\hline Spiel & $\begin{array}{l}\text { Kredits } \\
\text { umme } \\
\text { (Y) } \\
\text { Mio. € }\end{array}$ & $\begin{array}{l}\text { Zinsen } \\
(\mathrm{X}) \\
\text { Mio.€ }\end{array}$ & $\begin{array}{l}\text { Die von } \\
\text { B subj. } \\
\text { wahrgeno } \\
\text { mmene } \\
\text { Vertraue } \\
\text { nswürdig } \\
\text { keit des } \\
\mathrm{U}\left(\mathrm{P}^{\mathrm{A}}\right)\end{array}$ & $\begin{array}{l}\text { Die von B subj. } \\
\text { eingeschätzte } \\
\text { Wahrscheinlich } \\
\text { keit, dass } \\
\text { negative } \\
\text { Umweltfaktoren } \\
\text { nicht eintreten } \\
\text { werden }\left(\mathrm{P}^{\mathrm{N}}\right)\end{array}$ & $\begin{array}{l}\text { Risiko der } \\
\text { Kreditgewähr } \\
\text { ung } \\
\left(\sigma^{2}\right) \\
\text { Mio. }\end{array}$ & $\begin{array}{l}\text { Mindestanforderung } \\
\text { an } \\
\text { persönliche } \\
\text { Risikoeinstellung } \\
\text { des Prinzipals (r) }\end{array}$ & $\begin{array}{l}\text { Risikoprämie bei der } \\
\text { Mindestanforderung an } \\
\text { persönliche } \\
\text { Risikoeinstellung des } \\
\text { Prinzipals (RP) } \\
\text { Mio.€ }\end{array}$ \\
\hline 1 & 1 & $\begin{array}{l}0,04 \\
(4 \%)\end{array}$ & 0,85 & 1 & 0,228 & $\mathrm{r}<8,78$ & 0.184 \\
\hline 2 & 1,7 & $\begin{array}{l}0,085 \\
(5 \%)\end{array}$ & 0,85 & 1 & 0,666 & $\mathrm{r}<3,00$ & 0.327 \\
\hline 3 & 3 & $\begin{array}{c}0,1668 \\
(5,56 \%)\end{array}$ & 0,85 & 1 & 2,089 & $\mathrm{r}<0,96$ & 0.593 \\
\hline
\end{tabular}

Wie man anhand Formel (3) errechnen kann, ist der Erwartungsnutzen in allen drei Spielen größer als Null. Damit ist die erste Bedingung der Kreditgewährung (Vertrauenshandlung) erfüllt. Allerdings kann man anhand der Tabelle deutlich erkennen, dass das Risiko $\left(\sigma^{2}\right)$ mit dem Zuwachs der Kreditsumme (Y) überproportional steigt und der durch die persönliche

\footnotetext{
${ }^{656}$ Ripperger, Ökonomik des Vertrauens, S. 123.
} 
Risikoeinstellung (r) gekennzeichnete Spielraum des Prinzipals für eine Vertrauenshandlung sich damit drastisch verkleinert. Ähnlich verhält sich auch die Risikoprämie so.

Als Resultat können wir an dieser Stelle Folgendes feststellen: In einer
Entscheidungssituation ist die Spielsumme im Vergleich zu anderen Variablen
überproportional wichtig!

\section{(2) Einfluss der Sicherungskraft auf das Nutzenskalkül des Kreditgebers}

Nun versuchen wir herauszufinden, welche Einflüsse verschiedene dingliche Sicherheiten bzw. ihre Sicherungskräfte auf das Nutzenskalkül des Kreditgebers (Sicherungsnehmers Prinzipals) haben. Um die Berechnungen einfach zu halten bleiben die Kreditsummen (Y), Zinssätze $(\mathrm{X})$ und die von $\mathrm{B}$ subjektiv wahrgenommene Vertrauenswürdigkeit des $\mathrm{U}\left(\mathrm{P}^{\mathrm{A}}\right)$ konstant. Bei der von $\mathrm{B}$ subjektiv eingeschätzten Wahrscheinlichkeit bzgl. negativer Umweltfaktoren $\left(\mathrm{P}^{\mathrm{N}}\right)$ werden nur die verschiedenen Sicherungskräfte der dinglichen Sicherheiten berücksichtig, also z.B.: ${ }^{657}$

\begin{tabular}{|c|c|}
\hline Sicherheit & Sicherungskraft $\left(\mathrm{P}^{\mathrm{N}}\right)$ \\
\hline Globalsicherungszession (GSZ) & 0,02 \\
\hline Sicherungsübereignung (SÜ) & 0,05 \\
\hline Faustpfandrecht (Fpf) & 0,30 \\
\hline Sicherungsgrundschuld (SG) & 0,60 \\
\hline
\end{tabular}

Die Spieltabellen werden dann wie folgt aussehen:

\footnotetext{
${ }^{657}$ Es wurde schon in $\underline{\mathbf{A}, \text { III, 3, b) }}$ erwähnt, dass die Rechtswissenschaft in wissenschaftstheoretischer Hinsicht Schwierigkeiten bei $\overline{\text { der Bildung }}$ von Beobachtungssätzen hat, so kann ich hier die Sicherungskräfte verschiedener Sicherheiten leider nur fiktiv abschätzen. Die Sicherungskraft der Sicherungsübereignung ist z.B. (wegen Sicherungskollisionen, fehlender Publizität, Besitzlosigkeit und der Möglichkeit des gutgläubigen Erwerbs, s. D, I, 1 und 2, a)) am geringsten. 0,05 bedeutet: von $100 €$ Kreditsumme rechnet der Kreditgeber (Sicherungsnehmer), dass er im Falle der Insolenz des Kreditnehmers (Sicherungsgebers) evtl. nur $5 €$ zurückbekommen könnte. Mit der Einführung eines elektronischen Zentralregister $(\underline{\mathbf{D}, \mathbf{I I}, \mathbf{3}, \mathbf{a}), \mathbf{b b})})$ könnte man künftig dann (anhand der Ergebnisse der Urteile) berechnen, wie hoch die eigentliche Sicherungskraft eines Sicherungsinstruments ist. Dies kommt einer Revolution der wissenschaftstheoretischen Beobachtung des $\underline{\text { Rechts }}$ gleich! Denn dadurch werden die Juristen zum ersten mal ein Werkzeug besitzen, mit dem sie die Wirkungen eines „Rechts(instituts)“ genau betrachten und justieren können!!
} 


\begin{tabular}{|c|c|c|c|c|c|c|c|}
\hline $\begin{array}{l}\text { Sicher } \\
\text { heiten }\end{array}$ & $\begin{array}{l}\text { Kredits } \\
\text { umme } \\
\text { (Y) } \\
\text { Mio.€ }\end{array}$ & $\begin{array}{l}\text { Zinsen } \\
(\mathrm{X}) \\
\text { Mio.€ }\end{array}$ & $\begin{array}{l}\text { Die von } \\
\text { B subj. } \\
\text { Wahrgen } \\
\text { ommene } \\
\text { Vertraue } \\
\text { nswürdig } \\
\text { keit des } \\
\mathrm{U}\left(\mathrm{P}^{A}\right)\end{array}$ & $\begin{array}{l}\text { Die von B subj. } \\
\text { Eingeschätzte } \\
\text { Wahrscheinlich } \\
\text { keit, dass } \\
\text { negative } \\
\text { Umweltfaktoren } \\
\text { nicht eintreten } \\
\text { werden }\left(\mathrm{P}^{\mathrm{N}}\right)\end{array}$ & $\begin{array}{l}\text { Risiko der } \\
\text { Kreditgewähr } \\
\text { ung } \\
\left(\sigma^{2}\right) \\
\text { Mio. }\end{array}$ & $\begin{array}{l}\text { Mindestanforderung } \\
\text { an } \\
\text { persönliche } \\
\text { Risikoeinstellung } \\
\text { des Prinzipals } ₫\end{array}$ & $\begin{array}{l}\text { Risikoprämie bei der } \\
\text { Mindestanforderung an } \\
\text { persönliche } \\
\text { Risikoeinstellung des } \\
\text { Prinzipals (RP) } \\
\text { Mio.€ }\end{array}$ \\
\hline GSZ & 1 & $\begin{array}{c}0,04 \\
(4 \%)\end{array}$ & 0,85 & 0,02 & 3,883 & $r<0,506$ & 0,982 \\
\hline SÜ & 1 & $\begin{array}{l}0,04 \\
(4 \%)\end{array}$ & 0,85 & 0,05 & 3,719 & $r<0,537$ & 0,958 \\
\hline Fpf & 1 & $\begin{array}{c}0,04 \\
(4 \%)\end{array}$ & 0,85 & 0,30 & 2,425 & $r<0,624$ & 0,235 \\
\hline SG & 1 & $\begin{array}{c}0,04 \\
(4 \%)\end{array}$ & 0,85 & 0,60 & 1,230 & $r<1,630$ & 0,511 \\
\hline
\end{tabular}

Durch diese Tabelle wird es deutlich: je höher die Sicherungskraft $\left(\mathrm{P}^{\mathrm{N}}\right)$ einer Sicherheit ist, desto ärmer ist das Risiko $\left(\sigma^{2}\right)$ eines Geschäfts und der Handlungsspielraum (r) des Kreditgebers (Sicherungsnehmers) ist desto größer.

Die vorstehenden Feststellungen anhand der (komplizierten) Modellierung scheinen einfach zu schein. Man könnte das Gefühl haben: zu welchen (scheinbar) einfachen Ergebnissen müssen nicht so komplizierte Wege gegangen werden. Dies ist jedoch nicht richtig.

Denn bei der Berechnung haben wir die Vertrauenswürdigkeit $\left(\mathrm{P}^{\mathrm{A}}\right)$ und Umweltfaktoren

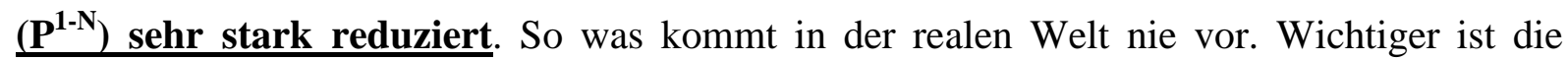
Aufstellung eines Modells, anhand dessen das computerisierte Registersystem die umfangreiche Datenverarbeitung bzgl. der Wirkungen einzelner Regelungsinstrumente übernehmen und ggf. Verbesserungsvorschläge machen kann. ${ }^{658}$

Jetzt verlassen wir eine Weile die Entscheidungssituation - „KreditfinanzierungsFreewheeling-Game“ (Vertrauensspiel) und betrachten das Ganze in einem noch größeren Zusammenhang. Da nach gängiger Meinung die Mehrheit der wirtschaftlich relevanten

\footnotetext{
${ }^{658}$ Wie verheerend die Unsicherheiten bzgl Vertrauenswürdigkeit $\left(\mathrm{P}^{\mathrm{A}}\right)$ und Umweltfaktoren $\left(\mathrm{P}^{1-\mathrm{N}}\right)$ in Krisensituation sein kann, s. D, I, 2, c); die Modellierung bereitet den Weg zur computerisierten Verwaltung des Vermögensrechts vor, und zwar mit der Geschwindigkeit des digitalen Zeitalters. Nur so ist ein Zusammenbruch der Informationsflüsse zu verhindern und die Echtzeit-Informationstransparenz zu verschaffen.
} 
Entscheidungsträger eher risikoavers ist, d.h. die meisten Entscheider für die Beseitigung der durch die Informationsasymmetrie bedingten Unsicherheit eine Summe bis zur Höhe der entsprechenden Risikoprämie zahlen würden, stellt die Risikoprämie eine Art von Transaktionskosten dar.

Die Höhe dieser Transaktionskosten spielt in der Entscheidung bzgl. der Geschäftswege eine entscheidende Rolle. Ein rationaler Nutzenmaximierer wählt immer den Weg, der ihn am wenigsten kostet. Mit anderen Worten, die effizienteste Institution gewinnt den Kampf, und als Jurist muss man klar erkennen, dass es nicht selbstverständlich ist, dass sich die Parteien immer für den Weg - „Absicherung des Geschäfts durch das Rechtssystem“ - entscheiden. ${ }^{659}$

Das Recht als Institution hat zahlreiche Herausforderer, wie z.B. das Vertrauen in der Abschlussphase, das Anreizsystem in der Durchführungsphase, Mediation im Streitfall usw. In einer Welt der Unsicherheit kann ich sicher behaupten, dass eine effizientere Gestaltung des (insbesondere Vermögens)Rechts im Interesse aller (auch der Juristen) liegt. Im Laufe dieser Arbeit werden wir uns mit Problemen dieser Art häufig auseinandersetzen müssen.

\section{bb) Nutzenkalkül des Agenten}

Bisher wurde das Nutzenkalkül des Agenten (Kreditnehmer U) darstellungstechnisch außen vor gelassen und die von $B$ subjektiv wahrgenommene Vertrauenswürdigkeit des $U\left(p^{A}\right)$ einheitlich auf 0.85 gesetzt. Das Nutzenkalkül des U in einem „KreditfinanzierungsFreewheeling-Game“ ist für das Zustandekommen des Geschäfts insoweit relevant, als es zugleich als Variable $\mathrm{P}^{\mathrm{A}}$ ins Nutzenkalkül der B einfließt. ${ }^{660}$ Wie hoch die tatsächliche Vertrauenswürdigkeit des U ist, kann aber nicht ohne weiteres allgemein quantifiziert werden. Zum Zweck der Operationalisierung müssen deshalb folgende Einschränkungen bei der Modellierung vorgenommen werden: ${ }^{661}$ wir nehmen an, dass B und U gleich schlau sind und

\footnotetext{
${ }^{659}$ Hier liegt der entscheidungstheoretische Hintergrund für das Effizienzproblem des Faustpfandprinzip im deutschen Recht, vgl. D, I, 2, a), aa), (1).

${ }^{660}$ Ripperger, Ökonomik des Vertrauens, S. 137.

${ }^{661}$ Zur allgemeinen Modellierung eines Spiels: Ayres, Playing Game with the Law, S. 1295
} 
die Strukturen des Spielbaums antizipieren können (Rationalitätsprinzip). ${ }^{662}$ Dieses Wissen stellt ihr gemeinsames Wissen (common knowledge) dar. Zudem wissen die Spieler auch, dass sie die Auszahlung des Spiels durch ihre eigene Handlung beeinflussen können. Deshalb nehmen sie den gesamten Prozess der dynamischen Korrelation gedanklich vorweg (statische Interpretation), um die eigene beste Strategie $\mathrm{zu}$ antizipieren. ${ }^{663} \mathrm{Im}$ Hinblick auf die Kooperation wissen wir schon, dass die Erstentscheidung der B von ihrer subjektiv wahrgenommenen Vertrauenswürdigkeit des $U\left(p^{A}\right)$ abhängt. Infolgedessen muss man sich zunächst mit dem Nutzenkalkül des U auseinander setzen. Der Ausgangspunkt des U ist der selbe wie der der B, nämlich durch die Kooperation den eigenen „Nutzen“ zu maximieren. An dieser Stelle stößt man auf einen besonders wertvollen Knotenpunkt von Philosophie, Ökonomik, Soziologie, Psychologie, Ethik und Recht, nämlich die Nutzenstruktur des Agenten (U). Im Folgenden versuche ich, bewusst auf die technische Ebene beschränkt, die subtilen Zusammenhänge darzustellen, um den Normzweck des (Kreditsicherungs)Rechts daraus zu gewinnen. Ein Anspruch auf Vollständigkeit und Systematik wird dabei aber nicht erhoben. Als Erstes wird leider auf das Philosophieren über „Empirismus und Rationalismus“ oder „Teleologische und Deontologische Ethik“ verzichtet, obwohl darin der eigentliche Ursprung vieler Grundsatzfragen liegt. Nur so ist eine technische Modellierung innerhalb eines begrenzten Raums möglich.

Im viktorianischen Zeitalter verwendeten die Philosophen das Wort „Nutzen“ als einen Indikator des Wohlbefindens oder Glücks eines Menschen. ${ }^{664}$ Obwohl die Mikroökonomik die Kardinalität des Nutzen zur „,mission impossible“ erklärt hat, ${ }^{665}$ ist die Grundidee des kardinalen Nutzens ${ }^{666}$ für die Modellierung des Nutzenkalküls des Agenten gar nicht so unbrauchbar, solange der Nutzenfaktor nur eine nicht zu konkretisierende Variable bleibt. In der Soziologie untersucht man menschliche Gesellschaften und die Dimensionen sozialen

\footnotetext{
${ }^{662}$ Zur Annahme der Rationalität in der Institutionenökonomik: Erlei u.a., Neue Institutionenökonomik, S. 4.; in der Spieltheorie: Rieck, Spieltheorie, S. 35.

${ }^{663}$ Rieck, Spieltheorie, S. 198.

${ }^{664}$ Varian, Mikroökonomik, S. 63.

${ }^{665}$ Varian, Mikroökonomik,S. $63 \mathrm{f}$.

${ }^{666}$ Varina, Mikroökonomik, S. 66: nach der kardinalen Nutzentheorie hat die Größe des Nutzens ökonomische Bedeutung.
} 
Handels und sozialer Beziehungen; der wichtigste Teil dabei ist die Kultur, welche die Kriterien liefert, mittels derer die Gesellschaftsmitglieder verschiedene Handlungen bewerten; solche Kriterien werden auch Werte genannt; sie sind eine von der Mehrheit geteilte allgemeine Vorstellung darüber, was gut und schlecht, was wünschenswert oder unerwünscht ist. ${ }^{667}$ Dies impliziert die (wünschenswerte) Zurückstellung eigener Interessen zugunsten der Interessen der Gemeinschaft und den Verzicht auf opportunistisches Verhalten. ${ }^{668}$ Durch die Sozialisation werden die Grundwerte (wie z.B. nicht töten, stehlen, betrügen; Liebe, Ehrlichkeit, Treue usw.) internalisiert, und sie beeinflussen dann von innen heraus das psychische Wohlbefinden des handelnden Subjektes. ${ }^{669}$ Aus diesem Grund entsteht das Phänomen des „unreinen Altruismus“, wonach der Wohltäter aus einem altruistischen Akt selbst einen gewissen Nutzen in Form von psychischer Befriedigung zieht. ${ }^{670}$ Die technische Umsetzung der oben erwähnten theoretischen Anschauungen sieht folgendermaßen aus: ${ }^{671}$ Wenn $\Delta \mathrm{U}_{\mathrm{B}}$ die durch die Handlung des $\mathrm{U}$ verursachte Nutzenveränderung bei der $\mathrm{B}$ und $\pi(-1$ $\leq \pi \leq 1)^{672}$ der Grad an Altruismus bzw. Opportunismus des $\mathrm{U}$ ist, dann gilt folgende Nutzenfunktion des $\mathrm{U}:^{673}$

$\mathrm{U}_{\mathrm{U}}=\mathrm{U}_{\mathrm{U}}\left(\mathrm{K}_{\mathrm{U}} ; \pi^{*} \Delta \mathrm{U}_{\mathrm{B}}\right)$

$\mathrm{K}_{\mathrm{U}}$ bezeichnet die Handlungskosten für U. Für die als Entscheidungsgrundlage dienende Nutzenstruktur des $U$ ist die Nutzenkorrelation $\pi$ in doppelter Hinsicht relevant: Erstens je mehr sich $\pi$ dem Wert Eins nähert, desto homogener wird sein Interesse im Verhältnis mit

\footnotetext{
${ }^{667}$ Joas, Soziologie, S. 18, 36, 83.

${ }^{668}$ Ripperger, Ökonomik des Vertrauens, S. 141.

${ }^{669}$ Joas, Soziologie, S. 137 ff, insbesondere S. 143 - Freud: Die innere Dynamik der Sozialisation.

${ }^{670}$ Ripperger, Ökonomik des Vertrauens, S. 138 ff., 142, 148: Für die ökonomische Analyse ist die Herkunft des altruistischen Akts (z.B. Mitgefühl - Adam Smith; Pflicht - Kant usw.) völlig bedeutungslos.

${ }^{671}$ Ripperger, Ökonomik des Vertrauens, S. 148 f.

${ }^{672}$ Ripperger, Ökonomik des Vertrauens, S. 149 f.

${ }^{673}$ Nach der herrschenden Meinung in der Mikroökonomik ist es nicht möglich, das „Glücksgefühl“ eines Subjektes zu bezifferen (s. Varian, Mikroökonomik, S. 66 f.). Deswegen verwendet man in der Theorie des Konsumentenverhaltens den Ordinalen Nutzenbegriff. Bei unserer Modellierung hier kommt man aber nicht um die Ausrichtung des Kardinalen Nutzens herum, weil wir nicht die gesamte Entscheidungsstruktur als eine „Black Box“ betrachten dürfen und die Verhältnisse zwischen den einzelnen Elementen klären müssen.
} 
dem der B; zweitens hat die Größe von $\pi$ hat einen direkten Einfluss auf die gesamte KostenNutzen-Rechnung des U. Wenn $\pi$ größer als 0 ist, kann U den Schaden bzw. Nutzen der B proportional internalisieren; wenn $\pi$ kleiner als 0 ist, befindet sich $U$ im Interessenkonflikt mit $B$ und neigt dazu, auf Kosten der B eigene Vorteile zu verfolgen; im Fall $\pi=0$, d.h. $\pi^{*} \Delta U_{B}=$ 0, dann orientiert sich $U$ ausschließlich an der „materiellen“ Kosten-Nutzen-Rechung des Geschäfts. ${ }^{674}$ Aus Sicht der Ökonomischen Analyse des Rechts können nur die Situationen , $\pi$ $\leq 0$ “ interessant sein. Die Gründe dafür werden wir erst später erörtern. Wie schon erwähnt, besteht die Hauptaufgabe des Zivilrechts darin, abstrakte Spielregeln für die Verkehrsteilnehmer bereit $\mathrm{zu}$ stellen, und diese Grundhaltung impliziert folgende Rahmenbedingungen für die Normgestaltung: Anonymität, Unbekanntheit und Rationalität der Geschäftspartner. Der Gesetzgeber einer Zivilrechtsnorm muss mit einem (,mitgefühllosen“) Herr $\pi=0$ rechnen, der sich nicht über die durch seine Handlung verursachten Gewinne oder Verluste bei den Geschäftspartnern freut oder trauert; er orientiert sich ausschließlich an seinem Profit aus dem Geschäft. Von diesem Standpunkt aus sehen wir uns die Entscheidungsstrukturen des U genauer an.

Abb. 9 - Nutzenkalkül des U im „,freewheeling game“

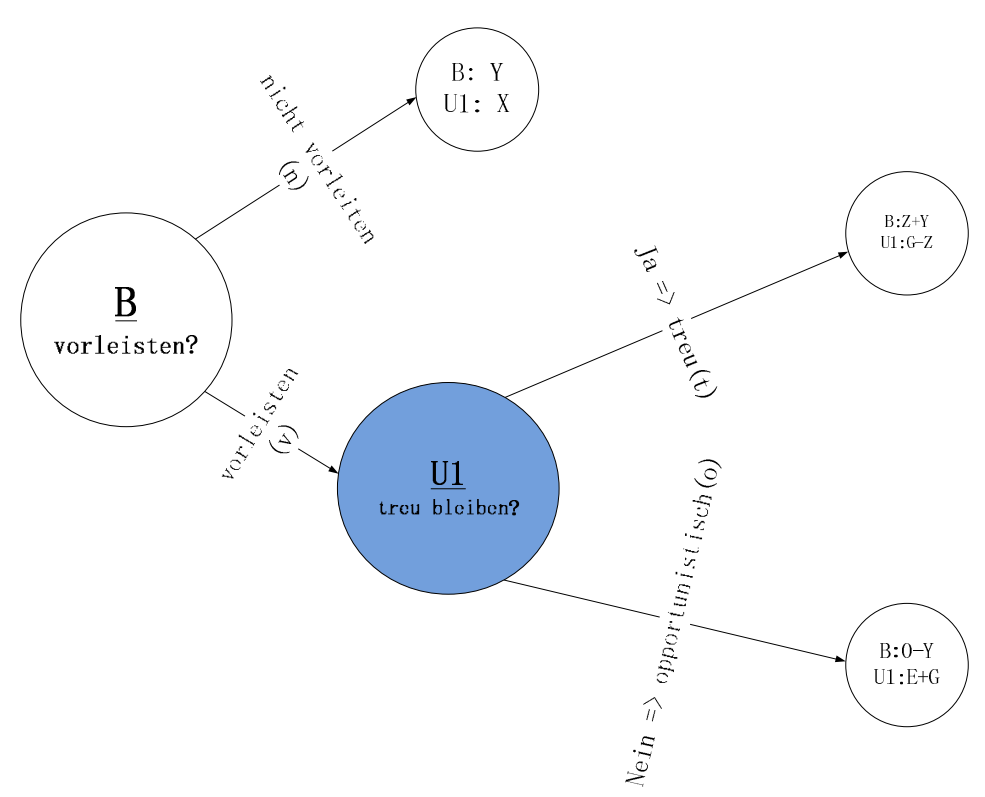

${ }^{674}$ Vgl. Ripperger, Ökonomik des Vertrauens, S. 149 f. 
U weiß, wenn B nicht vorleistet, dann scheitert die Kooperation, und sie werden jeweils nur die Reservationsnutzen von $\mathrm{X}$ und $\mathrm{Y}$ haben. Eine Nutzensteigerung gibt es nicht. Um den Weg zur Vorleistung der B zu finden, muss U folgende Gedankenspiele durchführen: Wie B sich entscheidet, hängt davon $\mathrm{ab}$, wie er selbst sich entscheiden wird. Da die $\mathrm{B}$ ihn nicht persönlich auskennt, unterstellt sie ihn vernünftigerweise als nutzenmaximierenden $(\pi=0)$ Geschäftsmann. Die Frage jetzt lautet - in welcher Konstellation würde er wahrscheinlich tendieren, sich opportunistisch $\mathrm{zu}$ verhalten? Um diese schwierige Frage des $\mathrm{U} \mathrm{zu}$ beantworten, benötigt man wieder die zwei Kernbegriffe der Spieltheorie, nämlich das Gefangenendilemma und das „Nash-Gleichgewicht““ ${ }^{675}$

In unserem Kreditfinanzierungsspiel liegt auch ein Gefangenendilemma vor. Die folgende Entscheidungsmatrix enthält die Auszahlungen der B und des U:

\begin{tabular}{|l|l|l|}
\hline Spielzüge & B & U \\
\hline N & Y & X \\
\hline VT & Z & G - Z \\
\hline VO & - Y & E + G \\
\hline
\end{tabular}

Auf Grund der fehlenden externen Restriktionen und Anreize in unserem „FreewheelingGame“ bestimmt auch hier der selbstzerstörerische Sog von Eigennutz und Angst vor $\pi \leq 0$, und zwar auf folgende Art und Weise:

Wenn U sich schon vor der Einigung dafür entschieden hat, sich die Kreditsumme nebst Zinsen einzuverleiben, greift hier das Strafrecht durch die drohende Sanktion (Freiheitsstrafe bis zu fünf Jahre wegen Betruges gem. $§ 263$ I StGB) in die Nutzenfunktion des U ein. U antipiziert, internalisiert diesen negativen Effekt, und die Kosten-Nutzen-Rechnung fällt damit $\mathrm{zu}$ ungunsten des $\mathrm{U}$ aus. ${ }^{676}$ Hier liegt das ökonomische Fundament der

\footnotetext{
${ }^{675}$ Varian, Mikroökonomik, S. 599 f.: John Forbes Nash (Nobelpreisträger für Wirtschaftswissenschaften 1994) ist ein amerikanischer Mathematiker. Er hat dieses fundamentale Konzept der Spieltheorie im Jahre 1951 formuliert. Der Film “A Beautiful Mind” schildert seine Lebensgeschichte und wurde im Jahre 2002 mit einem Oscar als bester Film ausgezeichnet.

${ }^{676}$ Posner, Economic Analysis of Law, S. 215 ff, 218; Ripperger, Ökonomik des Vertrauens, S. 149 f.
} 
Generalprävention des Strafrechts. Dadurch sieht man, wo die Grenze des vom Strafrecht beherrschten Ordnungsraumes liegt.

In unserem Beispiel (vor der Einigung) will der U jedoch eine Geschäftsbeziehung mit B aufbauen und nicht als Betrüger agieren. Deswegen kommt die strafrechtliche Sanktion wegen fehlenden Vorsatzes im Hinblick auf die Nutzenfunktion des U nicht in Betracht. Anhand der Nutzenfunktion des $\mathrm{U}$ wollen wir uns mit dem Ordnungsproblem nach der Einigung und Kreditgewährung genauer auseinandersetzen. Wie schon erwähnt, bezeichnet $\mathrm{K}_{\mathrm{U}}$ die Gesamtkosten des $\mathrm{U}$ für seine Handlung. Wenn $\mathrm{U}$ sich für die Einhaltung der Vereinbarung, also Rückzahlung der Kreditsumme nebst Zinsen, entscheidet, dann gilt der entgangene Gewinn durch Vertrauensbruch als Opportunitätskosten für sein vertrauenswürdiges Verhalten. ${ }^{677}$ Im Rahmen eines „Freewheeling-Game“ müssen wir einen „extrem rücksichtslosen Nutzenmaximierer“ zu Grunde legen. Das heißt also: U betrachtet $\mathrm{K}_{\mathrm{U}}=\mathrm{Y}+\mathrm{Z}$. Nach der Kosten-Nutzen-Rechnung wird der U sich gegen die Einhaltung der Vereinbarung entscheiden, wenn der Nutzen opportunistischen Verhaltens $(Y+Z)$ bzw. die Opportunitätskosten des vertrauenswürdigen Verhaltens $\left(\mathrm{K}_{\mathrm{U}}\right)$ größer als der internalisierte Nutzen wäre. Also wenn

$\left(\mathrm{Z}+\mathrm{Y}=\mathrm{K}_{\mathrm{U}}\right)>\pi^{*} \Delta \mathrm{U}_{\mathrm{B}}$

Da bei dem nutzenmaximierenden $U \pi=0$ und damit $\pi^{*} \Delta \mathrm{U}_{\mathrm{B}}=0$ ist, ist die obige Ungleichung stets erfüllt. D.h. U wird sich in einem schrankenlosen „FreewheelingGame" immer für opportunistisches Verhalten entscheiden. B antizipiert dies, leistet dann nicht vor. Am Ende kommen U und B nicht über den Reservationsnutzen X und Y hinaus. Hier liegt die ökonomische Grundlage des Vertragsrechts. Soweit ist das allgemeine Verständnis über das Phänomen Gefangenendilemma in Bezug auf unser „Kreditfinanzierungs-Freewheeling-Game“.

Die Tatsache ist aber, wir leben noch, und die Welt ist nicht ins schwarze Loch dieses Dilemmas gesunken. Es stellt sich die Frage, welche unsichtbare Hand die menschliche

\footnotetext{
${ }^{677}$ Mankiw, Principles of Economics, S. 24: Opportunitätskosten sind entgangene Gewinne, die dadurch entstehen, dass vorhandene Möglichkeiten (Opportunitäten) zur Nutzung von Ressourcen nicht wahrgenommen werden; Ripperger, Ökonomik des Vertrauens, S. 150.
} 
Gesellschaft formt? Die von Adam Smith entdeckte oder die von dem Gefangendilemmas oder von den beiden? Anders als das auf Rationalität und Nutzenmaximierung basierende Standardmodell stellen zahlreiche experimentelle Studien fest, dass Menschen signifikant positive Kooperationsbereitschaft zeigen, und zwar sowohl in einmaligen als auch in wiederholten Dilemmaspielen. ${ }^{678}$ Was für andere Faktoren, wie z.B. Altruismus, unbewusster Informationsfluss durch persönliche Eindrücke, evolutionäre biologische Anlagen etc., dabei ins Spiel kommen, ist nicht Gegenstand dieser Arbeit. ${ }^{679}$ Aber eine rein spieltheoretische Erklärung dafür verdient meiner Meinung nach erhöhte Aufmerksamkeit für die kommende Analyse.

Abb. 10 - Kreditfinanzierung: „freewheeling game“ vs ,shadow of the law“680

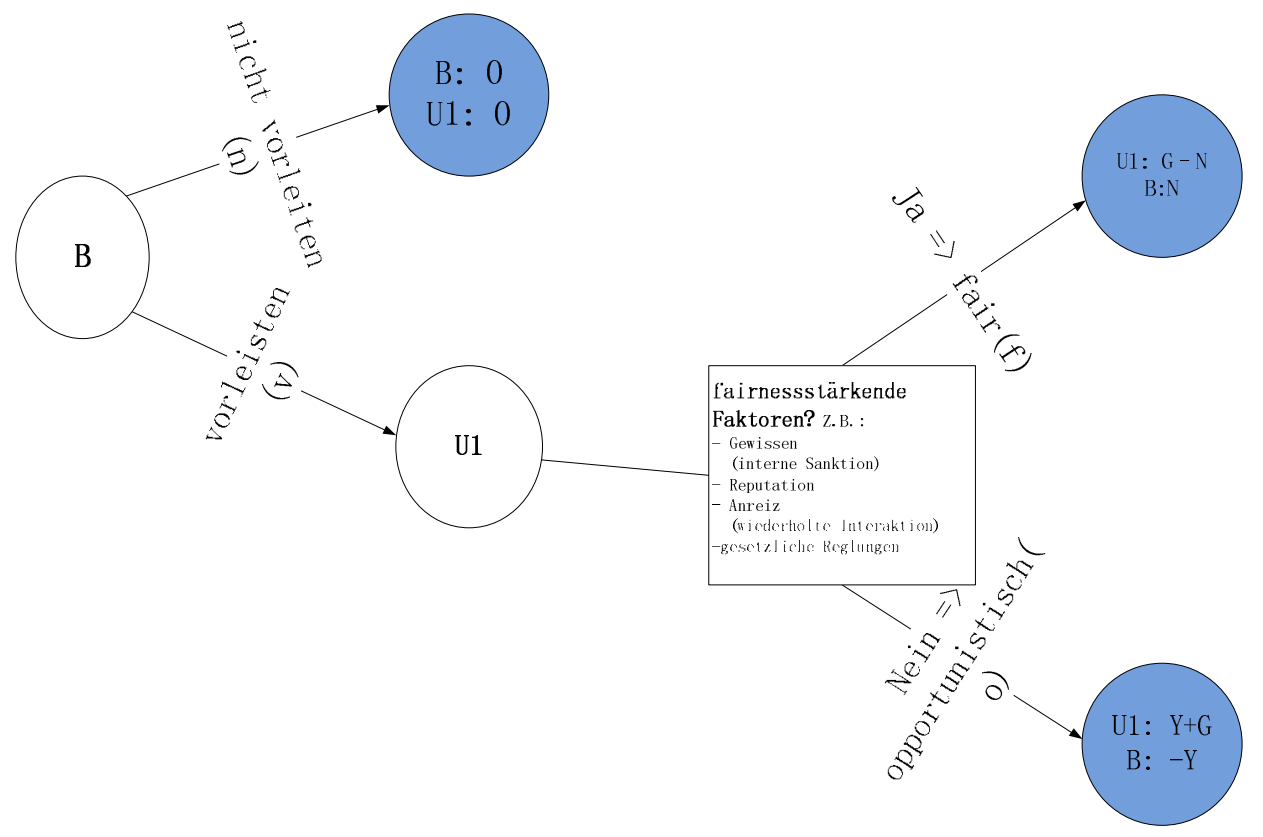

\footnotetext{
${ }^{678}$ M.w.N. Vogt, Kooperation im Gefangenen-Dilemma durch endogenes Lernen, S. 1 ff.

${ }^{679}$ M.w.N. Heiner, Rational Cooperation in One-Shot Situations, S. 29.

${ }^{680}$ Vgl. Baird u.a., Game theory and the law, S. 50 ff.: Dynamic interaction and the Extensive Form Game.
} 


\section{b) Die „entsprechenden technischen“ Zielvorgaben}

Ein Register muss die Grundfunktion haben, dem Verkehr eine schnelle präzise verlässliche Echtzeit-Informationsquelle über die rechtlich relevanten Tatsachen und Rechtsverhältnisse bzgl. der Vertragsgegenstände bereitzustellen. Aus Sicht der Spieltheorie stellen sich für ein modernes Privatvermögensrecht vor allem zwei wichtige Fragen. Zum einen wie lässt sich die Unsicherheiten bzgl. Umweltfaktoren $\left(\mathrm{P}^{1-\mathrm{N}}\right)$ für die Entscheidungsfindung (auf Seiten des Prinzipals) reduzieren. Zum anderen wie kann man opportunistische Verhalten (auf Seiten des Agenten) eindämmen. Ein ideales Registersystem soll folgende Eigenschaften haben: zentralisiert, abschließend, absolut und digitalisiert. ${ }^{681}$ Nur so können das Spannungsfeld der Risikokonzentration entschärft und die Entstehung von Vertrauensdilemma verhindert werden.

\section{aa) zentralisiert}

Am Beispiel des US-Registerwesens haben wir gesehen, wie gefährlich ein dezentralisiertes Registerwesen sowohl aus rechtlicher als auch aus tatsächlicher Sicht ist. Die dezentrale Lösung verursacht Informationsasymmetrie und verschlingt hohe Transaktionskosten. Als institutioneller Träger dieses Prinzips könnte man überlegen, welche Rechtsform die Organisation, ${ }^{682}$ die das Zentralregister führt, haben soll. ${ }^{683}$ Wichtig dabei ist, dass diese Organisation sachlich unabhängig bleibt, weil sie wichtige Wirtschaftsinformationen verwalten und schützen muss. Die zentralisierte (öffentlich-rechtliche) Verwaltung des Registers unterscheidet sich von der (privaten) Verwahrung und Verwaltung von Bucheffekten des schweizerischen Rechts, die eine Pyramidenstruktur hat und die Vermögenswerte (hauptsächlich Wertpapiere) als solche verwahrt. ${ }^{684}$ Während sich die Bucheffekten zwischen den Verwahrungsstellen bewegen, bleiben die Registrierungen im

${ }^{681}$ Die technischen Möglichkeiten der Realisierung dieser Ziele bietet zum einen die RFID-Technik für die externe Datenerfassung (s. D, II, 3, a) und zum anderen das „Cloud-Computing“ für die interne Datenverwaltung und-verarbeitung (s. D, II, 3, b).

\footnotetext{
${ }^{682}$ Reich, Das stille Pfandrecht der Niederlande, S. 256 ff: hier schlägt die Verfasserin ein öffentliches Register als Publizitätsträger vor; zur Erleichterung der administrativen Umsetzung und Kostensenkung wurde elektronisches Verfahren angesprochen.

${ }^{683}$ Überlegenswert ist eine Registerführung durch den BGH, eine öffentlich-rechtliche Anstalt oder des Bundesjustizministerium; persönlich finde ich die Rechtsform einer öffentlich-rechtlichen Anstalt im Hinblick auf die Gebührenerhebung, flexible Organisation, Haftungsproblematik etc. am besten geeignet.

${ }^{684}$ Botschaft - BEG, 9322.
} 
Zentralregister. Interessanterweise kann man nach Art. 24 und 25 des schweizerischen Bucheffektengesetzes eine Sicherheit an Bucheffekten bestellen. Die Registrierung solcher Sicherheiten wird bei der Verwahrungsstelle (Banken oder Effektenhändler) vollzogen. Dies ist wiederum eine dezentrale Buchführung der Belastungen, die dem Transparenzgebot des modernen Verkehrs nicht gerecht sein kann. Außerdem schwächt die dezentrale Struktur die Verkehrsicherheit, weil sich der gutgläubige Erwerb bei ihr schwieriger gestalten lässt als bei der zentralen Lösung, weil man sich dort nur an eine Stelle wenden muss und komplizierte Zuständigkeitsregelungen sich erübrigen. Wir werden später noch sehen, warum die zentrale Lösung großen Nutzen mit sich bringt.

Nach dem Abstraktionsprinzip verläuft das Geschäft auf zwei Schienen, nämlich dem Planungs- und Vollzugsgeschäft. Das Zentralregister soll im Grunde genommen die Funktion haben, das Vollzugsgeschäft und damit die vermögensrechtliche Lage zu dokumentieren.

\section{bb) abschließend und Auswirkungen auf die Zivilrechtskodifikation}

\section{$\S 12$ Anwendungsbereich}

Soweit es tunlich ist, hat die Bestellung einer Sicherheit an einem Grundstück, einer beweglichen Sache, einer Forderung oder einem Wertpapier (Sicherungsgüter) nach den Bestimmungen dieses Gesetzes zu erfolgen.

Für die Rechtssicherheit und zur Bekämpfung der Informationsasymmetrie ist die Abgeschlossenheit die wichtigste Eigenschaft des neuen Registers. Abschließend ist ein Registersystem, wenn keine wichtigen Wirtschaftsgüter nicht erfasst sind und keine Verfügungsvorgänge außerhalb des Systems zugelassen werden. Dies scheint aber auf den ersten Blick gewöhnungsbedürftig und nicht machbar. Denn es existiert in Deutschland nicht einmal ein allgemeines Pfandregister; außerdem sind Briefgrundpfandrechte, die sich außerhalb des Grundregisters bewegen, hierzulande üblich. Die Gründe für die Abgeschlossenheit des Registers sind vielfältig und tiefgründig und können nur Schritt für Schritt (in den kommenden Ausführungen) erklärt und konkretisiert werden. Das abschließende Register dient als die einzige Informationsquelle letztendlich der Aufhebung der Informationsasymmetrie, die nicht nur für die Einzeltransaktion, sondern insbesondere auch aus volkswirtschaftlicher Sicht sinnvoll ist. Ich bin davon überzeugt, dass es, wenn ein 
solches Register in den USA existieren würde, nicht zu dem Vertrauenszusammenbruch in der Finanzkrise gekommen wäre.

Bisher fungiert das Grundbuch in formeller Hinsicht als institutionelles Abgrenzungsmerkmal gegenüber dem Recht der beweglichen Sachen. ${ }^{685}$ An dieser Stelle stellt sich für das deutsche Recht eine Systemfrage, denen wenn man die Verfügung (Übereignung und Bestellung eines beschränkten dinglichen Rechts) aller wichtigen Wirtschaftsgüter zugunsten der Verkehrssicherheit und Transparenz in einem einzigen Register erfassen möchte, bedeutet dies weitestgehend die Aufhebung der traditionellen Unterscheidung zwischen Immobiliarund Mobiliarsachenrecht. Der Anwendungsbereich der gegenwärtigen Regelung über die Übereignung beweglicher Sachen reduziert sich dann nur noch auf diejenigen beweglichen Sachen, die minderwertig, für eine Registrierung nicht geeignet oder aufgrund privatautomoer Bestimmung nicht von dem Register erfasst sind. Wenn die materiellen Regelungen des Registerrechts wegen dessen systemischer Bedeutung nicht außerhalb des Zivilcodes als Spezialgesetz errichtet werden sollen, dann stellt sich vor der Systemänderung zunächst die Frage, ob die Aufgabe des vom historischen Gesetzgeber vorgesehenen dualistischen Prinzips dogmatisch tragbar und sinnvoll ist? Das deutsche Liegenschaftsrecht stammt interessanterweise nicht aus dem rezipierten römisch-gemeinen Pandektenrecht des 19. Jahrhunderts, sondern aus dem preußischen Recht. ${ }^{686}$ Bis heute sieht die deutsche Jurisprudenz die Existenzberechtigung des Liegenschaftsrechts in seiner überragenden Bedeutung für die individuelle Entfaltung und dem besonderen öffentlichen Interesse. ${ }^{67}$ Bezüglich der Funktion von beweglichen Sachen ist die Haltung viel ambivalenter:

„Demgegenüber (Liegenschaftsrecht) ist die funktionelle Bedeutung der beweglichen Sachen recht unterschiedlich, so unterschiedlich, daß eine gemeinsame Wertung kaum möglich ist; man denke nur an Begriffe wie - Konsumgüter, Produktionsgüter, Geld - und wird feststellen müssen, daß sich der Gesetzgeber mit der in den einzelnen Stadien des Wirtschaften Kreislaufs verschiedenartigen Funktion dieser Güter kaum wird abgeben können. Er wird sich begnügen, eine für alle diese Güter mehr oder weniger passende technische Regelung zu

\footnotetext{
${ }^{685}$ Vgl. Böhringer, Grundstückswert, BWNotZ 1986, 160 f.

${ }^{686}$ M.w.N.: MüKo Vor $§ 873$, Rn. 10 f.

${ }^{687}$ Baur/Stürner, Sachenrecht, § 2 Rn. 14 f. ; § 14 Rn. 1 f.
} 
treffen, die im wesentlichen sich mit dem Schutz des Eigentums und dessen Übertragung befaßt. "688

Hier muss man eigentlich fragen, was für zwingende Unterschiede es zwischen dem Immobiliar- und Mobiliarsachenrecht als subjektives Recht gibt, die zu der dualistischen Regelung führen? Im Gegensatz zu der herrschenden Meinung sehe ich auf der Ebene des subjektiven Rechts keinen trefflichen Grund dafür. Denn sowohl das Immobiliar- als auch das Mobiliarsachenrecht qualifizieren sich als Vermögensrecht, und in einer modernen Gesellschaft dienen sie gleichermaßen als Grundlage individueller Entfaltung. Im Hinblick auf die grenzüberschreitende Verbriefung von durch Mobiliarsicherheiten besicherten Forderungen gewinnt das Mobiliarsachenrecht vor dem Hintergrund der Globalisierung eine immer größere Bedeutung im modernen Privatvermögensrecht. Gerade in diesem Bereich ist das Bedürfnis nach einer Verstärkung der Verkehrssicherheit dringender als je zuvor. Es ist überlegenswert, ob man das Mobiliarsachenrecht auch in den Genuss der Vorzüge des Immobiliarsachenrechts kommen lassen sollte. Der eigentliche Grund für die dualistische Regelung im deutschen Recht liegt darin, dass die beweglichen Sachen, die sich ständig im Wirtschaftskreislauf fortbewegen, als Gegenstand des Mobiliarsachenrechts schwer zu erfassen sind. Mit der neuen Informationstechnologie ist aber die rechtliche Erfassung beweglicher Sachen mit sehr niedrigen Transaktionskosten (die in der Logistik sowieso entstehen, ausführlich s. RFID - Technik) möglich. Dies wird eine gigantische und nachhaltige Auswirkungen auf die bestehenden Rechtsordnungen haben.

\section{cc) absolut}

Die zentralisierte und abschließende Verwaltung des Registers schafft die notwendige Voraussetzung für die Gewährleistung durchdringender Rechtssicherheit in der Verfügungskette. Als Maßstab kann man grundsätzlich die Grundstrukturen des Grundbuchs, ${ }^{689}$ insbesondere die des gutgläubigen Erwerbs, weiterhin verwenden. Die Verkehrsteilnehmer dürfen blind dem Schweigen des Registers ebenso wie seinem Reden

\footnotetext{
${ }^{688}$ Baur/Stürner, Sachenrecht, § 2 Rn. 15.

${ }^{689}$ Vgl. Wagemann, Grundstückregister, S. 153 f.: Das deutsche Grundbuch ist durch eine relativ weitreichende materielle Publizität gekennzeichnet. Anders als in den USA und Frankreich eintragen werden hier nicht eine bloße Informationshinweise auf die Belastung oder Titelurkunden eingetragen, sondern die dingliche Rechte.
} 
trauen; schädlich ist nur die positive Kenntnis der Unrichtigkeit des Registers. Im Zeitalter der Globalisierung ist die Absolutheit des Registers die Schlüsselfunktion im Wettbewerb um die Führungsrolle im Prozess der sukzessiven Herausbildung der Regeln des grenzüberschreitenden Verkehrs, die man auf keinen Fall (z.B. durch die Einführung des $\S$ 1192 Abs. 1a BGB auf Druck kurzsichtiger auf Sensation gerichteter Medienberichterstattungen) aufgeben darf. Deshalb ist es empfehlenswert diese hohe Rechtssicherheit des Zentralregisters im Gesetz ausdrücklich und unmissverständlich zu verankern. Nur so können Geschäftspartner, die aus großer geographischer Entfernung kommen, verschiedene kulturelle Hintergründe haben und je nach Geschäftsarten kurz- oder langfristig investieren, auf einem zuverlässigen rechtlichen Fundament planen und handeln. Sonst drohen aus Sicht der Institutionenökonomik das Vertrauensspiel und ein Effizienzverlust.

\section{dd) digitalisiert}

Obwohl die Zusammenlegung von Immobiliar- und Mobiliarsachenrecht im Hinblick auf die systemische Klarheit, Rechtssicherheit und Rechtsökonomik wünschenswert ist, konnte der historische Gesetzgeber des BGB dieses Ideal unter den damaligen technischen Bedingungen niemals erreichen. Mit der rasanten Entwicklung und Verbreitung der neuen Informationstechnologie (Supercomputer, Massenspeicher, Internet, RFID etc.) vor etwa 20 Jahren $^{690}$ sind die modernen Gesetzgeber in der Lage, diesen Traum auch zu verwirklichen. Die neue Gestaltung des Vermögensrechts ist damit kein Luftschloss mehr, sondern eine reale Chance.

Die Digitalisierung des Registerwesens bietet viele Vorteile ${ }^{691}$ und verzeichnet den Trend der Entmaterialisierung des (Vermögens)Rechts als Teil der digitalen Gesellschaft. Außer den zwei wichtigsten Vorteilen, nämlich Transparenzbeschaffung und Erhöhung der Verkehrssicherheit, senkt die mediatisierte Führung von Registern die Transaktionskosten,

\footnotetext{
${ }^{690}$ Widipedia: Im Jahr 1993 wurde das Internet zum World Wide Web, das WWW-Zeitalter hatte damit begonnen (http://de.wikipedia.org/wiki/Internet).

${ }^{691}$ Alces/Lloyd, Reform of the Article 9 Filing System, S. 99 ff, 105: schon am Anfang des Internetzeitalters haben die amerikanischen Juristen in der elektronischen Verarbeitung große Chance zur Verbesserung des Defizits des Art. 9 UCC - Filing System gesehen.
} 
worauf wir später im Bezug auf konkrete Techniken und Beispiele noch zurückkommen werden.

Auf Grund der mediatisierten Verwaltung von Registrierungsdaten wird die Geschwindigkeit der Geschäftsabwicklung dramatisch erhöht, da ein Berechtigter über das Internet das Zentralregister überall und jederzeit nutzen kann. Wie schon erwähnt, ist eine der Ursachen der Finanz- und Wirtschaftskrise die Abkoppelung des Finanzmarktes von der Realwirtschaft. Während die Preisbildung auf dem Finanzmarkt binnen Sekunden und überall auf der Welt vollzogen ist, dauert sie in der Realwirtschaft Tage oder Monate. Dieses Phänomen geht zum Teil auf das Ungleichgewicht in den Verwaltungssystemen zurück. Denn während der Finanzmarkt weitestgehend digitalisiert und vernetzt ist, lässt die Durchdringung der Digitalisierung und Vernetzung der Geschäftsabwicklung in der Realwirtschaft noch viele Wünsche offen. Deshalb bietet das digitale Zentralregister mit seinen transparenten Inhalten über die realen Verhältnisse das beste Gegenmittel gegen die schnelle Verbreitung von Panik auf dem Finanzmarkt. Mit der Einführung des zentralen Registers lassen sich auch die rechtlichen Verfügungsvorgänge beschleunigen.

\section{Konstruktion des elektronischen Zentralregisters}

\section{$\S 14$ Registereintragung}

(1) Zur Bestellung der Sicherheit sind die Einigung des Berechtigten und des anderen Teils sowie die Eintragung der Sicherheit in das zentrale Sicherheitsregister erforderlich.

(2) Soweit ein Sicherungsgut mit elektronischer automatischer Identifikationsvorrichtung ausgestattet ist, wird die Einigung in der automatischen Erfassung vermutet.

(3) Ein Verbraucher ist berechtigt, die automatische Erfassung der Einigung zu verweigern.

(4) Die sonstigen formellen Voraussetzungen der Eintragung richten sich nach der Registerordnung.

Oben haben wir bei dem Bestimmtheitsgrundsatz festgestellt, dass er aufgrund des zunehmenden Bedarfs der Wirtschaft an Flexibilität und Freisetzung von Vermögenswerten 
dem Globalisierungszeitalter nicht mehr gerecht wird. Dennoch gehört dieser Grundsatz zu den unverzichtbaren Grundsäulen des modernen Sachenrechts weltweit. Bisher müssen sich die Rechtswissenschaft und Judikation mit Einzelfalllösungen zufrieden geben und infolgedessen herrscht allgemein in der Praxis Rechtsunsicherheit, die die Effizienz und Friedensfunktion des Rechts in erheblichem Maße beeinträchtigt.

\section{a) Datenerfassung durch RFID-Technologie}

Meines Erachtens kann man diese Verzwicktheit, die der moderne Kapitalfluss mit sich bringt, ohne Heranziehung von Hilfsmitteln der neuesten Informationstechnologie juristisch kaum lösen! Juristisch gesehen geht es beim Bestimmtheitsgrundsatz im Kern um die Feststellung der Rechtskraft bzgl. einzelner Gegenstände. Dieses Ziel ist dem der Logistik ähnlich. In der Logistik soll ein Auto-ID-System physikalische Objekte wie verschiedene Sachgüter automatisch, schnell, unverwechselbar und fehlerfrei identifizieren, um eine möglichst effiziente Verknüpfung des Güter- und Informationsflusses zu erreichen. ${ }^{692}$ Zur Erreichung dieses einfachen Ziels verwendet die Industrie zurzeit hauptsächlich den Barcode bzw. Strichcode, dessen Vorteilhaftigkeit darin besteht, dass er einen hohen Standardisierungsgrad zu sehr niedrigen Kosten für das „Medium Barcode“ (ein Stück Papier) erreicht. Aufgrund seiner relativ einfachen Konstruktion hat der Barcode auch unaufhebbare Schwächen. So kann es passieren, dass der Barcode in ungünstigen Umweltbedingungen der industriellen Produktion verschmutzt wird und nicht eingelesen werden kann. Außerdem ist der Barcode relativ einfach zu entfernen und kann deshalb keinen hohen Sicherheitsstandard gewährleisten. Die Todsünde des Barcode besteht in seiner geringen Speicherkapazität, was für eine Informationsgesellschaft lebenswichtig ist. Deswegen hat die Industrie eine neue Auto-IDLösung entwickelt, die meiner Meinung nach eine revolutionäre Veränderung unserer Gesellschaft herbeiführen wird. Der goldene Schlüssel heißt RFID (Radio Frequenc Identification) - eine Technik, die meiner Überzeugung nach die Rechtswissenschaft von analogen in den digitalen Zeitalter bringen wird.

\footnotetext{
${ }^{692}$ Marek, RFID - Kosten und Nutzen, S. 3.
} 
Abb. 11 - Radio Frequenc Identification ${ }^{693}$
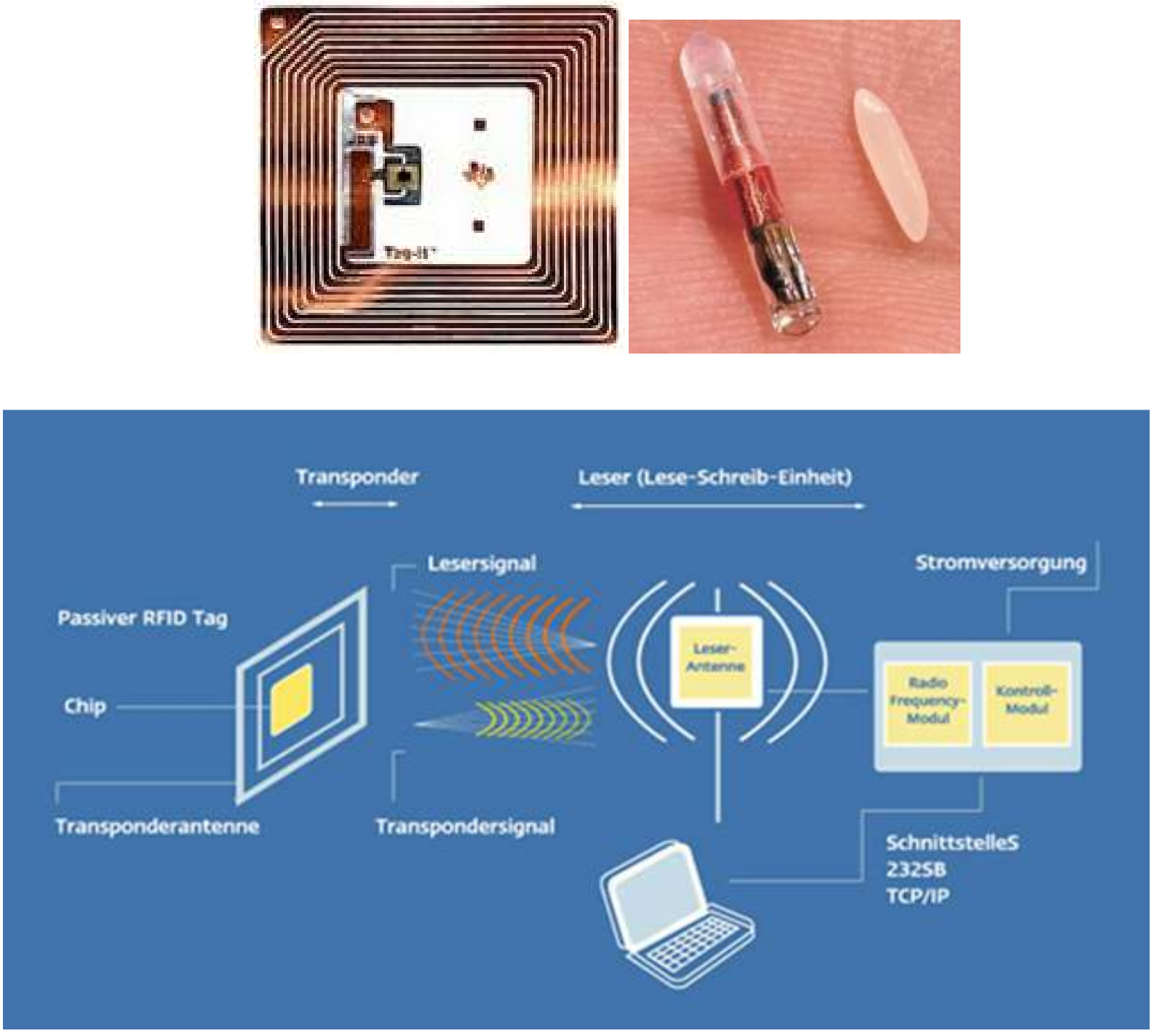

Die Abkürzung RFID steht für „Radio Frequency Identification“ - eine Technologie, die es ermöglicht, Objekte per Funk zu identifizieren. ${ }^{694}$ In der Logistikwissenschaft gibt es eine Fülle von Literatur, die sich mit RFID auseinandersetzt. Im Folgenden können wir uns aber nur auf die Abschnitte konzentrieren, die für die Lösung unserer juristischen Probleme von

\footnotetext{
${ }^{693}$ www.cnpd.lu; http://billkosloskymd.typepad.com/photos/uncategorized/2007/09/10/rfid_2.jpg; http://www.bibliotheca-rfid.com/files/publicSite/mediaFiles/technology/technologieRfidChart.png;

${ }^{694}$ Marek, RFID - Kosten und Nutzen, S. 6.
} 
Bedeutung sind, was wiederum die Grundkenntnisse über diese relativ neue Technologie voraussetzt. ${ }^{695}$ Das RFID-System besteht aus drei Komponenten: Transponder (auch Tag genannt), Lesegerät und EDV-System. Der (passive), mit einer einmaligen Identifikationsnummer versehene Transponder enthält einen Mikrochip mit Speichermedium und eine Antenne. Durch eine induktive Kopplung versorgt das Lesegerät, das auch mit WLAN- oder Bluetooth-Technik arbeitet, den Transponder mit Energie, und per Funk über die Antenne werden Daten auf den Mikrochip gelesen oder geschrieben. Diese Schritte geschehen vollautomatisch und sparen im Gegensatz zum Barcode den manuellen Lesevorgang. Über die Schnittstelle werden die auf dem Mikrochip gespeicherten Daten an ein EDV-System übermittelt und dort verarbeitet. Für Spezialverwendungen kann man den Transponder mit Sensoren ausstatten, mit denen eine Messung von Umgebungsparametern wie Temperatur, Druck oder Beschleunigung etc. vorgenommen werden kann. ${ }^{696}$

Auf Grund der vorstehenden Konstruktion bringt die RFID-Technik im Vergleich zum Barcode vielfältige Einsatzmöglichkeiten mit sich. Mit der einmaligen Identifikationsnummer kann ein RFID-System die Objekte fast hundertprozentig richtig erfassen. Da der Transponder so klein wie ein Reiskorn gemacht werden kann und der Lesevorgang keinen optischen Kontakt benötigt, kann man ihn nicht nur am, sondern auch im Objekt anbringen, so dass die Sicherheit, insbesondere im Hinblick auf Diebstahl- oder Fälschungsschutz, wesentlich erhöht werden kann; außerdem ist eine gleichzeitige oder individuelle automatische Erfassung von mehreren Objekten möglich (sog. Pulkerfassung), ${ }^{697}$ was eine gigantische Einsparung von Arbeitskraft und -zeit darstellt. In Kombination mit einem Ortungssystem wie z.B. GPS sind die Standorte bzw. Bewegungsvorgänge des Objekts in Echtzeit verfolgbar, was eine Just-in-Time-Logistik in Kombination mit Make-to-OrderVerfahren ermöglicht, die das Zwischenlager auflöst. Der ausschlaggebende Vorteil des RFID

\footnotetext{
695 Finkenzeller, RFID - Handbuch, S. 11 ff.: Dies ist ein lesenswertes Buch über die vielfältigen Einsatzmöglichkeiten der RFID Technik.

${ }^{696}$ Engelhart-Nowitzki/Lackner, Chargenverfolgung, S. 32.

${ }^{697}$ Rhensius/Deindl, Metastudie RFID, S. 96 f.
} 
steckt in seiner hohen Speicherkapazität (im Moment bis zu ca. $64 \mathrm{kByte}^{698}$ ), welche den Zugang zum Informationsmanagement öffnet.

Da die RFID-Technologie noch relativ neu ist und eine entsprechende Gesamtinfrastruktur noch fehlt, ist sie noch nicht so verbreitet wie das Barcode-System. ${ }^{699}$ Auf lange Sicht wird sich die RFID-Technik aber gegenüber dem Barcode durchsetzen. ${ }^{700}$ Denn durch die von der RFID-Technik ermöglichte Automatisierung können Unternehmen nicht nur Personalkosten drastisch senken, sondern auch Produktionsprozesse etc. fehlerfrei gestalten. Die Produktivität wird durch die Reduktion von Taktzeiten wesentlich erhöht. Im Moment arbeitet die Industrie daran, den Preis von (passiven) Transpondern z.B. durch Einsatz von polymeren Materialien unter 4 - 5 Cent pro Stück zu senken und gleichzeitig die Umweltverträglichkeit dieser Technologie zu verbessern. ${ }^{701}$ Bei einer Massenanwendung könnte der Preis noch wesentlich günstiger werden. Der Barcode selbst - ein Stück bedrucktes Papier - ist zwar billig; er fordert aber den Einsatz von Personal für das Einscannen. Da der Barcode aufgrund fehlender Speicher nicht veränderlich ist, ist seine Durchdringung in der Logistikkette und im Informationsmanagement sehr begrenzt.

\section{aa) Was bedeutet die RFID-Technologie für das Rechtssystem?}

Bisher behandeln (viele) Rechtssysteme bewegliche und unbewegliche Sachen mit einem dualistischen System. Während die Liegenschaft aufgrund ihrer physikalischen Eigenschaften (kostengünstig) registrierungsfähig ist und deswegen hohe Rechtssicherheit genießt, ist solche Rechtstechnik der beweglichen Sachen nicht zugänglich.

\footnotetext{
${ }^{698}$ Finkenzeller, RFID - Handbuch, S. 30.

${ }^{699}$ Gross, RFID-gestützte logistische Geschäftsprozesse, S. 1 ff, 2, 46 f. (mit Fallstudien von Metro Group, Infineon Technologies AG etc.)

700 Konkrete Fallstbeispiele: Rhensius/Deindl - Metastudie RFID; weitere Anwendungsstudien unter: www.RFID.org

701 Zur Zeit setzen die deutschen Großkonzerne voll auf die RFID-Technik, bei Siemens s.: http://www.automation.siemens.com/rfid/de/competence-in-rfid.html; Volkswagen will durch Einsatz der RFIDTechnik im Wareneingang den manuellen Aufwand um bis zu 80 Prozent verringern: http://www.logistikinside.de/volkswagen-durchbruch-fuer-rfid-in-der-materiallogistik-821323.html
} 
Mit der Einführung und Verbreitung der RFID-Technik im Wirtschaftsleben (von der Produktion bis hin zum Konsum) ist eine vorher nicht existierende Gestaltungsdimension in der Rechtsdogmatik eröffnet worden.

Bisher setzen verschiedene Branchen (Produktion, Logistik, Handel, Nutzer) in der Wertschöpfungskette unabhängig voneinander die RFID-Technik ein. Dies ist aber aus gesamtwirtschaftlicher Sicht als verschwenderisch zu werten. Da die RFID-Chips über Speicherfunktion verfügen und überschreibbar und deshalb wiederverwendbar sind, muss man nur die Produzenten dazu bewegen, Transponder an oder (ab einem Produktwert von 50 $€)$ in den Produkten anzubringen, damit die gesamte Wertschöpfungskette (Logistik, Handel, Nutzer) diese Technologie ebenfalls nutzen kann. Diese Vorgehensweise wird die Effektivität und Fehlerfreiheit der Gesamtwirtschaft enorm steigern, denn beim Barcode muss man jedes Mal die Etiketten erneut manuell herstellen, anbringen und einscannen. Wenn der Staat den Nutzen dieser Technik begreift und sie schnell einsetzen möchte, ist es sogar empfehlenswert, eine gesetzliche RFID-Obliegenheit der Produzenten vorzuschreiben; diese können dann die Kosten in den Preis mit einbeziehen. Für die geringwertigen beweglichen Sachen, wie z.B. Bierflaschen, ist eine Rückgabepflicht der Transponder wie beim Dosenpfand denkbar; mit der Wiederverwendung der Transponder sinken die Kosten nochmals drastisch! Mit der zurzeit verfügbaren Technik ist dies schon machbar.

Auf die geschilderte Weise werden fast alle wichtigen beweglichen Sachen mit RFIDTranspondern versehen, die auch für die Einführung eines elektronischen Zentralregisters für die beweglichen Sachen verwendet werden können, was nur eine bereits vorhandene Ressource nutzt und keine Zusatzkosten für die Wirtschaft verursacht. Auf einen Schlag werden die Argumente gegen die Einführung des Registerpfandrechts in den 20er Jahren des 20 Jahrhundert. weitgehend beseitigt sein. Denn mit der Durchdringung der RFID-Technik sind die von der Berliner Handelskammer vorgebrachten Argumente (etwa hohe Kosten des Registerwesens, hoher Einsichtsaufwand, Minderung der Effektivität des Handels) nicht nur gegenstandslos, sondern man kann sie ganz im Gegenteil sogar für die Einführung des elektronischen Zentralregisters einsetzen.

Auf der Grundlage des elektronischen Registers kann man das bisherige dualistische System weitestgehend aufheben und die hohe Rechtssicherheit des Grundregisters sich auf das Mobiliarsachenrecht erstrecken lassen. Die gegenwärtigen Regelungen über die beweglichen 
Sachen haben dann hauptsächlich drei Funktionen: Erstens fungieren sie als Auffangnormen für die Fälle, in denen die RFID-Technik wegen der physikalischen Eigenschaften (z.B. Agrarerzeugnisse, Rohstoffe etc.) oder Geringwertigkeit des Objekts nicht einsetzbar ist. Außerdem gelten sie subsidiär gegenüber den auf der RFID-Technik basierenden Normen, weil der Gesetzgeber aus privatautonomen Gründen die Verkehrsteilnehmer nicht zur Verwendung der RFID-Technik zwingen kann. Schließlich kommen die gegenwärtigen Regelungen noch zum Einsatz, wenn der Transponder verloren geht oder missbräuchlich entfernt wird; allerdings wirken die RFID-Regelungen in der non-liquet-Situation indirekt über die richterliche freie Beweiswürdigung gem. § $286 \mathrm{I} \mathrm{ZPO}^{702}$ mit.

Die Echtzeitfunktion ${ }^{703}$ des elektronischen Registers bietet Lösungen für die mit der herkömmlichen Methode unlösbaren Probleme. Durch seine zentralisierte Verwaltung und Absolutheit wirkt das Register mit Echtzeitfunktion effektiv der Informationsasymmetrie im Massenverbriefungsgeschäft entgegen. Zur Bekämpfung einer künftigen Finanzkrise wird vor allem vorgeschlagen, die Eigenkapitalquote der Banken zu erhöhen. Die minimal erhöhte Eigenkapitalquote ist im Vergleich zu der astronomischen Spielsumme auf dem Finanzmarkt in der Krisensituation nur ein kleiner Tropfen auf einen sehr heißen Stein. Diese Lösung trifft die Ursache der Finanzkrise, nämlich den Vertrauenszusammenbrauch, aber nicht.

Aus Sicht der Dogmatik stellt die Echtzeit- und Unverwechselbarkeitsfunktion des RFIDRegisters einen neuen Lösungsweg für das verfahrene Bestimmbarkeitskriterium zur Verfügung. ${ }^{704}$ Das Argument gegen den Anteilserwerb und die dogmatisch korrekte Anwendung der Verfügungstheorie bei Warenlagern mit wechselnden Beständen, nämlich dass die anteilsmäßige Aufteilung der Sicherungsmasse voraussetzt, dass man sämtliche Sicherungsnehmer kennt, ${ }^{705}$ wird damit entkräftet, weil das elektronische Zentralregister jederzeit in der Lage ist, entsprechende Auskunft zu erteilen. Auch wird die bisher

\footnotetext{
${ }^{702}$ Anders/Gehle, Zivilprozessrecht, S. 71.

${ }^{703}$ Die Echtzeitfunktion ist ein lang ersehnter Traum vieler; lautet kurz erwähnt hat Alces (Abolisch the Article 9 System, S. 679 ff, 684) und zwar schon im Jahr 1995: „, ... the best filing system would be a system that could assure instantaneous filing and response ..."
}

${ }^{704}$ s. D, I, 1 ff.;
${ }^{705}$ s. D, I, 1, d) 
unbefriedigende Praxis der Raumsicherung überflüssig, da die RFID-Technik eine mühelose Identifizierung des individuellen Gegenstands ermöglicht, selbst wenn diese durcheinander aufbewahrt werden. Die Identifikationsfunktion verstärkt zusätzlich die Rechtsstellung des Eigentümers der beweglichen Sachen, indem sie Diebstähle wesentlich erschwert, vor allem, wenn bei etwas größeren Gegenständen der Transponder (nach dem Zufallsprinzip) ins Objekt montiert oder bei Elektrogeräten auf Chipsätzen eingebaut ist. So macht Diebstahl von Elektrogeräten fast keinen Sinn mehr, weil man sie nicht verkaufen kann. Bei Selbstnutzung muss der Dieb stets damit rechnen, dass er jederzeit ermittelt wird. Die Entfernung des Transponders aus dem Chipsatz macht das Gerät aber unbrauchbar.

Aufgrund der Funktion der Echtzeitinventur des Registers kann man sowohl im Insolvenzverfahren als auch in der Einzelvollstreckung die Verpfändung und Verwertung viel effizienter gestalten, weil die Verfügung über Grundstückrechten und Forderungen im Register vollzogen wird. Die Möglichkeit einer Online-Verwertung könnte den Nutzen von Gläubiger und Schuldner maximieren.

Die massenhafte Datenerhebung durch den Einsatz der RFID-Technik ruft aber auch Bedenken hervor; insbesondere aus datenschutzrechtlicher Sicht wird der Schutz der digitalen Persönlichkeit immer wichtiger.

In der Informationsgesellschaft kommt man leider nicht um Massendatenerhebungen herum, weil die Informationstechnologie einfach unermesslichen Nutzen mit sich bringt. Die Massendatenerhebung durch private Hand ist im vollen Gange, sei es bei Schufa, OnlineBanking/Shopping, Bonuspunkten für Konsum oder elektronischer Personalausweis usw. In der Wirtschaft wird sich die RFID-Technologie meiner Meinung nach wegen der günstigeren Kosten-Nutzen-Rechnung durchsetzen, und zwar in der gesamten Wertschöpfungskette. Wenn aber sowieso massenhaft Daten erhoben werden, ist es die Pflicht des Staates, die Art und Weise der Datenerhebung zu regeln und die gesammelten Daten auch dem Gemeinwohl zugute kommen zu lassen. Es ist aus volkswirtschaftlicher Sicht richtig und wichtig, dass der Staat durch Errichtung eines Zentralregisters diese Daten sichert, vor Missbrauch schützt und in Krisenzeiten, in denen die nationale Sicherheit durch Informationsasymmetrie bedroht ist, die gesammelten Daten auch verwertet. Es ist in der Tat ein Balanceakt, wie der heutige Gesetzgeber die Rechte und Pflichten der Verkehrsteilnehmer sowohl aus privatrechtlicher als auch aus öffentlich-rechtlicher Sicht wohl ausgewogen bestimmt. 


\section{bb) Gestaltung des elektronischen Zentralregisters}

Im Informationszeitalter hat das Papier als Speichermedum weitestgehend ausgedient; das Papier ist vor allem dem Massengeschäft nicht gewachsen, verursacht viel zu hohe Kosten bei der Aufbewahrung, Vervielfältigung oder Übermittlung. Im Rahmen der mediatisierten Verwahrung und Verwaltung von Rechten stellt sich die Frage, ob der Besitz als Rechtsscheinträger für Mobiliar noch sinnvoll ist oder ob das elektronische Register seine Rechtsscheinfunktion übernehmen kann? Die aufgrund der RFID-Technik ermöglichte Zusammenlegung der Registrierung von Liegenschaften und Mobiliar ist ein juristisches Neuland, das selbstverständlich auch Probleme mit sich bringt. Im Weiteren werden wir werden versuchen, die Vorstellung der Mediatisierung eines Zentralregisters zu konkretisieren. Die Grundstrukturen und Rechtstechniken des (elektronischen) Grundregisters bleiben wegen seiner hohen Rechtssicherheit und Effizienz vorbildlich. Aus Platzgründen werden aber im Folgenden nur die Punkte diskutiert, die durch die Einführung der RFID-gestützten Registrierung von Mobiliar neu entstehen würzeln.

\section{(1) Was soll erfasst werden?}

Zunächst muss man überlegen, was durch das elektronische Zentralregister erfasst werden soll. Im Großen und Ganzen lässt sich dieses Register als Rechtsobjekteregister einordnen. ${ }^{706}$ Ziel der Errichtung eines solchen Registers ist die Ausnutzung der durch die RFID-Technik hervorgerufenen Informationsdurchdringung in der Verfügungskette zum Zweck der Transparenzbeschaffung und der Erhöhung der Sicherheit des Rechtsverkehrs. Als Maßstab dafür wurde die „Abgeschlossenheit“ genannt. Zur Konkretisierung dieser Zielsetzung muss das Zentralregister möglichst alle vermögensrechtlichen Gegenstände wie z.B. Grundstücke, bewegliche Sachen, Forderungen und Wertpapiere etc. umfassen. Auf dieser Grundlage muss man die Informationsdurchdringung noch weiter vorantreiben, d.h. die rechtlichen Bewegungsvorgänge und Zustände müssen ebenfalls erfasst werden. Es ist wünschenswert, dass weitere Vermögensgegenstände, z.B. Rechte, bei der Normengestaltung miteinbezogen werden. Dies erfordert allerdings noch weitere eingehende Untersuchungen, die im Rahmen dieser Arbeit leider nicht mehr möglich sind. Die folgende Tabelle versucht die wichtigsten

\footnotetext{
${ }^{706}$ Vgl. Krafka, Registerrecht, S. 1 ff.
} 
Positionen, die in dem Zentralregister erfasst werden sollen, aufzulisten; selbstverständlich ohne Anspruch auf Vollständigkeit.

\begin{tabular}{|c|c|}
\hline Rechtsinhaber & $\begin{array}{l}\text { Name/Organisationsname, }{ }^{707} \text { Geburtsdatum, Adresse, E- } \\
\text { Mailadresse (freiwillig); Steuer-ID. }{ }^{708}\end{array}$ \\
\hline \multirow{3}{*}{ Gegenstand } & Sachen $^{709}$ (Grst.-Nr.; RFID-Nr. ${ }^{710}$ - Beschreibung) \\
\hline & Forderungen $^{711}$ (Gläubiger, Schuldner, Betrag) \\
\hline & Wertpapiere (Identifikationsdaten, Verwahrungsstelle) \\
\hline Belastungen & Nutzungsrechte, Pfandrechte, Vormerkungen \\
\hline Verfügungsvorgänge & $\begin{array}{l}\text { Datum, Beteiligte, Verfügungsart, }{ }^{712} \text { Betrag, Ergebnisse eines } \\
\text { Rechtsstreits / Auszahlungssumme im Insolvenzverfahren. }\end{array}$ \\
\hline
\end{tabular}

${ }^{707}$ Im Hinblick auf die nachträglichen Veränderungen auf der Rechtsubjektseite ist die Vergabe einer SteuerIdentifikationsnummer für einzelne Rechtssubjekte zu empfehlen.

${ }^{708}$ Alces/Lloyd, Reform of the Article 9 Filing System, S. 99 ff, 112.

${ }^{709}$ Oben bei dem Bestimmtheitsgrundsatz ist schon erwährt worden, dass dieser Grundsatz im geltenden Recht zugunsten der Mobilisierung von Sachwerten durch Bestimmbarkeitskriterium aufgelockert wird. Hierzu eine ambivalente Ausführungen in Baur/Stürner, Sachenrecht, § 55 Rn.5: Der Grundsatz der Spezialität - als Pfand können nur einzelne Sachen dienen; das Gesetz kennt kein „Generalpfandrecht“ am gesamten beweglichen Vermögen des Schuldners, kein Pfandrecht an einer Sachgesamtheit. Doch ist eine zusammenfassende Bezeichnung mehrerer verpfändeter Sachen unschädlich. ... ... Daher lassen sich auch Warenlager mit wechselnden Bestand verpfänden, ... ... der Spezialitätsgrundsatz ein Gesamtpfandrecht nicht ausschließt $(\S$ 1222 BGB)““

Bei einem RFID-gestützten Register soll eine Sachgesamtheit nicht eintragungsfähig sein; auf den dogmatisch bedenklichen Begriff der Sachgesamtheit ist das Rechtssystem nicht mehr angewiesen.

${ }^{710}$ Um festzustellen, um welchen Gegenstand es sich handelt, braucht man bei Sachen, die mit RFIDTransponder versehen sind, nur noch die darin gespeicherte Identifikationsnummer, weil man über diese Nummer zu ausführlichen Produktinformationen gelangt, die schon der Produzent im Chip gespeichert hat. Eine Beschreibungsanforderung wie es bei Article 9-108 (a) und 9-502 UCC, die in der Praxis schwer zu handhaben und ineffizient ist und deswegen die Rechts- und Verkehrssicherheit beeinträchtigt, ist hinfällig.

${ }^{711}$ Es ist empfehlenswert, auch jeder Forderung mit einer Identifikationsnummer auszustatten.

${ }^{712}$ Mit Verfügungsart ist nur der Teil des Verfügungsgeschäfts gemeint, der eine absolute Rechtswirkung erzeugt; nicht gemeint damit ist der Teil, der relative Rechtswirkungen (z.B. Verpflichtung) betrifft. 


\section{(2) Registerzwang?}

Da man nicht an allen beweglichen Gegenständen RFID-Transponder anbringen kann und ein Transponder nicht in allen Fällen mit dem Objekt fest verbunden ist, muss man subsidiär auf die gegenwärtigen Regelungen über die beweglichen Sachen zurückgreifen. Die Gestaltung dieses subsidiären Verhältnisses ist ein wichtiger Punkt in dem neuen Registerrecht. Außerdem muss der bisherige für die Liegenschaft geltende Antragsgrundsatz, wonach die Registerstelle nur auf Antrag der Parteien tätig wird, ${ }^{713}$ für die massenhafte automatische Erfassung von beweglichen Gegenständen dahin modifiziert werden, so dass gesetzlich vermutet wird, dass die Parteien in die Eintragung ihrer Rechte ins elektronische Zentralregister einwilligen. Aufgrund der Privatautonomie und des gegenwärtig herrschenden allgemeinen Verständnises über das informationelle Selbstbestimmungsrecht können sich die Parteien vor der automatischen Erfassung einer Übereignung dagegen entscheiden, so dass die Übereignung der Gegenstände gar nicht vom dem Register erfasst wird. Nach der automatischen Eintragung kann eine Partei auch von der Registerstelle die Lösung der Eintragung verlangen, soweit sie einen Anspruch darauf hat oder die andere betroffene Partei oder Dritte damit einverstanden ist (sog. Obliegenheitslösung). In diesem Fall greifen dann die gegenwärtigen sachenrechtlichen Übereignungsnormen, und der Käufer verliert die Vorteile des Registerrechts, insbesondere den Schutz vor Diebstahl und Verlust, weil er als Eigentümer nicht mehr im Register zu sehen ist und seine Rechtsstellung als Eigentümer nur über $\S 1006$ BGB geschützt ist. Insoweit darf ich auf die vorstehenden Ausführungen über das elektronische Zentralregister verweisen.

Anders als bei der Übereignung von beweglichen Sachen muss es für Liegenschaften, Forderungen, Wertpapiere und die Bestellung von beschränkten dinglichen Rechten aufgrund der Abgeschlossenheit des Zentralregisters einen Registerzwang geben. Dies ist nicht nur eine Notwendigkeit der dogmatischen Vollkommenheit, sondern auch im Hinblick auf die Transparenz und Sicherheit des Rechtsverkehrs besonders wichtig. Dingliche Beschränkungen dürfen wegen ihrer absoluten Wirkung nicht geheim bleiben. Der Registerzwang für Forderungen lässt sich insbesondere im Hinblick auf die Schaffung von Transparenz bei Massenverbriefungsgeschäften gut begründen. Da das moderne Wertpapier

\footnotetext{
${ }^{713} \S 13$ Abs.1 Satz 1 GBO; Baur/Stürner, Sachenrecht, § 16 II, Rn. 7 f.
} 
im Grunde genommen nur noch mediatisiert verwahrt und verwaltet wird und an ihm auch Sicherheiten bestellt werden können, ist es sinnvoll, dass das Wertpapier auch vom Zentralregister erfasst wird.

Der Registerzwang bildet auch die Grundlage für den Einsatz einer neuen Rechtsfigur, nämlich die Bucheffekte, worauf wir zurückkommen werden.

\section{(3) Rechtswirkungen der Eintragung und Prioritätsverhältnis}

Korrespondierend mit dem Registerzwang sollte man die Eintragung einer (übertragenden, belastenden, aufhebenden oder ändernden) Verfügung ins Register grundsätzlich als konstitutive Komponente (Wirksamkeitsvoraussetzung) gestalten.

Aufgrund des durch die RFID-Technik ermöglichten effizienten Informationssystems ist eine weitesgehende Zusammenlegung des bisher dualistisch gestalteten Verfügungssystems des Mobiliar- und Immobiliarsachenrechts machbar, sinnvoll und empfehlenswert. Die Verfügungsgrundsätze des deutschen Immobiliarsachenrechts, die mit hoher Rechtssicherheit verbunden sind, können dann auch dem Mobiliarsachenrecht zugängig gemacht werden.

Das Wirksamwerden eines Registerantrags richtet sich dann wie bei $\S 17$ GBO nach dem Eingang des Antrags. Aufgrund der automatischen Datenerfassung und -übertragung durch das RFID-Systems fallen (im Mobiliarsachenrecht) i.d.R. das Wirksamwerden zwischen Parteien und Drittwirksamkeit dann die zusammen. Mit Hilfe von elektronischer Erfassung und Übermittlung kann man sogar den Zeitpunkt des Antrags, der für Rangbestimmung, Verfügungsbeschränkungen und Gutgläubigkeit maßgebend ist, ${ }^{714}$ sekundengenau festhalten.

Die moderne RFID-Technik kann zwar den Verfügungszeitpunkt sekundengenau festhalten und die zeitliche Reihenfolge bestimmen. Das automatisierte Verfahren kann allerdings keine normative bzw. rechtspolitische Entscheidung über die Bestimmung der Prioritätsverhältnisse bei Sicherungskonflikten treffen. Insoweit muss der Prioritätsgrundsatz im bestimmten Fällen durchbrochen werden. Es scheint so, dass sowohl der $\mathrm{BGH}^{715}$ als auch der $\mathrm{UCC}^{716}$ die

\footnotetext{
${ }^{714}$ Baur/Stürner, Sachenrecht, § 16 Rn. 17.

${ }^{715}$ Zur Vertragsbruchtheorie: BGHZ 56, 173, 179; ausführlich: Baur/Stürner, Sachenrecht, § 59 Rn. 54.
} 
Schutzbedürftigkeit des Endes der Verfügungskette anerkannt haben, weil eine Schutzversagung die Gefährdung der gesamten Verfügungskette bedeuten würden. Auf die vielfältigen Begründungen dieses rechtspolitischen Zieles muss an dieser Stelle nicht nochmals eingegangen werden.

\section{(4) Einsichts- und Nutzungsrechte}

Um die digitale Persönlichkeit oder das Geschäftsgeheimnis des Rechtsinhabers zu schützen, kann man sich grundsätzlich im Rahmen der formellen Publizität an $\S 12$ Abs. 1 GBO orientieren, der für die Einsichtnahme ein berechtigtes Interesse verlangt. Dabei braucht das Interesse nicht gerade ein rechtliches zu sein; es genügt auch ein wirtschaftliches, familiäres oder öffentliches; man muss dieses Interesse lediglich darlegen und nicht beweisen. ${ }^{717}$ Aufgrund der Mediatisierung des Registers kann der Interessent die Einsicht online beantragen; nachdem die Zentralregisterstelle die Identität des Antragstellers festgestellt ${ }^{718}$ und sein berechtigtes Interesse anerkannt hat, dann kann sie dem Interessenten digitalen Einsichtsraum zur Verfügung stellen. Eine andere, viel schnellere Einsichtsmöglichkeit besteht darin, dass die betroffene Partei dem Interessenten ihre Zustimmung erteilt. ${ }^{719}$

Um die Rechts- und Verkehrssicherheit zu erhöhen, kann man auch ein vereinfachtes Einsichtsverfahren z.B. für Kaufinteressenten bereitstellen, das nur Auskunft darüber gibt, ob ein Objekt mit Rechten Dritter belastet ist. Ziel dieses Verfahrens ist, die Hürde eines gutgläubigen Erwerbs zu erhöhen und die Rechtsstellung des Eigentümers zu stärken.

\footnotetext{
${ }^{716}$ White/Summers, Uniform Commercial Code, Vol. 4 S. 286 ff.: Nach Article 9 - 324 ff. UCC genießt das sog. „Purchase Money Security Interest“ (ähnlich wie der deutsche Eigentumsvorbehalt) eine „Super Priority“, d.h. „Second in Time, First in Right“, wenn der „Purchase Money Secured Creditor“ innerhalb von 20 Tagen nach der Inbesitznahme sein Recht registrieren lässt. Anders als die deutsche Rechtsprechung, die den Banken die Priorität versagt, schützt der Article 9 - 324 (b) UCC sie, indem er für die Verpfändung von Lagerbeständen die Zustimmung der Banken verlangt, die ein „Security Interest“ an den Lagerbeständen haben. Insoweit ist die Sicherungskraft des „Purchase Money Security Interest“ des UCC viel stärker als die deutsche Sicherungsübereignung, und es ist dogmatisch sauberer.

${ }^{717}$ Vgl. m.w.N.: Baur/Stürner, Sachenrecht, § 15 Rn. 55.

${ }^{718}$ Bevor das auf demelektronischen Personalausweis basierende Identifikationsverfahren Wirklichkeit wird, kommt als denkbares Identifikationsverfahren die zurzeit verbreitete Lösung, nämlich Identifikation durch die Post - Postident-Verfahren - in Betracht. Dieses Verfahren könnte auch bei juristischen Personen verwendet werden; dazu müsste der Vertreter der juristischen Person das Postident-Verfahren durchführen.

${ }^{719}$ Hier muss der betroffene Rechtsinhaber bei der Post seiner Zustimmung abgeben und die Post diese Zustimmung an die Zentralregisterstelle weiterreichen.
} 
Angesichts der Menge und Umfassendheit der gespeicherten Daten ist das Zentralregister gleichzeitig vielfältig einsetzbar. ${ }^{720}$ Da die Gesamtheit dieser Daten in gewisser Hinsicht ein öffentliches Gut darstellt, sollte ihr Nutzungsrecht auch öffentlich-rechtlich geregelt werden.

\section{(5) Schutz des RFID-Transponders und der Registereintragungen}

Da der Transponder einen der wichtigsten Bestandteile der RFID-Technik bildet und zugleich das schwächste Glied des gesamten Systems ist, verdient er einen besonderen Schutz. Grundsätzlich kann man den Transponder in zweierlei Hinsicht schützen: Physikalisch und rechtlich.

Physikalisch muss man dafür sorgen, dass ein Transponder nicht ohne erheblichen Aufwand vom Objekt entfernt werden kann. Das Einbauen des Transponders in den Chipsatz eines elektronischen Gerätes ist die sicherste Lösung überhaupt, weil die Entfernung des Transponders gleichzeitig die Zerstörung des Gerätes bedeutet. Außerdem kann man den Transponder in das Objekt einmontieren, damit er von draußen nicht sichtbar ist und für Diebstahl schnellerer Art uninteressant bleibt. ${ }^{721}$

Da die Produkte vom Hersteller mit Transponder ausgestattet und ins Zentralregister eingetragen sind, herrscht im Zentralregister vom Anfang bis Ende der Verfügungskette völlige Informationstransparenz.

Das Zentralregister bzw. das Suberfassungssystem der Verkehrsteilnehmer (Lieferant, Händler, Logistikfirma, Supermarkt etc.) kann die unbefugte Entfernung des Transponders sofort bemerken und Alarm schlagen. Man kann natürlich den Transponder mit kriminellen Methoden unbemerkt entfernen. Das erfordert den Einsatz technischer Mittel und hinterlässt Spuren. Außerdem bleibt das Zeitfester für die Kriminellen wegen der Echtzeitfunktion der RFID-Technik trotzdem sehr kurz, und das Ungleichgewicht von Nutzen und Kosten macht die rechtswidrige Entfernung von Transpondern höchstwahrscheinlich uninteressant.

\footnotetext{
${ }^{720}$ Eine der wichtigsten Funktionen des Registers besteht darin, in Krisenzeiten die Belastungsverhältnisse systemisch wichtiger Geldinstitute klarzustellen, um einen Vertrauenszusammenbruch zu verhindern; Außerdem ist das Zentralregister eine wichtige Quelle für die Statistikerhebung durch verschiedene Organisationen.

${ }^{721}$ Insoweit muss die Befugnis eines Eigentums aus § 903 BGB (mit dem Eigentum beliebig zu verfahren, also den Transponder zu entfernen) zugunsten der Rechtssicherheit eingeschränkt werden (vgl. mit dem Rechtsgedanke der $\S 305$ ff BGB).
} 
Zum Schutz des informationellen Selbstbestimmungsrechts der Verkehrsteilnehmer sind folgende Maßnahmen überlegenswert: Die Geschäftsparteien als privatautonome Rechtssubjekte können jederzeit von der Zentralregisterstelle verlangen, die Eintragungen ihrer beweglichen Sachen zu sperren oder zu löschen. ${ }^{722}$ Nach entsprechender Mitteilung an die Zentralregisterstelle ist der Rechtsinhaber außerdem berechtigt, den Transponder zu entfernen. Damit rechne ich eigentlich nur bei einem Teil der Endverbraucher, die eine besonders starke Skepsis gegenüber der Digitalisierung ihrer Rechte haben. Für den großen Teil der Endverbraucher und die Händler oder Lieferanten können die RFID-Transponder im Grunde genommen nur Vorteile bringen. Sie müssen sich insbesondere nicht mehr vor einem tatsächlichen oder rechtlichen Verlust ihrer registrierten Sachen fürchten. Um die Verkehrssicherheit zu gewährleisten, ist ein Rechtsinhaber zu vorstehenden Handlungen berechtigt, wenn die Rechtsposition eines Dritten nicht betroffen ist.

Was die Verwaltung angeht, muss die Stelle des Zentralregisters so organisiert werden, dass keine (verschlüsselten) Eintragungsinformationen illegal nach außen durchsickern können. Die illegale Beschaffung von Eintragungsinformationen muss unter strenge strafrechtliche Androhung gestellt werden. Zivilrechtlich dürfen illegal beschaffte Eintragungsinformationen nicht verwertet werden. Diejenigen, die Eintragungsinformationen illegal beschaffen, riskieren den Totalverlust ihrer Rechtspositionen.

Die einzige Möglichkeit, rechtlich verwertbare Eintragungsinformationen zu beschaffen, ist also, die Einsicht ins Register bei der Registerstelle zu beantragen.

\section{b) Datenverarbeitung durch Cloud-Computing}

Ein weiterer wichtiger Trend der aktuellsten Entwicklung der Informationsgesellschaft zeichnet sich im Nutzen des Internets $a b$, indem man die zurzeit noch dezentralisierte Datenverarbeitung durch PC über das Internet auf Rechenzentrum verlagert, wo Rechenkapazität, Speicher und - Datenverwaltung von professionellen Betreibern wie der deutschen Telekom bereitstellen (sog. Cloud-Computin ${ }^{723}$ ). Auf die Managementebene will

\footnotetext{
${ }^{722}$ Mit der Sperrung entzieht der Rechtsinhaber seine Sache vorübergehend dem Rechtsverkehr; er kann jederzeit die Aufhebung der Sperrung beantragen, wenn er die Sache veräußern oder belasten möchte.

${ }^{723}$ Rittinghouse/Ransome, Cloud Computing, S. 2.
} 
das Cloud-Computing eine effizientere Nutzung des IT- Ressourcen ermöglichen; noch wichtiger ist, dass die Effizienz und Flexibilität der Datenverarbeitung dadurch enorm gesteigert werden können. ${ }^{724}$ Die IT-Welt hat schon ihre eigene Antwort auf die Globalisierung gefunden:

„in our real-time, global economy where product life cycles are short, companies need to be good at bringing new products to market ... ..., the value proposition delivered by most companies lies in the way they manage their business processes, ... ... It lies in the way they tailor their prcesses to meet constantly changing market conditions, ... ... the cloud is ... a platform managing the delivery of computing services ... ... “725

Die Verbindung zwischen dem Einsatz der RFID-Technik (mit ihren mobilen Erfassungsgeräten) und der Datenverarbeitung durch das Cloud-Computing eröffnet der Rechtswissenschaft einen bisher noch nie dagewesenen Möglichkeit, nämlich die vollständige Regulierung sachenrechtlicher Bewegungsvorgänge des Mobiliars. Wenn man dies wie ich als realistisch betrachtet, dann kommt man zwangsläufig zu dem Ergebnis, dass auch die weitestgehende Aufhebung des dualistischen Systems (Immobiliar- und Mobiliarsachenrecht) nur eine Frage der Zeit ist, weil dieser Weg den Kampf um die Sicherheit, Transparenz und Effizienz gewinnen wird. ${ }^{726}$

\section{Zentrales elektronisches Register als „Game-Changer“}

Das Zentrale elektronische Register ist ein Instrument, das nicht nur viele juristische Probleme löst; es entfaltet auch andere positive Wirkungen, die die Gesamtsicherheit und effizienz erhöhen.

\section{a) Auswirkung auf die Rechtsgrundsätze}

Mit der Einführung eines einheitlichen Verfügungssystems wird die dualistische Sachenrechtsordnung aufgehoben. Die ersten direkten Folgen davon sind die enorme

\footnotetext{
${ }^{724}$ Stanoevska-Slabeva/Wozniak, Grid and Cloud Computing, S. 28.

${ }^{725}$ Hugos/Hulitzky, Business in the Cloud, S. 109.

${ }^{726}$ Institutionenökonomische Grundlage s.D, II, 2, a), aa).
} 
Systemsvereinfachung und die Erleichterung der Normensuche bei der Rechtsanwendung. Da das künftige Verfügungssystem die Grundzüge die Regeln des deutschen Grundstückrechts weitgehend übernimmt, gewährleistet es eine sehr hohe Rechtssicherheit.

Mit der Einführung des gesetzlichen Registerpfandrechts ist die Kautelarjurisprudenz nicht mehr gezwungen, die vom Zivilcode nicht vorgesehenen dinglichen Sicherheiten (Sicherungsübereignung etc.) mit Hilfe des Abstraktionsprinzips hervorzubringen. Die Verschwommenheit der Grenze zwischen Schuld- und Sachenrecht in der gegenwärtigen deutschen Rechtsordnung wird durch die Kodifizierung des Sicherungsvertrags, also des schuldrechtlichen Gegenstücks des Registerpfandrechts, beseitigt. So ist das hinter dem numerus clausus stehende Fundament des Sachenrechts, nämlich der Absolutheitsgrundsatz, wieder verfestigt.

\section{b) Elektronisches Verwertungsverfahren durch die Zentralregisterstelle}

Trade-off-Situation zwischen dem freihändigen Verkauf und dem gesetzlichen verobjektivierten Verfahren, ${ }^{727}$ das zur Ineffizienz der Verwertung führt, wird durch die Verwendung elektronischen Verwertungsverfahrens aufgehoben. Für die Praxis könnte das elektronische Verwertungsverfahren aufgrund seiner Einfachheit, Schnelligkeit und Möglichkeit einer Internetauktion maximale Kostenvorteile gegenüber dem alten System verschaffen. Die Gewinnmaximierung wird vermutet, natürlich kann der Sicherungsgeber eine andere Verwertungsmöglichkeit anbieten, die noch mehr Erlös bringen könnte. Dieser Nachweis kann für ihn sehr schwer zu erbringen sein, denn der potentielle Käufer kann auch in der Online-Aution mitbieten. Die Auswirkungen der elektronischen Rechtsverwahrung und -verwaltung wird meiner festen Überzeugung nach dazu führen, dass manche Rechtsgebiete (gänzlich oder weitgehend) ihre Bedeutung verlieren. In Zukunft könnte z.B. das Insolvenzrecht ihre Bedeutung (weitgehend) verlieren, weil zum einen das Problem der Sicherungskollision weitgehend gelöst ist, ${ }^{728}$ zum anderen das Zentralregister die

\footnotetext{
${ }^{727}$ s. C, IV, 4, d), cc), (2).
}

${ }^{728}$ Aufgrund der Rückkehr zum Prioritätsgrundsatz (Problem des alten Systems, s. D, I, 1, b) und c) i.V.m. D, I, 2, a), aa) mit der technischen Unterstützung des Zentralregisters (s. D, II, b) i.V.m. D, II, 3, a), bb), (3)) werden Sicherungskollisionen gar nicht entstehen. 
Echtzeitfunktion bietet, die aufgrund seiner Daten und standarisierten Verfahrens jederzeit in der Lage ist, die vollständige Liquidation durchzuführen.

\section{c) Informationstransparenz als systemstabilisierender Faktor}

Nicht juristisch sondern ökonomisch bzw. spieltheoretisch ist das neue System der mediatisierten Rechtsverwahrung und -verwaltung besonders verwertvoll. Denn es stellt eine vollständige Informationstransparenz bzgl. der Vermögensrechte her, die als systemstabilisierend wirkt. Hierzu darf ich auf die Ausführungen bzgl. der Beschreibung der Ursachen der Finanzkrise 2008, der Entstehung eines Vertrauensdilemmas und der Analyse der Nutzensstrukturen der Wirtschaftsakteure verweisen. ${ }^{729}$ Durch die Modernisierung des Verfügungssystems passt sich der Rechtsverkehr wieder an die Mobilität und Geschwindigkeit des Informations- und Globalisierungszeitalters an.

\section{Machbarkeits- und Akzeptanzprognose}

Auf den ersten Blick scheint die geschilderte Zusammenlegung von Liegenschafts- und Mobiliarsachenrecht durch die Unterstützung der RFID-Technik wirklichkeitsfremd und stellt die Konzepte der bisherigen Rechtsordnungen auf den Kopf. Es ist berechtigt die Frage zu stellen, ob diese Idee auch tatsächlich die Chance hat, Realität zu werden?

Das wirtschaftliche Nutzungspotenzial der RFID-Technik haben wir oben schon erörtert. Aufgrund ihrer besonderen Eigenschaften (automatisch, robust, wieder verwendbar, großer Speicher, beschreibbar, ohne Sichtkontakt lesbar, Pulkerfassung etc.) wird sich die RFIDTechnik auf lange Sicht gegenüber dem Barcode durchsetzen. Im Gegensatz zum Barcode muss sie nur einmal vom Produzenten eingesetzt werden, und die gesamte Wertschöpfungskette kann davon profitieren. Infolgedessen erfordert die Implementierung eines elektronischen Zentralregisters nur eine geringe Investition. Da die Grundbücher in Deutschland schon digitalisiert sind, müsste man evtl. nur noch vorhandene

\footnotetext{
${ }^{729}$ Bzgl. der Informationsasymmetrie wegen problematischen Bestimmtheits- und Publizitätsgrundsatzes, s. D, I, 1 und 2; bzgl. die Entstehungen eines Vertrauensdilemmas, s. D, I, 2, c), bb) i.V.m. d); bzgl. der Nutzenstrukturen der Wirtschaftsakteure, s. D, II, 2, a).
} 
Softwareprogramme für Mobiliarpfandrechte erwerben und modifizieren. Mit der Errichtung eines solchen digitalen Zentralregisters investiert man in eine zukunftsfähige Infrastruktur, die die Rechtssicherheit und-flexibilität auch im Zeitalter des Internets und der Massengeschäfte einwandfrei gewährleisten kann. Die Gesamtwirkung auf die Effizienz der Volkswirtschaft wäre unermesslich!!

Der Einsatz von Informationstechnologie wird das gesamte Rechtssystem nachhaltig verändern. In Zukunft wird die Staatsanwaltschaft nicht mehr (viel) von Diebstählen überlastet sein; die Informationsasymmetrie bei Verbriefungsgeschäften wird aufgehoben; Verfügungen werden über das Internet vollzogen und eingetragen; die Beweisführung im Prozess wird einfacher; Echtzeitpfändung und Online-Versteigerung in der Zwangsvollstreckung wird zum Normalfall. Viele mit den herkömmlichen Rechtsmethoden nicht zu bewältigende Probleme werden mit Leichtigkeit gelöst, wie man anhand dieser Arbeit feststellen kann.

Obwohl ein digitalisiertes Zentralregister immense Vorteile bringen könnte und sowohl aus wirtschaftlicher als auch aus technischer Sicht machbar ist, bleibt die Frage offen, ob man es unter den gegebenen politischen Rahmenbedingungen durchsetzen kann; mit anderen Worten, ob die Masse es auch akzeptieren wird. Dabei ist es sehr wichtig, den Schutz der digitalen Persönlichkeit voranzutreiben. Wie oben schon erwähnt, ist die Digitalisierung der Gesellschaft unaufhaltsam; Fakt ist, dass zur Zeit überall durch private Hand fleißig Daten gesammelt werden (Stichwörter: Google; digitale Verwaltung des Banken- und Börsensystems; Schufa; Bonuspunkte für Konsum; Mobiltelefon; Internet etc.); Die aussichtslose Antidigitalisierungsbewegung ist mit Unwissen, Naivität, Nervosität und Angst verbunden, die durch Aufklärungsarbeit weitestgehend beseitigt werden können. Sobald die Bevölkerung in den Genuss der RFID-Technik kommt, wird sie wahrscheinlich diese Technik auch besser annehmen. Denn dadurch können die normalen Verbraucher nicht nur viel Zeit beim Einkaufen sparen, sondern auch ihre Rechte viel besser schützen, weil Diebstähle (insbesondere bei Elektrogeräten) praktisch nicht mehr möglich sind, weil die Gefahr eines gutgläubigen Erwerbs äußerst gering ist. Die durchgängige Senkung der Transaktionskosten in der gesamten Wertschöpfungskette kommt letztendlich auch den Verbrauchern in Form von sinkenden Preisen zugute. 
Es ist eine Herausforderung und Pflicht des Staates, diese Wandelung der Gesellschaft anzuerkennen und ein Normensystem bereitzustellen, das den Nutzen der Informationstechnologie maximiert und ihre unerwünschten externen Effekte unter Kontrolle bringt. Diese sehr komplexe Umwandlung der Rechtsordnung verlangt in der Tat die Zusammenarbeit von Experten aus verschiedenen Rechtsgebieten. Ein besonders starker Anreiz für den Staat bzgl. der Einführung des elektronischen Zentralregisters besteht darin, dass das Register auch steuerrechtlich eingesetzt werden kann.

\section{Das neue Registerrecht und Bucheffekten}

Mit der mediatisierten Verwahrung und Verwaltung privater Vermögensrechte ist eine neue Rechtsfigur entstanden, nämlich die Bucheffekten. Nach der einhelligen Meinung der schweizerischen Jurisprudenz stellt die Bucheffekten als Wertrecht als ein neues Vermögensobjekt sui generis dar, und für ihn gelten grundsätzlich die zessionsrechtlichen Regeln. ${ }^{730}$ Mit der Einführung des von der RFID-Technik unterstützten elektronischen Zentralregisters ist der heutige Gesetzgeber in der Lage, den wesentlichen Teil der Verfügung, also sowohl die Übertragung und als auch die Belastung von Vermögenspositionen, ins Register zu verlagern. Dann stellen sich in der Tat viele neue Fragen: Wie ist das Verhältnis zwischen dem elektronischen Registerrecht und den Bucheffekten? Sind sie unterschiedliche Rechtsgestalten? Unterliegen sie gemeinsamen Regeln? Wie ist künftig das (private) Vermögensrecht zu gestalten?

Als Endpunkt der mediatisierten Verwahrung und Verwaltung von (privaten) Vermögensrechten sehe ich die Bucheffekten ${ }^{731}$ bzw. das körperlose Wertrecht! Das gegenwärtige Sachenrechtsnormsystem wird dann nur noch subsidiär anwendbar sein. $\mathrm{Ob}$ man diesen Endpunkt auch auf einen Schlag erreichen kann, ist mehr als fraglich und sehr unwahrscheinlich. Denn die Banken und Geldhäuser werden mit an Sicherheit grenzender Wahrscheinlichkeit erbitterten Widerstand gegen die Verwahrung und Verwaltung der Wertpapiere (insbesondere auf der Übertragungsebene) durch eine Zentralregisterstelle leisten.

\footnotetext{
${ }^{730}$ M.w.N.: Botschaft - BEG, 9339 ff.

${ }^{731}$ Das elektronische Grundbuch schafft schon die Voraussetzungen für den ersten Schritt in diese Richtung, genauer: Biederer, Die rechtlichen Voraussetzungen elektronischer Grundstückstransaktionen in rechtsvergleichender Sicht, S. $21 \mathrm{f}, 80 \mathrm{f}$ und $105 \mathrm{f}$.
} 
Deshalb kann man in einem ersten Schritt die Belastungsebene ins Zentralregister verlagern. Dies ist für die Finanztransparenz und -sicherheit sehr wichtig.

Das elektronische Registerrecht ist nur ein Zwischenschritt zum vollkommenen elektronischen Wertrecht, dessen Verwahrungs- und Verwaltungsregelung noch unerforscht ist. Aus volkswirtschaftlicher Sicht ist eine zentralisierte Verwaltung von Vermögensrechten undenkbar, schadet die Effizienz und gefährdet das Fundament der freien Marktwirtschaft. Auf der anderen Seite erfordert die Gestaltung eines künftigen Rechtssystems mit hoher Rechtssicherheit und Flexibilität eine starke Zentralisierung. Es ist eine gemeinsame Aufgabe für Ökonomen, Juristen und Wissenschaftler aus anderen Disziplinen, sich weiterhin intensiv Gedanken darüber zu machen. ${ }^{732}$

Als zur Zeit optimale Lösung sehe ich die Aufspaltung von Verwahrung und Verwaltung des Vermögensrechts in der Weise, dass die Zentralregisterstelle die Verwahrung und die Dokumentierung der Verfügungsvorgänge über die digitalisierten Wertrechte übernimmt; Da die Vervielfältigung solcher Werte fast transaktionskostenfrei erfolgen kann, ist die Auslagerung bzw. die Dezentralisierung des Verwaltungswesens machbar (sog. Dualistische Lösung).

\footnotetext{
${ }^{732}$ In der Tat ist dies eine neue Auflage der klassischen Diskussion von Kapitalismus vs. Kommunismus und Hayek vs. Keynes vor dem Hintergrund der Globalisierung und Digitalisierung der Gesellschaft.
} 


\section{E. Zusammenfassung und Ausblick}

Rein juristisch-technisch gesehen ermöglicht das Abstraktionsprinzip die Bewältigung vielfältiger Lebensvorgänge, wie z.B. Bestellung nichtakzessorischer Sicherheiten, Verkauf von noch nicht hergestellten Sachen, Verkauf unter Eigentumsvorbehalt (EV), Ratenkäufe etc. ${ }^{733}$ Aus Sicht der Rechtswissenschaft, aber auch in praktischer Hinsicht mit Blick auf die Betriebskosten ${ }^{734}$ des Rechtswesens ist das Abstraktionsprinzip mit seiner klaren Trennung von Schuld- und Sachenrecht das beste Werkzeug, ${ }^{735}$ das wir im Moment haben, mit dem man der immer systemloseren Entwicklung der verschiedenen Rechtsordnungen noch entgegenhalten kann. ${ }^{736}$ Man sollte es verteidigen, bevor diese großartige Entdeckung aus politischen Gründen im Wege der Vereinheitlichung des europäischen Zivilrechts untergeht! ${ }^{737}$

\footnotetext{
${ }^{733}$ Stadler, Gestaltungsfreiheit und Verkehrsschutz durch Abstraktion, S. 733: im Frankeich stößt der EV bis heute auf konstruktive Schwierigkeiten.
}

${ }^{734}$ Hommerich u.a., Statistisches Jahrbuch der Anwaltschaft 2007/2008, S. 37: mittelbare Indizien für die Betriebskosten verschiedener Rechtssysteme kann folgende Tabelle bieten. Auf jeden Fall brauchen die CaseLaw-Systeme wesentlich mehr Anwälte für Bewältigung juristischer Probleme als die „Code“-Systeme. Ob Frankreich mit seinem Registersystem besser dastehen, lässt sich aber hiervon nicht ableiten; Es hängt noch von vielen anderen Faktoren ab, wie z.B. Strenge der Lizenzzulassung, Tradition der Konfliktlösung, oder Ressourcen verschlingende Subsysteme (z.B. das deutsche Steuerrecht) ect.

\begin{tabular}{|c|c|c|c|}
\hline Land & Anwälte & Bevölkerung & Einwohner pro Anwalt \\
\hline Deutschland & 138.679 & 82.422 .299 & 594,3 \\
\hline Frankreich & 45.686 & 60.876 .136 & 1332,5 \\
\hline Vereinigtes Königreich (UK) & 151.043 & 60.609 .153 & 401,3 \\
\hline Vereinigte Staaten (USA) & 1.116 .167 & 298.244 .215 & 267,2 \\
\hline
\end{tabular}

${ }^{735}$ Brox, BGB-AT Rn. 117 ff, Medicus, BGB-AT Rn. 220 ff.

${ }^{736}$ Wieling, ZEuP 2001, 301 ff; Stadler, S. 719 ff, 738, 741.

737 Warum sich das Abstraktionsprinzip trotz seiner Überlegenheit gegenüber romanischen und angloamerikanischen Rechtsordnungen nicht durchsetzen kann, Stadler, Gestaltungsfreiheit und Verkehrsschutz durch Abstraktion, S. 738, Zitat: „Verantwortlich hierfür waren und sind u.a. die politischen Rahmenbedingungen in der ersten Hälfte unseres Jahrhunderts......; In Frankreich etablierten Code Civil...; in den USA aus methodischen Unterschiede ...“. Ich persönlich glaube daran, dass das Abstraktionsprinzip in China, wo sich im Moment eine Kodifikationsvorbereitung stattfindet, eine realistische Chance haben würde, wenn Überzeugungsarbeit erfolgreich innerhalb kurzem Zeitfenster (etwa 3 - 5 Jahren) erfolgreich geleistet werden könnte. 
Unter den neuen Rahmenbedingungen der Rechtsgrundsätze, die die vorstehende Arbeit anbietet, sind die Echtpunkte eines dem Informations- und Globalisierungszeitalter gerechten modernen Vermögensrechts am Beispiel der Kreditsicherung aufgestellt.

Anders als die Konstruktion dieser Ideen wird ihre Verwirklichung angesichts des Entwicklungsstands der Infrastrukturen der Informationsgesellschaft sicherlich noch einige Zeit dauern. Eins ist meiner Meinung nach sicher: Das Abstraktionsprinzip wird sich als das wahre Fundament des modernen Vermögensrechts durchsetzen. Denn nur dieses Gestaltungsprinzip kann den hinter der vom modernen Verkehr abverlangten Sicherheit, Mobilität und Effizienz stehenden ökonomischen Grundsätzen und Nutzenstrukturen gerecht werden. In dem Zeitalter der Globalisierung und Digitalisierung kann sich keine Rechtsordnung die Entbehrung der Grundkonstruktion des Abstraktionsprinzips leisten.

Es ist aber eine andere Frage, ob andere Rechtsordnungen das Abstraktionsprinzip auch wörtlich so akzeptieren. Insoweit ist das Bekenntnis zum Abstraktionsprinzip kein einsamer Kampf gegen den Rest der Welt, sondern der Mut zur Wahrheit und Klarheit. Je mehr sich der globale (Kapital-/Waren-) Verkehr und die internationale Arbeitsteilung voranschreiten, desto mehr wird die ökonomische Notwendigkeit und Vorteilhaftigkeit des Abstraktionsprinzips ersichtlich!

Mit dem durch das elektronische Zentralregister komplettierten Abstraktionsprinzip kann man zum ersten Mal die völlige informationelle Durchdringung und Beherrschung der Verfügungskette und die effizientste Gestaltung eines Vermögenswertes erreichen. Hier liegt der Übergang des Industriezeitalters zum digitalen Zeitalter für das Recht und dieser Mechanismus wird nicht nur das Recht revolutionieren! 


\section{Literaturverzeichnis}

Adams, Michel: Ökonomische Analyse der Sicherungsrechte - ein Beitrag zur Reform der Mobiliarsicherheiten, Königstein, 1980 (zitiert: Adams, Ökonomische Analyse der Sicherungsrechte)

Alces, Peter A./Lloyd, Robert: An Agenda for Reform of the Article 9 Filing System, in: Kolahoma Law Review, Vol. 44:99 (zitiert: Alces/Lloyd, Reform of the Article 9 Filing System)

Alces, Peter A.: Abolish the Article 9 Filing System, in: Minnesota Law Review, Vol. 79:679 (zitiert: Alces, Abolisch the Article 9 Filing System)

Anzenbacher, Arno: Einfürung in die Philosophie,8. Aufl., Freiburg im Breisgau, 2002 (zitiert: Anzenbacher, Philosophie)

Anders, Monika/ Gehle, Burkhard: Das Assessorexamen im Zivilrecht, 9. Aufl., Köln, 2008 (zitiert: Anders/Gehle, Zivilprozessrecht)

Apolte, Thomas: Wohlstand durch die Globalisierung, München, 2006 (zitiert: Apolte, Wohlstand durch die Globalisierung)

Aretz, Stphanie: Das Abstraktionsprinzip - Das einzig wahre?, JA 1998, 242 (zitiert: Aretz, Abstraktionsprinzip)

Arrow, K.J.: Essays in the Theory of Risk-Bearing, Amsterdam, 1970 (zitiert: Arrow, Theory of Risk-Bearing)

Ayres, Ian: Playing Games with the Law, S. 1294, in: Game Theory and the Law, Cheltenham, 2007 (zitiert: Ayres, Playing Games with the Law)

Baird, Douglas G./Gertner, Robert H./Picker, Randal C.: Game theory and the law, 3. Ed., Cambridge, 2003 (zitiert: Baird u.a., Game theory and the law)

Bamberger/Bearbeiter: Kommentar zum Bürgerlichen Recht, 2. Aufl., München, 
Basler/Bearbeiter: Kommentar zum Zivilgesetzbuch, 3. Aufl., Basel, 2007

Baumann, Wolfgang: Ökonomie und Recht - Ökonomische Effizienzjurisprudenz, RNotZ 2007, 297 ff. (zitiert: Baumann, Ökonomische Effizienzjurisprudenz)

Baur,Fritz/Baur, Jürgen/Stürner, Rolf: Sachenrecht, 18. Aufl., München, 2009 (zitiert: Baur/Stürner, Sachenrecht)

Beale, Hugh: The Future of Secured Credit in Europe, in: European Company and Financial Law Review, Berlin, 2008 (zitiert: Beale, Secured Credit in Europe)

Becker, Gary Stanley: The economic approach to human behavior, Chicago, 1999 (zitiert: Becker, economic approach to human behavior)

Becker-Eberhard, Ekkehard: Die Forderungsgebundenheit der Sicherungsrechte, Bielefeld, 1993 (zitiert: Ekkehard, Forderungsgebundenheit)

Bericht der Forum-Gruppe für Hypothekarkredite (2004)

Bernhardt, Roger/Burkhart, Ann M: Real Property, 4. Ed., St. Paul, Minn, 2000 (zitiert: Bernhardt/Burkhart, Real Property)

Bernstorff, Christoph: Einführung in das Englische Recht, 3. Aufl., 2006 (zitiert: Bernstorff, Englisches Recht)

Biederer, Jens: Die rechtlichen Voraussetzungen elektronischer Grundstückstransaktionen in rechtsvergleichender Sicht, Berlin, 2006 (zitiert: Biederer, Die rechtlichen Voraussetzungen elektronischer Grundstückstransaktionen in rechtsvergleichender Sicht)

Bigus, Jochen/Langer, Thomas/Schiereck, Dirk: Warum gibt es Kreditsicherheiten, in: Kredit und Kapital, Bd. 38 (2005), S. 573-617 (zitiert: Bigus/Langer/Schiereck, Warum gibt es Kreditsicherheit) 
Blaurock, Uwe: Aktuelle Probleme aus dem Kreditsicherungsrecht, 3. Aufl., Köln, 1990 (zitiert: Blaurock, Kreditsicherungsrecht)

Bloech, Jürgen: Einführung in die Produktion, 6. Aufl., Berlin, 2008 (zitiert: Bloech, Produktion)

Böhringer, Walter: Der Grundstückswert bei Hofübergaben, BWNotZ, 1986, 160 ff. (zitiert: Böhringer, Grundstückswert)

Botschaft - BEG: zum Bucheffektengesetz sowie zum Haager Wertpapierübereinkommen, vom 15. November 2006 (Schweiz)

Botschaft - ZGB: Botschaft zur Änderung des Schweizerischen Zivilgesetzbuches (Register-Schuldbrief und weitere Änderungen im Sachenrecht), vom 27. Juni, 2007 (Schweiz)

Böttcher, Christina: Das abstrakte Schuldversprechen in der Kreditsicherung, Frankfurt a.M., 2007

Brandenburger, Adam/Nalebuff, Barry: The right game - use game theory to shape strategy, Boston Mass., 2009 (zitiert: Brandenburger/Nalebuff, The right game)

Bridge, Michael G.: The sale of goods, Oxford, 2003 (zitiert: Bridge, The sale of goods)

Brinkmann, Moritz: The Position of Secured Creditors in Insolvency, in: The Future of Secured Credit in Europe (zitiert: The Position of Secured Creditors in Insolvency)

Brox, Hans:

Allgemeiner Teil des BGB, 34. Aufl., München, 2010 (zitiert: Brox, BGB - AT)

Besonderes Schuldrecht, 28. Aufl., München, 2003 (zitiert: Brox, BGB - BT)

Handels- und Wertpapierrecht, 16. Aufl., München, 2003 (zitiert: Brox, Wertpapierrecht) 
Buchholz, Stephan:

Sicherungsvertraglicher Rückgewähranspruch bei Grundschulden, ZIP 1987, 891 (zitiert: Buchholz, Rückgewähranspruch bei Grundschulden)

Zur Entstehung und Entwicklung der ,abstrakten Hypothek“: die Grundschuld als Sonderform der Hypothek im ostelbischen Raum. In: Wissenschaft und Kodifikation im 19. Jahrhundert Band 3, Frankfurt a.M., 1976 (zitiert: Buchholz, Abstrakte Hypothek)

Bülow, Peter:

Qualifizierte Freigabeklausel in der Sicherungstreuhand: Die Diskussion ist offen, JZ 1997, 500 (zitiert: Bülow, Freigabeklausel)

Recht der Kreditsicherheiten, 7. Aufl., Heidelberg, 2007 (zitiert: Bülow, Kreditsicherheiten)

Bürge, Alfons: Das französische Privatrecht im 19. Jahrhundert : zwischen Tradition und Pandektenwissenschaft, Liberalismus und Etatismus, 2. Aufl., Frankfurt a.M., 1995 (zitiert: Bürge, französisches Privatrecht)

Canaris, Claus-Wilhem:

Deckungsgrenze und Bewertungsmaßstab beim Anspruch auf Freigabe von Sicherheiten gemäß $§ 242$ BGB, ZIP 1996, 1577 (zitiert : Canaris, Deckungsgrenze und Freigabeanspruch)

Verlängerter Eigentumsvorbehalt und Forderungseinzug durch Banken, NJW 1981, 249 (zitiert: Canaris, Eigentumsvorbehalt und Forderungseinzug)

Voraussetzungen und Inhalt des Anspruchs auf Freigabe von Globalsicherheiten gemäß § 242 BGB, ; ZIP 1997, 813 (zitiert : Canaris, Anspruch auf Freigabe von Globalsicherheiten)

\section{Clemente, Clemens:}

Recht der Sicherungsgrundschuld, 4. Aufl., Köln, 2008 (zitiert: Clemente, Sicherungsgrundschuld)

Sicherungsabreden im Spiegel der neuren Rechtsprechung, ZIP 1985, 193 ff. (zitiert: 
Clemente, Sicherungsabrede)

Coase, Ronald H.: The Problem of Social Cost, in: Journal of Law and Economics, Vol. 3, 1960, S. 1 - 44 (zitiert: Coase, The Problem of Social Cost)

Coing, Helmut/Honsell, Heinrich, Einleitung zum BGB, in: Staudinger - Eckpfeiler des Zivilrechts, S. 1 ff., 1. Aufl., Berlin, 2005. (zitiert: Coing/Honsell, Einleitung zum BGB)

Creifelds, Carl: Rechtswörterbuch, 17. Aufl., München, 2002

Deffains, Bruno/Demougin, Dominique: Das doppelte Holdup-Problem und der Wettbewerb der Rechtssysteme, in: Ökonomische Analyse der europäischen Zivilrechtsentwicklung, Tübingen, 2007 (zitiert: Deffains/Demougin, HoldupProblem und Wettbewerb der Rechtssysteme)

Dicken, Peter: Global shift - mapping the changing contours of the world economy, 5. Ed., London, 2009 (zitiert: Global Shift)

Djankov, Simeon/Mcliesh, Caralee/Shleifer, Andrei: Private Credit in 129 Countries, In: Journal of financial economics, Bd. 84 (2007), S.299-329 (zitiert: Djankov/Mcliesh/Shleifer, Private Credit in 129 Countries)

Döring, Frank Markus: Risiko und Risikobegrenzung für den Sicherungsgeber bei der Sicherungsgrundschuld, Frankfurt a.M., 2001 (zitiert: Döring, Risikobegrenzung bei der Sicherungsgrundschuld)

Drobnig, Ulrich: Mobiliarsicherheiten - Vielfalt oder Einheit? - Vergleichder Generalbericht, Baden-Baden, 1999 (zitiert: Drobnig, Mobiliarsicherheiten)

Drucksachen des Reichstags III, Wahlperiode 1924/26 Nr. 1811. (abgedruckt im Zentralblatt für Handelsrecht, 1926, S. 99 - 101)

Dulckeit, Gerhard: Die Verdinglichung obligatorischer Rechte, Tübingen, 1951

Eickmann, Dieter:

Aktuelle Rechtsfragen zur Sicherungsgrundschuld, ZIP 1989, 137 ff. (zitiert: 
Eickmann, Rechtsfragen zur Sicherungsgrundschuld)

Die fiduziarisch gegebene isolierte Grundschuld als Rangsicherungsmittel, NJW 1981, 545 ff. (zitiert: Eickmann, Grundschuld als Rangsicherungsmittel)

Gefährliche Grundschuld? In: Festschrift für Harm Peter Westermann zum 70. Geburtstag, Köln, 2008, S.175 ff. (178 f.) (zitiert: Eickmann, Gefährliche Grundschuld?)

Eidenmüller, Horst:

Effizienz als Rechtsprinzip, 3. Aufl., 2005 (zitiert: Eidenmüller, Effizienz als Rechtsprinzip)

Secured Creditors in Insolvency Proceedings, in: The Future of Secured Credit in Europe (zitiert: Secured Creditors in Insolvency Proceedings)

Eisenführ, Franz/Weber, Martin/Langer, Thomas: Rationales Entscheiden, 4. Aufl., Berlin, 2003 (zitiert: Eisenführ/Weber/Langer, Rationales Entscheiden)

Eisenhardt, Ulrich: Die Entwicklung des Abstraktionsprinzips im 20. Jahrhundert, in: Wirkungen europäischer Rechtskultur - Festschrift für Karl Kroeschell zum 70. Geburtstag, S. 218 ff. (zitiert: Eisenhardt, Abstraktionsprinzip im 20. Jahrhundert)

Engelhardt-Nowitzki, Corinna/Lackner, Elisabeth: Chargenverfolgung : Möglichkeiten, Grenzen, Anwendungsgebiete, Wiesbaden, 2006 (zitiert: Engelhardt/Lackner, Chargenverfolgung)

Erlei, Mathias/Leschke, Martin/Sauerland, Dirk: Neue Institutionenökonomik, 2. Aufl., Stuttgart, 2007 (zitiert: Erlei u.a., Neue Institutionenökonomik)

Erman, Walter: Handkommentar zum Bürgerlichen Gesetzbuch, Bd. 2, 11. Aufl., Münster, 2004

Feilner, Hans: Sicherungsübereignung oder Reigsterpfand?, Kulmbach, 1929

Ferid, Murad /Sonnenberger Hans Jürgen: Das französische Zivilrecht, 2. Aufl., Heidelberg, 2004 (zitiert: Murad/Sonnenberger, französisches Zivilrecht) 
Ferrari, Franco, Vom Abstraktionsprinzip und Konsensualprinzip zum Traditionsprinzip - $\mathrm{Zu}$ den Möglichkeiten der Rechtsangleichung im Mobiliarsachenrecht, ZEuP 1993, S. 52 ff. (zitiert: Ferrari, Vom Abstraktionsprinzip und Konsensualprinzip zum Traditionsprinzip)

Finkenzeller, Klaus: RFID-Handbuch : Grundlagen und praktische Anwendungen von Transpondern, kontaktlosen Chipkarten und NFC, 5. Aufl., München, 2008 (zitiert: Finkenzeller, RFID-Handbuch)

Fletcher, George P.: The Basic Concepts of Legal Thoughts, New York, 1996 (zitiert: Fletcher, Legal Thoughts)

Frambach, Hans und Eissrich, Daniel: Transaktionskosten konzeptionelle Überlegungen $\mathrm{zu}$ einem fundamentalen und kontrovers diskutierten Ansatz der Institutionenökonomik, in: Institutionenökonomik: theoretische Konzeptionen und empirische Studien, Frankfurt a.M., 2002 (zitiert: Frambach, Transaktionskosten)

Ganter, Hans Gerhard: Die ursprüngliche Übersicherung, WM 2001, 1 ff. (zitiert: Ganter, Übersicherung)

Gaberdiel, Heinz: Zur Eintragungsfähigkeit sicherungsvertraglicher Einreden bei der Grundschuld, DnotZ 2005, 718 ff. (zitiert: Gaberdiel, Eintragungsfähigkeit sicherungsvertraglicher Einreden)

Gerhardt, Walter: Die neuere Rechtsprechung zu den Mobiliarsicherheiten - Teil 1, JZ 1986, 672 ff. (zitiert: Gerhardt, Mobiliarsicherheiten)

Gierke, Otto: Der Entwurf eines bürgerlichen Gesetzbuchs und das deutsche Recht, 1889 (zitiert: Gierke, Entwurf des BGB)

Graham-Siegenthaler, Barbara: Kreditsicherungsrechte im internationalen Rechtsverkehr, Bern, 2005 (zitiert: Graham-Siegenthaler, Kreditsicherungsrechte)

Gross, Sandra: Eine Informationssystem-Architektur für RFID-gestützte logistische Geschäftsprozesse - Fallbeispiele, Konzepte, Handlungsempfehlungen, Bamberg, 2006 (zitiert: RFID-gestützte logistische Geschäftsprozesse)

Haft, Fritjof: Einführung in das juristische Lernen, 6. Aufl., Bielefeld, 1997 (zitiert: 
Haft, Juristisches Lernen)

Hagen, Louis: Der Pfandbrief - Verbriefung Made in Germany, in: Kreditwesen 2003, S. 652 f. (zitiert: Hagen, Pfandbrief)

Häsemeyer, Ludwig: Die Bedeutung der Form im Privatrecht, JuS 1980, 1 ff. (zitiert: Häsemeyer, Form im Privatrecht)

Hayek, Friedrich A. von: Recht, Gesetzgebung und Freiheit : eine neue Darstellung der liberalen Prinzipien der Gerechtigkeit und der politischen Ökonomie, Bd. Die Illusion der sozialen Gerechtigkeit, München, 1981 (zitiert: Hayek, Recht, Gesetzgebung und Freiheit)

Heck, Philipp: Grundriß des Sachenrechts, 2 Neudr. D. Ausg., Tübingen, 1930 (zitiert: Heck, Sachenrecht)

Heiner, Ronald: Rational Cooperation in One-Shot Simultaneous PD-Situations, Saarbrücken, 1995 (zitiert: Heiner, Rational Cooperation in One-Shot Situations)

Hellmund, Fritz: Sicherungsübereignung und Registerpfandrecht, Göttingen, 1929 (zitiert: Hellmund, Sicherungsübereignung und Registerpfandrecht)

Helmedag, Fritz: Zur Vermarktung des Rechts - Anmerkungen zum Coase-Theorem, in: Auf der Suche nach dem Kompaß - Politische Ökonomie als Bahnsteigkarte für 21. Jahrhundert, S. 53 ff, Köln, 1999 (zitiert: Helmedag, Vermarktung des Rechts)

Hies, Michael: Die Refinanzierung deutscher Hypothekenbanken, Frankfurt a.M., 1996 (zitiert: Hies, Die Refinanzierung deutscher Hypothekenbanken)

Hoepner, Olaf: Die Zweckerklärung bei der Sicherungsgrundschuld in der neueren Rechtsprechung des Bundesgerichtshofs, BKR 2002, 1025 ff. (zitiert: Hoepner, Zweckerklärung)

Hoffmann, Carsten: Mortgage und Charge - Gestaltungsmoeglichkeiten im englischen Kreditsicherungsrecht, Berlin, 2002 (zitiert: Hoffmann, Mortgage und Charge)

Hoffman, Helmut: Die Entwicklung des Internetrechts, NJW 2001, Beilage, S.5 
(zitiert: Hoffman, Internetrecht)

Honsell, Heinrich: Einleitung zum BGB, in: Staudinger - Eckpfeiler des Zivilrechts, 1. Aufl., Berlin, 2005 (zitiert: Honsell, Einleitung zum BGB)

Hommerich u.a.: Statistisches Jahrbuch der Anwaltschaft 2007/2008

Hromadka, Wolfgang: Die Entwicklung des Faustpfandprinzips im 18. Und 19. Jahrhundert, Köln, 1971 (zitiert: Hromadka, Faustpfandprinzip)

Huber, Ulrich: Savigny und das sachenrechtliche Abstraktionsprinzip, in: Festschrift Canaris, S. 471, München, 2007 (zitiert: Huber, Savigny und das sachenrechtlichte Abstraktionsprinzip)

Hugos, Michael H./Hulitzky, Derek: Business in the cloud : what every business needs to know about cloud computing, Hoboken, NJ, 2011 (zitiert: Hugos/Hulitzky, Business in the cloud)

Jäckle, Wolfgang: Die Sicherungsgrundschuld bei Störungen des Kreditverhältnisses, JZ 1982, 50 (zitiert: Jäckle, Sicherungsgrundschuld)

Jakobs, Horst Heinrich: Gibt es den dinglichen Vertrag? In: Zeitschrift der Savignystiftung für Rechtsgeschichte, 2002, Bd. 119, p. 269ff. (zitiert: Jakobs, Gibt es den dinglichen Vertrag?)

Jansen, Harald: Verfügungsrechte und Transaktionskosten, in: Institutionenökonomie und Betriebswirtschaftslehre, S. 101 ff, München, 2005 (zitiert: Jansen, Verfügungsrechte und Transaktionskosten)

Jensen, Michael C./Meckling, William H.: Theory of the Firm - Managerial Behavior, Agency Costs and Ownership Structure, in: Journal of Financial Economics, Bd. 3, S. 305 ff. (zitiert: Jensen/Meckling, Theory of the Firm)

Jeroscheg, Erich: Eigentum an beweglichen Sachen : französisches Recht und Rechtsvergleich, Frankfurt a.M., 2000 (zitiert: Jeroscheg, Eigentum an beweglichen Sachen)

Joas, Hans: Lehrbuch der Soziologie, 3. Aufl., Frankfurt a.M., 2007 (zitiert: Joas, 
Soziologie)

Johow, Reinhold: Beschränkte dingliche Rechte und materielles Zwangsversteigerungsrecht, in: Die Vorlagen der Redaktoren für die erste Kommission zur Ausarbeitung des Entwurfs des BGB, Sachenrecht Teil II, Unveränd. Nachdr. De Gruyter, 1982 (zitiert: Johow, beschränkte dingliche Rechte)

Karner, Ernst: Gutgläubiger Mobiliarerwerb - zum Spannungsverhältnis von Bestandschutz und Verkehrsinteressen, Wien, 2006 (zitiert: Karner, Gutgläubiger Mobiliarerwerb)

Kaser, Max/Knütel, Rolf: Römisches Privatrecht, 18. Aufl., München, 2005 (zitiert: Kaser, Römisches Privatrecht)

Krafka, Alexander: Grundsätze des Registerrechts, München, 2004 (zitiert: Krafka, Registerrecht)

Kelly, Paul J.: Utilitarianism and Distributive, Oxford, 1990 (zitiert: Kelly, Utilitarianism and Distributive)

Kelsen, Hans: Was ist Gerechtigkeit?, Stuttgart, 2000 (zitiert: Kelsen, Gerechttigkeit)

Kessal-Wulf, Sipylle: Recht der Kreditsicherung, in: Staudinger - Eckpfeiler des Zivilrechts, S. 405 ff., 1. Aufl., Berlin, 2005 (zitiert: Kessal-Wulf, Kreditsicherung)

Kieninger, Eva-Maria:

Nationale, europäische und weltweite Reformen des Mobiliarsicherungsrechts, Teil I: WM 2005, 2305 ff; Teil II 2353 ff. (zitiert: Kienigner, Reformen des Mobiliarsicherungsrechts)

Europäisches Mobiliarkreditsicherungsrecht, in: Kreditsicherheiten, S. 109 ff., Bern, 2008 (zitiert: Kieninger, Europäisches Mobiliarkredtisicherungsrecht)

Kneiff, Elisabeth: Bedeutung des Registers und des guten Glaubens in einem künftigen deutschen Gesetz über das Registerpfandrecht, Berlin, 1930 (zitiert: Kneiff, Registerpfandrecht) 
Krimphove, Dieter: Das europäische Sachenrecht, 1. Aufl., Lohmar, 2006 (zitiert: Krimphove, Das europäische Sachrenrecht)

Krophlloer, Jan: Bürgerliches Gesetzbuch, 12. Aufl., München, 2010 (zitiert: Krophlloer, Bürgerliches Gesetzbuch)

Kutschker, Michael/Schmid, Stefan: Internationales Management, 6 Aufl., München, 2008 (zitiert: Kutschker, Internationales Management)

Lange, Heinrich: Das kausale Element im Tatbestand der klassischen Eigentumstradition, Leipzig, 1930. (zitiert: Lange, Eigentumstradition)

Langerfeldt, Michael: Das Gefangenendilemma, in: Wirtschaftswissenschaftliches Studium, 2003, S. 226 ff. (zitiert: Das Gefangenendilemma)

Lareida, Eva: Der Schuldbrief aus wertpapierrechtlicher Sicht, Zürich, 1986 (zitiert: Der Schuldbrief aus wertpapierrechtlicher Sicht)

Larenz, Karl/Wolf, Manfred: Allgemeiner Teil des Bürgerlichen Rechts, 8. Aufl., München, 1997 (zitiert: Larenz/Wolf, BGB - AT)

Larenz, Karl/Canaris, Claus-Wilhelm: Lehrbuch des Schuldrecht - Besonderer Teil, München, 1994 (zitiert: Larenz/Canaris, Schuldrecht - BT)

Laux, Helmut: Entscheidungstheorie, 7. Aufl., Berlin, 2007 (zitiert: Laux, Entscheidungstheorie).

Lehmann, Michael: Globalisierung und Zivilrecht, in: FS Canaris (2008), S. 729 ff. (zitiert: Lehmann, Globalisierung und Zivilrecht)

Lettel, Tobias: Der Grundsatz der akzessorischen Haftung im Zivil- und Handelsrecht, JA 2004, 238 ff. (zitiert: Lettel, Akzessorische Haftung)

Leist, Gerhard Alexander: Die Sicherung von Forderungen durch Übereignung von Mobilien, Frankfurt a.M., 1889 (zitiert: Leist, Sicherungsübereignung)

Leonhard, Rudolf: Über die Gefahren einer Beseitigung der Verpfändung beweglicher 
Sachen durch bloßen Vertrag nebst einem Anhange über die beabsichtigte Beseitigung des constitutum possessorium, in: Beträge zur Erläuterung des Deutschen Rechts, Bd. 25 (1881), S. 177 - 221 (zitiert: Leonhard, Beseitigung der Verpfändung beweglicher Sachen)

Liebscher, Marc/Bantle, Mathias: Einführung in das polnische Recht, München, 2005 (zitiert: Liebscher/Bantle, polnisches Recht)

Litten, Rüdiger/Crista, Sever: Asset Backed Securities in Zeiten von Basel II, WM 2003, 213 ff. (zitiert: Litten/Crista, Asset Backed Securities)

London Economics, The Cost and Benifits of Integration of EU Mortgage Markets, 2005

LoPucki, Lynn M./Warren, Elizabeth:

Secured Credit, 5. Ed., New York, 2006 (zitiert: LoPucki/Warren, Secured Credit)

The Spearing Tool Filing System Disaster, in: Ohio State Law Journal, Vol. 68:281 (zitiert: LoPucki, Filing System Disaster)

Lübtow, Ulrich, Das Grundpfandrecht am Vorbehaltseigentum, JuS 1963, 171 ff (zitiert, Lübtow, Grundpfandrecht am Vorbehaltseigentum)

Lukas, Meinhard, Attachment/Creation of a Security Interest - Commentary, in: The Future of Secured Credit in Europe, S. 143 ff. (zitiert: Lukas, Attachment/Creation)

Lwowski, Hans-Jürgen:

„Quiet" Creation of Security Interest or Filing, in: The Future of Secured Credit in Europe, S. 174 ff. (zitiert: Lwowski, „Quiet“"Creation of Security Interest)

Rechtsprechung zur Sicherungsübereignung, ZIP 1980, 953 ff. (zitiert: Lwowski, Sicherungsübereignung)

Neef, Andreas: Zur Eintragungsfähigkeit sicherungsvertraglicher Einreden bei der Grundschuld, Berlin, 2004 (zitiert: Neef, Eintragungsfähigkeit sicherungsvertraglicher Einreden) 
Nietsch, Michael: Grundschulderwerb nach dem Risikobegrenzungsgesetz - Der Ausschluss des gutgläubigen einredefreien Erwerbs nach § 1192 Ia BGB, NJW 2009, 3606 ff, 3609 (zietiert: Nietsch, Der Ausschluss des gutgläubigen einredefreien Erwerbs nach § 1191 Ia BGB)

McCormack, Gerard: Registration of Company Charges, 2. Ed., Bristol, 2005 (zitiert: McCormack, Registration of Company Charges.

Mallmann, Roman/Heinrich, Erbo: Schriftform bei Geschäften im Internet, ZRP 2000, 470 (zitiert: Mallmann/Heinrich, Schriftform im Internet)

Malzer, Hans Michael: Zivilrechtliche Form und prozessuale Qualität der digitalen Signatur nach dem Signaturgesetz, DNotZ 1998, 96 (zitiert: Malzer, digitale Signatur nach dem Signaturgesetz)

Mankiv, N. Gregory: Principles of Economics, 4. Ed., 2006 (zitiert: Mankiv, Principles of Economics)

Marek, Christoph: RFID - Kosten und Nutzen, Saarbrücken, 2007 (zitiert: Marek, RFID - Kosten und Nutzen)

Marx, Karl/Engels, Friedrich: Manifest der Kommunistischen Partei (Nachdr.), S. 23, Stuttgart, 1995 (zitiert: Marx/Engels, Manifest der Kommunistischen Partei)

Mathis, Klaus: Effizienz statt Gerechtigkeit?, 2. Aufl., Berlin, 2005 (zitiert: Mathis, Effizienz statt Gerechtigkeit?)

Medicus, Dieter:

Allgemeiner Teil des BGB, 10. Aufl., Heidelberg, 2010 (zitiert: Medicus, BGB - AT)

Bürgerliches Recht, 22. Aufl., 2009 (zitiert: Medicus, Bürgerliches Recht)

Die Akzessorietät im Zivilrecht, JuS 1971, S. 497 ff. (zitiert: Medicus, Akzessorietät)

Entscheidungen des $\mathrm{BGH}$ als Marksteine für die Entwicklung des allgemeinen Zivilrechts, NJW 2000, 2921 (zitiert: Medicus, Entscheidung des BGH als Marksteine) 
Grundwissen zum Bürgerlichen Recht, 9. Aufl., München, 2011 (zitiert: Medicus, GWB)

Melsheimer, Klaus: Sicherungsübereignung oder Registerpfandrecht - Eine politologische Studie über den Kampf von Interessengruppen um die Reform des Kreditsicherungsrechts, Köln, 1967 (zitiert: Melsheimer, Sicherungsübereignung oder Registerpfandrecht - eine politologische Studie)

Mertens, Bernd: Gesetzgebungskunst im Zeitalter der Kodifikationen - Theorie und Praxis der Gesetzgebungstechnik aus historisch-vergleichender Sicht, Tübingen, 2004 (zitiert: Mertens, Gesetzgebungskunst im Zeitalter der Kodifikationen)

Meyer, André: Die Regelung der Sicherungsgrundschuld in $§ 1192$ Abs. 1a BGB - ein nicht durchgachter Schnellschuss des Gesetzgebers, WM 2010, 58 ff. (zitiert: Meyer, $\S 1192$ Abs. 1a BGB - ein Schnellschuss des Gesetzgebers)

Meyer, Peter: Einheitliches europäisches Grundpfandrecht oder Wettbewerb der Rechtsordnungen?, EuZW 2004, 389 ff. (zitiert: Meyer, einheitliches europäisches Grundpfandrecht oder Wettbewerb der Rechtsordnungen?)

McCormack, Gerard: Secured Credit under English and American Law, Cambridge, 2004 (zitiert: McCormack, Secured Credit)

Motive zu dem Entwurf eines Bürgerlichen Gesetzbuchs, Bd. 3, Nachdr. der Ausg. Berlin, 1899.

Mugdan, Benno: Die gesamten Materialien zum Bürgerlichen Gesetzbuch für das Deutsche Reich - Bd. 3 (Sachenrecht), Nachdr. der Ausg. Berlin 1899, 1979 (zitiert: Mugdan, Sachenrecht)

MüKo/Bearbeiter:

Münchener Kommentar zum Bürgerlichen Gesetzbuch,

- Allgemeiner Teil, Bd. 1, 5. Aufl., 2007

- Schuldrecht Allgemeiner Teil, Bd. 2, 5. Aufl., 2007

- Sachenrecht, Bd. 6, 5. Aufl., 2009

Oechsler, Jügen: Vertragstypen, in: in: Staudinger - Eckpfeiler des Zivilrechts, 1. 
Aufl., S. 493 ff. (zitiert: Oechsler, Vertragstypen)

Obermüller, Manfred: Die Kreditklemme und der Niedergang der Kreditsicherheiten, NZI 2010, 201 ff. (zitiert: Obermüller, Niedergang der Kreditsicherheiten)

Peters, Frank: Kauf und Übereignung, Jura 1986, 449 ff. (zitiert: Peters, Kauf und Übereignung)

Petersen, Thieß: Das Gefangenendilemma, in: Das Wirtschaftsstudium, 2008, S. 500 ff. (zitiert: Das Gefangenendilemma)

Palandt/Bearbeiter: Bürgerliches Gesetzbuch, 69. Aufl. 2010

Pallas, Maren: Die Rechtsstellung des Sicherungsgebers bei der Verwertung des Sicherungseigentums, 2003 (zitiert: Pallas, Rechtsstellung des Sicherungsgebers bei der Verwertung)

Patti, Salvatore: Codice Civile Italiano - das italienische Zivilgesetzbuch, München, 2007 (zitiert: Patti, Codice Civile Italiano)

Peters, Frank: Der Entzug des Eigentums an beweglichen Sachen durch gutgläubigen Erwerb, Tübingen, 1991 (zitiert: Peters, Der Entzug des Eigentums durch gutgläubigen Erwerb)

Picker, Eduard: Bürgerliches Recht - Die Schlacht der Kreditoren, JuS 1988, 375 ff. (zitiert: Picker, Die Schlacht der Kreditoren)

Pöggeler, Wolfgang: Die Akzessorietät im Zivilrecht - Irrtümer und Wahrheiten, JA, 2001, S. 65 ff. (zitiert: Pöggeler, Akzessorietät im Zivilrecht)

Pohl, Hans: Die Entwicklung der deutschen Volkswirtschaft (1830 - 1880), in: Wissenschaft und Kodifikation des Privatrechts im 19. Jahrhundert, Band 2, Frankfurt a.M., 1977 (zitiert: Pohl, deutsche Volkswirtschaft (1830 - 1880))

Posner, Richard A.: Economic Analysis of Law, 6. ed., New York, 2003 (zitiert: Posner, Economic Analysis of Law) 
Posner, Eric A.: Agency Models in Law and Economics, in: Game Theory and the Law, S. 47 ff, Cheltenham, 2007 (zitiert: Posner, Agency Models in Law and Economics)

Pospiech, Lutz: The Future of Secured Credit in Europa - Bericht über die Konferenz vom 12. - 14. Juli 2007 in München, WM 2007, 1950 ff. (zitiert: Pospiech, The Future of Secured Credit in Europe)

Protokolle der Kommission für die zweite Lesung des Entwurfs des Bürgerlichen Gesetzbuches, Bd.3, Nachdr. der Ausg. Berlin 1897

Ranieri, Filippo: Die Lehre der abstrakten Übereignung in der deutschen Zivilrechtswissenschaft des 19. Jahrhunderts, in: Wissenschaft und Kodifikation des Privatrechts im 19. Jahrhundert, Frankfurt a.M., 1982 (zitiert: Ranieri, Abstrakte Übereignung im 19. Jahrhundert)

Rehbein, Dieter: Sicherung und Sicherungszweck, in: Festschrift Heinsius, 659 ff., Berlin, 1991 (zitiert: Rehbein, Sicherung und Sicherungszweck)

Reich, Barbara: Das stille Pfandrecht der Niederlande - Ziel oder bloßer Schritt auf dem Weg zur Reformierung der deutschen Sicherungsübereignung?, Göttingen, 2006 (zitiert: Reich, Das stille Pfandrecht der Niederlande)

Reinicke, Dietrich/Tiedtke, Klaus: Kreditsicherung, 5. Aufl., Neuwied, 2006 (zitiert: Reinicke/Tiedtke, Kreditsicherung)

Reimann, Mathias/Ackmann, Hans-Peter: Einführung in das US-amerikanische Privatrecht, München, 2004 (zitiert: Reimann/Ackmann, US-amerikanisches Privatrecht)

Rhensius, Tobias/Deindl, Matthias: Metastudie RFID : eine umfassende Analyse von Anwendungen, Nutzen und Hindernissen der RFID-Implementierung ; mit 140 Fallbeispielen und mehr als 20 empirischen Studien, 2. Aufl., Achen, 2009 (zitiert: Rhensius/Deindl, Metastudie RFID)

Rieck, Christian: Spieltheorie - Eine Einführung, 6. Aufl., Eschborn, 2006 (zitiert: Rieck, Spieltheorie) 
Ricken, Stephan: Verbriefung von Krediten und Forderungen in Deutschland, Düsseldorf, 2008 (zitiert: Ricken, Verbriefung von Krediten und Forderungen)

Rimmelspracher, Bruno: Kreditsicherungsrecht, 3. Aufl., München, 2005 (zitiert: Rimmelspracher, Kreditsicherungsrecht)

Ripperger, Tanja:

Die Effizienz des Vertrauensmechanismus bei der Organisation internationaler Transaktionen, in: Jahrbuch für neue politische Ökonomie, Bd. 18, 1999, S. 257 ff. (zitiert: Ripperger, Vertrauensmechanismus)

Ökonomik des Vertrauens : Analyse eines Organisationsprinzips, 2. Aufl., Tübingen, 2005 (zitiert: Ripperger, Ökonomik des Vertrauens)

Rittinghouse, John W./Ransome, James F.: Cloud Computing : implementation, management, and security, Boca Raton, 2010 (zitiert: Rittinghouse/Ransome, Cloud Computing)

Roemer, Heiner: Ausgewählte Probleme aus dem Bereich der Grundpfandrechte, MittRhNotK 1991, 69 ff. (zitiert: Roemer, Grundpfandrechte)

Roßnagel, Alexander: Digitale Signaturen im Rechtsverkehr, NJW-CoR 1994, 96 (zitiert: Roßnagel, Digitale Signaturen im Rechtsverkehr)

Roth, Wulf-Hennig: Secured Credit and the Internal Market - The Fundamental Freedoms and the EU's Mandate for Legislation, in: The Future of Secured Credit in Europe, S. 36 ff. (zitiert: Roth, Secured Credit and the Internal Market)

Röver, Jan-Hendrik: Vergleichende Prinzipien dinglicher Sicherheiten : eine Studie zur Methode der Rechtsvergleichung, München, 1999 (zitiert: Röver, Vergleichende Prinzipien dinglicher Sicherheiten)

\section{Savigny, Friedrich Carl:}

Das Obligationenrecht als Teil des heutigen römischen Rechts, Bd. 2, Neudr. [d. Ausg. Berlin 1853]. (zitiert: Savigny, Obligationenrecht)

System des heutigen römischen Rechts, Bd. 3, 2. Neudr. der Ausg., Berlin 1840 
(zitiert: Savigny, System)

Schanz, Günther: Der Manager und sein Gehirn - Neurowissenschaftliche Erkenntnisse im Dienst der Unternehmensführung, Frankfurt a.M., 1998 (zitiert: Der Manager und sein Gehirn)

Schäfer, Hans-Bernd/Ott, Claus: Lehrbuch der ökonomischen Analyse des Zivilrechts, 4. Aufl., Berlin, 2005 (zitiert: Schäfer/Otto, ökonomische Analyse des Zivilrechts)

Schlosser, Hans: Außenwirkungen verfügungshindernder Abreden bei der rechtsgeschäftlichen Treuhand, NJW 1970, 681 ff. (zitiert: Schlosser, rechtsgeschäftliche Treuhand)

Schloz, Hellmut/Lwowski, Hans-Jürgen, Das Recht der Kreditsicherung, 7. Aufl., Berlin, 2000 (zitiert: Schloz/Lwowski, Kreditsicherung)

Schnur, Wolfgang: Grundprobleme der Wirkungsweise von Akzessorietätsprinzip und Sicherungsabrede, Jura 2005, 361 ff. (zitiert: Schnur, Wirkungsweise von Akzessorietätsprinzip und Sicherungabrede)

\section{Schmid-Tschirren, Christina:}

Der Register-Schuldbrief - Neues Instrument für die Banken, in: Kreditsicherheiten, Bern, 2008, S. 1 ff. (zitiert: Schmid-Tschirren, Register-Schuldbrief)

«Papierlose» Wertpapiere, in: FS für Heinrich Koller, S. 183 ff, Basel, 2006 (zitiert: Schmid-Tschirren, Papierlose Wertpapiere)

Schmidt, Karsten: Darlehen, Darlehensversprechen und Darlehenskrediteröffnung im Konkurs, JZ 1976, 756 ff. (zitiert: Schmidt, Darlehen im Konkurs)

Schotter, Andrew.: The Evolution of rules. In: Economic as a Process. Essays in the New Institutional Economics. Cambridge University Press, Cambridge 1986, S. 117 (zitiert: Schotter, The Evolution of rules)

Schreiber, Klaus: Das Sicherungseigentum und seine Verwertung, JR 1984, 485 ff. (zitiert: Schreiber, Sicherungseigentum und seine Verwertung) 
Segré-Bericht: Der Aufbau eines Europäischen Kapitalmarkts, Europäische Wirtschaftsgemeinschaft - Kommission, Brüssel, 1966 (zitiert: Segré-Bericht, Aufbau eines Europäischen Kapitalmarkts)

Seiler, Hans Hermann: Sachenrecht - Allgemeine Lehren, in: Staudinger - Eckpfeiler des Zivilrechts, 1. Aufl., S. 877 ff, Berlin, 2005 (zitiert: Seiler, Sachenrecht)

\section{Serick, Rolf:}

Die Verwertung von Sicherungseigentum, BB 1970, 541 ff. (zitiert: Serick, Verwertung von Sicherungseigentum)

Eigentumsvorbehalt und Sicherungsübertragung, Band I - IV, Heidelberg, 1963 1976 (zitiert: Serick, Eigentumsvorbehalt und Sicherungsübertragung)

Freigabeklauseln, Deckungsgrenze und Haftobergrenze, NJW 1997, 1529 (zitiert: Serick, Freigabeklauseln, Deckungsgrenze und Haftobergrenze)

Gewohnheitsrecht und fehlende vertragliche Deckungsobergrenze bei fiduziarischen Kreditsicherheiten, WM 1997, 345 (zitiert: Serick, Deckungsobergrenze bei fiduziarishen Kreditsicherheiten)

Shogren, Jason F./Shin, Seung Y./Hayes, Dermot J./Kliebenstein, James B.: Resolving Differences in Willingness to Pay and Willingness to Accept, in: The American Economic Review, Vol. 84, No. 1., S. 255 ff. (zitiert: Shogren u.a., Resolving Differences in Willingness to Pay and Willingness to Accept)

Sigman, Harry C.:

Improvements (?) to the UCC Article 9 Filing System, in: Gonzaga Law Review, Vol. 46:2 (zitiert: Article 9 UCC Filing System)

Perfection and Priority of Security Rights, in: The Future of Secured Credit of Europe, S. 143 ff. (zitiert: Sigman, Perfection and Priority)

Sohst, Wolfgang: Das spanische Bürgerliche Gesetzbuch - Código civil español und spanisches Notargesetz ; Text und Kommentar, Berlin, 2005 (zitiert: Sohst, Código civil español)

Stadler, Astrid: Gestaltungsfreiheit und Verkehrsschutz durch Abstraktion, Tübingen, 
1996 (zitiert: Stadler, Gestaltungsfreiheit und Verkehrsschutz durch Abstraktion)

Stanoevska-Slabeva, Katarina/Wozniak, Thomas/Ristol, Santi: Grid and cloud computing : a business perspective on technology and applications, Heidelberg, 2010 (zitiert: Stanoevska-Slabeva/Wozniak/Ristol, Grid and cloud computing)

Staudinger/Bearbeiter: Kommentar zum Bürgerlichen Gesetzbuch, §§ 1113 - 1203, Berlin, 2002

Stavrianos, L.S.: A Global History - From Prehistory to the $21^{\text {st }}$ Century, 7 Aufl., New Jersey, 1999 (zitiert: Stavrianos, A Global Histroy: From Prehistory to the $21^{\text {st }}$ Century)

\section{Stöcker, Otmar M.:}

Die Eurohypothek, Berlin, 1992 (zitiert: Stöcker, Eurohypothek)

Die treuhänderisch gehaltene Sicherungsbuchgrundschuld zur Verbriefung und Syndizierung von Krediten, in: Die Bank, 2004, S. 55 ff. (zitiert: Stöcker, Sicherungsbuchgrundschuld zur Verbriefung von Krediten)

Stone, Bradford: Uniform Commercial Code, 6. Ed., St. Paul, Minn, 2005 (zitiert: Stone, Uniform Commercial Code)

Stürner, Rolf: Perfection and Priority of Security Rights - Commentary, in: The Future of Secured Credit in Europa, S. 174 (zitiert: Stürner, Perfection and Priority)

Thonabauer, Günther/Nösslinger, Barbara/Höger, Andreas: Leitfadenreihe zum Kreditrisiko, Wien, 2004 (zitiert: Thonabauer u.a., Kreditrisiko)

Thaler, H. Richard: Toward a positive theory of consumer choice, in: Journal of Economic Behavior and Organization, 1, $39 \mathrm{ff}$. (zitiert: Thaler, theory of consumer choice)

Varian, Hal R.: Grundzüge der Mikroökonomik, 7. Aufl., München, 2007 (zitiert, Varian, Mikroökonomik)

Veneziano, Anna: Attachment/Creation of a Security Interest, in: The Future of 
Secured Credit in Europe, S. 113 ff. (zitiert: Attachment/Creation of a Security Interest)

Verhandlungen des Deutschen Industrie- und Handelstages, 1926

Vogt, Carsten: Kooperation im Gefangenen-Dilemma durch endogenes Lernen, Magdeburg, 2001 (zitiert: Vogt, Kooperation im Gefangenen-Dilemma durch endogenes Lernen)

Vortmann, Jürgen: Raumsicherungsübereignung und Vermieterpfandrecht, ZIP 1988, 626 ff. (zitiert: Vortmann, Raumsicherungsübereignung)

Wallerstein, Immanuel: The Modern World-System as a Capitalist World-Economy, in: The Globalization Reader, 3rd ed., Malden, 2008, S. 55 ff., (zitiert: Wallerstein, A Capitalist World-Economy)

Wagemann, Steffi Katrin: Funktion und Bedeutung von Grundstücksregistern, Heidelberg, 2002 (zitiert: Wagemann, Grundstücksregister)

Weber, Hansjörg:

Der Rückübertragungsanspruch bei der nichtvalutierten Sicherungsschuld, AcP 169, 237 (zitiert: Weber, Rückübertragungsanspruch)

Kreditsicherungsrecht, 8. Aufl., München, 2006 (zitiert: Weber, Kreditsicherungsrecht)

Weissbuch über die Integration der EU-Hypothekarkreditmärkte, EU-Kommission, Brüssel, 2007

Wenzel, Frank: Der Anspruch des Kreditgebers auf Verstärkung von Sicherheiten, WiB 1994, 596 ff. (zitiert: Wenzel, Der Anspruch auf Verstärkung von Sicherheiten)

Westermann, Harry: Sachenrecht, 11. Aufl. 2005 (zitiert: Westermann, Sachenrecht)

White, James J./Summers Robert S.: Uniform Commercial Code, Vol. 1 - 4, 5. ed., St. Paul, Minn, 2004 (zitiert: White/Summers, Uniform Commercial Code) 
Wieacker, Franz: Privatrechtsgeschichte der Neuzeit, 2. unveränd. Nachdr. d. 2., neubearb. Aufl. von 1967, Göttingen, 1996 (zitiert: Wieacker, Privatrechtsgeschichte)

Wiegand, Wolfgang/Brunner, Fürsprecher: Übersicherung und Freigabeanspruch, NJW 1995, 2513 (zitiert: Wiegand/Brunner, Übersicherung und Freigabeanspruch)

Wieling, Hans: Das Abstraktionsprinzip für Europa!, ZEuP 2001, 301 ff. (zitiert: Wieling, Das Abstraktionsprinzip für Europa!)

Winkel, Harald: Der Umschwung der wirtschaftswissenschaftlichen Auffassungen um die Mitte des 19. Jahrhunderts, in: Wissenschaft und Kodifikation des Privatrechts im 19. Jahrhundert, Band 4, Frankfurt a.M., 1977 (zitiert: Winkel, wirtschaftswissenschaftliche Auffassung um die Mitte des 19. Jahrhunderts)

Wolf, Manfred:

Beständigkeit und Wandel im Sachenrecht, NJW 1987, 2647 (zitiert: Wolf, Wandel im Sachenrecht)

Sachenrecht, 19. Aufl., München, 2003 (zitiert: Wolf, Sachenrecht)

Wolff, Martin/Raiser, Ludwig: Sachenrecht, 10 Aufl., Tübingen, 1957 (zitiert: Wolff/Raiser, Sachenrecht)

Wolters, Jan Christoph: Die Freigabeklausel im Kreditsicherungsvertrag, BadenBaden, 1995 (zitiert: Wolters, Die Freigabeklausel im Kreditsicherungsvertrag)

Zitelmann, Ernst: Die Möglichkeit eines Weltrechts, Allg. Österr. Gerichtszeitung, Bd. 39 (1888), Nr. 25 - 27, Wiederabdruck 1916 (zitiert: Zitelman, Die Möglichkeit eines Weltrechts) 